\title{
Imaging the brain : neuronal correlates of cognitive impairment in children with frontal lobe epilepsy
}

Citation for published version (APA):

Braakman, HM. (2013). Imaging the brain : neuronal correlates of cognitive impairment in children with frontal lobe epilepsy. [Doctoral Thesis, Maastricht University]. Maastricht University. https://doi.org/10.26481/dis.20130614hb

Document status and date:

Published: 01/01/2013

DOI:

10.26481/dis.20130614hb

Document Version:

Publisher's PDF, also known as Version of record

\section{Please check the document version of this publication:}

- A submitted manuscript is the version of the article upon submission and before peer-review. There can be important differences between the submitted version and the official published version of record.

People interested in the research are advised to contact the author for the final version of the publication, or visit the DOI to the publisher's website.

- The final author version and the galley proof are versions of the publication after peer review.

- The final published version features the final layout of the paper including the volume, issue and page numbers.

Link to publication

\footnotetext{
General rights rights.

- You may freely distribute the URL identifying the publication in the public portal. please follow below link for the End User Agreement:

www.umlib.nl/taverne-license

Take down policy

If you believe that this document breaches copyright please contact us at:

repository@maastrichtuniversity.nl

providing details and we will investigate your claim.
}

Copyright and moral rights for the publications made accessible in the public portal are retained by the authors and/or other copyright owners and it is a condition of accessing publications that users recognise and abide by the legal requirements associated with these

- Users may download and print one copy of any publication from the public portal for the purpose of private study or research.

- You may not further distribute the material or use it for any profit-making activity or commercial gain

If the publication is distributed under the terms of Article $25 \mathrm{fa}$ of the Dutch Copyright Act, indicated by the "Taverne" license above, 


\section{IMAGING THE BRAIN}

Neuronal correlates of cognitive impairment in children with frontal lobe epilepsy 
H.M.H. Braakman

ISBN/EAN:

Print:

Design and Layout:

Photographs:

Cover:
IMAGING THE BRAIN: Neuronal correlates of cognitive impairment in children with frontal lobe epilepsy

978-90-9027494-2

Ipskamp Drukkers, Nijmegen

M.K.P. Poll \& H.M.H. Braakman

J. van Ingen

Footbridge, Passu, Pakistan

The printing of this thesis was financially supported by the Nationaal Epilepsie Fonds, Kempenhaeghe Sector for Research and Development, School for Mental Health and Neuroscience (MHeNS), Maastricht University Medical Centre, UCB Pharma B.V. Breda, EISAI B.V. and GlaxoSmithKline. 


\section{IMAGING THE BRAIN}

\section{Neuronal correlates of cognitive impairment in children with frontal lobe epilepsy}

\section{PROEFSCHRIFT}

Ter verkrijging van de graad van doctor aan de Universiteit Maastricht, op gezag van de Rector Magnificus, Prof. dr. L.L.G. Soete, volgens het besluit van het College van Decanen,

in het openbaar te verdedigen op vrijdag 14 juni 2013 om 12.00 uur

$$
\text { door }
$$




\section{Promotores:}

Prof. dr. A.P. Aldenkamp

Prof. dr. J.S.H. Vles

\section{Copromotores:}

Dr. ir. W.H. Backes

Dr. P.A.M. Hofman

\section{Beoordelingscommissie:}

Prof. dr. J.E. Wildberger (voorzitter)

Prof. dr. K.P.J. Braun (Universitair Medisch Centrum Utrecht)

Prof. dr. B.M. Jansma

Prof. dr. L. Lagae (Universitair Ziekenhuis Leuven)

Prof. dr. R.J. van Oostenbrugge 


\section{Table of Contents}

$\begin{array}{lll}\text { Chapter } 1 \text { Introduction } & 7\end{array}$

Chapter 2 Cognitive and behavioural complications of frontal lobe 17 epilepsy in children

2.1 Cognitive and behavioural complications of frontal lobe epilepsy in $\quad 18$ children: a review of the literature

2.2 Cognitive and behavioural findings in children with frontal lobe epilepsy

Chapter 3 Microstructural and functional MRI studies of cognitive impairment in epilepsy

Microstructural and functional MRI studies of cognitive impairment in epilepsy

Chapter 4 Grey matter responses: functional MRI results

Frontal lobe connectivity and cognitive impairment in pediatric frontal lobe epilepsy

Chapter 5 Brain morphology: volumetric MRI results

Reduced frontal and extra-frontal cortex volumes are associated with cognitive impairment in frontal lobe epilepsy

Chapter 6 White matter properties: diffusion tensor imaging results

White matter abnormalities and cognitive impairment in children with frontal lobe epilepsy

Chapter 7 Functional network topology: results of graph theoretical analysis

Abnormal modular organization of functional networks in cognitively impaired children with frontal lobe epilepsy

Chapter 8 General Discussion 


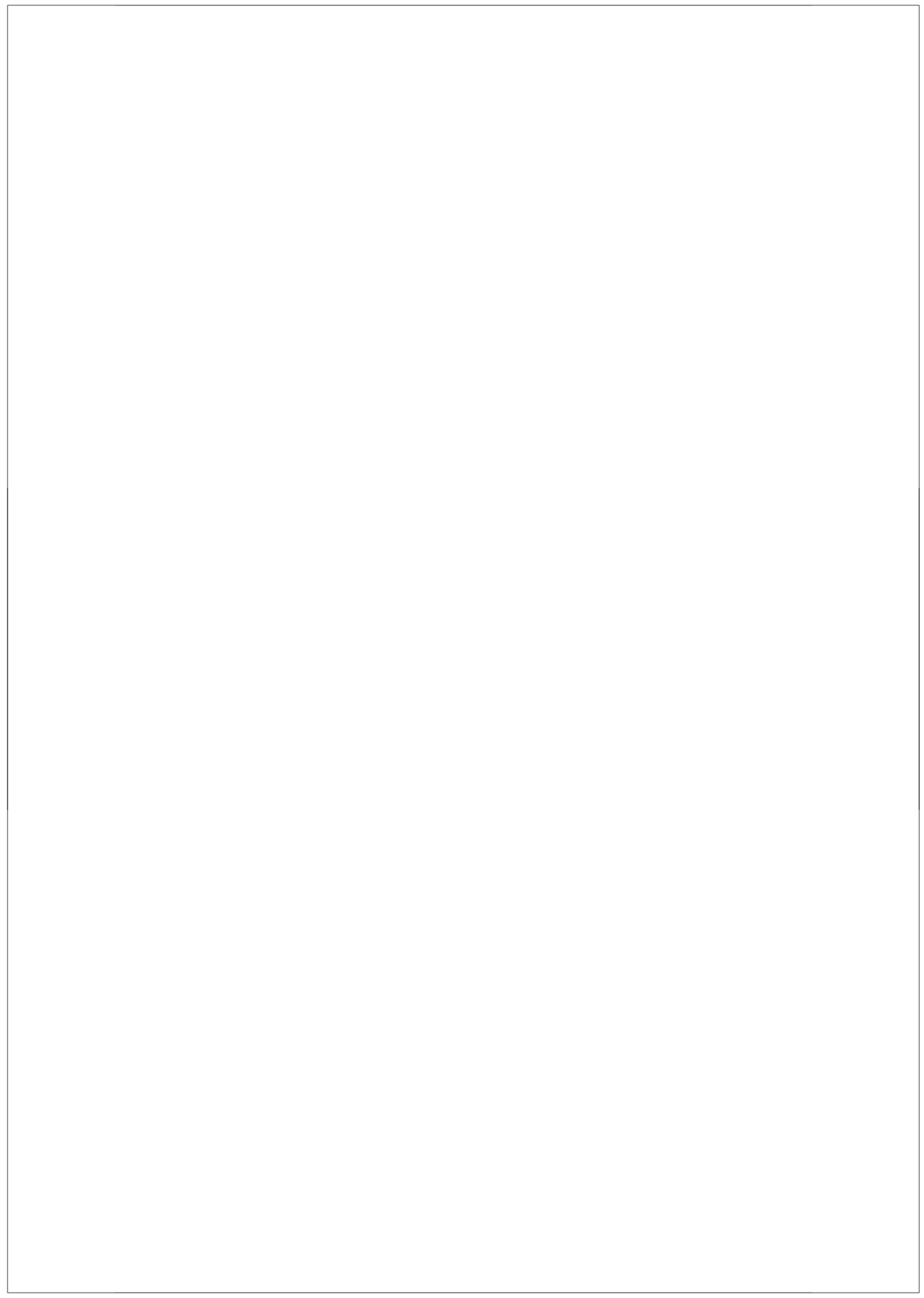




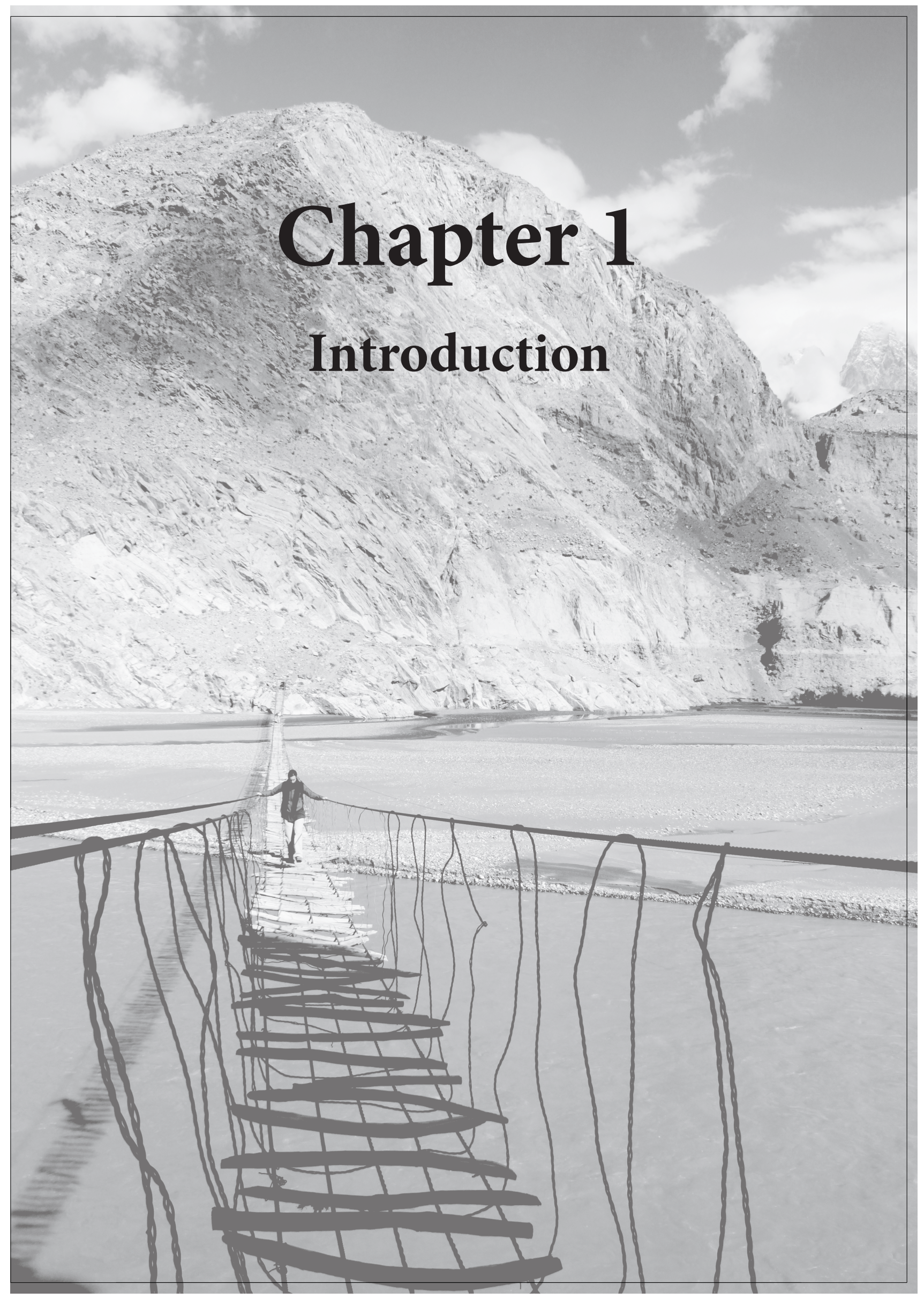




\section{Epilepsy}

Epilepsy is the most common neurological disorder in childhood and is characterized by an enduring predisposition to generate epileptic seizures and by neurobiologic, cognitive, psychological and social consequences of this condition. ${ }^{1}$

Worldwide, about 65 million people are estimated to have epilepsy. ${ }^{2}$ In developed countries, the mean annual incidence of epilepsy is nearly 50 per 100.000 . The incidence rate is highest in children, ranging from 50 to 150 per 100.000 per year. The prevalence approximates 700 per $100.000 .^{3}$ For the Netherlands, this means that every year, around 8.000 people are newly diagnosed with epilepsy, and a total of roughly 112.000 people have epilepsy.

The diagnosis epilepsy is made after the occurrence of at least two unprovoked epileptic seizures. An epileptic seizure is a transient occurrence of signs and/ or symptoms due to abnormal excessive or synchronous neuronal discharge in the brain. ${ }^{1}$ Seizures are classified into two major types: generalized seizures and partial seizures. Generalized seizures are those in which the first clinical changes indicate initial involvement of both hemispheres. The EEG patterns during seizures initially are bilateral and reflect abnormal neuronal discharge that is widespread in both hemispheres. ${ }^{4}$ For example, an abrupt loss of consciousness and blinking of both eyes with corresponding EEG changes in both hemispheres (Figure 1). Partial seizures are those in which, in general, the first clinical and electroencephalographic (EEG) changes indicate abnormal neuronal discharge that is limited to a part of one hemisphere. ${ }^{4}$ For example, a seizure which starts with a sudden stiffening of the right leg (only) with corresponding EEG changes in the left frontal lobe (Figure 2). Subsequently, partial epilepsies can be classified according to their anatomical origin, such as temporal lobe epilepsies and frontal lobe epilepsies.

After separating epilepsies with partial seizures from epilepsies with generalized seizures, an etiological division can be made. Etiologically, three subtypes are distinguished: 1) structural or metabolic epilepsies, 2) genetic epilepsies, and 3) epilepsies of unknown cause. In structural or metabolic epilepsy (previously called symptomatic epilepsy) the epileptic seizures are a result of one or more identifiable structural lesions of the brain or of a metabolic condition that is associated with a substantially increased risk of developing epilepsy. In genetic (previously called idiopathic) epilepsy there is no underlying cause other than a possible hereditary predisposition. Epilepsy of unknown cause (previously 


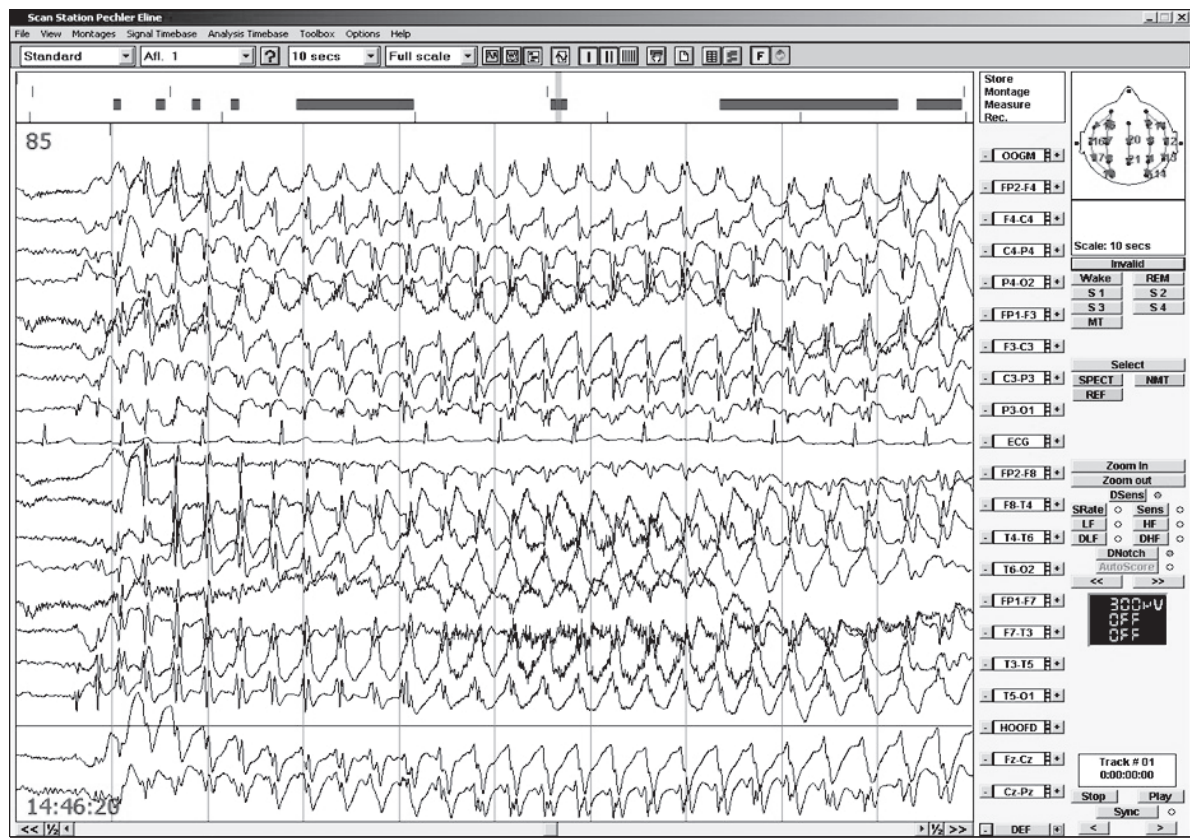

Figure 1. EEG of a generalized seizure in a 9-year-old child. The epileptic activity is bilateral and widespread in both hemispheres (i.e., all electrodes demonstrate rhythmic epileptic spike and wave complexes).

called cryptogenic epilepsy) is used for defining syndromes for which no etiology has been identified. ${ }^{4}$

\section{Frontal lobe epilepsy}

Frontal lobe epilepsy (FLE), that is localization-related epilepsy with a primary seizure focus anywhere within the frontal lobe, represents the second most common form of localization-related epilepsies, after temporal lobe epilepsy. While the exact incidence of FLE is unknown, it is estimated that 20 to 30 percent of patients with localization-related epilepsy has an epileptogenic focus in the frontal lobe. ${ }^{5,6}$ As the frontal lobe is the largest of all brain lobes, a wide variety of different types of seizures can occur from a frontal lobe origin, depending on the localization of the seizure focus and subsequent spread of seizure activity. ${ }^{7}$

In general, frontal lobe seizures are brief (varying from seconds to two minutes), stereotypic (every seizure is similar in an individual patient), often nocturnal, and frequent. Clinical features often include an abrupt onset consecutive to a precedent aura, impaired consciousness, motor signs such as tonic posturing, myoclonia and automatisms (for example kicking or bicycling of the legs), 


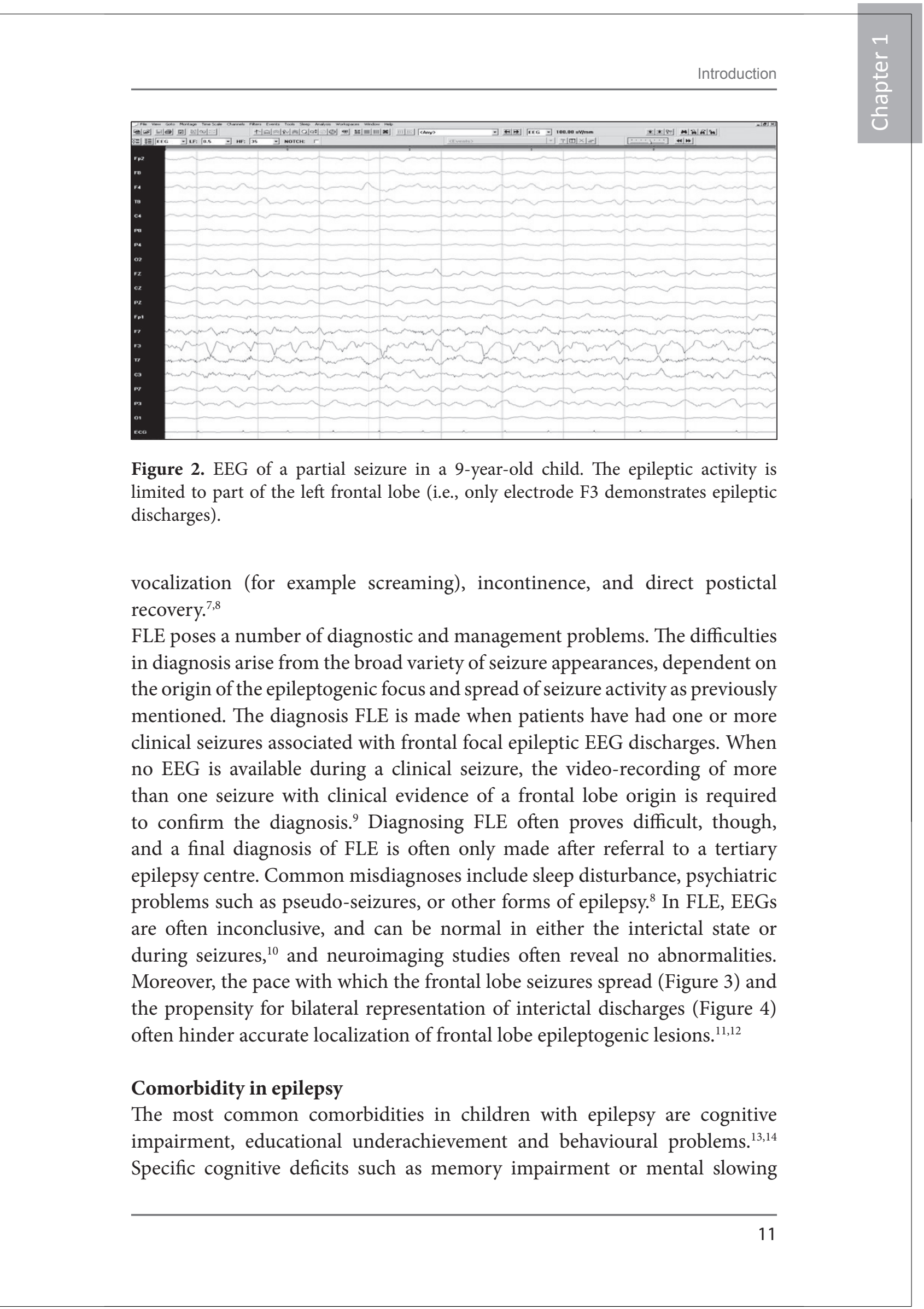




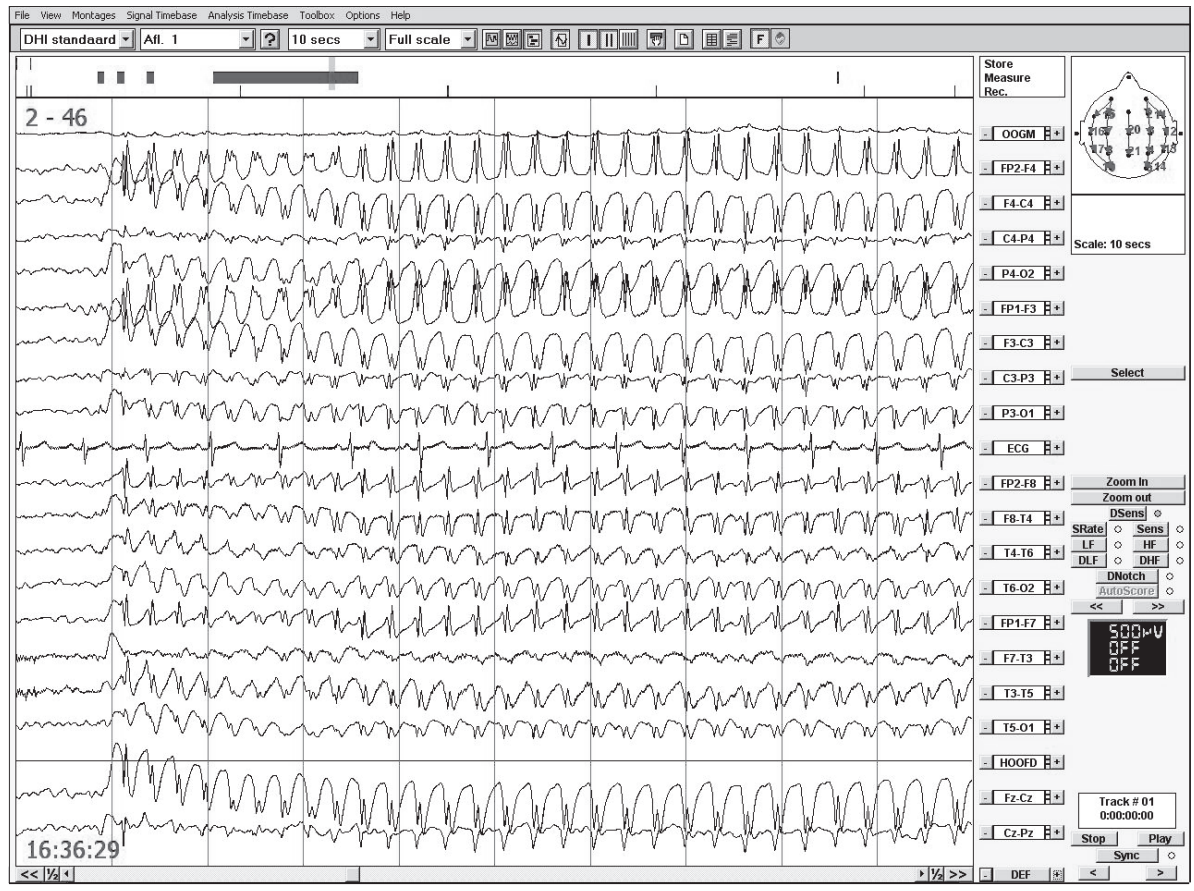

Figure 3. EEG of a frontal seizure in an 11-year-old child with a rapidity of seizure spread that suggests a bifrontal onset (i.e., the epileptic spike and wave complexes start and have their highest amplitude within both frontal lobes (all F-electrodes)).

may occur in children regardless of intelligence level and influence academic achievement and social interactions. ${ }^{15}$

In adults with FLE, cognitive deficits and behavioural disturbances range from impaired attention to difficulty with the more complex behaviours involved in planning, selecting goals, anticipating outcomes, and initiating actions. ${ }^{16-21}$ The impact of FLE on cognitive functioning and behaviour in children remains largely unknown. Moreover, the exact mechanisms that cause cognitive impairment in FLE remain unsolved.

\section{Aims and outline of this thesis}

Within this thesis, we first aimed to gain insight in cognitive functioning and behaviour in children with FLE. Therefore, in chapter 2, we reviewed the literature to investigate the main comorbid disorders, i.e., cognitive impairment and behavioural disturbances in children with FLE. Subsequently, we investigated the cognitive and behavioural outcomes in 71 children with FLE of unknown cause seen at the Epilepsy Centre Kempenhaeghe and investigated potential risk factors for cognitive impairment and behavioural disturbances. 


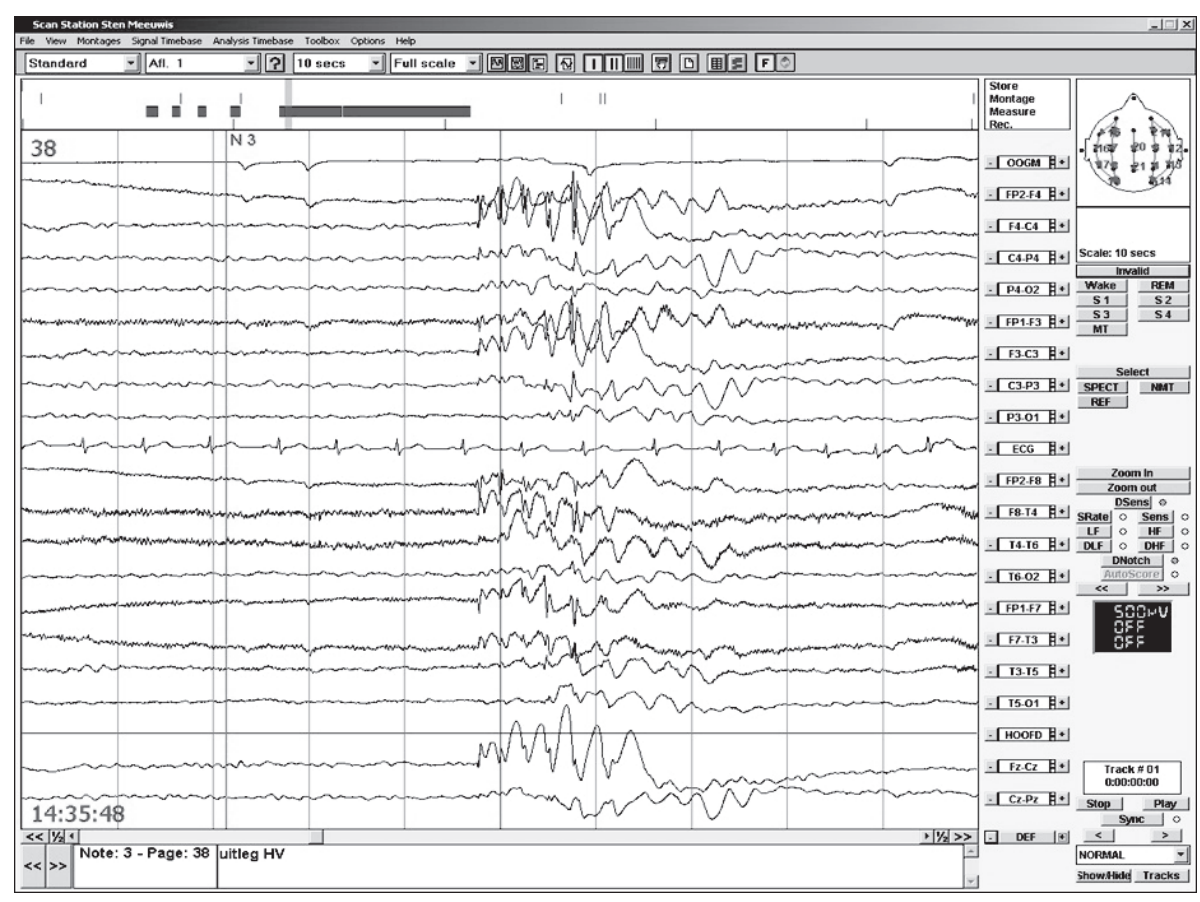

Figure 4. EEG of an interictal paroxysm consisting of bifrontal (i.e., on all F-electrodes) synchronous epileptiform discharges without clinical manifestations in a 4-year-old child with frontal lobe epilepsy.

Our second aim was to gain more insight in the neuronal correlates of cognitive impairment in children with FLE of unknown cause. FLE of unknown cause implies that affected patients have no macrostructural brain abnormalities that could explain the cognitive impairment. Thus, clues for an etiology of cognitive impairment may be found at the brain's functional or microstructural level. We hypothesized that with advanced magnetic resonance imaging (MRI) techniques, that is, functional MRI (fMRI), volumetric MRI, and diffusion tensor imaging (DTI), and graph theoretical analysis, we could detect abnormalities at the functional or microstructural level that are associated with cognitive impairment.

In chapter 3, the rationale to apply these newer MRI techniques in the investigation of cognitive impairment in children with epilepsy was addressed in a literature review of previous MRI studies addressing cognitive functioning in epilepsy.

Hereafter, we applied three different MRI techniques, i.e., fMRI in chapter 4, volumetric MRI in chapter 5, and DTI in chapter 6, in a prospectively enrolled cohort of children with FLE of unknown cause as well as an equal number of 
healthy age-matched controls, to investigate functional and microstructural abnormalities associated with FLE and cognitive impairment. To be able to investigate differences between cognitively unimpaired and impaired patients, all enrolled cases and controls underwent full neuropsychological assessment. The topological organization of the cerebral network was studied in chapter 7. In this chapter, we compared graph theoretical measures derived from functional brain networks of children with FLE with those of the healthy controls and related findings to cognitive performance.

Finally, chapter 8 is a general discussion of the results and conclusions from the constituting chapters. 


\section{References}

1. Fisher RS, van Emde Boas W, Blume W, Elger C, Genton P, Lee P, Engel J Jr. Epileptic seizures and epilepsy: definitions proposed by the International League Against Epilepsy (ILAE) and the International Bureau for Epilepsy (IBE). Epilepsia 2005;46:470-472.

2. Ngugi AK, Bottomley C, Kleinschmidt I, Sander JW, Newton CR. Estimation of the burden of active and life-time epilepsy: a meta-analytic approach. Epilepsia 2010;51:883-890.

3. Hirtz D, Thurman DJ, Gwinn-Hardy K, Mohamed M, Chaudhuri AR, Zalutsky R. How common are the "common" neurologic disorders? Neurology 2007;68:326-337.

4. Berg AT, Berkovic SF, Brodie MJ, Buchhalter J, Cross JH, van Emde Boas W, Engel J, French J, Glauser TA, Mathern GW, Moshé SL, Nordli D, Plouin P, Scheffer IE. Revised terminology and concepts for organization of seizures and epilepsies: report of the ILAE Commission on Classification and Terminology, 2005-2009. Epilepsia 2010;51:676-685.

5. Williamson PD. Frontal lobe seizures. Problems of diagnosis and classification. Adv Neurol 1992;57:289-309.

6. Manford M, Hart YM, Sander JW, Shorvon SD. National General Practice Study of Epilepsy (NGPSE): partial seizure patterns in a general population. Neurology 1992;42:1911-1917.

7. Jobst BC, Siegel AM, Thadani VM, Roberts DW, Rhodes HC, Williamson PD. Intractable seizures of frontal lobe origin: clinical characteristics, localizing signs, and results of surgery. Epilepsia 2000;41:1139-1152.

8. Sinclair DB, Wheatley M, Snyder T. Frontal lobe epilepsy in childhood. Pediatr Neurol 2004;30:169-176.

9. Provini F, Plazzi G, Tinuper P, Vandi S, Lugaresi E, Montagna P. Nocturnal frontal lobe epilepsy. A clinical and polygraphic overview of 100 consecutive cases. Brain 1999;122:1017-1031.

10. Williamson PD, Spencer DD, Spencer SS, Novelly RA, Mattson RH. Complex partial seizures of frontal lobe origin. Ann Neurol 1985;18:497-504.

11. Rasmussen T. Characteristics of a pure culture of frontal lobe epilepsy. Epilepsia 1983;24:482-493.

12. Wieser HG, Swartz BE, Delgado-Escueta AV, Bancaud J, Walsh GO, Maldonado H, Saint-Hilaire JM. Differentiating frontal lobe seizures from temporal lobe seizures. In: Chauvel P, Delgado-Escueta AV, eds. Advances in Neurology, vol 57. Frontal lobe epilepsy. New York: Raven Press, 1992:267-285.

13. Aldenkamp AP, Weber B, Overweg-Plandsoen WC, Reijs R, van Mil S. Educational underachievement in children with epilepsy: A model to predict the effects of epilepsy on educational achievement. J Child Neurol 2005;20:175-180.

14. Motamedi G, Meador K. Epilepsy and cognition. Epilepsy Behav 2003;4:S25-38.

15. Sparrow S, Davis S. Recent advances in the assessment of intelligence and cognition. J Child Psychol Psychiatry 2000;41:117-131.

16. Helmstaedter C, Kemper B, Elger CE. Neuropsychological aspects of frontal lobe epilepsy. Neuropsychologia 1996;34:399-406.

17. Helmstaedter C, Gleibner U, Zentner J, Elger CE. Neuropsychological consequences of epilepsy surgery in frontal lobe epilepsy. Neuropsychologia 1998;36:333-341.

18. Upton D, Thompson PJ. General characteristics of frontal lobe epilepsy. Epilepsy Res 1996;23:169177.

19. Upton D, Thompson PJ. Neuropsychological test performance in frontal-lobe epilepsy: the influence of aetiology, seizure type, seizure frequency and duration of disorder. Seizure 1997;6:443-447.

20. Upton D, Thompson PJ. Age at onset and neuropsychological function in frontal lobe epilepsy. Epilepsia 1997;38:1103-1113.

21. Exner C, Boucsein K, Lange C, Winter H, Weniger G, Steinhoff BJ, Irle E. Neuropsychological performance in frontal lobe epilepsy. Seizure 2002;11:20-32. 


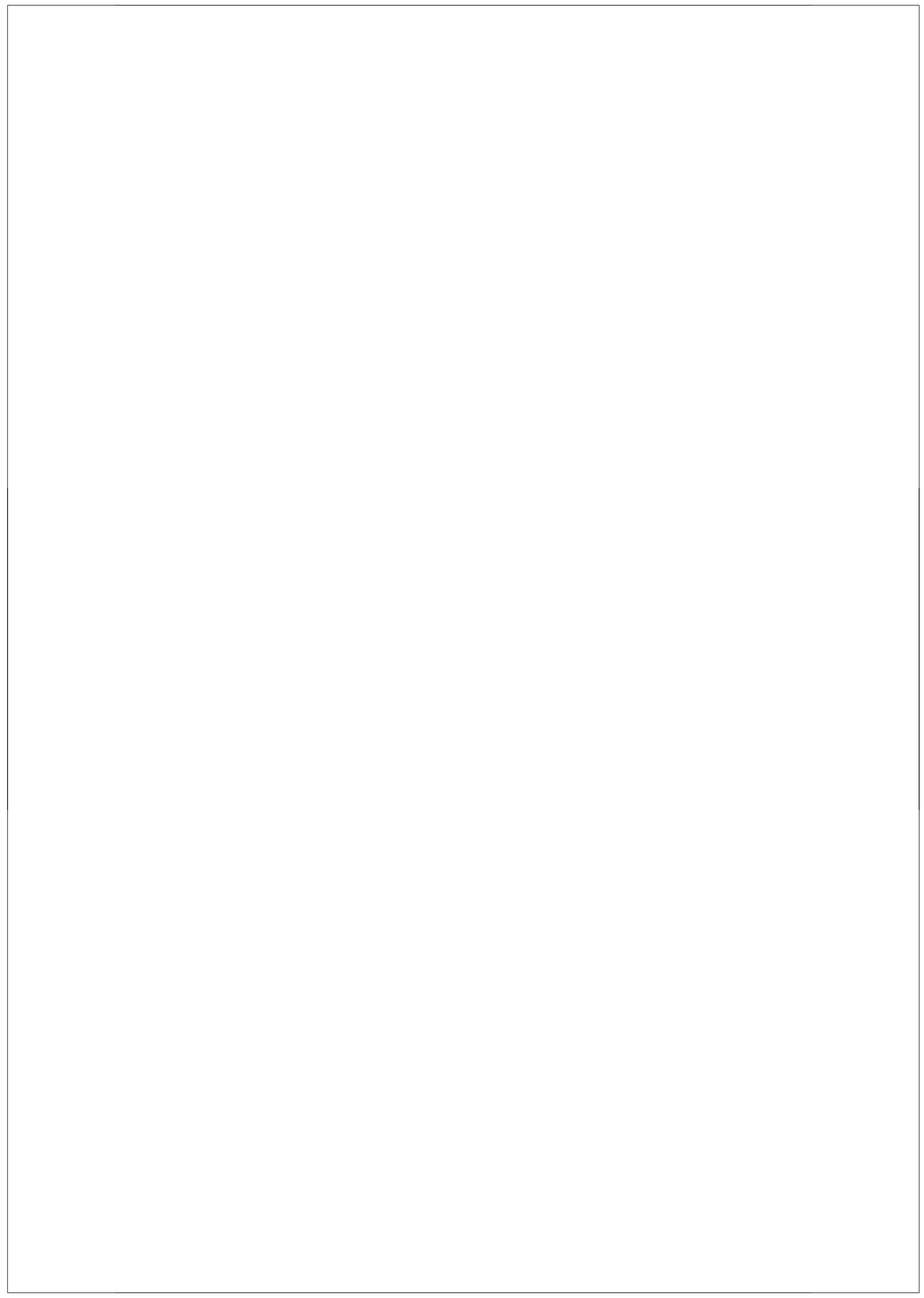




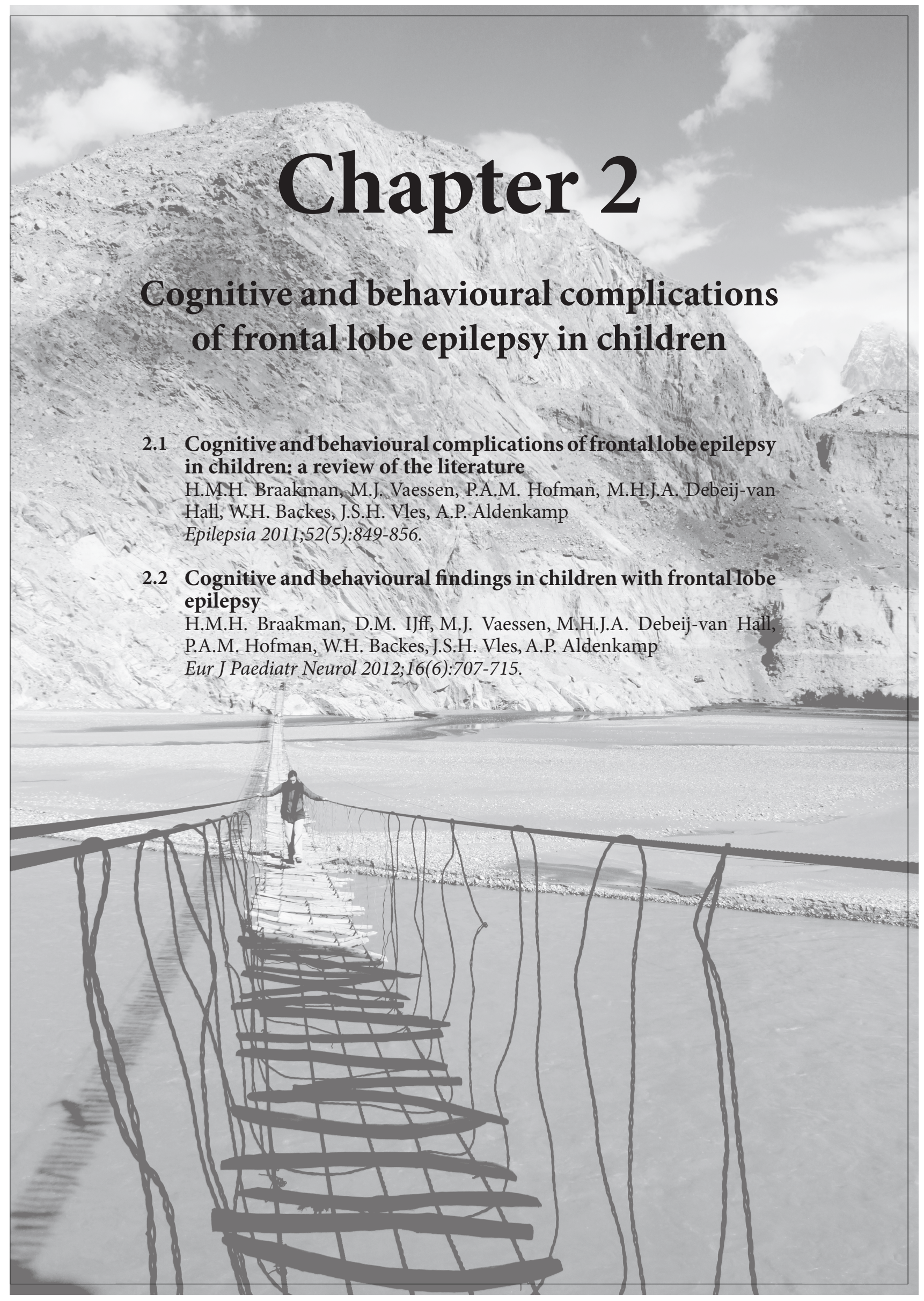




\section{Summary}

Frontal lobe epilepsy (FLE) is considered the second most common type of the localization-related epilepsies of childhood. Still, the etiology of FLE in children, its impact on cognitive functioning and behaviour, as well as the response to antiepileptic drug treatment in children has not been sufficiently studied. This review focuses on these aspects of FLE in childhood, and reveals that FLE in childhood is most often cryptogenic, and impacts on a broad range of cognitive functions. The nature and severity of cognitive deficits are highly variable, although impaired attention and executive functions are most frequent. Young age at seizure onset is the only potential risk factor for poor cognitive outcome that has been consistently reported. The behavioural disturbances associated with FLE are also highly variable, although attention deficit/hyperactivity disorder seems most frequent. In $40 \%$ of children with FLE satisfactory seizure control could not be achieved. This is a higher percentage than reported for the general population of children with epilepsy. Therefore, pediatric FLE, even if cryptogenic in nature, is frequently complicated by impairment of cognitive function, behavioural disturbances and therapyresistance. Given the impact of these complications, there is a need for studies of the etiology of frontal lobe epilepsy-associated cognitive and behavioural disturbances, as well as pharmacotherapy-resistance. 


\section{Cognitive and behavioural complications of frontal lobe epilepsy in children: a review of the literature}

\section{Introduction}

Frontal lobe epilepsy (FLE) is considered the second most common type of the localization-related (partial) epilepsies of childhood, after temporal lobe epilepsy, and accounts for $20-30 \%$ of partial epilepsies, although data on its exact incidence are lacking. ${ }^{1}$

The frontal lobes play pivotal roles in cognitive functioning and behaviour, as they mediate essential functions: 1) basic neurological functions, including motor functions, control of continence, and olfaction; 2) voluntary eye movements; 3) speech and language abilities; 4) executive functions; 5) motivational behaviours; and 6) social competency. ${ }^{2}$ Consequently, both structural lesions and functional lesions, such as an epileptic focus, within the frontal lobes may interfere with a variety of these functions and can lead to impairments of cognitive functioning and behavioural disturbances. In adults with FLE, cognitive deficits and behavioural disturbances range from impaired attention to difficulty with the more complex behaviours involved in planning, selecting goals, anticipating outcomes and initiating actions. ${ }^{3-8}$ The impact of FLE on cognitive functioning and behaviour in children remains largely unknown.

In addition to neuropsychological complications, FLE is frequently complicated by pharmacotherapy-resistance. In adult patients referred to epilepsy surgery centres, frontal lobe epilepsy represents $15 \%-30 \%$ of pharmacotherapyresistant seizure disorders. ${ }^{3,9}$ For adults, pharmacotherapy-resistant epilepsy is associated with increased morbidity from seizures and medication, social isolation, unemployment, and overall reduced quality of life. ${ }^{10}$ Yet not all patients with FLE will develop pharmacoresistance, and the mechanisms that result in either seizure control or refractoriness have not been explored. This review summarizes the available literature on the etiology of FLE in children, its impact on cognitive functioning and behaviour, as well as the response to antiepileptic drug treatment, and it explores areas for future research. Surgical therapy and the effects of surgical therapy on cognitive and behavioural outcomes fall outside the scope of this review. 
Table 1. Etiology of frontal lobe epilepsy in children.

\begin{tabular}{lcl} 
References & Number of patients & Etiology on basis of MRI \\
\hline Auclair et al. ${ }^{25}$ & 8 & $\begin{array}{l}3 / 8 \text { symptomatic } \\
5 / 8 \text { cryptogenic }\end{array}$ \\
Aoyagi et al. ${ }^{24}$ & 12 & $5 / 12$ symptomatic \\
& & $7 / 12$ cryptogenic \\
Jocić-Jakubi et al. ${ }^{26}$ & 10 & $10 / 10$ cryptogenic \\
Lagae et al. ${ }^{12}$ & 7 & $7 / 7$ cryptogenic \\
Lawson et al. & & $12 / 38$ symptomatic \\
& 38 & $26 / 38$ cryptogenic \\
Nolan et al. ${ }^{23}$ & 25 & $7 / 25$ symptomatic \\
& & $18 / 25$ cryptogenic \\
Sinclair et al. ${ }^{14}$ & 22 & $4 / 22$ symptomatic \\
& & $18 / 22$ cryptogenic \\
Total & 122 & $91 / 122(25 \%)$ symptomatic \\
\end{tabular}

\section{Search strategy and selection criteria}

Data for this review were identified by searches of PubMed (National Centre for Biotechnology Information; NCBI; http://www. ncbi.nlm.nih.gov/ pubmed/) in January 2010 using the Medical Subject Heading (MeSH) terms "Epilepsy, Frontal Lobe", "Epilepsies, Partial" and "Epilepsy, Complex Partial". For the latter two, the text variable "frontal" was added to narrow the search. Subheadings "classification", "complications", "drug therapy", "epidemiology", "etiology", "psychology", "radiography" and "therapy" were applied, with limits: "All child 0-18 years" and "English". References from relevant original and review articles and book chapters were also used.

\section{Etiology of FLE in childhood}

The average age at onset of FLE ranges from 4.6 to 7.5 years. ${ }^{11-14}$ From the available literature, it is difficult to assess the relative incidences of the three etiologies of FLE: symptomatic, cryptogenic and idiopathic. In general, most studies focus on adults. Moreover, existing pediatric studies are case series that frequently include etiology in their exclusion criteria, or reports of single cases, leading to substantial bias. ${ }^{11,13,14-22}$ We found seven studies, with a total of 122 children with FLE that applied magnetic resonance imaging (MRI) to determine FLE etiology in unselected groups; we have summarized their respective findings in Table 1. ${ }^{12-14,23-26}$ Cryptogenic FLE was most common in children, as MRI revealed no structural abnormalities in 91 out of 122 children (75\%), whereas 31 children (25\%) had lesions suggesting a symptomatic nature of their FLE. 


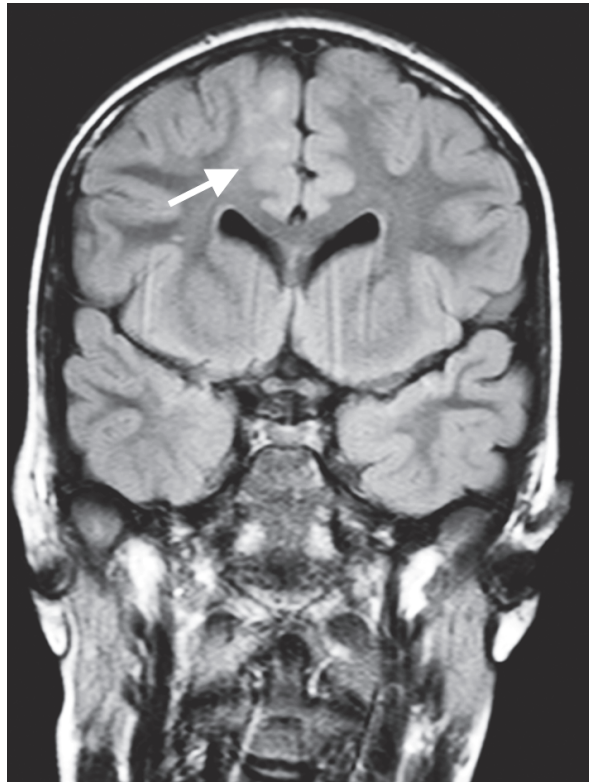

Figure 1. Coronal fluid-attenuated inversion recovery (FLAIR) image; arrow marks an area of focal cortical dysplasia.

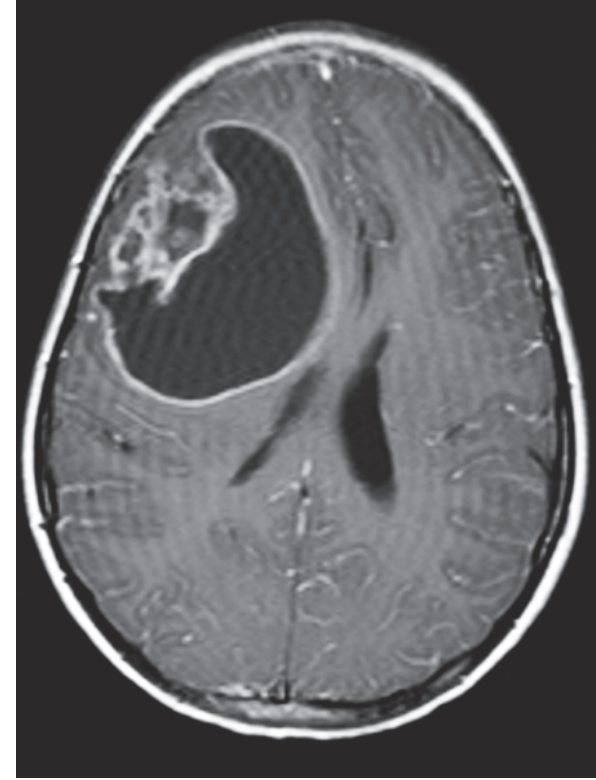

Figure 2. Axial T1-weighted gadoliniumenhanced image of a high-grade astrocytoma.

In studies that included children with symptomatic FLE, the etiology of the lesions differed. ${ }^{13,14,23-26} \mathrm{We}$ found a total of six studies, including 31 patients; focal cortical dysplasia $(n=13)$ (see Figure 1$)$, infarction $(n=5)$, and low-grade and high-grade tumors $(\mathrm{n}=3)$ (see Figure 2 ) were most frequent. Rarely, lesions resulted from hemorrhage $(n=1)$, cortical tuber $(n=1)$, or porencephaly $(n=$ 1). ${ }^{13,14,24-26}$ In one study, MRI lesions were not further specified $(n=7){ }^{23}$

\section{Cognitive and behavioural functioning in children with FLE}

\section{Cognitive functioning in children with FLE}

The associations between FLE and cognitive and behavioural functioning have been studied in more detail. The first representative case describing cognitive deficits associated with cryptogenic FLE was reported by Boone et al. in $1988 .{ }^{15}$ They described a 13 -year-old girl with impaired performance on tasks that measure attention and concentration and impairments of verbal fluency, ability to shift cognitive set, motor speed, motor functioning, planning abilities, and response inhibition. Other frontal lobe executive functions 
Table 2. A summary of the main studies of children with FLE who had undergone neuropsychological assessment and their findings.

\begin{tabular}{|c|c|c|}
\hline References & $\begin{array}{l}\text { Number of } \\
\text { patients }\end{array}$ & Neuropsychological impairments \\
\hline Auclair et al. ${ }^{25}$ & 8 & Attention deficits \\
\hline Culhane-Shelburne et al. ${ }^{17}$ & 12 & Deficits in executive functions \\
\hline Hernandez et al..$^{21}$ & 16 & Deficits in executive functions, attention, and behaviour \\
\hline Lassonde et al. ${ }^{16}$ & 16 & $\begin{array}{l}\text { Deficits in executive functions, attention, behaviour, and } \\
\text { motor skills }\end{array}$ \\
\hline Lendt et al. ${ }^{18}$ & 12 & $\begin{array}{l}\text { Deficits in motor coordination, short- and long-term } \\
\text { memory, attention, and executive functions }\end{array}$ \\
\hline Nolan et al. ${ }^{23}$ & 25 & Memory impairment \\
\hline Prévost et al. ${ }^{22}$ & 21 & $\begin{array}{l}\text { Deficits in attention, behaviour, language, memory, and } \\
\text { cognition }\end{array}$ \\
\hline Riva et al. ${ }^{19}$ & 8 & Deficits in attention, behaviour, and executive functions \\
\hline Riva et al..$^{20}$ & 17 & Deficits in executive functions \\
\hline Sinclair et al. ${ }^{14}$ & 14 & $\begin{array}{l}\text { Below normative IQ scores, impaired fine-motor } \\
\text { coordination, deficits in attention, behaviour and } \\
\text { executive functions }\end{array}$ \\
\hline
\end{tabular}

such as categorization, sequencing, and conceptual flexibility had remained intact. The deficits were reversible once seizures were sufficiently controlled with antiepileptic drug (AED) treatment. Similarly, in 1989, Jambaqué and Dulac observed deterioration of verbal fluency and attention span and marked behavioural and affective changes in an 8-year-old boy of normal intelligence, as well as reduced motor speed and planning ability with deterioration of handwriting, which abated with adequate seizure control. ${ }^{27}$ The fact that cognitive deficits improved in these two patients with the initiation of successful AED treatment suggests that they were caused by the seizures or interference by underlying epileptiform activity in affected frontal areas. In addition to these two illustrative case reports, our literature search yielded 10 case series, with a total of 149 children with FLE who had undergone neuropsychological assessment. ${ }^{14,16-22,25,28}$ A summary of the main studies and their findings is recorded in Table 2. Most existing studies are comparative in nature and compare cognitive functioning of children with FLE with children with temporal lobe epilepsy and generalized epilepsy. ${ }^{16,17,21,28}$ In this comparison, children with FLE typically have impairments in executive functions [mainly planning ability, response inhibition, (visuospatial) organization, verbal search, mental flexibility, impulse control, working memory and programming of complex motor sequences], motor coordination, and attention deficits. ${ }^{16,17,21,28}$ The term "executive functions" refers to the mental processes involved in the realization of goal-directed behaviour, whether expressed through a mental or a motor act. ${ }^{29}$ They are generally thought to control formulation, planning, 
and effective performance of goal-directed actions. ${ }^{29}$ Perhaps as a result, the impairments in executive functions also give rise to impaired reading and mathematical skills. ${ }^{12}$

FLE impacts on a wide scale of cognitive domains other than the executive functions. In one case series of six children with a left frontal epileptogenic focus, a clear dissociation in linguistic performance between comprehension and production was noted. ${ }^{30}$ Linguistic comprehension was initially impaired, but gradually improved to reach normal performance levels by age 7 , whereas linguistic production, even at later stages, remained poor. This dissociation in the development of linguistic performance in children with left-sided FLE suggests a complex interplay between brain maturation dynamics and FLE-associated dysfunction, modulating the succession of stages in language development. Other researchers have also noted language deficits in children with FLE, including impaired verbal fluency and impaired verbal search. ${ }^{15,16,22,27}$

Memory deficits have long been attributed mainly to temporal lobe epilepsy; their association with FLE remains controversial. Because memory deficits have been associated specifically with mesial temporal lobe pathology, children with FLE may not be routinely tested for their memory skills. Nevertheless, four studies have noted these deficits in their patients with FLE. ${ }^{18,22,23,31}$ In one study, longer duration of active epilepsy was the most significant risk factor for memory impairment. ${ }^{23}$ In contrast, other case series have examined this subject and found memory functions intact. ${ }^{27}$

The overall impact of FLE on intelligence, as measured by intelligence quotient (IQ) scores, remains a subject of debate. Intelligence is defined as a person's capacity to (1) acquire knowledge (i.e., learn and understand), (2) apply knowledge (solve problems), and (3) engage in abstract reasoning. ${ }^{32}$ Although some case series of children with FLE have reported that IQ was spared, despite various impairments of cognitive function, ${ }^{19,20}$ others have reported a decline in IQ scores. ${ }^{14,22,28}$ Here, too, selection bias is an important issue; a normal IQ score has been used as an inclusion criterion for neuropsychological assessment in case series. ${ }^{16,17,21}$ Interesting similarities between the cognitive impairments of children and adult patients with FLE exist. In adults, neuropsychological deficits are also prevalent. The nature and severity of cognitive deficits in adult FLE patients are highly variable, although here, too, impaired attention and executive functions are most frequent. ${ }^{3,4,6-8}$ Unfortunately, studies tend to focus on the typical frontal lobe functions (e.g. executive functions), disregarding functions typical of other lobes, such as memory, which is regarded as a temporal lobe function. . $^{1920,33}$ 


\section{How site-specific are cognitive deficits?}

One would assume that the pattern of deficits observed in patients with epilepsy reflects the functions controlled in the area that yields the epileptic focus. Indeed, temporal lobe epilepsy is associated with cognitive deficits specific to the temporal lobe functions, mainly learning (especially reading) and memory. Yet, frontal lobe dysfunction has been noted in up to $84 \%$ of children and adolescents with temporal lobe epilepsy. ${ }^{34,35}$ These patients had impairments in mental flexibility and set shifting, perseveration, inhibitory control, verbal fluency, and maintenance of attention. ${ }^{35}$ It has been hypothesized that a wider anatomical and functional network connects temporal and frontal lobes and allows the temporal epileptogenic focus to affect the frontal and prefrontal functional regions. ${ }^{34,35}$ In accordance with this hypothesis, recent functional neuroimaging studies demonstrated hypometabolism in the prefrontal regions of patients with TLE. ${ }^{36}$ This hypometabolism may represent a dynamic process of protection against epileptiform discharge propagation by frontal lobe function inhibition. ${ }^{36}$ Nevertheless, it is likely responsible for the cognitive deficits, suggestive of frontal lobe dysfunction, presented by these patients.

There is more evidence that localized epileptic foci impact on connected distal structures and regions. In patients with an epileptogenic focus in the hippocampus, ipsilateral reductions in grey-matter density in the lateral temporal lobe, as well as extra-temporal regions, including the thalamus, posterior cingulate cortex, cerebellum, and frontal and parietal opercular cortex have been noted. ${ }^{37}$ This suggests that structural changes occur in areas connected to, although not part of, the epileptogenic focus. ${ }^{37}$

Whether these structural changes in areas connected to the epileptogenic focus are permanent or reversible remains a subject of debate. ${ }^{35,36}$ Similarly the post aut propter debate is relevant here; we do not know whether such structural changes precede or follow functional disconnection and thus whether they are causally associated with cognitive impairment.

The same principle applies to hemispheric specificity in the frontal lobes. Although one expects linguistic impairments specifically in FLE with a left hemispheric epileptogenic focus, no such correlations between the affected hemisphere and hemisphere-specific cognitive deficits have been noted. ${ }^{3,20,33}$ Because epileptic discharges have a tendency for fast propagation, it is possible that the functioning of other connected frontal areas is simultaneously affected. ${ }^{20}$ This may include areas of the contralateral lobe. ${ }^{3}$ Two separate case series did not detect differences in test performance between subjects with bilateral and unilateral foci. ${ }^{17,33}$

All previously discussed studies provide evidence that, through neural networks, epileptogenic foci affect connected regions and the functions that 
are organized in such areas. It is, therefore, clear that the relationship between site of the epileptogenic focus and type of cognitive impairment is far from straightforward. Studying the frontal neural networks in patients with FLE, or in fact temporal lobe epilepsy with frontal lobe dysfunction, may yield important clues on the association between the site of the epileptogenic focus and the pattern of cognitive deficits. Recently, prospective memory, that is, the ability to fulfill previously planned intentions, was studied in patients with juvenile myoclonic epilepsy (JME), their unaffected siblings, and healthy controls. Not only patients with JME, but also their siblings, showed deficits on the prospective memory task. ${ }^{38}$ These findings strongly support a genetic predisposition of the distinct neuropsychological impairment patterns, which might be caused by thalamo-frontal-cortical network dysfunction. This hypothesis is supported by a quantitative MRI study on newly diagnosed patients with JME demonstrating impaired executive functioning and structural changes in both the frontal lobes and thalami in early disease. ${ }^{39}$

\section{Risk factors}

Risk factors for the development and severity of cognitive deficits in children with FLE are unclear. Studies of the impact of epilepsy-related factors, such as age at seizure onset and seizure type or frequency, have revealed mostly conflicting results. Age at onset has been proposed as a risk factor associated with cognitive impairments, ${ }^{19,20,22,28,33,40}$ as has seizure frequency, ${ }^{19,28,40}$ localization of the epileptic focus, ${ }^{19}$ use of more than two AEDs, ${ }^{28,40}$ and duration of epilepsy. ${ }^{20,23}$ Although these associations seem to have some merit, they have been opposed by other studies. ${ }^{22,33}$ Developmental regression associated with periods of poor seizure control or status epilepticus has been described in patients with autosomal dominant nocturnal FLE. ${ }^{40}$ In other studies, similar correlations between cognitive impairment and seizure frequency could not be established. ${ }^{20}$ The only potential risk factor that came up in multiple studies was the age at seizure onset; younger ages at onset were a risk factor for poor cognitive outcome. An early onset of epilepsy and longer duration of the disorder, rather than the frequency of the seizures, led to impairments in frontal functions; these, however, show large inter-individual differences. ${ }^{16,19,20,22}$

\section{Prevalence of cognitive impairment in FLE: the great unknown}

The prevalence of cognitive impairment in children with FLE remains unclear. Very few epidemiologic studies have been performed, and this is an area that warrants future research. Upon examination of the existing case series, it seems that cognitive impairment is frequent in children with FLE, although considerable intra- and inter-individual variation in cognitive performance 
exists. ${ }^{19}$ Interestingly, in children with FLE, the learning difficulties may even precede seizure onset. ${ }^{22}$ This suggests an underlying condition - which could be microstructural or functional in nature - that manifests itself both in cognitive impairment and seizures.

\section{Behavioural disturbances in children with FLE}

It has long been recognized that frontal lobe dysfunction can result in a range of behavioural problems, including distractibility, disinhibition, and aggression, ${ }^{15}$ and direct evidence exists of frontal lobe dysfunction in schizophrenia and depression. ${ }^{40,41}$ Because the cognitive impairments associated with FLE include attention deficits and impairments of response inhibition and impulse control, ${ }^{16-}$ $18,21,33$ it makes sense that these give rise to behavioural disturbances. Several case series mention behavioural disturbances in children with FLE. ${ }^{12,14-19,21,22,25-}$ ${ }^{27,40}$ Behavioural disturbances come in many varieties in children with FLE; they can be (1) the only manifestation of frontal seizures, (2) be characteristic of the postictal phase, or (3) represent a lasting "interictal" condition associated with FLE.

FLE seizures can manifest themselves with various behavioural changes such as mood change, sudden agitation or quietness, subtle changes of awareness or awakening, and subtle decrease in motor activity or social interaction. ${ }^{42}$

In one report of two cases, postictal or interictal psychosis was noted secondary to frequent frontal lobe seizures, which presented as delusional thinking, depression, paranoia, aggression, and bizarre behaviour in conjunction with brief stereotypic events of sudden screaming, agitation, and physical aggression. ${ }^{43}$ Psychosis disappeared with adequate seizure control.

The behavioural disturbances associated with FLE are highly diverse, although attention deficit/hyperactivity disorder (ADHD) seems most frequent. ADHD is defined as symptoms of inattentiveness and/or hyperactivity and impulsivity inappropriate for age and gender, to a degree sufficiently significant to cause impairment in daily functioning. ${ }^{44}$ The attention deficits in these children are thought to be attributable to an inability to ignore irrelevant stimuli. ${ }^{25}$ Combined with a tendency to respond impulsively, ADHD is likely to develop in children with FLE. ${ }^{19,21,22}$ The prevalence of ADHD in children with FLE has not been systematically studied, although a prevalence of up to $67 \%$ has been reported in a case series. ${ }^{22}$ The majority of these children exhibited typical ADHD, whereas a minority exhibited oppositional behaviour, impulsivity, or anxiety as a comorbidity of FLE. ${ }^{22}$ Other studies have described psychotic as well as autistic features in children with FLE. ${ }^{42,43}$

Parent ratings of behaviour and social functioning in their children with FLE indicated greater than normal problems with attention, ${ }^{14,16,21}$ social 
withdrawal, ${ }^{14,16}$ thought problems, ${ }^{14,16}$ and internalizing behaviour in general. ${ }^{14,21}$

The risk factors for these behavioural disturbances are not fully understood. Seizure frequency and poor seizure control have been proposed as risk factors associated with attention difficulties and inability to inhibit impulsive responses, as these disturbances improved with adequate seizure control. ${ }^{18,19,27,40}$ The efficacy of seizure control in these cases suggests that a functional disturbance of the brain regions involved in the regulation of attention and behaviour is responsible for the induction of these symptoms.

Even if the behavioural disturbances seem FLE-related, it needs to be emphasized that no systematic studies have investigated whether these behavioural disturbances are more prevalent in children with FLE than in the normal population. Regardless of whether they are FLE related, these behavioural disturbances interfere with the children's school performance, which may be aggravated by cognitive deficits. In a previously discussed case series, all children with FLE and attention deficits with or without hyperactivity required special academic support. ${ }^{16}$

Given the impact of these behavioural disturbances and their seemingly high prevalence, there is a need for studies of the etiology of FLE-associated behavioural disturbances. Various hypotheses now exist. First, functional anatomic relationships have been considered; the high prevalence of similar psychiatric changes among patients with primary frontal and primary temporal epileptogenic zones has been related to the intimate connection of the frontal and temporal limbic systems. ${ }^{45}$ Second, cognitive and behavioural problems can be the result of the epilepsy-related factors, including the age of onset of seizures, the number of seizures, the occurrence of secondary generalized seizures, and the location and extension of the epileptic focus. ${ }^{42}$ Third, the association between psychosis or ictal fear and FLE has been related to the reciprocal connections between amygdala, orbitofrontal, and anterior cingulated regions and between the frontal and temporal lobes through the uncinate fasciculus and the superior longitudinal fasciculus. ${ }^{46}$ Fourth, aggressive behaviour has been related to activation of limbic structures and loss of frontal suppression of limbic activity. Spreading of discharges from primary foci to other frontal, temporal or limbic structures may be another explanation. ${ }^{47}$ Separately, the epileptic activity may impact on the normal maturation of the brain; in epilepsy of early onset this disturbed maturation may explain specific deficiencies. ${ }^{42}$ 
Table 3. Therapy-resistance observed in existing studies.

\begin{tabular}{lcl} 
References & N (total) & \% Therapy resistance \\
\hline${\text { Jocić-Jacubi et al. }{ }^{26}}^{2}$ & 19 & $0(0 / 19)$ \\
Lagae et al. $^{12}$ & 10 & $70(7 / 10)$ \\
Prévost et al. $^{22}$ & 21 & $52(11 / 21)$ \\
Sinclair et al. ${ }^{14}$ & 22 & $50(11 / 22)$ \\
Total & 72 & $40(29 / 72)$ \\
\hline
\end{tabular}

\section{Response to antiepileptic drug treatment}

Treatment failure is a significant problem in epilepsy, including FLE. Treatment failure is defined as recurrent seizure(s) after the intervention has been adequately applied. ${ }^{48}$ Drug-resistant epilepsy is defined as failure of adequate trials of two tolerated, appropriately chosen, and used antiepileptic drug schedules (whether as monotherapies or in combination) to achieve sustained seizure freedom. ${ }^{49}$ Seizure freedom is defined as freedom from seizures, for a minimum of three times the longest preintervention interseizure interval or 12 months, whichever is longer. ${ }^{48}$

To assess the prevalence of treatment failure in FLE, we have combined data of all studies that reported on treatment content and outcome. We found only four studies, describing a total of 72 children with FLE, that recorded response to AED treatment. ${ }^{12,14,22,26}$ The response to therapy varied between these studies and is recorded in Table 3 , showing that seizure control was eventually achieved in 43 of the 72 children assessed (60\%); Seizure freedom was achieved after 8 weeks to 37 months. ${ }^{22,26}$ None were seizure free without AED use, 29 of 43 were seizure free with monotherapy, 14 of 43 with polytherapy. Monotherapy most frequently consisted of valproic acid or carbamazepine, ${ }^{19-22,40}$ whereas clobazam, lamotrigine, vigabatrin, phenytoin, phenobarbital, topiramate, levetiracetam and oxcarbazepine were used most frequently as adjunctive drugs. $^{21,22,40}$ Importantly, 29 (40\%) of 72 children assessed in these studies could not attain seizure control. This exceeds the $30 \%$ reported for the general epilepsy population..$^{50}$

Most studies investigating treatment outcome in children with FLE assess outcome after epilepsy surgery in children with drug-resistant FLE. These studies have been performed in tertiary reference centres or centres for epilepsy surgery and are, therefore, subject to selection bias. ${ }^{11,13,18,23}$

In epilepsy in general, regardless of localization, young age at seizure onset, a history of status epilepticus, the presence of underlying pathology, changes in type of epilepsy during the clinical course, and neonatal seizures have been identified as risk factors for therapy resistance. ${ }^{51}$ Specific causes of therapy 
resistance in FLE remain elusive. Drug target availability and drug delivery are among the many aspects that warrant additional study.

\section{Conclusions}

Pediatric FLE, even if cryptogenic in nature, is frequently complicated by impairment of cognitive function, behavioural disturbances, and therapy resistance. Cognitive impairment generally consists of impairment of executive functions and attention deficits, with consequences for school performance, although inter-individual variability is high, and even "typical" temporal lobe impairments such as memory impairment are found. Risk factors remain controversial, although a young age at seizure onset has been associated with cognitive impairments during childhood.

The behavioural disorders show even stronger inter-individual variability and might have a negative impact on existing cognitive impairment. ADHD is the most common disorder complicating pediatric FLE.

AED therapy-resistance may be more frequent in children with FLE than in other types of epilepsy, although its causative mechanisms need further research.

The fact that all these complications occur at a young age is troublesome. The brain is at its most vulnerable in childhood, when neurological disturbances such as FLE can impact on brain maturation and the acquisition of cognitive skills. FLE can impact on cognitive functioning in childhood, leading to learning disabilities. In turn, these disabilities may have a negative influence throughout life, in terms of social skills and level of education. 


\section{References}

1. Manford M, Hart YM, Sander JW, Shorvon SD. National General Practice Study of Epilepsy (NGPSE): partial seizure patterns in a general population. Neurology 1992;42:1911-1917.

2. Cummings JL, Miller BL. Conceptual and clinical aspects of the frontal lobes. In Bruce L, Miller MD, Jeffrey L, Cummings MD (Eds).The human frontal lobes: functions and disorders (the science and practice of neuropsychology), $2^{\text {nd }}$ ed, Chapter 2. The Guilford Press, New York, 2007:pp. 11-21.

3. Helmstaedter C, Kemper B, Elger CE. Neuropsychological aspects of frontal lobe epilepsy. Neuropsychologia 1996;34:399-406.

4. Helmstaedter C, Gleibner U, Zentner J, Elger CE. Neuropsychological consequences of epilepsy surgery in frontal lobe epilepsy. Neuropsychologia 1998;36:333-341.

5. Upton D, Thompson PJ. (1996) General characteristics of frontal lobe epilepsy. Epilepsy Res 1996;23:169-177.

6. Upton D, Thompson PJ. Neuropsychological test performance in frontal-lobe epilepsy: the influence of aetiology, seizure type, seizure frequency and duration of disorder. Seizure 1997;6:443-447.

7. Upton D, Thompson PJ. Age at onset and neuropsychological function in frontal lobe epilepsy. Epilepsia 1997;38:1103-1113.

8. Exner C, Boucsein K, Lange C, Winter H, Weniger G, Steinhoff BJ, Irle E. Neuropsychological performance in frontal lobe epilepsy. Seizure 2002;11:20-32.

9. Helmstaedter C. Behavioral aspects of frontal lobe epilepsy. Epilepsy Behav 2001;2:384-395.

10. Sillanpää M, Jalava M, Kaleva O, Shinnar S. Long-term prognosis of seizures with onset in childhood. N Engl J Med 1998;338:1916-1918.

11. Kral T, Kuczaty S, Blümcke I, Urbach H, Clusmann H, Wiestler OD, Elger C, Schramm J. Postsurgical outcome of children and adolescents with medically refractory frontal lobe epilepsies. Childs Nerv Syst 2001;17:595-601.

12. Lagae L, Pauwels J, Monté CP, Verhelle B, Vervisch J. Frontal absences in children. Eur J Paediatr Neurol 2001;5:243-251.

13. Lawson JA, Cook MJ, Vogrin S, Litewka L, Strong D, Bleasel AF, Bye AM. Clinical, EEG, and quantitative MRI differences in pediatric frontal and temporal lobe epilepsy. Neurology 2002;58:723-729.

14. Sinclair DB, Wheatley M, Snyder T. Frontal lobe epilepsy in childhood. Pediatr Neurol 2004;30:169176.

15. Boone KB, Miller BL, Rosenberg L, Durazo A, McIntyre H, Weil M. Neuropsychological and behavioral abnormalities in an adolescent with frontal lobe seizures. Neurology 1988;38:583-586.

16. Lassonde M, Sauerwein HC, Jambaqué I, Smith ML, Helmstaedter C. Neuropsychology of childhood epilepsy: pre- and postsurgical assessment. Epileptic Disord 2000;2:3-12.

17. Culhane-Shelburne K, Chapieski L, Hiscock M, Glaze D. Executive functions in children with frontal and temporal lobe epilepsy. J Int Neuropsychol Soc 2002;8:623-632.

18. Lendt M, Gleissner U, Helmstaedter C, Sassen R, Clusmann H, Elger CE. Neuropsychological outcome in children after frontal lobe epilepsy surgery. Epilepsy Behav 2002;3:51-59.

19. Riva D, Saletti V, Nichelli F, Bulgheroni S. Neuropsychological Effects of Frontal Lobe Epilepsy in Children. J Child Neurol 2002;17:661-667.

20. Riva D, Avanzini G, Franceschetti S, Nichelli F, Saletti V, Vago C, Pantaleoni C, D’Arrigo S, Andreucci E, Aggio F, Paruta N, Bulgheroni S. Unilateral frontal lobe epilepsy affects executive functions in children. Neurol Sci 2005;26:263-270.

21. Hernandez MT, Sauerwein HC, Jambaqué I, de Guise E, Lussier F, Lortie A, Dulac O, Lassonde M. Attention, memory, and behavioral adjustment in children with frontal lobe epilepsy. Epilepsy Behav 2003;4:522-536. 
22. Prévost J, Lortie A, Nguyen D, Lassonde M, Carmant L. Nonlesional frontal lobe epilepsy (FLE) of childhood: clinical presentation, response to treatment and comorbidity. Epilepsia 2006;47:21982201.

23. Nolan MA, Redoblado MA, Lah S, Sabaz M, Lawson JA, Cunningham AM, Bleasel AF, Bye AM. Memory function in childhood epilepsy syndromes. J Paediatr Child Health 2004;40:20-27.

24. Aoyagi K, Masao A, Goldberg E, Nakazawa S. Lateralization of the frontal lobe functions elicited by a cognitive bias task is a fundamental process. Lesion study. Brain Dev 2005;27:419-423.

25. Auclair L, Jambaqué I, Dulac O, LaBerge D, Siéroff E. Deficit of preparatory attention in children with frontal lobe epilepsy. Neuropsychologia 2005;43:1701-1712.

26. Jocić-Jakubi B, Jovanović M, Janković DS, Lagae L. Frontal-onset absences in children: associated with worse outcome? A replication study. Seizure 2009;18:275-278.

27. Jambaqué I, Dulac O. Reversible frontal syndrome and epilepsy in a 8-year-old boy. Arch Fr Pediatr 1989;46:525-529.

28. Nolan MA, Redoblado MA, Lan S, Sabaz M, Lawson JA, Cunningham AM, Bleasel AF, Bye AM. Intelligence in childhood epilepsy syndromes. Epilepsy Res 2003;53:139-150.

29. Lezak MD. Executive functions: neuropsychological assessment. Oxford University Press, Oxford, 1995.

30. Cohen H, Le Normand MT. Language development in children with simple-partial left-hemisphere epilepsy. Brain Lang 1998;64:409-422.

31. Jambaqué I, Dellatolas G, Dulac O, Ponsot G, Signoret JL. Verbal and visual impairment in children with epilepsy. Neuropsychologia 1993;31:1321-1337.

32. Wechsler D. The measurement of adult intelligence. Williams \& Wilkins, Baltimore, MD, 1994.

33. Hernandez MT, Sauerwein HC, Jambaqué I, De Guise E, Lussier F, Lortie A, Dulac O, Lassonde M. Deficits in executive functions and motor coordination in children with frontal lobe epilepsy. Neuropsychologia 2002;40:384-400.

34. Igarashi K, Oguni H, Osawa M, Awaya Y, Kato M, Mimura M, Kashima H. Wisconsin Card Sorting Test in children with temporal lobe epilepsy. Brain Dev 2002;24:174-178.

35. Rzezak P, Fuentes D, Guimarães CA, Thome-Souza S, Kuczynski E, Li LM, Franzon RC, Leite CC, Guerreiro M, Valente KD. Frontal lobe dysfunction in children with temporal lobe epilepsy. Pediatr Neurol 2007;37:176-185.

36. Nelissen N, van Paesschen W, Baete K, Van Laere K, Palmini A, Van Billoen H, Dupont P. Correlations of interictal FDF-PET metabolism and ictal SPECT perfusion changes in human temporal lobe epilepsy with hippocampal sclerosis. Neuroimage 2006;32:684-695.

37. Cormack F, Gadian DG, Vargha-Khadem F, Cross JH, Connelly A, Baldeweg T. Extra-hippocampal grey matter density abnormalities in paediatric mesial temporal sclerosis. Neuroimage 2005;27:635643.

38. Wandschneider B, Kopp UA, Kliegel M, Stephani U, Kurlemann G, Janz D, Schmitz B. Prospective memory in patients with juvenile myoclonic epilepsy and their healthy siblings. Neurology 2010;75:2144-2155.

39. Pulsipher DT, Seidenberg M, Guidotti L, Tuchscherer VN, Morton J, Sheth RD, Hermann B. Thalamofrontal circuitry and executive dysfunction in recent-onset juvenile myoclonic epilepsy. Epilepsia 2009;50:1210-1219.

40. Derry CP, Heron SE, Phillips F, Howell S, MacMahon J, Phillips HA, Duncan JS, Mulley JC, Berkovic SF, Scheffer IE. Severe autosomal dominant nocturnal frontal lobe epilepsy associated with psychiatric disorders and intellectual disability. Epilepsia 2008;49:2125-2129.

41. Mayberg HS. Frontal lobe dysfunction in secondary depression. J Neuropsychiatry Clin Neurosci $1994 ; 6: 428-442$. 
42. Fohlen M, Bulteau C, Jalin C, Jambaqué I, Delalande O. Behavioural epileptic seizures: a clinical and intracranial EEG study in 8 children with frontal lobe epilepsy. Neuropediatrics 2004;35:336-345.

43. Sinclair DB, Snyder T. Psychosis with frontal lobe epilepsy responds to carbamazepine. J Child Neurol 2008;23:431-434.

44. Diagnostic and Statistical Manual of Mental Disorders DSM-IV TR, 4th ed. American Psychiatric Publishing, Washington, DC, 2000.

45. Blumer D, Wakhlu S, Davies K, Hermann B. Psychiatric outcome of temporal lobectomy for epilepsy: incidence and treatment of psychiatric complications. Epilepsia 1998;39:478-486.

46. Mega MS, Cummings JL, Salloway S, Malloy P. The limbic system: an anatomic, phylogenetic, and clinical perspective. J Neuropsychiatry Clin Neurosci 1997;9:315-330.

47. Sumer MM, Atik L, Unal A, Emre U, Atasoy HT. Frontal lobe epilepsy presented as ictal aggression. Neurol Sci 2007;28:48-51.

48. Kwan P, Brodie MJ. Definition of refractory epilepsy: defining the indefinable? Lancet Neurol 2009;9:27-29.

49. Kwan P, Arzimanoglou A, Berg AT, Brodie MJ, Allen Hauser W, Mathern G, Moshé SL, Perucca E, Wiebe S, French J. Definition of drug resistant epilepsy: consensus proposal by the ad hoc Task Force of the ILAE Commission on Therapeutic Strategies. Epilepsia 2010;51:1069-1077.

50. Kwan P, Brodie MJ. Early identification of refractory epilepsy. N Engl J Med 2000;342:314-319.

51. Ohtsuka Y, Yoshinaga H, Kobayashi K. Refractory childhood epilepsy and factors related to refractoriness. Epilepsia 2000;41:14-17. 


\section{Abstract}

Background: Frontal Lobe Epilepsy (FLE) is the second most frequent type of partial epilepsy and its onset is generally in childhood. Though cognitive and behavioural impairments have been described as co-morbid disorders in epilepsy, their extent in FLE, particularly in children, remains unknown.

Aims: In this study, we assess cognitive skills and behaviour in a cohort of pediatric FLE patients.

Methods: We measured the performance of 71 children with cryptogenic FLE on intelligence tests, neuropsychological tests, and behavioural questionnaires. Age-dependent normative values were used for reference. Results were related to epilepsy-factors including age at epilepsy onset, duration of epilepsy, seizure frequency, localization of the epileptic focus and drug load.

Results: Pediatric FLE patients performed worse on intellectual and neuropsychological tests compared to reference values, and had a delay in school achievement. The performance of patients was typically worse on tasks measuring visual-spatial functions, memory, psychomotor speed and alertness. High seizure frequency was associated with lower scores on the arithmetic subtest of the intelligence scale; the other epilepsy-factors had no statistically significant influence on intelligence test or neuropsychological test outcome. Behavioural problems included attention problems, anxiety and internalizing behaviour. These were not significantly related to epilepsy-factors.

Conclusions: Children with cryptogenic FLE show a broad range of cognitive and behavioural impairments, compared to reference values. While high seizure frequency may affect performance on selected cognitive measures, other epilepsy-factors do not seem to influence cognition and behaviour. Study of microstructural or functional brain abnormalities that underlie these cognitive and behavioural impairments is warranted. 


\section{Cognitive and behavioural findings in children with frontal lobe epilepsy}

\section{Introduction}

Frontal Lobe Epilepsy (FLE) is the second most frequent type of partial epilepsy after temporal lobe epilepsy and accounts for $20-30 \%$ of the partial epilepsies. ${ }^{1}$ The average age at onset of FLE ranges from 4.6 to 7.5 years. ${ }^{2}$ The frontal lobes play pivotal roles in cognitive functioning and behaviour, as they mediate essential functions: 1) basic neurological functions, including motor functions, control of continence, and olfaction, 2) voluntary eye movements, 3) speech and language abilities, 4) executive functions, 5) motivational behaviours, and 6) social competency. ${ }^{3}$ Consequently, an epileptic focus within the frontal lobes may interfere with these functions and can lead to impairments of cognitive functioning and behavioural disturbances.

The extent of cognitive and behavioural impairment has not been systematically studied in FLE, particularly not in children. Available studies have shown that cognitive deficits and behavioural disturbances range from impaired attention to difficulties with the more complex behaviours involved in executive functions. ${ }^{4-12}$ Whether FLE impacts on intelligence remains controversial. ${ }^{7-9,13,14}$ The impact of epilepsy-factors, such as duration of epilepsy and seizure frequency, on the development of cognitive deficits and behavioural disturbances also remains unknown. Given the lack of data regarding cognitive function, intelligence scores and behavioural disturbances in pediatric FLE, we have investigated whether children with FLE referred to our tertiary outpatient clinic deviate from age-related normative values on intelligence, neuropsychological tests, and behavioural questionnaires. In addition, we have studied the influence of epilepsy-factors on test outcomes.

\section{Materials and Methods}

\section{Subject selection}

In this clinical cohort study, we included all children aged 6 to 16 years with a confirmed diagnosis of cryptogenic (i.e. no abnormalities on brain MRI) frontal lobe epilepsy, referred to our tertiary epilepsy centre in the period between June 2005 and February 2010, who had a neuropsychological assessment performed. All children and parents gave informed consent prior to testing. 


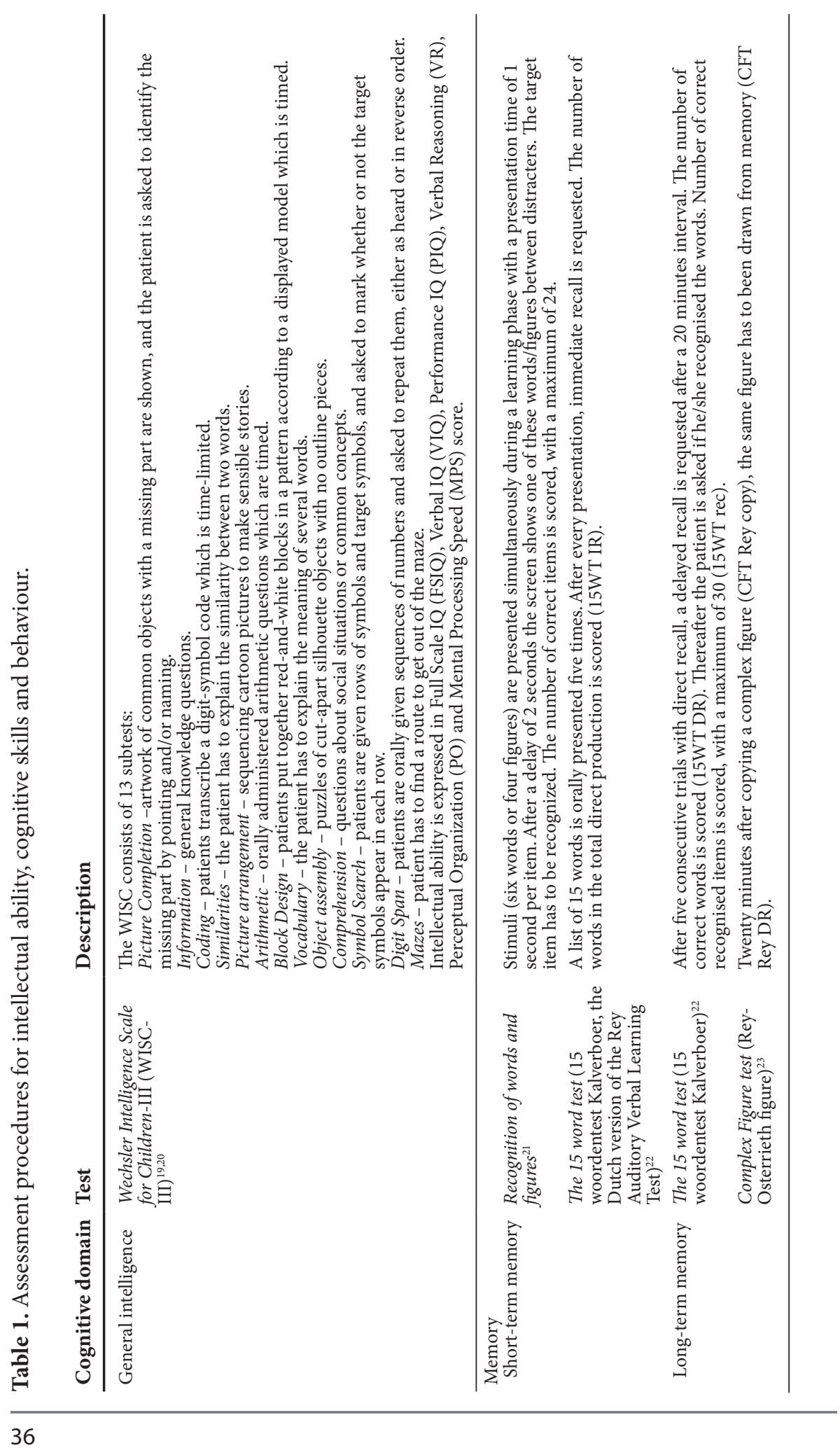




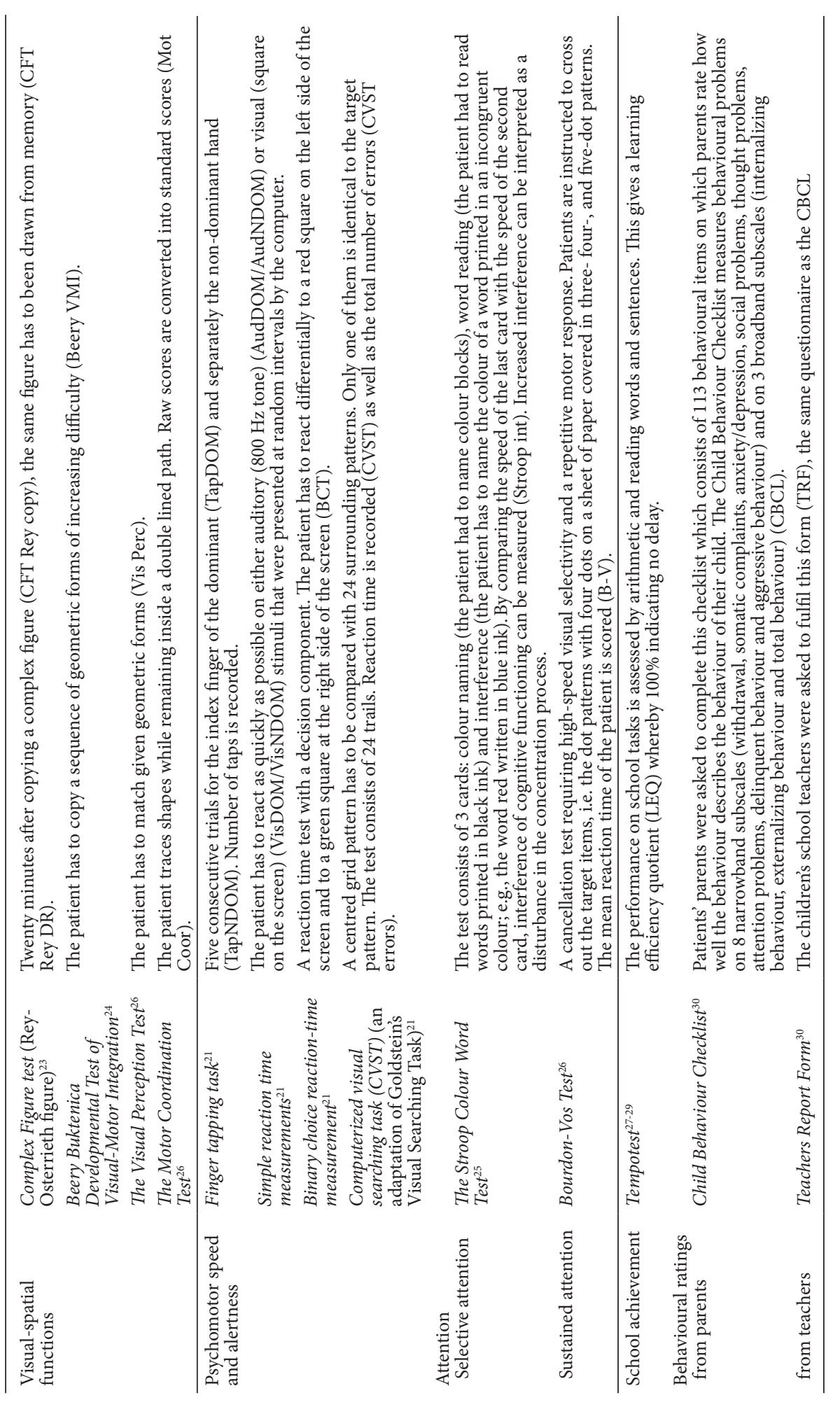


The study was approved by the Ethical Committee of our Epilepsy Centre. Exclusion criteria were frontal lobe seizures thought to be a result of spread to the frontal lobes, multiple seizure foci or interictal epileptiform activity in areas outside the frontal lobe documented on previous EEG studies, brain lesions on previous MRI- or CT-scans or symptomatic epilepsy, progressive neurological disorders, or cognitive impairment due to other causes.

The epilepsy-factors recorded at the time of neuropsychological assessment were: age at epilepsy onset, duration of active epilepsy, seizure frequency, localization of the epileptic focus and antiepileptic drug load. Drug load was computed by dividing the prescribed daily dose by the daily dose as defined by the World Health Organization. ${ }^{15-18}$ In children using two or more AEDs, cumulative drug loads were calculated.

Age-related normative values derived from standardization samples were used as reference values for neuropsychological test results.

For statistical analysis, we categorized patients into short ( $\leq 5$ years) vs. long ( $>5$ years) duration of FLE, young ( $\leq 5$ years) vs. old ( $>5$ years) age at seizure onset, low ( $\leq 1$ seizure per week) vs. high ( $>1$ /week) seizure frequency, low $(\leq 1.0)$ vs. high $(>1.0)$ drug load, and left vs. right frontal focus vs. bifrontal focus, based on seizure semiology and EEG.

\section{Assessment procedures}

Intellectual ability, cognitive skills and behaviour were assessed by trained neuropsychologists in our tertiary Epilepsy Centre using the procedures listed in Table 1. This broad neuropsychological assessment routine covers all cognitive domains.

\section{Statistical analysis}

Data were analysed using the Statistical Package for Social Sciences (SPSS, version 16.0 for Windows). Differences in neuropsychological test results between the FLE cohort and the reference values were tested with onesample $t$-tests at the $5 \%$ significance level. To be able to compare the different neuropsychological test results, Z-scores were computed. Subdivisions on duration of epilepsy, age at seizure onset, seizure frequency, localization of the epileptic focus and drug load were made to explore the effect of epilepsyfactors on the neuropsychological findings. The two-samples $t$-test with a significance level of 5\% (Bonferroni corrected) was used to correct for multiple comparisons. 

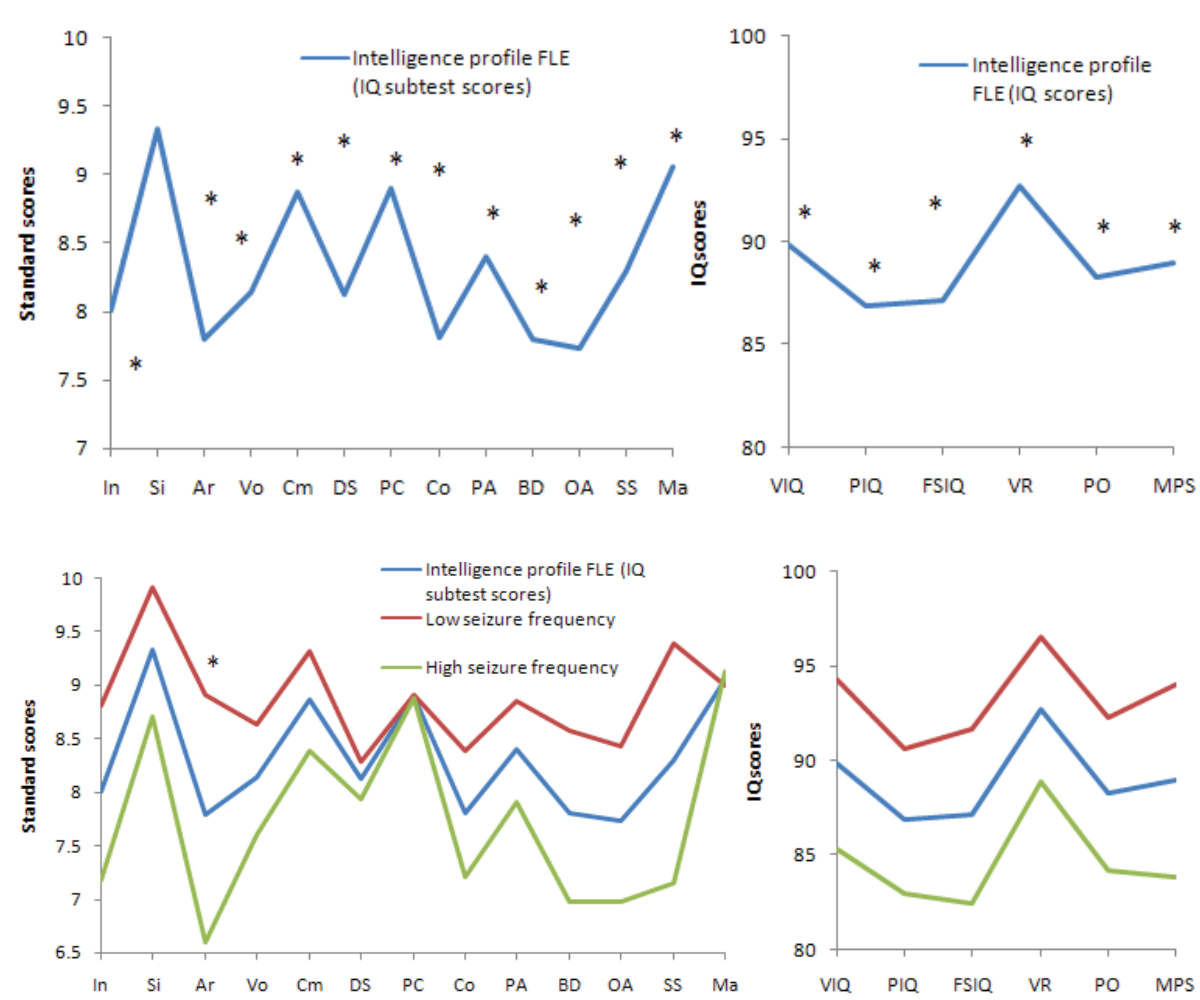

Figure 1a and b. Intelligence profile of children with frontal lobe epilepsy. ${ }^{*}$ The difference between the results of the study group and reference values remains statistically significant after Bonferroni correction.

Figure $2 \mathbf{a}$ and $\mathbf{b}$. Influence of seizure frequency on intelligence subtests (a) and IQ scores (b).

*Statistically significant difference between patients with a low and high seizure frequency after Bonferroni correction. In: Information, Si: Similarities, Ar: Arithmetic, Vo: Vocabulary, Cm: Comprehension, DS: Digit Span, PC: Picture Completion Co: Coding, PA: Picture Arrangement, BD: Block Design, OA: Object Assembly, SS: Symbol Search, Ma: Mazes, VIQ: Verbal IQ, PIQ: Performance IQ, FSIQ: Full Scale IQ, VR: Verbal Reasoning factor, PO: Perceptual Organisation factor, MPS: Mental Processing Speed.

\section{Results}

We enrolled a total of 71 children in the study: Table 2 summarizes their demographic and clinical characteristics.

\section{Intelligence tests}

Figure 1 shows the results of intelligence (sub)tests. The intelligence scores in the children with FLE reveal significantly (Bonferroni corrected) weaker 
Table 2. Demographical and clinical characteristics of the study group.

\begin{tabular}{|c|c|}
\hline Characteristic & $\mathbf{N}[\%]$ \\
\hline $\mathbf{N}$ & 71 \\
\hline $\begin{array}{l}\text { Age } \\
\text { Mean age }( \pm S D) \text { at assessment }\end{array}$ & $129 \pm 2.8$ months \\
\hline Gender (male : female) & $46: 25$ \\
\hline $\begin{array}{l}\text { Age at onset } \\
\text { Mean age }( \pm \mathrm{SD}) \text { at seizure onset } \\
\text { Young age at seizure onset ( } \leq 5 \text { years }) \\
\text { Old age at seizure onset ( }>5 \text { years })\end{array}$ & $\begin{array}{l}69 \pm 45 \text { months } \\
34[48 \%] \\
37[52 \%]\end{array}$ \\
\hline $\begin{array}{l}\text { Duration of epilepsy } \\
\text { Mean duration ( } \pm \text { SD) of epilepsy } \\
\text { Short duration of epilepsy ( } \leq 5 \text { years) } \\
\text { Long duration of epilepsy ( }>5 \text { years) }\end{array}$ & $\begin{array}{l}63 \pm 39 \text { months } \\
33[46 \%] \\
38[54 \%]\end{array}$ \\
\hline $\begin{array}{l}\text { Seizure frequency } \\
\text { Low seizure frequency ( } \leq 1 \text { seizure/week }) \\
\text { High seizure frequency }(>1 \text { seizure/week })\end{array}$ & $\begin{array}{l}37[52 \%] \\
34[48 \%]\end{array}$ \\
\hline $\begin{array}{l}\text { Seizure focus based on history and EEG } \\
\text { Focus left frontal } \\
\text { Focus right frontal } \\
\text { Focus bifrontal } \\
\text { Focus frontotemporal (left or right) }\end{array}$ & $\begin{array}{l}16[23 \%] \\
12[17 \%] \\
40[56 \%] \\
3[4 \%]\end{array}$ \\
\hline $\begin{array}{l}\text { AED treatment } \\
\text { No AED } \\
\text { Monotherapy } \\
\text { Polytherapy } \\
\text { Low drug load }(\leq 1.0) \\
\text { High drug load }(>1.0)\end{array}$ & $\begin{array}{l}6[8 \%] \\
39[55 \%] \\
26[37 \%] \\
47[66 \%] \\
24[34 \%]\end{array}$ \\
\hline $\begin{array}{l}\text { Education type } \\
\text { Regular education } \\
\text { Special education }\end{array}$ & $\begin{array}{l}50[70 \%] \\
21[30 \%]\end{array}$ \\
\hline $\begin{array}{l}\text { School achievement } \\
\text { Reading words [ } n=47] \text {, mean \% } \\
\text { Percentage patients with LEQ }<80[n=27] \\
\text { Reading sentences [ } n=44], \text { mean } \% \\
\text { Percentage patients with LEQ }<80[n=29] \\
\text { Arithmetic [ } n=46], \text { mean } \% \\
\text { Percentage patients with LEQ }<80[n=47]\end{array}$ & $\begin{array}{l}71 \% \text { (LEQ) } \\
57 \% \\
71 \% \text { (LEQ) } \\
66 \% \\
76 \% \text { (LEQ) } \\
71 \%\end{array}$ \\
\hline
\end{tabular}

EEG, electroencephalogram; AED, antiepileptic drugs; LEQ, learning efficiency quotient (80-100\% is normal and indicates no delay).

function level across all categories, relative to reference values. However, the IQ-scores are still within the (low) average range. A high seizure frequency led to significantly lower scores $(\mathrm{p}<0.05)$ on the Information $(\mathrm{p}=0.014)$ and Arithmetic $(\mathrm{p}=0.003)$ verbal subtests, as well as on the Block Design $(\mathrm{p}=0.024)$ and Symbol Search $(\mathrm{p}=0.023)$ performance subtests. Significant differences were also found for the IQ factors Verbal IQ $(\mathrm{p}=0.012)$, Performance IQ ( $\mathrm{p}$ $=0.034)$, Full Scale IQ $(\mathrm{p}=0.009)$, Perceptual Organization $(\mathrm{p}=0.025)$ and Mental Processing Speed ( $p=0.021$; see Figure 2). After correction for multiple comparisons, only the arithmetic scores remain statistically significant. Age at seizure onset, seizure duration, localization of the epileptic focus and drug load had no effect on intelligence scores (data not shown). 
Table 3. Neuropsychological test results and reference values, corrected for age.

\begin{tabular}{|c|c|c|c|}
\hline \multirow[t]{2}{*}{ Test } & \multirow{2}{*}{$\begin{array}{c}\text { FLE patients } \\
\text { Mean } \pm \text { SD }\end{array}$} & \multicolumn{2}{|c|}{ Reference values } \\
\hline & & Mean \pm SD & p-value \\
\hline \multicolumn{4}{|l|}{ Psychomotor speed and alertness } \\
\hline Auditory dominant hand reaction time (AudDOM) & $323.82 \pm 103.1$ & $320.9 \pm 53.2$ & 0.826 \\
\hline Auditory non-dominant hand reaction time (AudNDOM) & $325.93 \pm 110.4$ & $297.0 \pm 46.5$ & 0.047 \\
\hline Visual dominant hand reaction time (VisDOM) & $375.65 \pm 96.2$ & $327.7 \pm 43.7$ & $0.000^{\mathrm{a}}$ \\
\hline Visual non-dominant hand reaction time (VisNDOM) & $409.59 \pm 132.8$ & $334.6 \pm 56.8$ & $0.000^{\mathrm{a}}$ \\
\hline Binary Choice reaction time (BCT) & $470.5 \pm 141.6$ & $450.7 \pm 99.1$ & 0.307 \\
\hline CVST reaction time (CVST) & $26.4 \pm 13.4$ & $19.63 \pm 5.7$ & $0.003^{\mathrm{a}}$ \\
\hline Number of errors CVST (CVST errors) & $5.0 \pm 5.5$ & $2.4 \pm 0.6$ & 0.005 \\
\hline Tapping rate dominant hand (TapDOM) & $43.1 \pm 7.2$ & $45.4 \pm 7.0$ & 0.031 \\
\hline Tapping rate non-dominant hand (TapNDOM) & $37.9 \pm 7.3$ & $38.7 \pm 5.5$ & 0.493 \\
\hline \multicolumn{4}{|l|}{ Attention } \\
\hline Bourdon-Vos reaction time $(\mathrm{B}-\mathrm{V})$ & $17.2 \pm 5.0$ & $14.7 \pm 3.1$ & 0.008 \\
\hline Stroop Colour Word Test t-score card 3-2 (Stroopint) & $79.73 \pm 32.7$ & $65.2 \pm 8.5$ & 0.107 \\
\hline \multicolumn{4}{|l|}{ Visual-spatial functions } \\
\hline Beery VMI & $88.1 \pm 11.1$ & $100 \pm 15$ & $<0.001^{\mathrm{a}}$ \\
\hline Visual Perception (Vis Perc) & $94.4 \pm 12.1$ & $100 \pm 15$ & $0.001^{\mathrm{a}}$ \\
\hline Motor Coordination (Mot Coor) & $86.8 \pm 11.4$ & $100 \pm 15$ & $<0.001^{\mathrm{a}}$ \\
\hline CFT Rey Copy & $22.0 \pm 8.6$ & $28.4 \pm 5.9$ & $<0.001^{\mathrm{a}}$ \\
\hline \multicolumn{4}{|l|}{ Memory } \\
\hline CFT Rey (delayed) recall (CFT Rey DR) & $11.8 \pm 6.8$ & $21.0 \pm 6.3$ & $<0.001^{\mathrm{a}}$ \\
\hline Recognition Words simultaneous (Rec words) & $14.8 \pm 3.8$ & $17.6 \pm 1.6$ & 0.011 \\
\hline Recognition Figures simultaneous (Rec Fig) & $9.4 \pm 2.9$ & $11.8 \pm 1.7$ & 0.005 \\
\hline 15 words test total direct reproduction (15WT IR) & $54.54 \pm 11.7$ & $50 \pm 10$ & $0.003^{\mathrm{a}}$ \\
\hline 15 words test recall (15WT DR) & $47.91 \pm 10.6$ & $50 \pm 10$ & 0.116 \\
\hline 15 words test recognition (15WT rec) & $28.83 \pm 1.9$ & $29.0 \pm 1.3$ & 0.437 \\
\hline
\end{tabular}

a: Remains statistically significant after Bonferroni correction.

Thirty percent of the children with FLE attended special education. We performed school achievement tests in 46 of the 50 children (92\%) who attended regular education. These tests showed learning efficiency quotients (LEQ) between 71 and $76 \%$, which is below the normal range of $80-100 \% .{ }^{27-29}$

\section{Neuropsychological tests}

Neuropsychological test results are recorded in Table 3 and visualized in Figure 3. Children with FLE attained lower scores on a broad set of neuropsychological tests, relative to reference values.

After correction for multiple comparisons, scores on tasks measuring visualspatial functions, memory, psychomotor speed and alertness, remained significantly worse compared to reference values. The memory impairments concerned specifically the acquisition of new information. Recall of learned information was less disturbed. Patients with a young age at seizure onset 


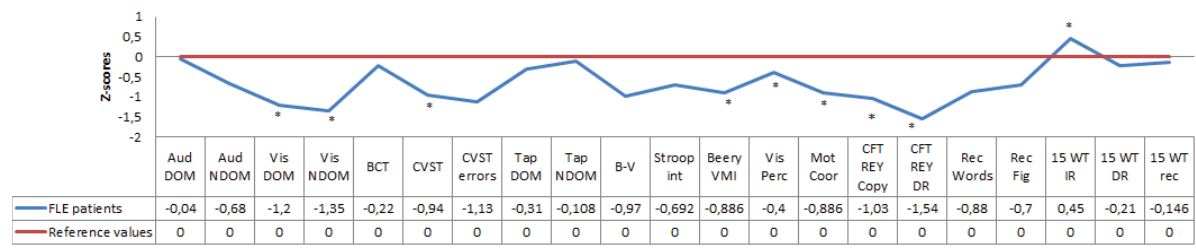

Figure 3. Neuropsychological profile of children with frontal lobe epilepsy. AudDOM: auditory dominant hand reaction time, AudNDOM: auditory non-dominant hand reaction time, VisDOM: visual dominant hand reaction time, VisNDOM: visual non-dominant hand reaction time, BCT: binary choice reaction time, CVST: computerized visual searching task reaction time, CVST errors: number of errors in CVST, Rec Words: recognition words, Rec Fig: recognition figures, TapDOM: tapping dominant hand, TapNDOM: tapping nondominant hand, Beery VMI: Visual Motor Integration, Vis Perc: visual perception, Mot Coor: motor coordination, CFT Rey Copy: copy Complex Figure Test Rey, CFT Rey DR: delayed recall Complex Figure Test Rey, B-V: Bourdon-Vos reaction time, Stroop int: Stroop interference score (time card 3-2), 15WT IR: 15 words test direct production, 15WT DR: 15 words test delayed recall, 15WT rec: 15 words test recognition.

*The difference between the results of the study group and reference values remains statistically significant after Bonferroni correction.

had significantly $(\mathrm{p}<0.05)$ slower reaction times (visual reaction time task performed with the dominant hand $(\mathrm{p}=0.049)$, the binary choice reaction task $(\mathrm{p}=0.026))$, and had significantly more difficulty tapping with the non-dominant hand $(\mathrm{p}=0.008)$. After correction for Full Scale IQ as well as correction for multiple comparisons age at seizure onset failed to be of statistical significance $(\mathrm{p}<0.002)$. Epilepsy factors including duration of epilepsy, seizure frequency, drug load, or focus localization had no significant impact on any of the neuropsychological scores (data not shown).

\section{Behavioural tests}

Forty-nine of 71 parents' (69\%) and 33 teachers' (46\%) questionnaires were available for analysis. Parents and teachers reported significant problems in the fields of "attention problems," "internalizing problems," as well as in their overall behaviour on the Child Behaviour Checklist (CBCL) and Teacher Report Form (TRF). Figure 4 shows the behavioural findings for the children with FLE.

Long duration of epilepsy (i.e. $>5$ years) was associated with higher "anxiety/ depression" ( $p=0.014)$ and "internalizing behaviour" ( $p=0.029)$ scores of the TRF. Young age at seizure onset was associated with higher "anxiety/ depression" ( $p=0.013$ ) CBCL scores. Higher "aggressive behaviour" ( $p=$ $0.020)$ and "externalizing behaviour" $(\mathrm{p}=0.005) \mathrm{CBCL}$ scores were reported for children with low seizure frequency (i.e. $\leq 1$ seizure/week). 

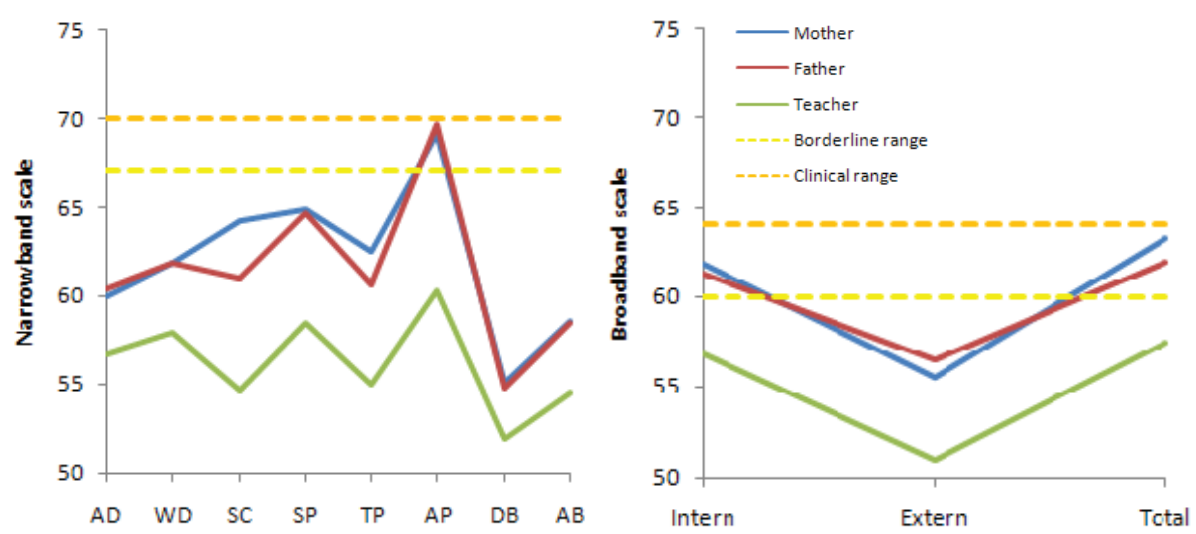

Figure 4. Behavioural profile of children with frontal lobe epilepsy (Child Behaviour Checklist and Teachers Report Form).

AD: anxiety/depression, WD: withdrawal, SC: somatic complaints, SP: social problems, TP: thought problems, AP: attention problems, DB: delinquent behaviour, AB: aggressive behaviour, Intern: internalizing problems, Extern: externalizing problems, Total: total problems. On the narrowband scales a T-score between 67 and 70 is seen as borderline; scores above 70 are seen as clinical scores. On the broadband scales, the borderline range is between 60 and 63 ; above 63 is the clinical range.

A left frontal epileptic focus was associated with higher "withdrawal" ( $\mathrm{p}=$ 0.032) CBCL scores. All the above mentioned results remained statistically significant after correction for Full Scale IQ. A bifrontal focus was associated with more "thought problems" ( $\mathrm{p}=0.041$ ) on the TRF, and fathers reported more "somatic complaints" in children with a young age at seizure onset $(\mathrm{p}=$ 0.021 ), although these results were not of statistical significance after correction for Full Scale IQ ( $\mathrm{p}=0.129$ and $\mathrm{p}=0.084$, respectively).

After final correction for multiple comparisons, all results were nonsignificant.

\section{Discussion}

Compared to reference values, children with cryptogenic FLE show a broad range of cognitive and behavioural impairments. Although the intelligence scores are within the normal range (within one standard deviation below the normative mean), they are significantly lower than the reference values on all subtests and IQ-scores. FLE thus has a suppressing effect on intelligence, resulting in a global decline of IQ-scores and subtest scores to the lower average range. Scores are lowest in patients with the highest seizure activity. 
The negative impact of frequent seizures on intelligence has been previously reported. ${ }^{7}$ In our study, poor mental calculation (Arithmetic) performance was significantly associated with high seizure frequency. This task makes high demands on attention and working memory, both well-established frontal lobe functions. In fact, the neuropsychological deficits observed in patients with FLE likely reflect the functions controlled in the area that yields the epileptic focus. Yet, this study shows that children with FLE also have significant impairments of visual-spatial functions, memory, psychomotor speed and alertness. FLE thus impacts on a broad scale of cognitive domains, broader than the typical frontal functions. Similar conclusions have been drawn in other studies analysing effects of frontal lobe lesions and epilepsy in children. ${ }^{5,31}$ These findings imply that broad neuropsychological assessment, covering cognitive domains not necessarily related to frontal lobe functions, is warranted in FLE. The wide range of cognitive impairment in FLE might be the result of rapid propagation of frontal lobe epileptic discharges to, thus effects on, the contralateral frontal lobe as well as other brain regions. ${ }^{9,32}$

Age at seizure onset, duration of epilepsy, seizure frequency, drug load, and localization of the epileptic focus did not affect neuropsychological outcome. Despite intelligence scores within the normal range, patients with FLE have broad-range impairments of neuropsychological performance. A delay in school achievement was seen in $71 \%$ of the children attending regular education and the need for special education was seen in $30 \%$ of the children. This emphasizes the need for detailed neuropsychological testing in addition to intelligence testing.

Parents and teachers report significantly more behavioural problems in children with FLE compared to normal children. Parents of children with FLE report more attention problems, anxiety and internalizing problems than those of the controls. Previous studies have reported similar problems in these aspects of behaviour in children with FLE. ${ }^{6,13}$ Teachers report less behavioural problems than parents, but report significantly more attention deficits and aggressive behaviour in children with FLE than in controls. Part of the behavioural problems observed in children with FLE is probably attributable to their attention problems. In addition, the children may react to constant negative feedback from their social environment. ${ }^{6}$

Epilepsy-factors did not influencebehavioural ratings. Behavioural disturbances interfere with the children's school performance, which may be aggravated by cognitive deficits.

These neuropsychological deficits can also precede seizure onset. ${ }^{14,33}$ Neuropsychological evaluation early in the course of the condition is therefore essential. $^{14}$ 
This study and its design have important intrinsic limitations. The tertiary reference centre setting may lead to selection bias and the use of a control groups without epilepsy and with other types of epilepsy may be superior to a normative reference. The cognitive and behavioural impairments measured may be characteristic of epilepsy in general, rather than FLE specifically. Therefore, comparison with other epilepsy types would be necessary to tease out which of these problems could be attributed to FLE.

The lack of correlations between cognitive and behavioural findings and epilepsy-factors could reflect limitations inherent to the tests chosen. No further process analysis was done to investigate how different subgroups treated the test information.

As pediatric FLE patients rarely display macrostructural brain abnormalities, ${ }^{2,13}$ neuronal injury associated with epilepsy is more likely to be expressed as a microstructural or functional abnormality. We hypothesize that these functional or microstructural disturbances of the brain regions do not only result in epilepsy, but also in cognitive and behavioural disturbances in our cohort of children with cryptogenic FLE.

Advanced MRI-techniques, including diffusion tensor imaging (DTI) and functional MRI (fMRI), that are capable of visualizing and assessing the level and integrity of microstructural and functional networks may reveal neuronal correlates of cognitive and behavioural impairment. In childhood, it is crucial to recognise intellectual, cognitive and behavioural deficits early so that access to appropriate educational interventions can be arranged, with the aim of minimising the long-term consequences on educational outcome and future employment opportunities.

In conclusion, children with cryptogenic FLE show a broad range of cognitive and behavioural disturbances and a substantial delay in their school achievements. While high seizure frequency may affect performance on selective cognitive measures, other epilepsy-factors do not seem to influence cognition and behaviour. Therefore, there are no epilepsy-factors that can be predictive or helpful in identifying patients at risk for cognitive and behavioural problems. These findings stress the importance of early interventions to prevent learning disabilities and social problems as well as the need to investigate underlying microstructural or functional abnormalities that underlie these cognitive and behavioural impairments. 


\section{References}

1. Manford M, Hart YM, Sander JW, Shorvon SD. National General Practice Study of Epilepsy (NGPSE): partial seizure patterns in a general population. Neurology 1992:42:1911-1917.

2. Braakman HMH, Vaessen MJ, Hofman PAM, Debeij-van Hall MHJA, Backes WH, Vles JSH, Aldenkamp AP. Cognitive and behavioural complications of frontal lobe epilepsy in children: a review of the literature. Epilepsia 2011;52:849-856.

3. Cummings JL, Miller BL. Chapter 2: Conceptual and clinical aspects of the frontal lobes. The Human Frontal Lobes, Second Edition: Functions and Disorders (The Science and Practice of Neuropsychology). Bruce L, Miller MD (Editor), Jeffrey L, Cummings MD (Editor). The Guilford Press, New York 2007.

4. Lassonde M, Sauerwein HC, Jambaqué I, Smith ML, Helmstaedter C. Neuropsychology of childhood epilepsy: pre- and postsurgical assessment. Epileptic Disord 2000;2:3-12.

5. Culhane-Shelburne K, Chapieski L, Hiscock M, Glaze D. Executive functions in children with frontal and temporal lobe epilepsy. J Int Neuropsychol Soc 2002;8:623-632.

6. Hernandez MT, Sauerwein C, Jambaqué I, De Guise E, Lussier F, Lortie A, Dulac O, Lassonde M. Attention, memory and behavioral adjustments in children with frontal lobe epilepsy. Epilepsy Behav 2003;4:522-536.

7. Nolan MA, Redoblado MA, Lah S, Sabaz M, Lawson JA, Cunningham AM, Bleasel AF, Bye AM. Intelligence in childhood epilepsy syndromes. Epilepsy Res 2003;53:139-150.

8. Riva D, Saletti V, Nichelli F, Bulgheroni S. Neuropsychological effects of frontal lobe epilepsy in children. J Child Neurol 2002;17:661-667.

9. Riva D, Avanzini G, Franceschetti S, Nichelli F, Saletti V, Vago C, Pantaleoni C, D’Arrigo S, Andreucci E, Aggio F, Paruta N, Bulgheroni S. Unilateral frontal lobe epilepsy affects executive functions in children. Neurol Sci 2005;26:263-270.

10. Helmstaedter C, Kemper B, Elger CE. Neuropsychological aspects of frontal lobe epilepsy. Neuropsychologia 1996;34:399-406.

11. Upton D, Thompson PJ. Epilepsy in the frontal lobes: Neuropsychological Characteristics. J Epilepsy 1996;9:215-222.

12. Exner C, Boucsein K, Lange C, Winter H, Weniger G, Steinhoff BJ, Irle E. Neuropsychological performance in frontal lobe epilepsy. Seizure 2002;11:20-32.

13. Sinclair DB, Wheatley M, Snyder T. Frontal lobe epilepsy in childhood. Pediatr Neurol 2004;30:169176.

14. Prévost J, Lortie A, Nguyen D, Lassonde M, Carmant L. Nonlesional frontal lobe epilepsy of childhood: Clinical presentation, response to treatment and comorbidity. Epilepsia 2006;47:2198-2201.

15. About the ATC/DDD system. World Health Organization Collaborating Centre for Drug Statistics Methodology. Available on http://www.whocc.no/atcddd/; 2008.

16. Lammers MW, Hekster YA, Keyser A, Meinardi H, Renier WO, van Lier H. Monotherapy or polytherapy for epilepsy revisited: a quantitative assessment. Epilepsia 1995;36:440-446.

17. Deckers CLP, Hekster YA, Keyser A, Meinardi H, Renier WO. Reappraisal of polytherapy in epilepsy: a critical review of drug load and adverse effects. Epilepsia 1997;38:570-575.

18. Canevini MP, De Sarro G, Galimberti CA, Gatti G, Licchetta L, Malerba A, Muscas G, La Neve A, Striano P, Perucca E; SOPHIE Study Group. Relationship between adverse effects of antiepileptic drugs, number of coprescribed drugs, and drug load in a large cohort of consecutive patients with drug-refractory epilepsy. Epilepsia 2010;51:797-804.

19. Wechsler D. Wechsler Intelligence Scale for Children - revised: Nederlandstalige uitgave. Lisse: Swets \& Zeitlinger; 1986. 
20. Wechsler D. Wechsler Intelligence Scale for Children derde editie NL, Handleiding en verantwoording. Harcourt, London; 2005.

21. Alpherts WCJ, Aldenkamp AP. FePSY: 'The Iron Psyche'. Instituut voor epilepsiebestrijding, Heemstede, the Netherlands; 1995.

22. Kalverboer AF, Deelman BG. De 15-woorden tests A en B: (een voorlopige handleiding) (15WT/ VWT). Groningen: Academisch Ziekenhuis Groningen, afd. Neuropsychologie; 1986.

23. Meyers JE, Meyers KR. Rey Complex Figure Test and Recognition Trial: Professional manual. Odessa Florida: Psychological Assessment Resources; 1995.

24. Beery KE, Buktenica NA, Beery NA. The Beery-Buktenica development test of visual-motor integration. $5^{\text {th }}$ edition. Minneapolis, MN: Pearson Assessments; 2003.

25. Hammes JGW. De Stroop Kleur-Woord Test. Handleiding. Lisse: Swets \& Zeitlinger; 1971.

26. Vos PG. Bourdon-Vos: Handleiding. Lisse: Swets \& Zeitlinger; 1988.

27. Vos T. Handleiding tempo-test-lezen (zinnen). Lisse: Swets \& Zeitlinger; 2000.

28. Vos T. Handleiding tempo-test-lezen (woorden). Lisse: Swets \& Zeitlinger; 2002.

29. Vos T. Handleiding tempo-test-rekenen. Harcourt Assessment bv, Amsterdam; 2004.

30. Achenbach TM, Edelbrock CS. Manual for the child behavior checklist and revised child behaviour profile. Burlington: University of Vermont Department of Psychiatry; 1983.

31. Jambaqué I, Dellatolas G, Dulac O, Ponsot G, Signoret JL. Verbal and visual impairment in children with epilepsy. Neuropsychologia 1993;31:1321-1337.

32. Sumer MM, Atik L, Unal A, Emre U, Atasoy HT. Frontal lobe epilepsy presented as ictal aggression. Neurol Sci 2007;28:48-51.

33. Taylor J, Kolamunnage-Dona R, Marson AG, Smith PE, Aldenkamp AP, Baker GA; SANAD study group. Patients with epilepsy: cognitively compromised before the start of antiepileptic drug treatment? Epilepsia 2010;51:48-56. 


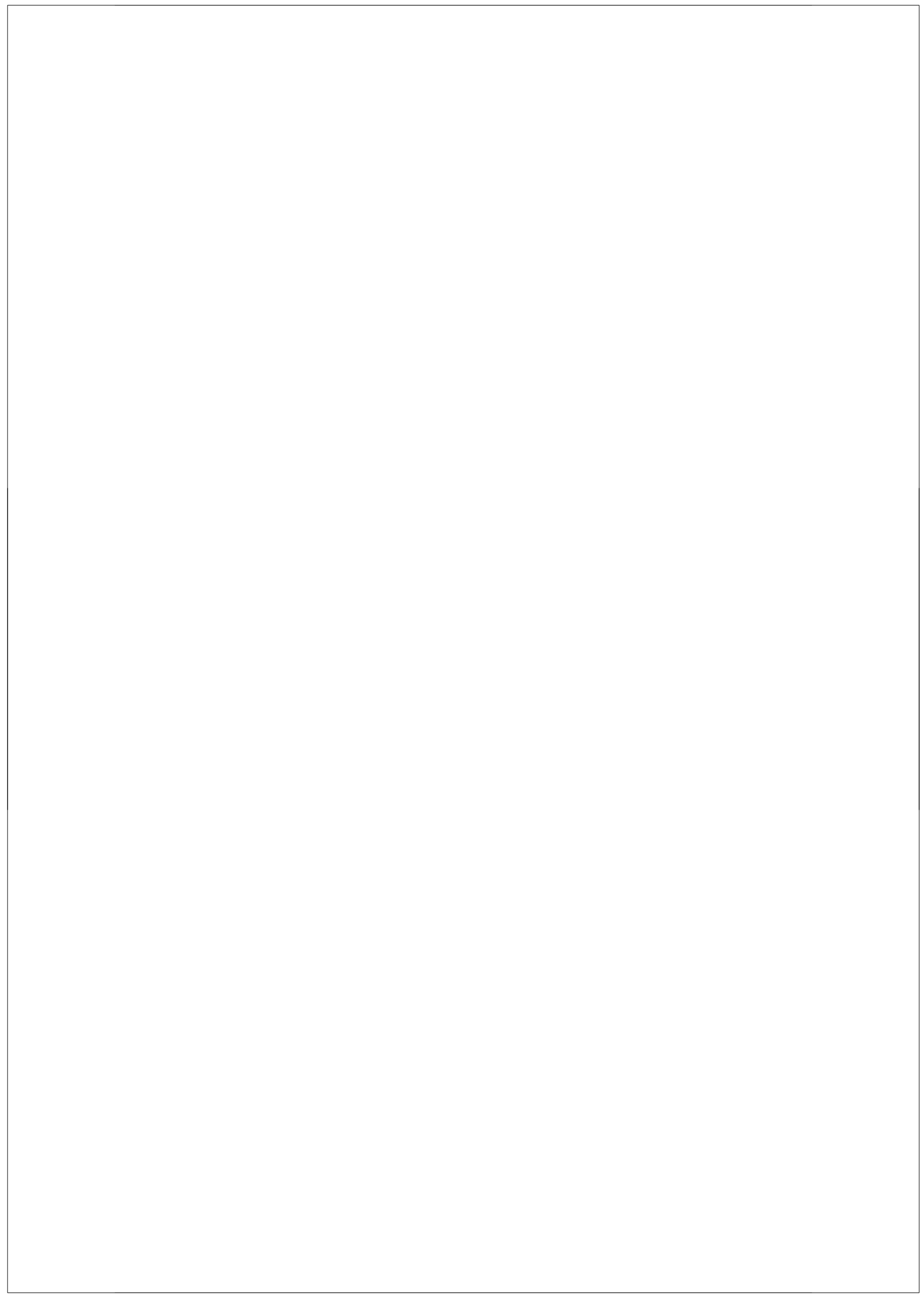




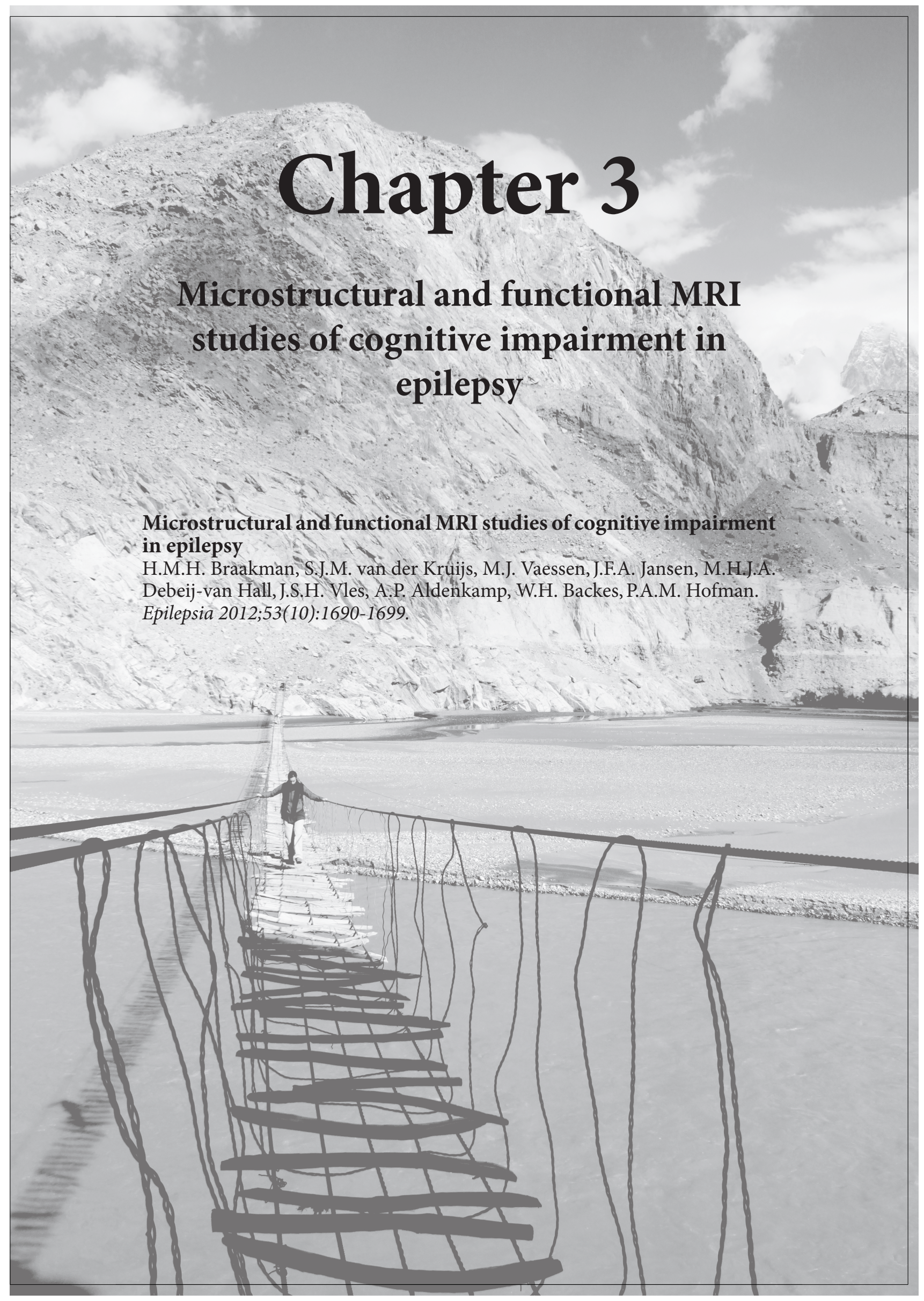




\section{Summary}

Cognitive impairment is the most common comorbidity in children with epilepsy, but its pathophysiology and predisposing conditions remain unknown. Clinical epilepsy characteristics are not conclusive in determining cognitive outcome. Because many children with epilepsy do not have macrostructural magnetic resonance imaging (MRI) abnormalities, the underlying substrate for cognitive impairment may be found at the microstructural or functional level. In the last two decades, new MRI techniques have been developed that have the potential to visualize microstructural or functional abnormalities associated with cognitive impairment. These include volumetric MRI, voxelbased morphometry (VBM), diffusion-tensor imaging (DTI), MR spectroscopy (MRS), and functional MRI (fMRI). All of these techniques have shed new light on various aspects associated with, or underlying, cognitive impairment, although their use in epilepsy has been limited and focused mostly on adults. Therefore, in this review, the use of all these different MRI techniques to unravel cognitive impairment in epilepsy is discussed both in adults and children with epilepsy. Volumetric MRI and VBM have revealed significant volume losses in the area of the seizure focus as well as in distant areas. DTI adds evidence of loss of integrity of connections from the seizure focus to distant areas as well as between distant areas. MRS and fMRI have shown impaired function both in the area of the seizure focus as well as in distant structures. For this review we have compiled and compared findings from the various techniques to conclude that cognitive impairment in epilepsy results from a network disorder in which the (micro)structures as well as the functionality can be disturbed. 


\section{Microstructural and functional MRI studies of cognitive impairment in epilepsy}

\section{Introduction}

Cognitive impairment and educational underachievement are among the most frequent comorbidities in children with epilepsy. These cognitive impairments can encompass a global intelligence deficit (characterised by a decreased intelligence quotient [IQ]) as well as impairments in specific cognitive domains, and show important interpersonal variability. ${ }^{1,2}$

The cognitive impairments occur in childhood and can lead to learning disabilities which, in turn, may exert a negative influence throughout life, in terms of social skills and level of education. Their pathophysiology is largely unknown, and associations with clinical epilepsy characteristics, such as seizure frequency, age at onset of epilepsy and seizure type remain inconclusive. ${ }^{3}$

Macrostructural magnetic resonance imaging (MRI) studies have revealed that among children with epilepsy, those with brain abnormalities (e.g.leukomalacia/ gliosis) performed worse than children without MRI abnormalities on a range of cognitive tests. ${ }^{4}$ Part of the variability in neuropsychological functioning thus may be due to underlying macrostructural brain abnormalities. Yet, many children with epilepsy complicated by cognitive deficits do not have macroscopic structural MR abnormalities (i.e. have epilepsy of unknown cause or epilepsy caused by a presumed genetic defect, previously termed cryptogenic or idiopathic epilepsy). ${ }^{5}$ In these children, cognitive dysfunction may be due to pathology at the microstructural or functional level. The (micro)structural and functional relationships in the brain can now be studied by techniques including volumetric MRI, voxel-based morphometry (VBM), diffusion tensor imaging (DTI), MR spectroscopy (MRS), and functional MRI (fMRI). These may show the neuronal correlate of cognitive impairments in epilepsy. In this review, we have assessed the utility of these MRI techniques in the detection of neuronal correlates for cognitive dysfunction in epilepsy, both in adult patients and in children.

\section{Methods}

Articles relevant to this review were identified by searches of the PubMed (National Centre for Biotechnology Information; NCBI; http://www.ncbi.nlm. nih.gov/pubmed/) database, performed January 9, 2012. We used the Medical 
Figure 1. Flowchart of literature review.

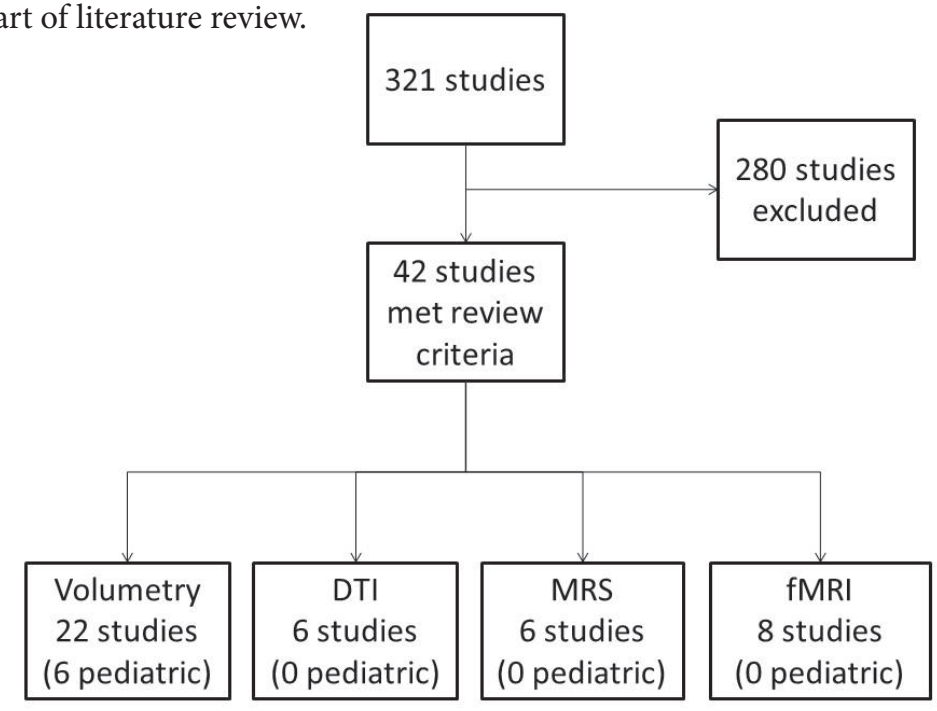

Subject Heading (MeSH) terms "Epilepsy," "Epilepsy, tonic-clonic," "Epilepsy, Frontal Lobe," "Epilepsy, Rolandic," "Epilepsy, Generalized," "Epilepsy, Absence," "Myoclonic Epilepsy, Juvenile," "Epilepsy, Complex Partial," "Epilepsy, Temporal Lobe," "Epilepsy, Partial, Motor," "Epilepsy, Partial, Sensory," "Epilepsies, Partial," "Magnetic Resonance Imaging," "Diffusion Magnetic Resonance Imaging," "Magnetic Resonance Spectroscopy," "Diffusion Tensor Imaging," "Cognition" and "Cognition Disorders" for this search, with limits: "Humans" and "English". We also used the following PubMed search terms: "epilepsy resting-state fMRI cognition," and "epilepsy functional connectivity cognition," with limits: "Humans" and "English". In addition, references from relevant original and review articles were used. We reviewed titles and abstracts of all articles indexed under the used search terms for their relevance to this review; for those considered applicable, the full-text article was retrieved.

\section{Results}

The literature search yielded 321 individual articles. Studies in patients with macrostructural brain abnormalities were excluded as well as MRI studies in postsurgical patients with epilepsy. After assessment of the titles and abstracts, 42 studies were considered applicable to this review, six of which were performed in children (Figure 1). The contributions of volumetric MRI, VBM, DTI, MRS and fMRI to our understanding of the pathology associated with cognitive impairment in epilepsy are reviewed per technique, starting 
with structural techniques, followed by metabolic and functional imaging techniques.

\section{Volumetric MRI}

In volumetric MRI, between-group comparisons are based on volume calculations of regions of interest. VBM is an MR analysis technique by which each brain is registered to a template to correct for the large interpersonal differences in brain anatomy, to enable detection of smaller differences in volume. $^{6}$

Volumetric MRI has been used to determine brain atrophy and to investigate its relation with cognitive dysfunction in epilepsy. Four studies focused exclusively on hippocampal volume related to cognitive impairment in adult patients with temporal lobe epilepsy (TLE). In patients with TLE who are left dominant for language, left hippocampal atrophy was associated with impairments in verbal learning and memory. ${ }^{7-9}$ Similarly, right hippocampal atrophy was associated with nonverbal learning and memory deficits. ${ }^{79}$ In the fourth study, the relationship between lateralized hippocampal atrophy and memory dysfunction was less evident in patients with right hippocampal atrophy than with left hippocampal atrophy..$^{10}$ Yet, impaired memory function has also been related to atrophy of structures other than the hippocampus in TLE. Atrophy of the thalamus, ${ }^{11,12}$ amygdala, ${ }^{13,14}$ and mammillary bodies ${ }^{14}$ has been associated with impaired memory performance in TLE.

Executive functions are generally considered to be frontal lobe functions. ${ }^{15}$ However, only one study has been able to associate atrophy of the (dorsal) prefrontal cortex with deficits in executive functions in patients with TLE. ${ }^{16} \mathrm{In}$ two other studies, frontal lobe volumes could not be associated with deficits in executive functions in juvenile myoclonic epilepsy (JME) ${ }^{17}$ and in TLE. ${ }^{18}$ Moreover, deficits in executive functions in patients with TLE have been associated with atrophy of nonfrontal regions, being the thalamus, ${ }^{11,18}$ and the caudate nucleus ipsilateral to seizure focus. ${ }^{19}$ It is important to note that the interpretation of these associations is limited by the fact that the studies have generally investigated volumes of a single structure, or a small number of interrelated structures. Moreover, the previously discussed associations between hippocampal volumes and cognitive function could not be reproduced in all studies that measured these. ${ }^{16,18}$

Studies of whole brain volumes have revealed associations between cognitive impairment and brain volume losses in patients with epilepsy. In adult patients with TLE, those with early age at epilepsy onset ( $<14$ years) had a reduction of total brain volume, especially of white matter, compared to patients with late age at epilepsy onset and healthy controls. These reductions in total white 
matter volume were correlated with poorer cognitive performance across multiple cognitive domains, including verbal, performance, and full-scale IQ; and verbal fluency, spatial orientation, verbal and nonverbal memory, and response inhibition. ${ }^{20}$ After four years, a portion of the participants was retested, which demonstrated evident cognitive deterioration in a subset of patients. These patients had lower baseline volumes of grey and white matter, smaller baseline left hippocampal volume, larger baseline cerebrospinal fluid (CSF) volume, and lower baseline intellectual capacity. ${ }^{21}$ The importance of white matter volumes could not be confirmed in another study. ${ }^{22}$ The importance of global atrophy, as a factor associated with decline in various cognitive domains, was confirmed by other investigators. ${ }^{23}$

Volume loss of the corpus callosum specifically, measured by VBM, has been associated with poorer measures of performance IQ, immediate memory, complex speeded psychomotor processing and speeded fine motor dexterity, but no other neuropsychological tests in adult patients with TLE. ${ }^{24}$ Volume loss of the corpus callosum was more pronounced in those with childhood onset of TLE. ${ }^{24}$

The few available studies in pediatric epilepsy have yielded conflicting results. In one study, total brain volumes of children with intractable epilepsy were decreased compared to healthy controls. Children with moderate to severe intellectual disability (IQ $<55$ ) had significantly smaller cerebral and cerebellar, but not hippocampal volumes. ${ }^{25}$ In another study, children with absence epilepsy demonstrated significantly smaller grey matter volumes of the left orbital frontal gyrus and both temporal lobes, but not full frontal lobe or total brain volume compared to age- and gender-matched children without epilepsy. These smaller volumes were not associated with full-scale IQ scores, but the authors speculate that these abnormalities might contribute to the reported deficits in cognition, language, behaviour and emotions in children with childhood absence epilepsy. ${ }^{26}$ Normal total brain volumes were also noted in children with recent-onset epilepsy of various etiologies, even though the patients performed worse on several cognitive tests compared to controls. ${ }^{27}$ In the control group of this study, an association was found between increasing cerebral white matter volume and better cognitive performance in the domains of intelligence, language, psychomotor speed, and some aspects of executive function, relationships that were absent in the epilepsy subjects. Only the subset of epilepsy children with educational problems exhibited significant volumetric reductions in left parietal and occipital lobe grey matter. No other volumetric abnormalities were observed in other lobar grey or white matter regions (Figure 2). ${ }^{27}$ Greater cortical thinning with age in frontal areas has been demonstrated in children and adolescents with complex partial seizures 
and below average IQ scores compared to healthy controls. ${ }^{28}$ In children with JME, deficits in executive functions have been associated with significantly smaller thalamic volumes as well as with more frontal CSF, compared to controls and patients with benign childhood epilepsy with centrotemporal spikes (BCECTS) ${ }^{29}$ Finally, cessation of growth of frontal and prefrontal lobe volumes has recently been described in two cognitively impaired children with BCECTS. The authors hypothesize that the decreased frontal and prefrontal lobe volumes may explain the cognitive (decline of IQ score) and behavioural impairments (hyperactivity and impulsiveness); volume changes in other structures were not assessed. ${ }^{30}$

\section{Diffusion tensor imaging}

DTI tractography visualizes and quantifies the integrity of specific white matter tracts in the brain, by using measures of water directionality. ${ }^{31}$ With this technique it is possible to investigate how subcortical white matter connects different cortical areas. ${ }^{32}$ Several metrics can be calculated from DTI scans, but the two most common are mean diffusivity (MD) or Average Diffusion Coefficient (ADC) and fractional anisotropy (FA) (Figure 3). MD reflects the amplitude of water diffusion, whereas FA reflects the directionality of water diffusion. In normal fiber tracts, water diffusion is directional (high FA), whereas in degenerated tracts, FA decreases and MD increases substantially. ${ }^{32}$ Two studies have investigated associations between cognitive function and integrity of specific white matter tracts. In the first, increased MD values of the left uncinate fasciculus (a major white matter tract connecting the anterior temporal and frontal lobes) were associated with poor performance on measures of auditory memory in patients with TLE with a left-sided seizure focus. Reduced FA and higher MD values of the right uncinate fasciculus were associated with poor performance on measures of visual memory in patients with left TLE. DTI parameters did not correlate with memory scores in patients with a right-sided seizure focus. ${ }^{33}$ The second study related mean FA and tract volumes of parahippocampal gyrus connections to memory performance; decreased mean FA of these connections ipsilateral to the seizure focus, but not volumes, was associated with poorer memory performance in patients with a left-sided seizure focus. Again, DTI parameters did not correlate with memory scores in patients with a right-sided seizure focus. ${ }^{34}$

Three other studies have assessed the integrity of multiple white matter regions or white matter tracts simultaneously and focused on regions or tracts that were likely important to cognitive performance. In the first study, regions in which epilepsy patients showed reduced FA compared to controls, i.e., anterior temporal lobe, mesial temporal lobe, cerebellum and frontoparietal 


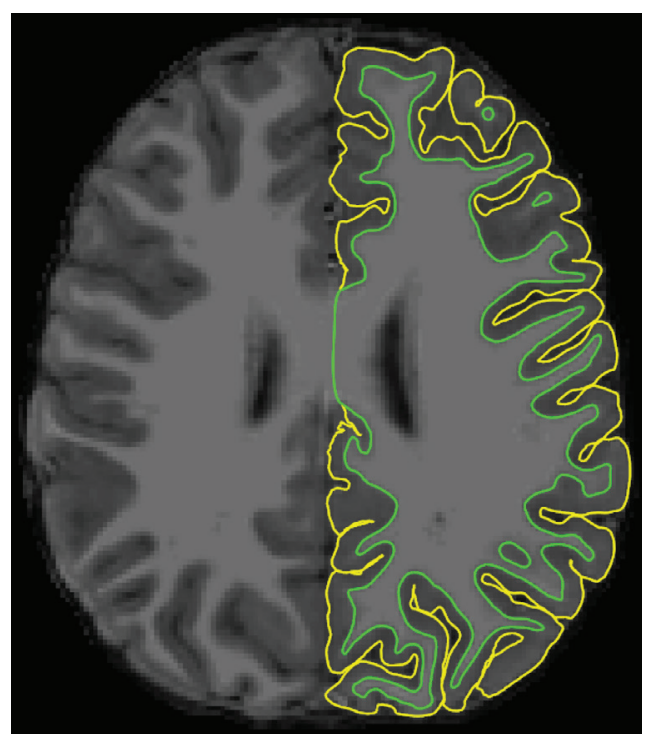

Figure 2. Axial T1-weighted MR image showing an example of grey and white matter tissue segmentation in a patient from the authors' clinic.

lobe, were further studied. A high mean FA in the anterior temporal lobe was correlated with better performance on delayed memory tasks and in the mesial temporal lobe with better immediate memory performance. Bilateral anterior lobe cerebellar FA was positively correlated with executive functioning. No correlations were found between the frontoparietal region and cognitive performances. ${ }^{35}$ The second study related the integrity of four cortical association tracts connecting frontal regions to more posterior regions (i.e., uncinate fasciculus, cingulum, inferior frontooccipital fasciculus and arcuate fasciculus) to executive functioning. Compared to healthy controls, correlations between frontotemporal tract integrity and executive functioning were absent or attenuated in patients with TLE. ${ }^{36}$ The third study related the integrity of multiple white matter tracts (i.e., uncinate fasciculus, arcuate fasciculus, fornix, parahippocampal cingulum, inferior frontooccipital fasciculus, and corticospinal tract) to cognitive function. Increased MD and decreased FA in many of these white matter tracts, alone or in combinations, especially in the left hemisphere, were associated with verbal memory and language performances. No correlations between DTI variables and performances on measures of nonverbal memory or fluency were found. ${ }^{22}$ In contrast to the first study, this latter study demonstrated that disruption of the integrity of white matter tracts, other than those regarded as relevant to the specific cognitive tasks, was associated with memory and language impairments. The authors therefore assume that a wider network of white matter tracts contributes to language and memory performance in TLE. This assumption can be extended to performance of executive functions in patients with frontal lobe epilepsy (FLE). 

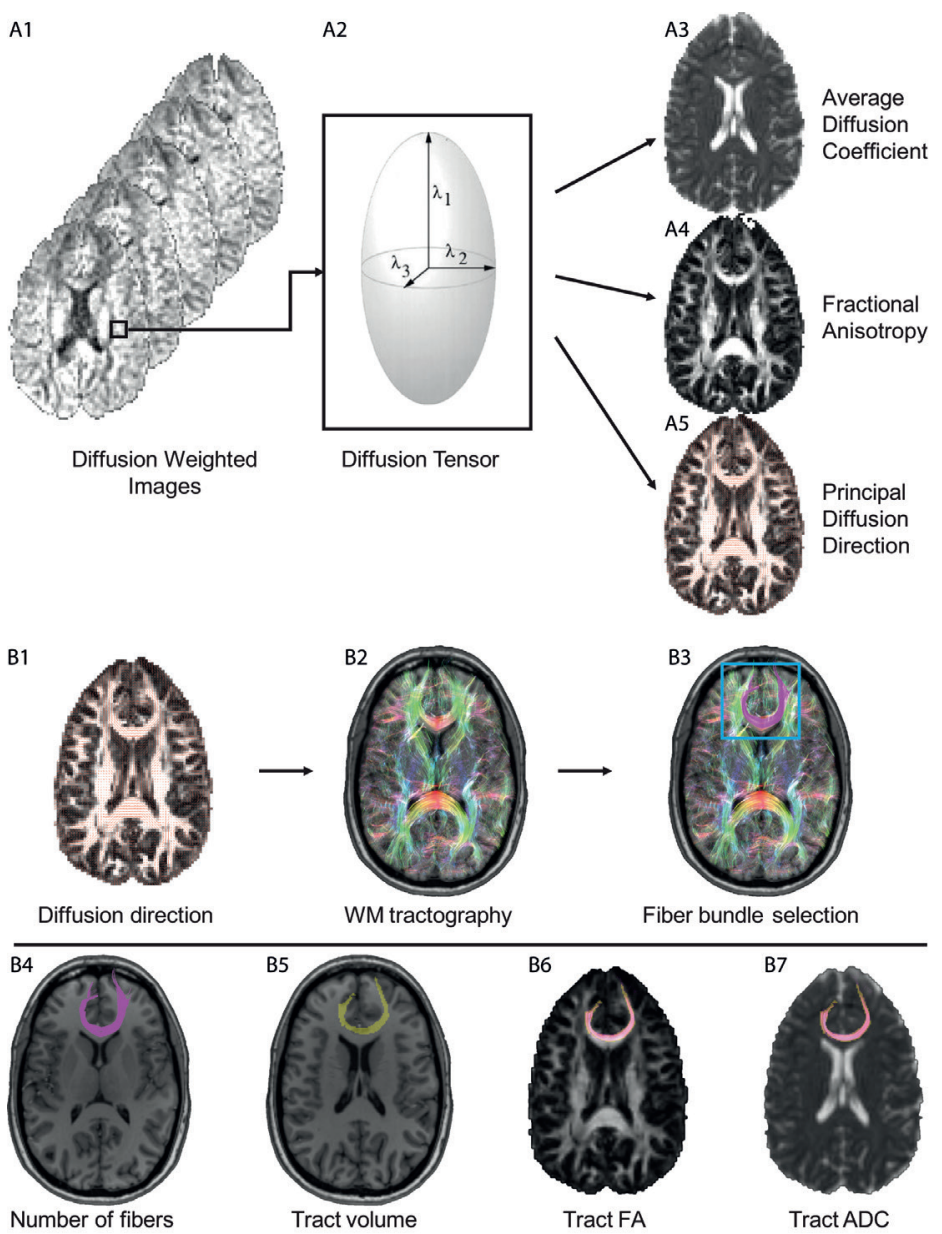

Figure 3. Diffusion weighted imaging and fiber tractography. This composite figure depicts some of the concepts of diffusion weighted imaging and fiber tractography. In panel (A1), a number of diffusion weighted (echo-planar) images are shown. For each image diffusion is measures in a different direction. The values from a voxel (black square) are fitted to the Diffusion Tensor Model (A2). From this tensor a number of parameters can be derived. The Apparent Diffusion Coefficient or Mean Diffusivity (A3) is the average over the magnitude of the eigenvalue of the tensor $\mathrm{ADC}=\left(\lambda_{1}+\lambda_{2}+\lambda_{3}\right) / 3$. The fractional Anisotropy (A4) quantifies the anisotropy of the tensor (i.e. the discrepancy between the largest eigenvalue and the other two).

$$
F A=\sqrt{3 / 2} * \sqrt{\left(\lambda_{1}-\langle\lambda\rangle\right)^{2}+\left(\lambda_{2}-\langle\lambda\rangle\right)^{2}+\left(\lambda_{3}-\langle\lambda\rangle\right)^{2}} / \sqrt{\lambda_{1}^{2}+\lambda_{2}^{2}+\lambda_{3}^{2}}
$$

The principle diffusion direction (A5) is simply the largest eigenvector of the tensor $\mathrm{V}_{\mathrm{r}}$. Panel (B) shows the principle of fiber tractography and fiber quantification. The principal diffusion direction (B1) is followed from voxel to voxel creating fiber tracts as shown in the middle (B2). By applying selection criteria, a set of fibers connecting different parts of the brain can be obtained (B3). A tract can be quantified by various parameters such as the number of fibers (B4), the volume of the tract (B5), the mean FA value of the voxel in the tract (B6) or the mean ADC within the tract (B7). This figure is an illustration from the authors' clinic. 
Executive functioning (i.e., category fluency scores) was positively correlated with white matter integrity of the anterior limbs of the internal capsules, left external capsule, and left occipital lobe. ${ }^{37}$ On a more general level, Mini-Mental Status Examination scores, as a screening tool for gross cognitive impairment, proved positively correlated with left frontal lobe and left thalamus FA in patients with FLE. ${ }^{37}$

Metabolic MRI parameters of cognitive function in epilepsy: spectroscopy Proton MR spectroscopy ( $\left.{ }^{1} \mathrm{H}-\mathrm{MRS}\right)$ provides a method for measuring metabolite levels in specific brain areas. $\mathrm{N}$-acetyl-aspartate (NAA) is the metabolite most commonly evaluated; it resides primarily in healthy neurons and precursor cells and can be regarded as a neuronal marker. Creatine $(\mathrm{Cr})$ is a ubiquitous compound found in neurons as well as glial cells and is related to the energy metabolism. Choline (Cho) is bound to cell membranes, myelin and complex brain lipids. A reduction in NAA signal or in its ratio to $\mathrm{Cr}$ and Cho is assumed to reflect neuronal loss or damage (Figure 4). ${ }^{38,39}$

The relation between metabolite ratios and cognition has almost exclusively been studied in adult patients with TLE related to mesial temporal sclerosis and has focused on hippocampal NAA/(Cho $+\mathrm{Cr})$ levels. The majority of these studies recorded reduced ratios of left, but not right, hippocampal NAA/ $(\mathrm{Cho}+\mathrm{Cr})$, which was associated with poorer verbal memory. ${ }^{14,40-42}$ Although a reduction of left-sided NAA/(Cho $+\mathrm{Cr})$ ratio correlated with lower IQ scores in one study, ${ }^{42}$ other investigators could not confirm this correlation. ${ }^{14}$ In contrast to the previously mentioned ${ }^{1} \mathrm{H}$-MRS studies, reduced right hippocampus $\mathrm{NAA} /(\mathrm{Cho}+\mathrm{Cr})$ ratios have also been found to correlate with poorer verbal memory performance. This correlation depended on the side of mesial temporal sclerosis. ${ }^{43}$ In one study, right hippocampal NAA $/(\mathrm{Cho}+\mathrm{Cr})$ ratio was associated with visual, delayed, and general memory scores ${ }^{40}$ whereas another study could not reproduce this association with nonverbal memory scores. ${ }^{43}$ Associations with attention scores also remain inconclusive. ${ }^{14,40}$ The only study that applied MRS in patients with idiopathic generalized epilepsy found that, in absence of macrostructural lesions in the temporal lobe, memory deficits were correlated with decreased NAA/(Cho $+\mathrm{Cr})$ ratios in the temporal lobes. ${ }^{38}$

\section{Functional MRI measures of cognitive function in epilepsy}

Functional MRI can be used to explore the relationship between brain activation and cognitive functioning. In fMRI, changes in the blood-oxygenlevel dependent (BOLD) signal accompany neural activity in the brain. The few studies that have related cognitive impairment in epilepsy to functional brain activity have been performed in adult patients with epilepsy. 
A

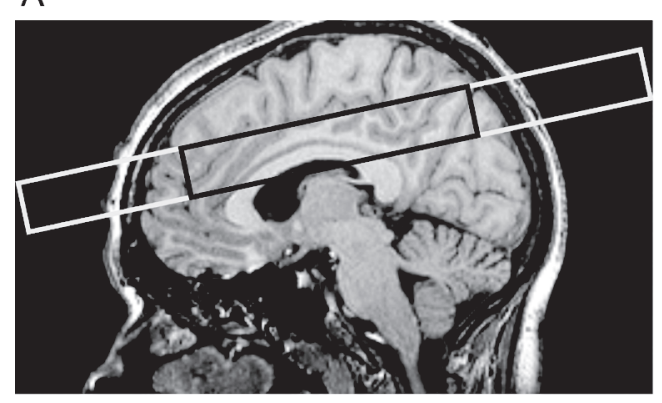

C

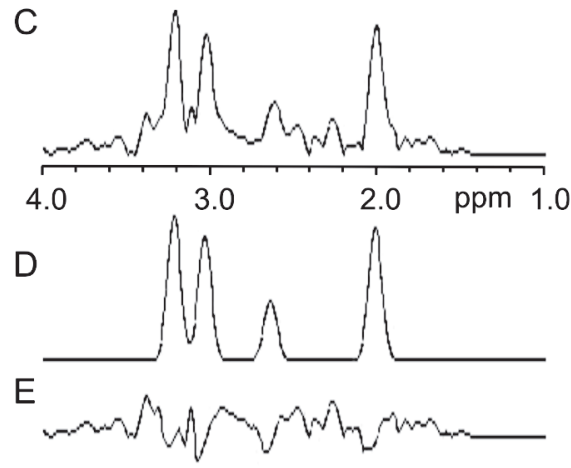

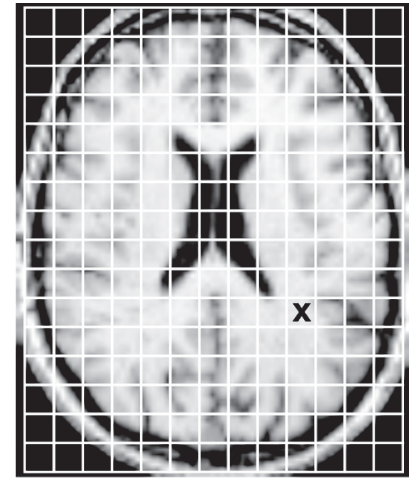

$\mathrm{F}$

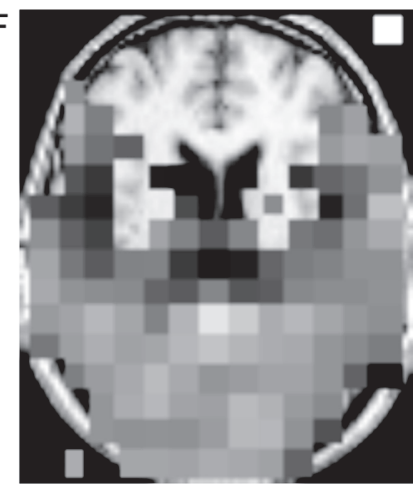

Figure 4. Spectroscopic imaging data acquired at $1.5 \mathrm{~T}$ of a patient with cryptogenic localization-related epilepsy with secondarily generalized seizures. This figure is an illustration from the authors' clinic. Orientation of the spectroscopic imaging slice overlaid on a sagittal T1-weighted image of the brain (A). The field of view and the selected spectroscopy box are indicated in white and black, respectively. (B) The spectroscopic imaging grid and the $\mathrm{NAA} /(\mathrm{Cho}+\mathrm{tCr})$ map of voxels overlaid on an oblique normalized transverse T1-weighted image (F). Original in vivo spectrum $(\mathbf{C})$ of the voxel marked with a black cross in (B), Gaussian fit estimation for the main metabolites (NAA, $\mathrm{N}$-acetyl-aspartate; cho, choline; and tCr, total creatine) (D), and the difference between the original spectrum and the Gaussian fit (E).

Functional MRI studies in patients with epilepsy with cognitive impairment have focused mainly on brain activation during memory tasks. Some of these studies suggest that localization-related epilepsy may influence the functional neuroanatomy of memory function. For example, patients with a left-sided seizure focus showed significantly more right-lateralized (instead of leftlateralized) medial temporal activation during memory test performance compared to healthy controls and patients with a right-sided seizure focus. This activation shift was associated with impaired verbal memory performance. ${ }^{44,45}$ Similar phenomena have been observed in patients with a right-sided seizure 
focus and nonverbal memory performance. ${ }^{44,46}$ In addition to such shifts of activation to the hemisphere contralateral to the seizure focus, activation can also be seen in areas that normally do not show activation during a particular task. One study revealed that patients with TLE with a left-sided seizure focus exhibited remarkably new activation in the left dorsolateral prefrontal cortex compared to healthy controls during verbal episodic memory task performance. ${ }^{47}$ As patients' episodic memory performance was poor, the authors hypothesized that the bad memory performance reflects a cortical dysfunction rather than a compensatory reorganization. ${ }^{47} \mathrm{~A}$ second study drew a similar conclusion based on the observation that patients with TLE with decreased activation in the inferior frontal area performed better on language tasks compared to patients with TLE with normal activation. ${ }^{48}$ Increased activation in areas involved in language functions might indicate that poorly performing patients have a greater neuronal demand for those tasks, and fewer neuronal demands are associated with better performance. ${ }^{48}$ Although this might seem plausible, other studies failed to find differences in activation between cognitively impaired patients and controls. In an fMRI study performed in patients with JME with impaired working memory performance, activation patterns did not differ from healthy controls. ${ }^{17}$ Moreover, in patients with cryptogenic localization-related epilepsy complicated by language impairment, fMRI did not show a different activation pattern during language tasks compared to controls. ${ }^{49}$

\section{Functional connectivity MRI}

Functional connectivity represents the temporal synchronization of neuronal activities between distant brain regions within a network. ${ }^{50}$ The few studies that have investigated this relation have used different analysis methods, hampering a comparative analysis. What we do know from functional connectivity studies in mesial TLE is that altered connectivity (i.e., either decreased or increased) is not only seen in the network of mesiotemporal structures (i.e., structures in which the seizure focus resides), ${ }^{51}$ but also in network structures distant from the seizure focus..$^{51-55}$ The exact relation between these altered functional networks and cognition in epilepsy remains elusive. Decreased functional connectivity may reflect diminished function of a structure in the network; increased functional connectivity may reflect enhanced function owing to compensatory mechanisms. ${ }^{51}$ For example, the decreased resting-state functional connectivity between language areas of patients with TLE with a left-sided seizure focus, compared to healthy controls, has been related to subtle language difficulties in this patient population.${ }^{52}$ Similarly, impaired language performance in patients with cryptogenic localization-related epilepsy was 
A

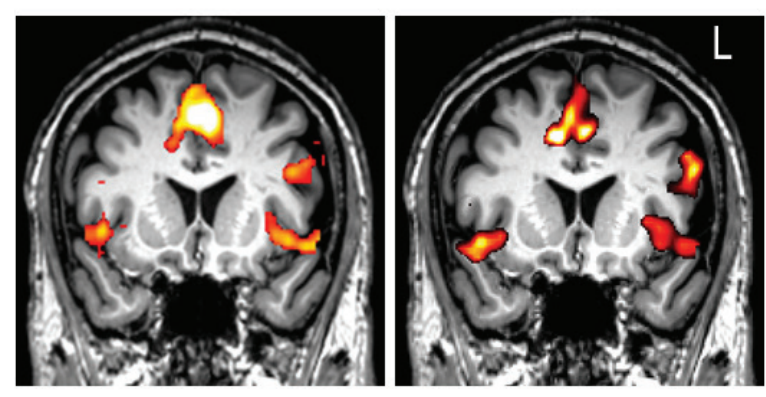

C

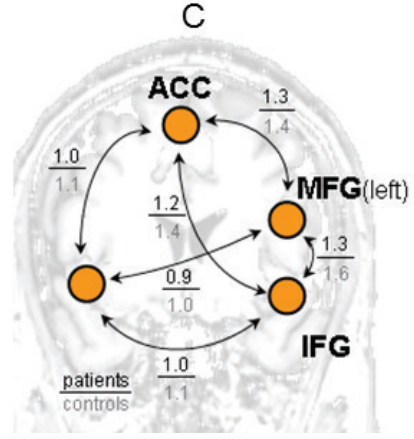

Figure 5. Mean activation patterns for patients with localization-related epilepsy (A) and healthy controls (B) during a text-reading paradigm. Characteristic activation clusters in the bilateral temporal cortex are shown with left-hemispheric dominance. The selected regions of interest with the functional connectivity values for patients (in black) and controls (in grey) for all the connections between these regions are schematically illustrated (C). Although no significant differences in activation patterns could be found between both groups ( $\mathbf{A}$ and $\mathbf{B}$ ), connectivity values in the language networks were decreased (C). This decrease in language network connectivity was associated with impaired language performance. Slice positions are specified in the Montreal Neurological Institute coordinate system. ACC, anterior cingulate cortex; IFG-1, left inferior frontal gyrus; IFG-r, right inferior frontal gyrus; MFG-1, left middle frontal gyrus; MTG-l, left middle temporal gyrus; MTG-r, right middle temporal gyrus. This figure is an illustration from the authors' clinic.

associated with decreased connectivity in the language networks (Figure 5). ${ }^{49}$ Increased functional connectivity in the connection linking the anterior to the posterior hippocampus contralateral to the seizure focus was correlated with better working memory performance in patients with TLE. ${ }^{51}$

\section{Perspective}

The novel MRI techniques have not been used extensively in epilepsy research, let alone to investigate the neuronal correlates of cognitive impairment complicating epilepsy. Although the onset of epilepsy is generally in childhood, MRI techniques have been rarely applied in children with epilepsy. Moreover, the available studies have mostly focused on specific structures in specific types of epilepsy and used different cognitive measures. The diversity in study groups and study designs hinders an in-depth comparison and interpretation of the results. In addition, this diversity can be an important reason for the variety in study results. Still, the available studies offer interesting insights 
into the structural, metabolic, and functional abnormalities associated with cognitive deficits.

All individual MRI techniques have shown abnormalities associated with cognitive impairment in epilepsy. Combined, the findings emphasize that cognitive impairment in epilepsy results from a network disorder in which both the (micro)structures as well as the functionality are disturbed. Abnormal volumes, white matter tracts, and activation patterns are not only seen in the area in which the seizure focus resides but also in areas connected to or distant from the seizure focus. For example, both volume loss of the hippocampus as well as reduction of total white matter volume has been associated with memory impairment in patients with TLE. ${ }^{9,20}$ The broad ranges of cognitive impairments that can be observed in patients with epilepsy ${ }^{23}$ are consistent with localized as well as widespread network disturbances.

It remains questionable whether microstructural abnormalities eventually result in impaired metabolite levels and function, reflected by cognitive impairment (and epilepsy) or whether functional disturbances (caused by epileptic activity) give rise to microstructural abnormalities, for example, white matter tract degeneration and volume loss secondary to this loss of function. To uncover the source of structural and functional abnormalities and establish cause and effect relationships, future studies should focus on network integrity, preferably by combining microstructural, metabolic as well as functional MRI techniques. Whether these abnormalities are influenced by epilepsy type, age at seizure onset, or duration of epilepsy and whether compensatory mechanisms can be activated warrants separate studies. For example, deficits in executive functions were associated with significantly smaller thalami and more frontal CSF in children with JME, but not in children with BCECTS. ${ }^{29}$ Cognitive impairment can be present before epilepsy onset. ${ }^{21,56}$ Therefore, disturbances of network integrity may give rise to both cognitive impairment and epilepsy. To understand the pathology underlying cognitive impairment in children with epilepsy and to predict cognitive outcome, longitudinal studies applying the different MRI techniques are still required. Ideally, these should include patients at the onset of seizures and investigate multiple epilepsy groups to see if findings are applicable for all types of epilepsy. In addition, the brain maturation process should be taken into account. Currently available studies have mainly investigated adults with longstanding epilepsy and are limited by short or no follow-up.

A combination of several techniques by multimodal measurements may be most informative about neuronal correlates of cognitive outcome in epilepsy. For example, by combining fMRI and DTI techniques, the functional impact of white matter tract abnormalities or the impact of functional impairments on 
white matter tract integrity can be evaluated. Subsequently, hypotheses about altered structure-function relationships accounting for cognitive impairment in epilepsy can be tested. New methods of data analysis may be needed to perform combined analyses of different techniques. Graph theoretical analysis is an example of a technique that converts fMRI data to abstract graphs to investigate the level of interaction between pairs of distinct brain regions. With this technique, disturbed local connectedness has been demonstrated in patients with mesial TLE. ${ }^{54}$ Up to now, only one study has related results of measurements by this technique to cognitive performance in epilepsy. Patients with chronic cryptogenic localization-related epilepsy displayed both local as well as global cerebral network disruptions compared to controls. These disruptions were more pronounced in cognitively impaired patients. ${ }^{57}$

In conclusion, all different novel MRI techniques have offered new insights into structural and functional abnormalities associated with cognitive impairment in epilepsy: cognitive impairment in epilepsy results from a network disorder in which both the microstructures as well as the functions are disturbed. Longitudinal studies starting at the time of diagnosis remain necessary. 


\section{References}

1. Bulteau C, Jambaque I, Viguier D, Kieffer V, Dellatolas G, Dulac O. Epileptic syndromes, cognitive assessment and school placement: a study of 251 children. Dev Med Child Neurol 2000;42:319-327.

2. Aldenkamp AP, Weber B, Overweg-Plandsoen WC, Reijs R, van Mil S. Educational underachievement in children with epilepsy: a model to predict the effects of epilepsy on educational achievement. J Child Neurol 2005;20:175-180.

3. Braakman HM, Vaessen MJ, Hofman PA, Debeij-van Hall MH, Backes WH, Vles JS, Aldenkamp AP. Cognitive and behavioral complications of frontal lobe epilepsy in children: a review of the literature. Epilepsia 2011;52:849-856.

4. Byars AW, deGrauw TJ, Johnson CS, Fastenau PS, Perkins SM, Egelhoff JC, Kalnin A, Dunn DW, Austin JK. The association of MRI findings and neuropsychological functioning after the first recognized seizure. Epilepsia 2007;48:1067-1074.

5. Berg AT, Berkovic SF, Brodie MJ, Buchhalter J, Cross JH, van Emde Boas W, Engel J, French J, Glauser TA, Mathern GW, Moshé SL, Nordli D, Plouin P, Scheffer IE. Revised terminology and concepts for organization of seizures and epilepsies: Report of the ILAE Commission on Classification and Terminology, 2005-2009. Epilepsia 2010;51:676-685.

6. Ashburner J, Friston KJ. Voxel-based morphometry -- the methods. Neuroimage 2000;11:805-821.

7. Trenerry MR, Jack CR Jr, Ivnik RJ, Sharbrough FW, Cascino GD, Hirschorn KA, Marsh WR, Kelly PJ, Meyer FB. MRI hippocampal volumes and memory function before and after temporal lobectomy. Neurology 1993;43:1800-1805.

8. Kilpatrick C, Murrie V, Cook M, Andrewes D, Desmond P, Hopper J. Degree of left hippocampal atrophy correlates with severity of neuropsychological deficits. Seizure 1997;6:213-218.

9. Baxendale SA, Van Paesschen W, Thompson PJ, Connelly A, Duncan JS, Harkness WF, Shorvon SD. The relationship between quantitative MRI and neuropsychological functioning in temporal lobe epilepsy. Epilepsia 1998;39:158-166.

10. Alessio A, Kobayashi E, Damasceno BP, Lopes-Cendes I, Cendes F. Evidence of memory impairment in asymptomatic individuals with hippocampal atrophy. Epilepsy Behav 2004;5:981-987.

11. Seidenberg M, Hermann B, Pulsipher D, Morton J, Parrish J, Geary E, Guidotti L. Thalamic atrophy and cognition in unilateral temporal lobe epilepsy. J Int Neuropsychol Soc 2008;14:384-393.

12. Stewart CC, Griffith HR, Okonkwo OC, Martin RC, Knowlton RK, Richardson EJ, Hermann BP, Seidenberg M. Contributions of volumetrics of the hippocampus and thalamus to verbal memory in temporal lobe epilepsy patients. Brain Cogn 2009;69:65-72.

13. Kälviäinen R, Salmenperä T, Partanen K, Vainio P, Riekkinen P, Pitkänen A. Recurrent seizures may cause hippocampal damage in temporal lobe epilepsy. Neurology 1998;50:1377-1382.

14. Martin RC, Hugg JW, Roth DL, Bilir E, Gilliam FG, Faught E, Kuzniecky RI. MRI extrahippocampal volumes and visual memory: correlations independent of MRI hippocampal volumes in temporal lobe epilepsy patients. J Int Neuropsychol Soc 1999;5:540-548.

15. Cummings JL, Miller BL. Chapter 2: Conceptual and clinical aspects of the frontal lobes. In Bruce L, Miller MD (Editor), Jeffrey L, Cummings MD (Editor) The Human Frontal Lobes, Second Edition: Functions and Disorders (The Science and Practice of Neuropsychology). The Guilford Press, New York, 2007:12-21.

16. Keller SS, Baker G, Downes JJ, Roberts N. Quantitative MRI of the prefrontal cortex and executive function in patients with temporal lobe epilepsy. Epilepsy Behav 2009;15:186-195.

17. Roebling R, Scheerer N, Uttner I, Gruber O, Kraft E, Lerche H. Evaluation of cognition, structural, and functional MRI in juvenile myoclonic epilepsy. Epilepsia 2009;50:2456-2465.

18. Tuchscherer V, Seidenberg M, Pulsipher D, Lancaster M, Guidotti L, Hermann B. Extrahippocampal 
integrity in temporal lobe epilepsy and cognition: thalamus and executive functioning. Epilepsy Behav 2010;17:478-482

19. Riley JD, Moore S, Cramer SC, Lin JJ. Caudaute atrophy and impaired frontostriatal connections are linked to executive dysfunction in temporal lobe epilepsy. Epilepsy Behav 2011;21:80-87.

20. Hermann B, Seidenberg M, Bell B, Rutecki P, Sheth R, Ruggles K, Wendt G, O’Leary D, Magnotta V. The neurodevelopmental impact of childhood-onset temporal lobe epilepsy on brain structure and function. Epilepsia 2002;43:1062-1071.

21. Hermann BP, Seidenberg M, Dow C, Jones J, Rutecki P, Bhattacharya A, Bell B. Cognitive prognosis in chronic temporal lobe epilepsy. Ann Neurol 2006;60:80-87.

22. McDonald CR, Ahmadi ME, Hagler DJ, Tecoma ES, Iragui VJ, Gharapetian L, Dale AM, Halgren E. Diffusion tensor imaging correlates of memory and language impairments in temporal lobe epilepsy. Neurology 2008;71:1869-1876.

23. Oyegbile TO, Bhattacharya A, Seidenberg M, Hermann BP. Quantitative MRI biomarkers of cognitive morbidity in temporal lobe epilepsy. Epilepsia 2006;47:143-152.

24. Hermann B, Hansen R, Seidenberg M, Magnotta V, O’Leary D. Neurodevelopmental vulnerability of the corpus callosum to childhood onset localization-related epilepsy. Neuroimage 2003;18:284-292.

25. Lawson JA, Vogrin S, Bleasel AF, Cook MJ, Burns L, McAnally L, Pereira J, Bye AM. Predictors of hippocampal, cerebral, and cerebellar volume reduction in childhood epilepsy. Epilepsia 2000;41:1540-1545.

26. Caplan R, Levitt J, Siddarth P, Wu KN, Gurbani S, Sankar R, Shields WD. Frontal and temporal volumes in Childhood Absence Epilepsy. Epilepsia 2009;50:2466-2472.

27. Hermann B, Jones J, Sheth R, Dow C, Koehn M, Seidenberg M. Children with new-onset epilepsy: neuropsychological status and brain structure. Brain 2006;129:2609-2619.

28. Tosun D, Caplan R, Siddarth P, Seidenberg M, Gurbani S, Toga AW, Hermann B. Intelligence and cortical thickness in children with complex partial seizures. Neuroimage 2011;57:337-345.

29. Pulsipher DT, Seidenberg M, Guidotti L, Tuchscherer VN, Morton J, Sheth RD, Hermann B. Thalamofrontal circuitry and executive dysfunction in recent-onset juvenile myoclonic epilepsy. Epilepsia 2009;50:1210-1219.

30. Kanemura H, Hata S, Aoyagi K, Sugita K, Aihara M. Serial changes of prefrontal lobe growth in the patients with benign childhood epilepsy with centrotemporal spikes presenting with cognitive impairments/behavioral problems. Brain Dev 2011;33:106-113.

31. Catani M, Howard RJ, Pajevic S, Jones DK. Virtual in vivo interactive dissection of white matter fasciculi in the human brain. Neuroimage 2002;17:77-94.

32. Beaulieu C, Does MD, Snyder RE, Allen PS. Changes in water diffusion due to Wallerian degeneration in peripheral nerve. Magn reson Med 1996;36:627-631.

33. Diehl B, Busch RM, Duncan JS, Piao Z, Tkach J, Lüders HO. Abnormalities in diffusion tensor imaging of the uncinate fasciculus relate to reduced memory in temporal lobe epilepsy. Epilepsia 2008;49:1409-1418.

34. Yogarajah M, Powell HWR, Parker GJM, Alexander DC, Thompson PJ, Symms MR, Boulby P, Wheeler-Kingshott CA, Barker GJ, Koepp MJ, Duncan JS. Tractography of the parahippocampal gyrus and material specific memory impairment in unilateral temporal lobe epilepsy. Neuroimage 2008;40:1755-1764

35. Riley JD, Franklin DL, Choi V, Kim RC, Binder DK, Cramer SC, Lin JJ. Altered white matter integrity in temporal lobe epilepsy: association with cognitive and clinical profiles. Epilepsia.2010;51:536-545.

36. Kucukboyaci NE, Girard HM, Hagler DJ, Kuperman J, Tecoma ES, Iragui VJ, Halgren E, McDonald $\mathrm{CR}$. Role of fiber tract integrity in task-switching performance of healthy controls and patients with temporal lobe epilepsy. J Int Neuropsychol Soc 2012;18:57-67. 
37. Wang XQ, Lang SY, Hong LU, Lin MA, Yan-Ling MA, Yang F. Changes in extrafrontal integrity and cognition in frontal lobe epilepsy: a diffusion tensor imaging study. Epilepsy Behav 2011;20:471-477.

38. Dickson JM, Wilkinson ID, Howell SJL, Griffiths PD, Grünewald RA. Idiopathic generalized epilepsy: a pilot study of memory and neuronal dysfunction in the temporal lobes, assessed by magnetic resonance spectroscopy. J Neurol Neurosurg Psychiatry 2006;77:834-840.

39. Rosen Y, Lenkinski RE. The recent advances in magnetic resonance neurospectroscopy. Neurotherapeutics 2007;4:330-345.

40. Namer IJ, Bolo NR, Sellal F, Nguyen VH, Nedelec JF, Hirsch E, Marescaux C. Combined measurements of hippocampal $\mathrm{N}$-Acetyl-Aspartate and T2 relaxation time in the evaluation of mesial temporal lobe epilepsy: correlation with clinical severity and memory performances. Epilepsia 1999;40:1424-1432.

41. Sawrie SM, Martin RC, Knowlton R. Faught E, Gilliam F, Kuzniecky R. Relationships among hippocampal volumetry, proton magnetic resonance spectroscopy, and verbal memory in temporal lobe epilepsy. Epilepsia 2001;42:1403-1407.

42. Mantoan MAS, Caboclo LOSF, de Figueiredo Ferreira Guilhoto LM, Lin K, da Silva Noffs MH, de Souza Silva Tudesco I, Belzunces E, Carrete H Jr, Bussoletti RT, Centeno RS, Sakamoto AC, Yacubian EM. Correlation between memory, proton magnetic resonance spectroscopy, and interictal epileptiform discharges in temporal lobe epilepsy related to mesial temporal sclerosis. Epilepsy Behav 2009;16:447-453.

43. Hanoğlu L, Özkara C, Keskinkiliç C, Altin Ü, Uzan M, Tuzgen S, Dinçer A, Ozyurt E. Correlation between $1 \mathrm{H}$ MRS and memory before and after surgery in mesial temporal lobe epilepsy with hippocampal sclerosis. Epilepsia 2004;5:632-640.

44. Powell HW, Richardson MP, Symms MR, Boulby PA, Thompson PJ, Duncan JS, Koepp MJ. Reorganization of verbal and nonverbal memory in temporal lobe epilepsy due to unilateral hippocampal sclerosis. Epilepsia 2007;48:1512-1525.

45. Wagner K, Frings L, Spreer J, Buller A, Everts R, Halsband U, Schulze-Bonhage A. Differential effect of side of temporal lobe epilepsy on lateralization of hippocampal, temporolateral, and inferior frontal activation patterns during a verbal episodic memory task. Epilepsy Behav 2008;12:382-387.

46. Vannest J, Szaflarski JP, Privitera MD, Schefft BK, Holland SK. Medial temporal fMRI activation reflects memory lateralization and memory performance in patients with epilepsy. Epilepsy Behav 2008;12:410-418.

47. Dupont S, Van de Moortele PF, Samson S, Hasboun D, Poline JB, Adam C, Lehéricy S, Le Bihan D, Samson Y, Baulac M. Episodic memory in left temporal lobe epilepsy: a functional MRI study. Brain 2000;123:1722-1732.

48. Weber B, Wellmer J, Schür S, Denckelacker V, Ruhlmann J, Mormann F, Axmacher N, Elger CE, Fernández G. Presurgical language fMRI in patients with drug-resistant epilepsy: effects of task performance. Epilepsia 2006;47:880-886.

49. Vlooswijk MC, Jansen JF, Majoie HJ, Hofman PA, de Krom MC, Aldenkamp AP, Backes WH. Functional connectivity and language impairment in cryptogenic localization-related epilepsy. Neurology 2010;75:395-402.

50. Zhang Z, Lu G, Zhong Y, Tan Q, Liao W, Wang Z, Wang Z, Li K, Chen H, Liu Y. Altered spontaneous neuronal activity of the default-mode network in mesial temporal lobe epilepsy. Brain Res 2010;1323:152-160.

51. Bettus G, Guedj E, Joyeux F, Confort-Gouny S, Soulier E, Laguitton V, Cozzone PJ, Chauvel P, Ranjeva JP, Bartolomei F, Guye M. Decreased basal fMRI functional connectivity in epileptogenic networks and contralateral compensatory mechanisms. Hum Brain Mapp 2009;30:1580-1591.

52. Waites AB, Briellmann RS, Saling MM, Abbott DF, Jackson GD. Functional connectivity networks are disrupted in left temporal lobe epilepsy. Ann Neurol 2006;59:335-343. 
53. Voets NL, Adcock JE, Stacey R, Hart Y, Carpenter K, Matthews PM, Beckmann CF. Functional and structural changes in the memory network associated with left temporal lobe epilepsy. Hum Brain Mapp 2009;30:4070-4081.

54. Liao W, Zhang Z, Pan Z, Mantini D, Ding J, Duan X, Luo C, Lu G, Chen H. Altered functional connectivity and small-world in mesial temporal lobe epilepsy. PLoS One 2010;5:e8525.

55. Luo C, Li Q, Lai Y, Xia Y, Qin Y, Liao W, Li S, Zhou D, Yao D, Gong Q. Altered functional connectivity in default mode network in absence epilepsy: a resting-state fMRI study. Hum Brain Mapp 2011;32:438-449.

56. Prévost J, Lortie A, Nguyen D, Lassonde M, Carmant L. Nonlesional Frontal Lobe Epilepsy (FLE) of Childhood: Clinical Presentation, Response to Treatment and Comorbidity. Epilepsia 2006;47:21982201.

57. Vlooswijk MC, Vaessen MJ, Jansen JF, de Krom MC, Majoie HJ, Hofman PA, Aldenkamp AP, Backes WH. Loss of network efficiency associated with cognitive decline in chronic epilepsy. Neurology 2011;77:938-944. 


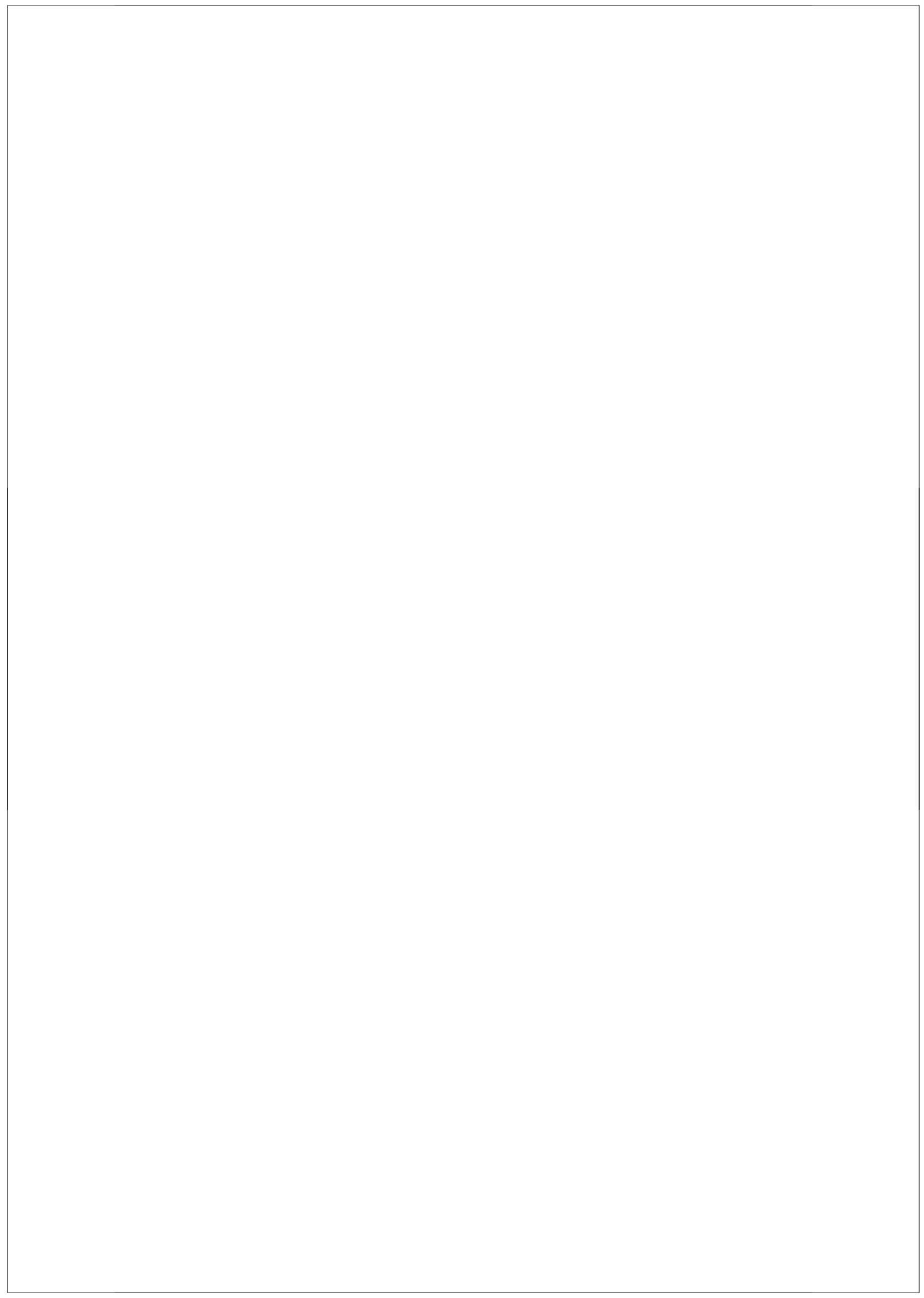




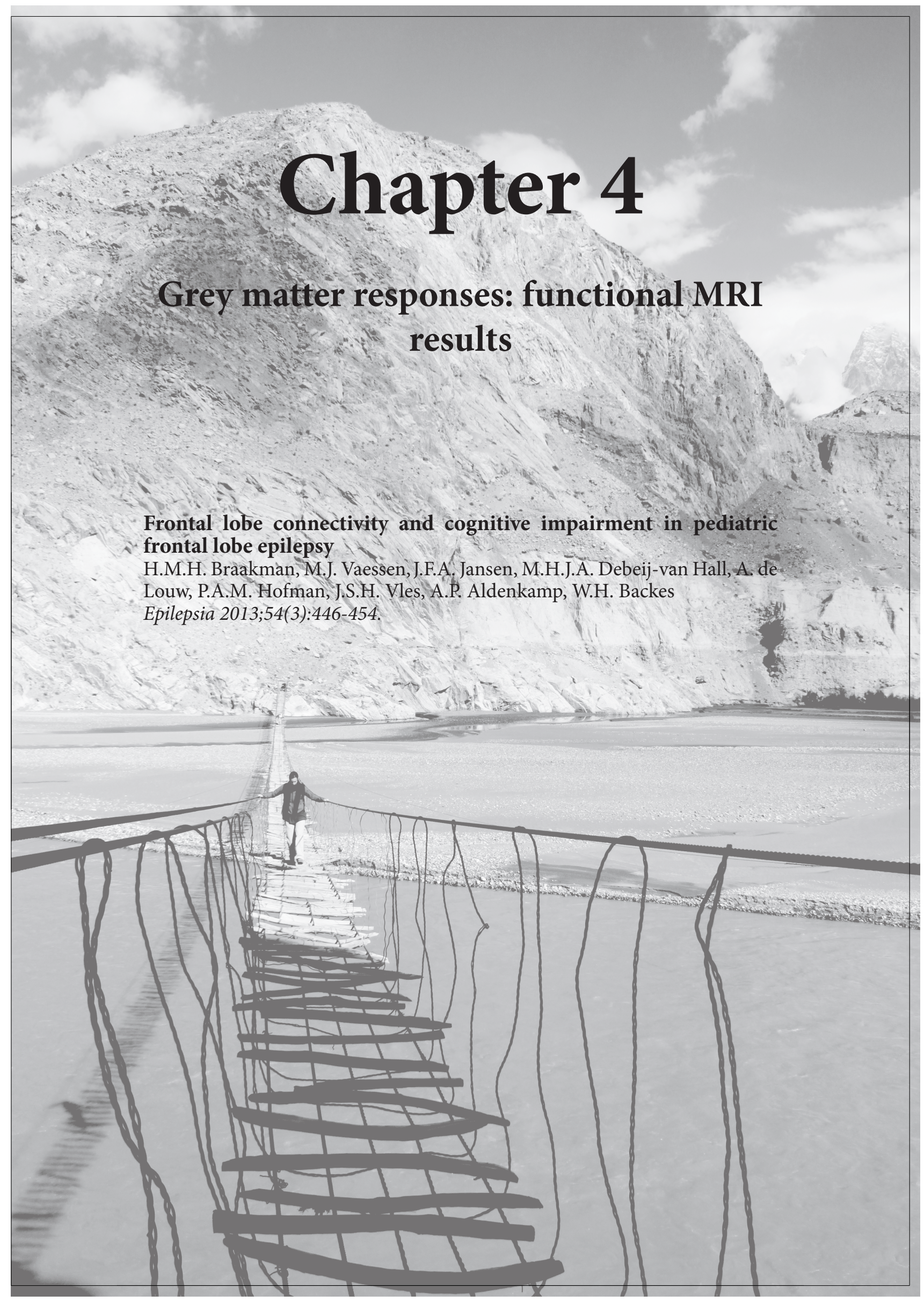




\section{Summary}

Purpose: Cognitive impairment is frequent in children with frontal lobe epilepsy (FLE), but its etiology is unknown. With functional magnetic resonance imaging (fMRI), we have explored the relationship between brain activation, functional connectivity, and cognitive functioning in a cohort of pediatric patients with FLE and healthy controls.

Methods: Thirty-two children aged 8-13 years with FLE of unknown cause and 41 healthy age-matched controls underwent neuropsychological assessment and structural and functional brain MRI. We investigated to which extent brain regions activated in response to a working memory task and assessed functional connectivity between distant brain regions. Data of patients were compared to controls, and patients were grouped as cognitively impaired or unimpaired.

Key findings: Children with FLE showed a global decrease in functional brain connectivity compared to healthy controls, whereas brain activation patterns in children with FLE remained relatively intact. Children with FLE complicated by cognitive impairment typically showed a decrease in frontal lobe connectivity. This decreased frontal lobe connectivity comprised both connections within the frontal lobe as well as connections from the frontal lobe to the parietal lobe, temporal lobe, cerebellum, and basal ganglia.

Significance: Decreased functional frontal lobe connectivity is associated with cognitive impairment in pediatric FLE. The importance of impairment of functional integrity within the frontal lobe network, as well as its connections to distant areas, provides new insights in the etiology of the broad-range cognitive impairments in children with FLE. 


\section{Frontal lobe connectivity and cognitive impairment in pediatric frontal lobe epilepsy}

\section{Introduction}

Frontal lobe epilepsy (FLE) is the second most common type of the localizationrelated epilepsies and its average age at onset ranges from 4 to 8 years. ${ }^{1,2}$ FLE in children is frequently complicated by cognitive impairment, but this cognitive impairment shows strong interindividual variability. ${ }^{2}$ Cognitive impairment generally comprises attention deficits and impaired executive functioning. In addition, a decline in intelligence quotient (IQ) scores, language impairment, and memory deficits have been described in children with FLE. ${ }^{2,3}$ Therefore, FLE does not impact on one specific function but on a broad range of cognitive domains, which frequently results in educational problems and the need for special education., ${ }^{2,4}$ The etiology of cognitive deficits in children with FLE is unknown and correlations with clinical epilepsy characteristics, including age at seizure onset and seizure frequency, remain inconclusive. ${ }^{2,4}$

With functional MRI (fMRI) techniques, the functional brain organization can be investigated. Functional network changes have been observed in adult patients with localization-related epilepsy of unknown cause complicated by language impairment. ${ }^{5}$ Because cognitive impairment is already present early in the course of FLE, ${ }^{3}$ we investigated correlations between cognitive impairment and brain organization in childhood with a focus on the role of the frontal lobe. Recently, we revealed whole-brain resting-state network abnormalities in the same cohort of children with FLE using graph theory. ${ }^{6}$ The current research work focuses on the specific role of the frontal lobe during verbal working memory processing. Our research questions were whether fMRI activation and connectivity results differ between children with FLE compared to healthy controls, and, if so, whether these differences relate to the cognitive impairment. In addition, we investigated whether in our patient cohort clinical epilepsy characteristics could be identified that are related to fMRI changes associated with cognitive impairment.

\section{Methods}

\section{Participants}

We performed this cohort study at the Epilepsy Centre Kempenhaeghe, Heeze, The Netherlands. The Medical Ethical Committees of Kempenhaeghe and the 
Maastricht University Medical Centre approved this study, which is registered by the Dutch Trial Register (NTR1749).

Inclusion criteria for the patients were the following: confirmed FLE of unknown cause, age between 8 and 13 years (children above the age of 8 years were considered capable to undergo MRI scanning without sedation), no other disease that could cause cognitive decline, and no history of brain injury. All patients had a normal structural brain MRI prior to inclusion, reconfirmed by a board certified neuroradiologist. The diagnosis FLE was made when patients have had one or more clinical seizures associated with frontal focal epileptic electroencephalography (EEG) discharges. When no EEG was available during a clinical seizure, the video-recording of more than one seizure with clinical evidence of a frontal lobe origin was required to confirm the diagnosis. ${ }^{7}$ We excluded patients with frontal lobe seizures resulting from spread to the frontal lobes or with interictal epileptiform EEG abnormalities outside the frontal lobes.

Healthy age-matched controls were recruited by advertisements in local newspapers. All controls followed regular education. Exclusion criteria were medical history of head trauma or other diseases that may cause cognitive impairment.

Exclusion criteria for both groups were contraindications for MRI such as metal implants or (one of the) parents unwilling to provide informed consent.

We collected the following data for all subjects: gender, age, education level, medical history, family history, and dominant handedness.

For the patients with FLE, the following clinical epilepsy characteristics were collected via chart review: age at onset, seizure duration, seizure type, seizure frequency, seizure occurrence, history of febrile seizures, history of status epilepticus, antiepileptic drug (AED) treatment, drug load, response to AED treatment, and localization of epileptic discharges on EEG (left frontal, right frontal, or bifrontal). We computed drug load as previously described. ${ }^{8}$ In children using two or more AEDs, cumulative drug loads were calculated.

\section{Neuropsychological testing}

We performed a neuropsychological assessment of all patients prior to inclusion (see Appendix S1 for neuropsychological test details). If neuropsychological assessment had been performed within 1 year prior to inclusion, and the assessment involved all necessary tests for this study, then those test results were used. If neuropsychological assessment had been performed $>1$ year earlier, we repeated part of the neuropsychological assessment (see Appendix S1). The healthy control group underwent this same neuropsychological assessment. For each participant, we evaluated test performance on three different cognitive 
domains to assess cognitive functioning, that is, global cognitive functioning, high-order cognitive functioning and fluid cognitive functioning. Global cognitive functioning reflects a trait-dependent ability. This ability shows only minor fluctuations over time (e.g., intelligence). Higher-order cognitive functioning consists of central functions that module and control more routine or fundamental skills (e.g., memory and verbal comprehension). Fluid cognitive functioning consists of fluctuating or state-dependent functions (e.g., attention or psychomotor speed).

Individual cognitive functioning was transformed into an impairment index, which reflects performance in the three above-mentioned cognitive domains, on a scale of 1 (severe impairment) to 8 (no impairment); see Appendix S2 for details.

Participants were grouped as cognitively impaired (i.e., an impairment index of $\leq 4$; which means that at least global cognitive functioning is impaired) or cognitively minimal or unimpaired (impairment index $>4$ ).

\section{MRI procedure \\ Image acquisition}

MRI was performed on a 3.0-Tesla unit equipped with an 8-channel head coil (Achieva; Philips Medical Systems, Best, The Netherlands). fMRI data were acquired using a whole-brain single-shot multislice blood oxygen leveldependent (BOLD) echo-planar imaging (EPI) sequence, with repetition time (TR) $2 \mathrm{~s}$, echo time (TE) $35 \mathrm{msec}$, flip angle 90 degrees, voxel size $2 \times 2 \times 4$ $\mathrm{mm}^{3}, 32$ contiguous slices per volume, and 19 and 5 volumes per acquisition. For anatomic reference, a T1-weigthed three-dimensional (3D) turbo field echo was acquired with the following parameters: TR $8.1 \mathrm{msec}$, TE $3.7 \mathrm{msec}$, flip angle 8 degrees, field of view (FOV) $256 \times 256$ x $180 \mathrm{~mm}^{3}$, and voxel size $1 \times 1 \times 1 \mathrm{~mm}^{3}$.

\section{fMRI activation task}

For the task-related fMRI we used a Sternberg letter recognition task, reflecting verbal working memory performance, to induce cerebral activation. In previous studies prefrontal and temporal areas were activated by this task. ${ }^{9-11}$ A set of letters was visually presented to be maintained in the working memory. Subsequently, subjects responded to the presentation of single letters by pressing a button with either their right or left hand to indicate whether or not the letter was in the memorized set of letters. In the baseline condition, subjects focused on a crosshair. The task consisted of six blocks (memory set of 1-3 letters for $4 \mathrm{~s}$ followed by 13 response letters of $2 \mathrm{~s}$ each) alternated with seven baseline rest condition blocks (30 s each). The contrast between activation in baseline condition and in the 
loads was used for further analysis. ${ }^{12}$ Prior to the actual fMRI scanning, all study subjects successfully practiced one block inside the scanner.

\section{Data analysis}

Image preprocessing

Analysis of the time series data was performed in the Statistical Parametric Mapping (SPM8) software application (Wellcome Department of Cognitive Neurology, London, United Kingdom). Dynamic images were realigned to correct for head movements. The corrected images were coregistered with the high-resolution T1 image. The T1 image was transformed into standard Montreal Neurological Institute (MNI) space through the unified segmentation process. ${ }^{13}$ The functional images were spatially normalized by applying the transformation parameters from the unified segmentation step. Finally the functional images were spatially smoothed (8-mm Gaussian kernel).

\section{Activation and functional connectivity analysis}

Brain activation was assessed in terms of activation contrast between the task and baseline condition according to the general linear model in SPM8. A simple standard random-effects analysis was performed to assess differences in cerebral activation between the patient and control groups thresholded at the $\mathrm{p}<0.05$ level, corrected for multiple comparisons. ${ }^{14}$ First, the activation maps of the two groups were compared on a pixel-by-pixel basis and clusters of significantly (family-wise error corrected) activated brain regions were reported. Second, based on the activation maps masks were created to select the brain regions of interest. The brain regions most significantly activated were selected as regions of interest. We always included the contralateral brain region (also when not significantly activated). Time-course data were low-pass-filtered to remove the effect of high-frequency signal components and corrected for effects of head movements by using the six motion correction parameters as covariates. The temporal correlation (Pearson's) of the filtered time series of all pairs of selected regions was calculated. The correlation coefficients between all regions were transformed into Fisher Z-values. ${ }^{15}$ Figure 1 demonstrates the sequence of steps between fMRI data time-series processing, connectivity matrix calculation, and statistical connectivity analysis.

\section{Statistical analysis}

Statistical data analysis was performed using the SPSS 16.0 software package (SPSS Inc., Chicago, IL, U.S.A.). Demographic and clinical characteristics were assessed using descriptive statistics. Values were expressed as mean value \pm standard deviation and between-group differences were assessed using analysis 


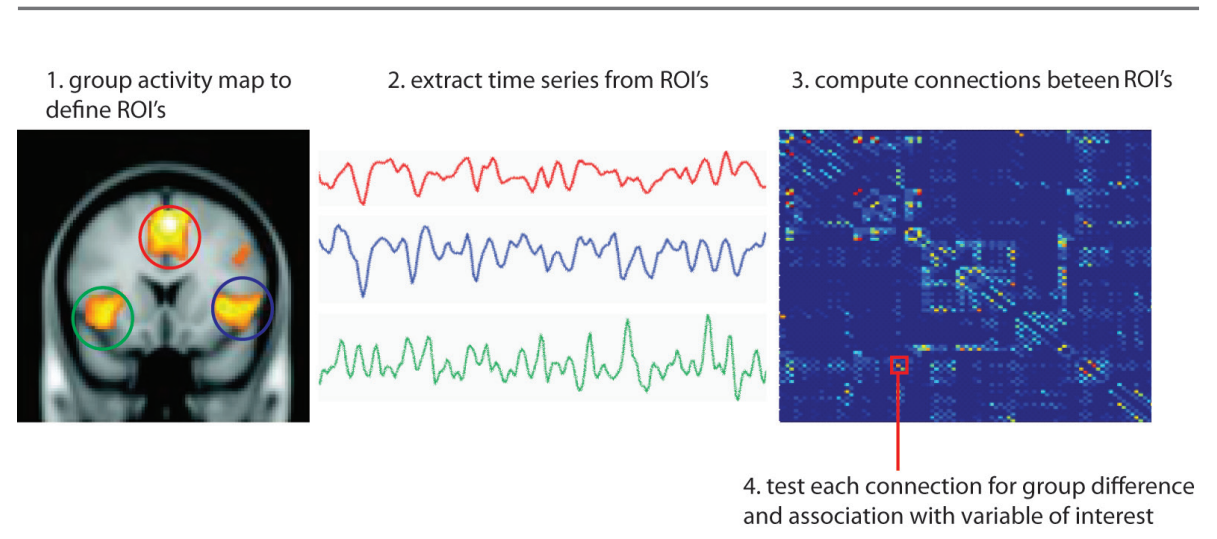

Figure 1. The sequence of steps between fMRI data time-series processing, connectivity matrix calculation, and statistical connectivity analysis.

of variance (ANOVAs). To test for differences in brain activation and brain connectivity between patients and controls as well as between cognitively impaired and unimpaired patients, with general linear model, a multivariate analysis with group and gender as fixed factor and age as covariate was used. Test results were categorized by their level of statistically significance (uncorrected p-value: $\mathrm{p}<0.05, \mathrm{p}<0.01$, and $\mathrm{p}<0.001$ ). By using a statistically significance category scheme and a plot of the connectivity matrix, a qualitative measurement of which connections and regions show an effect of interest can be made. Finally, the influence of clinical epilepsy characteristics on brain functionality was investigated. For statistical analysis, we categorized patients into short $(\leq 5$ years) versus long ( $>5$ years) seizure duration, young $(\leq 5$ years) versus old $(>$ 5 years) age at seizure onset, low ( $\leq 1$ seizure per week) versus high ( $>1$ seizure per week) seizure frequency, low $(\leq 1.0)$ versus high $(>1.0)$ drug load, and left versus right versus bifrontal focus, based on seizure semiology and EEG.

\section{Results}

We eventually included 32 patients and 41 controls (see Appendix S3). Their demographic and clinical characteristics are recorded in Table 1.

\section{Cognitive performance}

For all included participants an impairment index could be calculated. Neuropsychological test results are recorded in Appendix S4.

Cognition was impaired in 16 children with FLE (50\%) and in three healthy controls (7\%). Demographic and clinical characteristics did not significantly differ between the two patient groups (see Appendix S5). 
Table 1. Demographic and clinical characteristics of the (A) control group and (B) epilepsy groups.

\begin{tabular}{|c|c|}
\hline Characteristic & Number of subjects (\%) \\
\hline \multicolumn{2}{|l|}{ A } \\
\hline Gender (male : female) & $19: 22$ \\
\hline $\begin{array}{l}\text { Age } \\
\text { Mean age }( \pm \mathrm{SD}) \text { at assessment }\end{array}$ & $10.5 \pm 1.5$ years \\
\hline \multicolumn{2}{|l|}{ B } \\
\hline Gender (male : female) & $18: 14$ \\
\hline $\begin{array}{l}\text { Age } \\
\text { Mean age }( \pm \text { SD) at assessment } \\
\text { Mean age }( \pm \text { SD) at seizure onset }\end{array}$ & $\begin{array}{l}11.3 \pm 1.3 \text { years } \\
4.9 \pm 2.8 \text { years }\end{array}$ \\
\hline $\begin{array}{l}\text { Duration of epilepsy } \\
\text { Mean duration }( \pm S D) \text { of epilepsy }\end{array}$ & $6.1 \pm 2.8$ years \\
\hline $\begin{array}{l}\text { Seizure type } \\
\text { Complex partial seizures only } \\
\text { Atypical absence seizures only } \\
\text { Atypical absences and other complex partial seizures } \\
\text { Secondary generalized tonic-clonic seizures }\end{array}$ & $\begin{array}{l}6(19) \\
13(41) \\
8(25) \\
5(15)\end{array}$ \\
\hline $\begin{array}{l}\text { History } \\
\text { Febrile seizures } \\
\text { Status epilepticus }\end{array}$ & $\begin{array}{l}9(28) \\
2(6)\end{array}$ \\
\hline $\begin{array}{l}\text { Seizure occurrence } \\
\text { Seizure free } \\
\text { Nocturnal seizures only } \\
\text { Diurnal seizures only } \\
\text { Both nocturnal and diurnal seizures }\end{array}$ & $\begin{array}{l}4(12) \\
1(3) \\
12(38) \\
15(47)\end{array}$ \\
\hline $\begin{array}{l}\text { Seizure frequency (in the past year) } \\
\text { Low seizure frequency }(\leq 1 \text { seizure/week) } \\
\text { High seizure frequency (>1 seizure/week) } \\
\text { Refractory } \\
\text { Not-refractory }\end{array}$ & $\begin{array}{l}16(50) \\
16(50) \\
21(66) \\
11(34)\end{array}$ \\
\hline $\begin{array}{l}\text { Seizure focus based on history and EEG } \\
\text { Focus left frontal } \\
\text { Focus right frontal } \\
\text { Focus bifrontal }\end{array}$ & $\begin{array}{l}8(25) \\
7(22) \\
17(53)\end{array}$ \\
\hline $\begin{array}{l}\text { AED treatment } \\
\text { No AED } \\
\text { Monotherapy } \\
\text { Polytherapy }\end{array}$ & $\begin{array}{l}1(3) \\
21(66) \\
10(31)\end{array}$ \\
\hline $\begin{array}{l}\text { Drug load } \\
\text { Low }<1.0 \\
\text { High } \geq 1.0\end{array}$ & $\begin{array}{l}26(81) \\
6(19)\end{array}$ \\
\hline
\end{tabular}

EEG: electroencephalogram; AED: antiepileptic drug.

\section{fMRI performance}

All participants were able to perform the Sternberg task. Patients gave significantly fewer correct answers than controls $(67 \pm 10$ out of 78 vs. 57 \pm 21 out of $78 ; \mathrm{p}<0.001$ ) during the Sternberg task. Cognitively impaired patients did not perform significantly worse than cognitively unimpaired patients ( $58 \pm 21$ out of 78 vs. $57 \pm 20$ out of 78 ; $p=0.849$ ), meaning that both groups accurately performed the task. We chose relatively low cognitive loads 

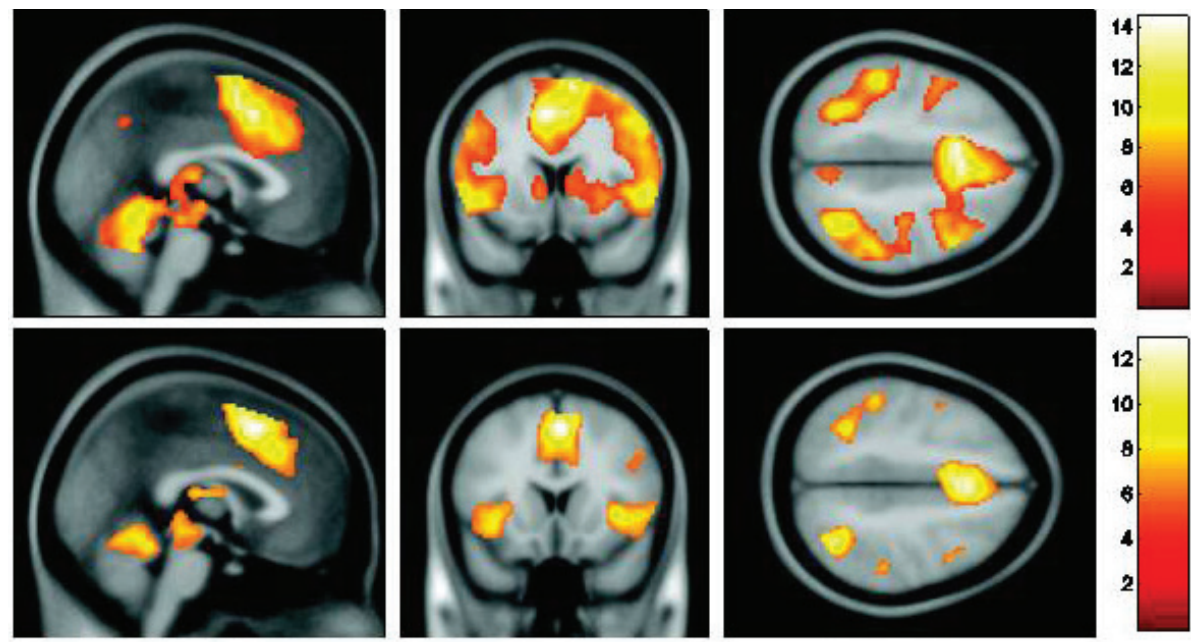

Figure 2. Activation maps for the Sternberg task. Mean group activation for the control group (upper panels) and patient group (lower panels) overlaid on the MNI template T1 image. Color bars represent $t$-values. Similar regions are activated in both groups and no significant differences (family-wise error corrected $\mathrm{p}<0.05$ ) could be found, although the patient group appears to show reduced activation.

(memory sets of 1-3 letters) in order that all participants (both 8-year old as well as 12-year old) could well perform the task. No differences were found between patients and healthy controls and between cognitively impaired and unimpaired patients for the different cognitive loads. This does not exclude that higher cognitive loads could indeed have made a difference between patients and controls. ${ }^{16,17}$

\section{Sternberg activation maps}

Quantitatively, patients showed lower cerebral activation in several regions during the Sternberg task compared to controls (see Figure 2). However, after correction for multiple comparisons (family wise error, SPM), this difference proved statistically not significant.

The brain regions mostsignificantlyactivated during Sternbergtaskperformance and their contralateral counterparts were selected as regions of interest. The 27 selected brain regions for further analysis included the anterior cingulate cortex, bilateral middle frontal gyrus, bilateral frontal pole, bilateral precentral gyrus, bilateral insula, bilateral superior parietal lobe, bilateral supramarginal gyrus, bilateral superior temporal gyrus, bilateral middle temporal gyrus, bilateral lateral occipital cortex, bilateral hippocampus, bilateral thalamus, bilateral pallidum, brainstem, and cerebellum. 


\section{Functional Connectivity}

All the 351 unique connections between these 27 selected areas ([27 x 26]/2) were used for brain connectivity analysis. Results of the between-group analysis of pair-wise connection strength were all corrected for gender and age. The results did not differ if the three cognitively impaired controls were excluded. Patients showed significantly less functional connectivity than controls, between areas throughout the entire brain (see the connectivity matrix in Figure $3 \mathrm{~A}$ ). The right superior parietal lobe, right and left thalamus, anterior cingulate cortex, as well as right hippocampus were the brain areas with least functional connectivity.

Cognitively unimpaired patients demonstrated significantly less functional connectivity than controls, between areas throughout the whole brain, specifically in the right and left thalamus, right middle frontal gyrus, and right superior parietal lobe (Figure 3B). In addition, cognitively impaired patients showed significantly less functional connectivity than controls, again between areas throughout the whole brain, although especially in the left precentral gyrus, right superior parietal lobe, right thalamus, and anterior cingulate cortex (Figure 3C).

Comparison of the cognitively impaired with unimpaired patients revealed a subset of 14 connections that showed significantly less functional connectivity. Remarkably, these connections encompassed frontal lobe connections only. These were not only connections between different frontal lobe areas, but also between the frontal lobe and distant brain areas, that is, the parietal lobe, temporal lobe, basal ganglia, and cerebellum (see Table 2 and Figure 4).

\section{Influence of clinical epilepsy characteristics}

The connection strengths of the 14 specific frontal lobe connections, which demonstrated decreased functional connectivity in cognitively impaired patients compared to cognitively unimpaired patients, were not associated with any of the clinical epilepsy characteristics, including age at seizure onset, duration of epilepsy, seizure occurrence, seizure frequency, side of seizure focus, history of febrile seizures or status epilepticus, use of monotherapy versus polytherapy, or drug load ( $\mathrm{p}>0.05)$.

For 2 of these 14 connections, we found an association between seizure type and functional connectivity. The connectivity between the right precentral gyrus and right superior parietal lobe $(\mathrm{p}=0.030)$ as well as the right precentral gyrus and right supramarginal gyrus $(\mathrm{p}=0.029)$ was less in patients with frontal absences and other complex partial seizures compared to patients with other seizure types. 

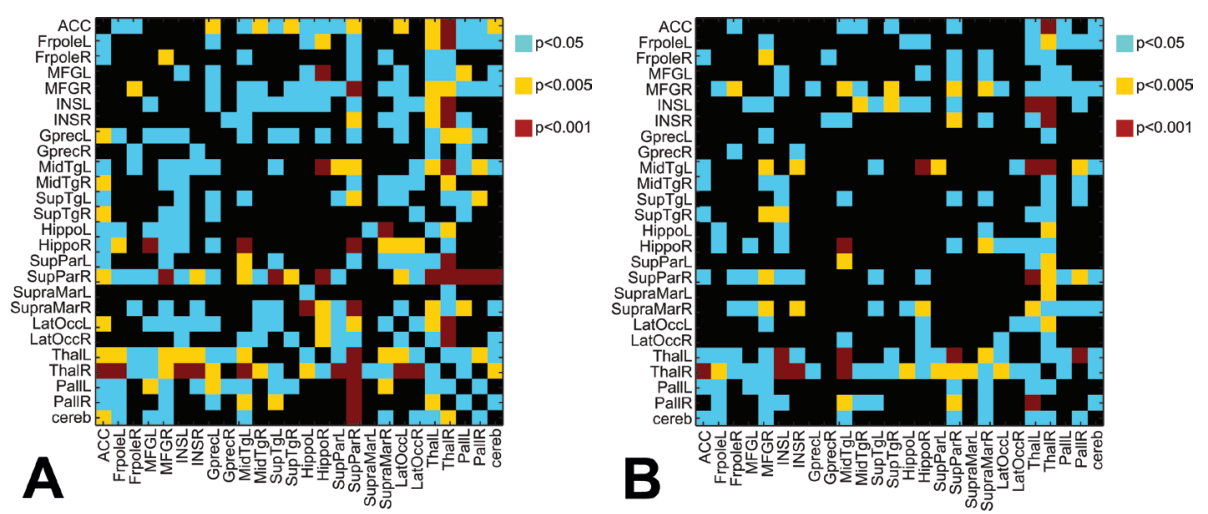

Figure 3. Connectivity matrix with the significance level (uncorrected p-values) of the (A) patient vs. control group differences, (B) cognitively unimpaired patient vs. control group differences, and (C) cognitively impaired patient - control group differences. Black matrix elements indicate that no significant difference was found for that connection between patients and controls (A), cognitively unimpaired patients and controls (B), or cognitively impaired patients and

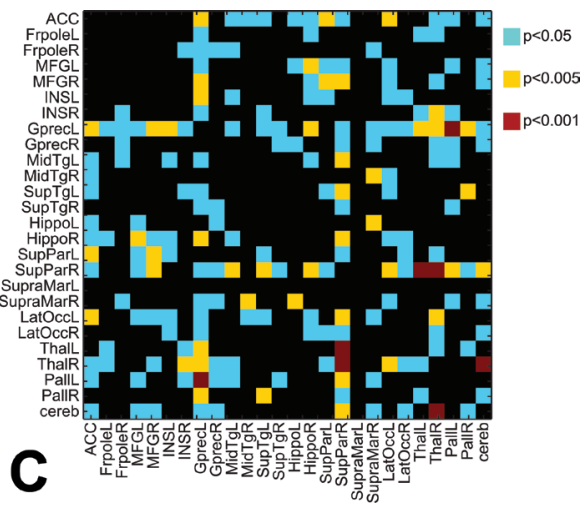
controls (C). In all other connections, functional connectivity was significantly less in the patient groups. From top to bottom (Y-axis) and left to right (X-axis): Frontal lobe areas: anterior cingulate cortex (ACC), left and right frontal pole (FrpoleL and FrpoleR), left and right middle frontal gyrus (MFGL and MFGR), left and right insula (INSL and INSR), left and right precentral gyrus (GprecL and GprecR). Temporal lobe areas: left and right middle temporal gyrus (MidTgL and MidTgR), left and right superior temporal gyrus (SupTgL and SupTgR), left and right hippocampus (HippoL and hippoR). Parietal lobe areas: left and right superior parietal lobule (SupParL and SupParR), left and right supramarginal gyrus (SupraMarL and SupraMarR). Occipital lobe areas: left and right lateral occipital cortex (LatOccL and LatOccR). Subcortical areas: left and right thalamus (ThalL and ThalR), left and right pallidum (PallL and PallR), cerebellum (Cereb).

\section{Discussion}

\section{Current findings}

Children with FLE displayed a widespread decrease in functional brain connectivity compared to controls during working memory task performance, whereas the mean activation pattern remained relatively similar. The widespread decrease in functional brain connectivity was similar in the cognitively 


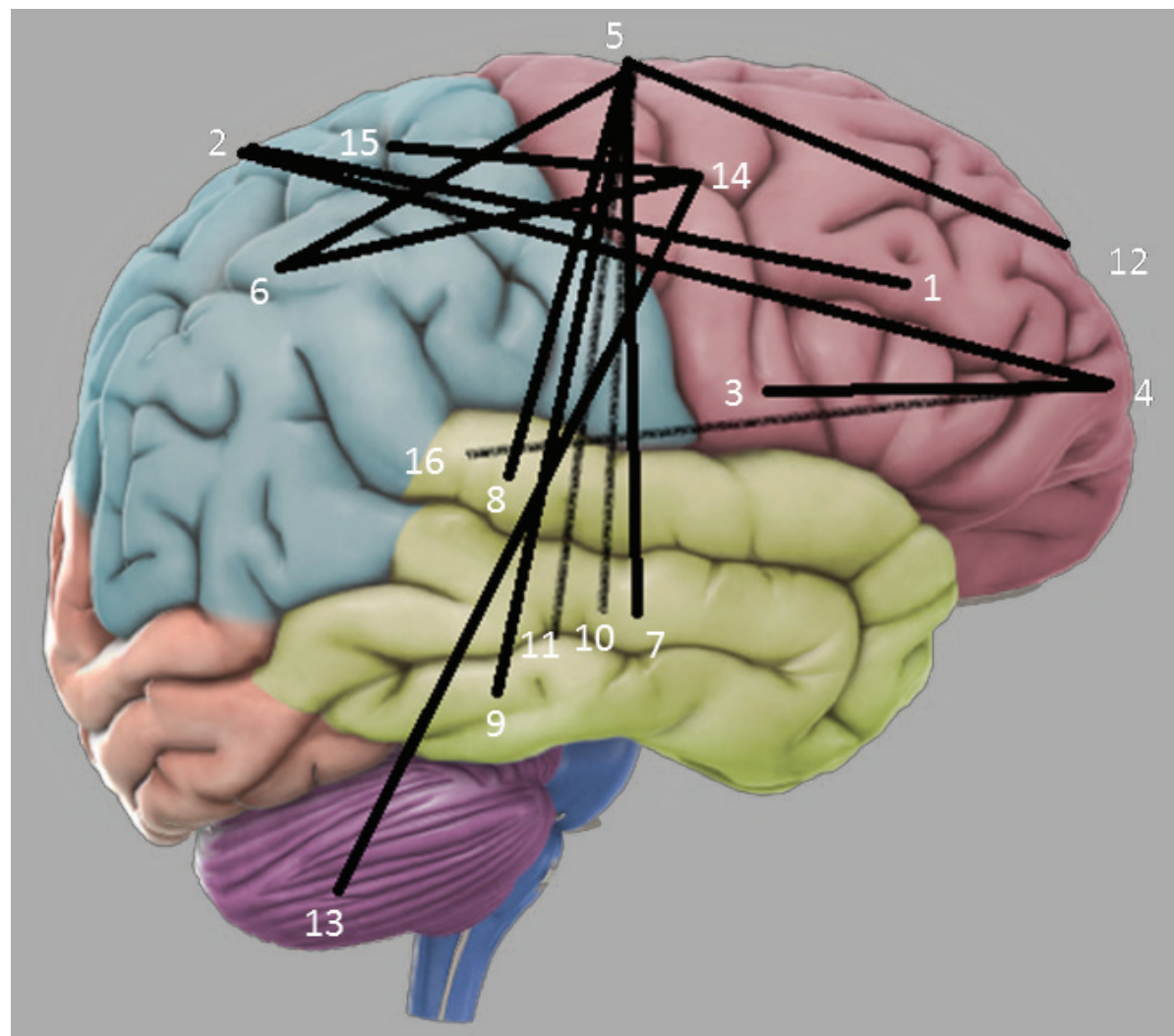

Figure 4. Subset of frontal lobe connections that showed significantly less functional connectivity in the cognitively impaired patients than in the cognitively unimpaired patients. 1. Anterior cingulate cortex; 2. Left superior parietal lobe; 3. Right insula; 4. Right frontal pole; 5. Left precentral gyrus; 6. Right superior parietal lobe; 7. Right middle temporal lobe; 8. Right superior temporal lobe; 9. Right hippocampus; 10. Left pallidum; 11. Right pallidum; 12. Left frontal pole; 13. Cerebellum; 14. Right precentral gyrus; 15. Right supramarginal gyrus; 16 . Left superior temporal gyrus.

impaired and unimpaired patients, which suggests that it is related to the epilepsy itself, irrespective of patients' cognitive performance. Alternatively, a common underlying cause could lead to both functional brain disturbances as well as to epilepsy.

\section{Link to cognitive impairment}

Patients with cognitive impairment showed decreased functional connectivity in a specific subset of connections. In line with our expectations, this subset encompasses only frontal lobe connections. These do not only connect different frontal lobe areas, but also connect the frontal lobe with distant brain areas, 
Table 2. The subset of frontal lobe connections that showed significantly less functional connectivity in the cognitively impaired patients than in the cognitively unimpaired patients.

\begin{tabular}{llll} 
Connections between different brain regions & $\begin{array}{l}\text { Signal change } \\
\text { in cognitively } \\
\text { unimpaired } \\
\text { patients, } \\
\text { mean } \pm \text { SD }\end{array}$ & $\begin{array}{l}\text { Signal change } \\
\text { in cognitively } \\
\text { impaired } \\
\text { patients, } \\
\text { mean } \pm \text { SD }\end{array}$ & palue \\
\hline Anterior cingulate cortex - Left superior parietal lobe & $0.70 \pm 0.30$ & $0.44 \pm 0.31$ & 0.017 \\
Right insula - Right frontal pole & $0.78 \pm 0.24$ & $0.44 \pm 0.38$ & 0.009 \\
Left precentral gyrus - Right superior parietal lobe & $0.48 \pm 0.45$ & $0.30 \pm 0.33$ & 0.035 \\
Left precentral gyrus - Right middle temporal gyrus & $0.59 \pm 0.32$ & $0.37 \pm 0.28$ & 0.048 \\
Left precentral gyrus - Right superior temporal gyrus & $0.46 \pm 0.36$ & $0.26 \pm 0.26$ & 0.026 \\
Left precentral gyrus - Right hippocampus & $0.38 \pm 0.35$ & $0.15 \pm 0.35$ & 0.042 \\
Left precentral gyrus - Left pallidum & $0.43 \pm 0.32$ & $0.16 \pm 0.27$ & 0.021 \\
Left precentral gyrus - Right pallidum & $0.35 \pm 0.35$ & $0.17 \pm 0.32$ & 0.016 \\
Left precentral gyrus - Left frontal pole & $0.40 \pm 0.25$ & $0.28 \pm 0.22$ & 0.004 \\
Right precentral gyrus - Right superior parietal lobe & $0.58 \pm 0.30$ & $0.32 \pm 0.37$ & 0.004 \\
Right precentral gyrus - Cerebellum & $0.46 \pm 0.24$ & $0.25 \pm 0.40$ & 0.045 \\
Right precentral gyrus - Right supramarginal gyrus & $0.83 \pm 0.37$ & $0.47 \pm 0.26$ & 0.004 \\
Left superior parietal lobe - Right frontal pole & $0.58 \pm 0.37$ & $0.36 \pm 0.37$ & 0.015 \\
Left superior temporal gyrus - Right frontal pole & $0.53 \pm 0.24$ & $0.36 \pm 0.22$ & 0.025 \\
\hline
\end{tabular}

$\mathrm{SD}$, standard deviation.

that is, the parietal lobe, temporal lobe, basal ganglia and cerebellum. This may explain the broad range of cognitive domains - including typical frontal lobe functions as well as extra-frontal functions - that reveal deficits in children with FLE of unknown cause. ${ }^{2,4}$ This broad range of cognitive impairment is not specific for FLE only; in patients with temporal lobe epilepsy (TLE), impairments of typical temporal lobe functions such as memory are observed alongside deficits of typical frontal lobe functions, such as executive functions. ${ }^{18}$ In TLE, decreased functional connectivity may also affect connections within the temporal lobes as well as those to distant areas.

This is the first study that relates fMRI results to cognitive functioning in children with epilepsy. The fact that FLE and its complications become apparent in childhood stresses the importance of studying this etiology in children. ${ }^{2}$

\section{Results of previous fMRI studies in adult patients with epilepsy}

The few studies that have related fMRI results to cognitive functioning have been performed in adults with TLE, not FLE. fMRI studies in adult patients with TLE revealed that memory impairment was associated with shifts of brain activation to the hemisphere contralateral to the seizure focus, ${ }^{19-21}$ or to other areas that did not show activation in controls during memory tasks. ${ }^{22} \mathrm{~A}$ decrease 
in activation in the inferior frontal area in TLE patients was associated with better language task performance, whereas patients with normal or increased activation patterns performed worse. ${ }^{23}$ Other studies did not find differences in brain activation patterns between cognitively impaired patients with epilepsy and controls. In an fMRI study performed in patients with juvenile myoclonic epilepsy, activation pattern in patients with impaired working memory performance did not differ from healthy controls. ${ }^{24}$ Moreover, patients with cryptogenic localization-related epilepsy complicated by language impairment did not show a different activation pattern during language task performance compared to controls. ${ }^{5}$

Similar to the findings in the current study, functional connectivity studies in adult patients with mesial TLE have shown that altered connectivity (i.e., either decreased or increased) is observed not only in the network of mesiotemporal structures, that is, structures in which the seizure focus resides, ${ }^{25}$ but also in network structures distant from the seizure focus. ${ }^{26-30}$ The exact relation between these altered functional networks and cognition in epilepsy remains to be elucidated. Decreased functional connectivity may reflect diminished function of a structure in the network; for example, the impaired language performance in patients with cryptogenic localization-related epilepsy was associated with decreased connectivity in the language networks. ${ }^{5}$ Increased functional connectivity may reflect enhanced function owing to compensatory mechanisms; increased functional connectivity between the anterior and posterior hippocampus contralateral to the seizure focus was correlated with better working memory performance in patients with TLE. ${ }^{25}$

\section{Methodological consideration on many connections}

When connection strengths between multiple brain regions are compared, results should be discussed in regard to the likelihood of encountering false positives. Standard multiple comparisons correction methods such as Bonferroni correction ${ }^{31}$ or false discovery rate (FDR) control ${ }^{32}$ are not tailored for application in connectivity analysis and might be too stringent.

The defined 27 regions of interest have 351 connections. Nine of these 27 brain regions ( 1 of 3 ) were frontal lobe regions (i.e., anterior cingulate cortex, bilateral middle frontal gyrus, bilateral frontal pole, bilateral precentral gyrus, and bilateral insula). This means that we consider 198 (56\%) possible frontal lobe and 153 (44\%) nonfrontal lobe connections. When the control for finding false positives is set to $5 \%(\mathrm{p}=0.05)$, we expect to encounter 18 false-positive connection-strength differences for the comparison between patients and controls. This set of false positives would equally distribute over the entire set of defined connections; thus would appear approximately as 10 frontal lobe and 
8 nonfrontal lobe connection differences. One could argue that the observed 14 connectivity abnormalities cannot be discerned from the expected number of false positives. Nonetheless, the 14 connections with decreased connectivity we found in the current study are all frontal lobe connections. This observation is very unlikely to result from false positives alone. Actually, the chance of finding 14 abnormal frontal and zero nonfrontal connections is equal to $\mathrm{p}=$ $(0.56)^{14} \cdot(1-0.56)^{0}=0.0003$. Therefore, we argue that the observation of multiple decreased frontal connections sustains the multiple comparison problem. However, the results should be interpreted with caution given the limitations of partially correcting for multiple comparisons. The recent work by Zalesky et al. ${ }^{33}$ could possibly infer on the significance of individual connections by using a network based statistics method.

\section{Conclusion}

Patients with FLE complicated by cognitive impairment showed decreased functional connectivity in a specific subset of frontal lobe connections. These include connections between different frontal lobe areas, as well as connections to distant brain areas. The importance of the loss of functional integrity within the frontal lobe network, as well as in its connections to distant areas provides new insights in the etiology of the broad-range cognitive impairments in children with FLE. Clinical epilepsy characteristics appear to have limited influence on the integrity of this frontal lobe network. 


\section{Appendix 1. Neuropsychological test details.}

\section{Cognitive domain Test}

General intelligence

\section{Memory \\ Short-term memory}

Long-term memory
Wechsler Intelligence Scale for Children-III (WISC-III). ${ }^{34}$

Recognition of words and figures. ${ }^{35 *}$

The 15 word test ( 15 woordentest Kalverboer, the Dutch version of the Rey Auditory Verbal Learning Test). ${ }^{36}$

The 15 word test (15 woordentest Kalverboer). ${ }^{36}$

Complex Figure test (Rey-Osterrieth figure). ${ }^{37}$

\section{Description}

The WISC consists of 13 subtests:

Picture Completion - artwork of common objects with a missing part are shown, and the patient is asked to identify the missing part by pointing and/or naming.

Information - general knowledge questions.

Coding - patients transcribe a digit-symbol code which is time-limited.

Similarities - the patient has to explain the similarity between two words.

Picture arrangement - sequencing cartoon pictures to make sensible stories.

Arithmetic - orally administered arithmetic questions which are timed.

Block Design - patients put together red-and-white blocks in a pattern according to a displayed model which is timed.

Vocabulary - the patient has to explain the meaning of several words.

Object assembly - puzzles of cut-apart silhouette objects with no outline pieces.

Comprehension - questions about social situations or common concepts.

Symbol Search - patients are given rows of symbols and target symbols, and asked to mark whether or not the target symbols appear in each row.

Digit Span - patients are orally given sequences of numbers and asked to repeat them, either as heard or in reverse order.

Mazes - patient has to find a route to get out of the maze.

Intellectual ability is expressed in Full Scale IQ, Verbal IQ, Performance IQ, Verbal Reasoning, Perceptual Organization and Mental Processing Speed score.

Stimuli (six words or four figures) are presented simultaneously during a learning phase with a presentation time of 1 second per item. After a delay of 2 seconds the screen shows one of these words figures between distracters. The target item has to be recognized. The number of correct items is scored, with a maximum of 24 .

A list of 15 words is orally presented five times. After every presentation, immediate recall is requested. The number of words in the total direct production is scored.

After five consecutive trials with direct recall, a delayed recall is requested after a 20 minutes interval. The number of correct words is scored. Thereafter the patient is asked if he/she recognized the words. Number of correct recognized items is scored, with a maximum of 30 .

Twenty minutes after copying a complex figure, the same figure has to been drawn from memory. 


\begin{tabular}{|c|c|c|}
\hline Cognitive domain & Test & Description \\
\hline \multirow[t]{4}{*}{$\begin{array}{l}\text { Visual-spatial } \\
\text { functions }\end{array}$} & $\begin{array}{l}\text { Complex Figure test } \\
\text { (Rey-Osterrieth figure). }{ }^{37}\end{array}$ & $\begin{array}{l}\text { Twenty minutes after copying a complex figure, the same } \\
\text { figure has to been drawn from memory. }\end{array}$ \\
\hline & $\begin{array}{l}\text { Beery Buktenica } \\
\text { Developmental Test } \\
\text { of Visual-Motor } \\
\text { Integration. }^{38}\end{array}$ & $\begin{array}{l}\text { The patient has to copy a sequence of geometric forms or } \\
\text { increasing difficulty. }\end{array}$ \\
\hline & $\begin{array}{l}\text { The Visual Perception } \\
\text { Test. }{ }^{39}\end{array}$ & The patient has to match given geometric forms. \\
\hline & $\begin{array}{l}\text { The Motor Coordination } \\
\text { Test. }^{39}\end{array}$ & $\begin{array}{l}\text { The patient traces shapes while remaining inside a double } \\
\text { lined path. Raw scores are converted into standarc } \\
\text { scores. }\end{array}$ \\
\hline \multirow[t]{4}{*}{$\begin{array}{l}\text { Psychomotor speed } \\
\text { and alertness }\end{array}$} & Finger tapping task. ${ }^{35}$ & $\begin{array}{l}\text { Five consecutive trials for the index finger of the dominan } \\
\text { and separately the non-dominant hand. Number of taps } \\
\text { is recorded. }\end{array}$ \\
\hline & $\begin{array}{l}\text { Simple reaction time } \\
\text { measurements. }\end{array}$ & $\begin{array}{l}\text { The patient has to react as quickly as possible on either } \\
\text { auditory }(800 \mathrm{~Hz} \text { tone) or visual (square on the screen) } \\
\text { stimuli that were presented at random intervals by the } \\
\text { computer. }\end{array}$ \\
\hline & $\begin{array}{l}\text { Binary choice reaction- } \\
\text { time measurement. }\end{array}$ & $\begin{array}{l}\text { A reaction time test with a decision component. The } \\
\text { patient has to react differentially to a red square on the } \\
\text { left side of the screen and to a green square at the right } \\
\text { side of the screen. }\end{array}$ \\
\hline & $\begin{array}{l}\text { Computerized visual } \\
\text { searching task (CVST) } \\
\text { (an adaptation of } \\
\text { Goldstein's Visual } \\
\text { Searching Task). }{ }^{35 *}\end{array}$ & $\begin{array}{l}\text { A centered grid pattern has to be compared with } 24 \\
\text { surrounding patterns. Only one of them is identical to } \\
\text { the target pattern. The test consists of } 24 \text { trails. Reaction } \\
\text { time is recorded (CVST) as well as the total number o } \\
\text { errors (CVST errors). }\end{array}$ \\
\hline \multicolumn{3}{|c|}{ 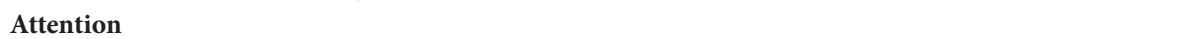 } \\
\hline Selective attention & $\begin{array}{l}\text { The Stroop Colour Word } \\
\text { Test. }^{39 *}\end{array}$ & $\begin{array}{l}\text { The test consists of } 3 \text { cards: color naming (the patient had } \\
\text { to name color blocks), word reading (the patient had to } \\
\text { read words printed in black ink) and interference (the } \\
\text { patient has to name the color of a word printed in an } \\
\text { incongruent color; e.g., the word red written in blue ink) } \\
\text { By comparing the speed of the last card with the speed o } \\
\text { the second card, interference of cognitive functioning can } \\
\text { be measured. Increased interference can be interpreted as } \\
\text { a disturbance in the concentration process. }\end{array}$ \\
\hline Sustained attention & Bourdon-Vos Test. ${ }^{40}$ & $\begin{array}{l}\text { A cancellation test requiring high-speed visual selectivity } \\
\text { and a repetitive motor response. Patients are instructed } \\
\text { to cross out the target items, i.e. the dot patterns with } \\
\text { four dots on a sheet of paper covered in three- four-, and } \\
\text { five-dot patterns. The mean reaction time of the patien } \\
\text { is scored. }\end{array}$ \\
\hline $\begin{array}{l}\text { Educational } \\
\text { achievement }\end{array}$ & Tempotest. ${ }^{41-43 *}$ & $\begin{array}{l}\text { The performance on school tasks is assessed by arithmetic } \\
\text { and reading words and sentences. This gives a learning } \\
\text { efficiency quotient (LEQ) whereby } 100 \% \text { indicating no } \\
\text { delay. }\end{array}$ \\
\hline
\end{tabular}

${ }^{*}$ Neuropsychological assessment for the control group and for the patients who had neuropsychological assessment more than twelve months earlier. 
Appendix 2. Impairment index composition details.

\section{Global cognitive functioning}

For the healthy controls two functions were used to assess global cognitive function: central information processing speed (Computerized Visual Searching Task (CVST) ${ }^{35}$ and educational achievement (learning efficiency quotients (LEQ)). ${ }^{41-43}$

By determining searching time (reaction time) and the errors made during the CVST task, an age-corrected cognitive performance score was generated, expressed in decile scores. Scores $\leq 3$ represent impairment. ${ }^{35}$

Learning efficiency quotients reflect someone's performance on school tasks (i.e. arithmetic and reading words and sentences). A score of $<80 \%$ indicates educational delay. ${ }^{41-43}$

If both tests are performed below normative values global cognitive functioning is impaired.

For the patients we used the Wechsler full scale IQ scores as a measure of global cognitive performance. FSIQ scores $<85$ indicate impairment. ${ }^{34}$

\section{Higher-order cognitive functioning}

The recognition words score was used to assess higher order cognitive functioning both for the controls as well as for the patients..$^{35}$ After correction for age, a decile score was generated. Scores $\leq 3$ represent impairment. ${ }^{35}$ For the 9 patients who had been neuropsychologically tested within one year prior to inclusion we used the 'Digit Span' subtest score of the WISC-III. ${ }^{34}$ If performance scores were below normative values (standard score $<8$ ), higher-order cognition was considered impaired.

\section{Fluid cognitive functioning}

The STROOP Colour Word Test Interference score ${ }^{38}$ as well as the auditory reaction times ${ }^{35}$ were used to assess fluid cognitive functioning. STROOP interference scores were converted into Z-scores. A Z-score of 0 or 1 indicated normal or good performance, whereas a $Z$ - score of $\leq-1$ indicated impaired performance. $^{38}$

For auditory reaction time measurements, after correction for age, decile scores were used. Scores $\leq 3$ represent impairment.

If both the STROOP interference scores as well as the auditory reaction times were performed below normative values, fluid cognitive functioning was considered impaired.

For the patients who had recently been neuropsychologically assessed $(n=6)$ we used the 'Coding' subtest score of the WISC-III. ${ }^{34}$ If performance scores 
were below normative values (standard score $<8$ ), fluid cognitive functioning was considered impaired.

The neuropsychological test results were subsequently converted into eight different impairment index scores.

An impairment index of 1 indicated most severe impairment as both global cognitive functioning, higher-order cognitive functioning, as well as fluid cognitive functioning are impaired. An impairment index of 8 indicates no impairment.

Children were grouped into 2 groups; one cognitively impaired group (i.e. an impairment index of $\leq 4$; which means that at least global cognitive functioning is impaired) and one cognitively minimal or unimpaired group (impairment index $>4)$.

\begin{tabular}{|c|c|c|}
\hline $\begin{array}{l}\text { Impairment } \\
\text { index }\end{array}$ & Impairment index details & $\begin{array}{l}\text { Number of } \\
\text { patients/controls }\end{array}$ \\
\hline 1 & $\begin{array}{ll}-\quad \text { Global cognitive functioning impaired } \\
\text { - } & \text { Higher-order cognitive functioning impaired } \\
& \text { cognitive functioning impaired }\end{array}$ & $5 / 0$ \\
\hline 2 & $\begin{array}{ll}\text { - } & \text { Global cognitive functioning impaired } \\
\text { - } & \text { Higher-order cognitive functioning impaired } \\
& \text { cognitive functioning not impaired }\end{array}$ & $4 / 1$ \\
\hline 3 & $\begin{array}{ll}\text { - } & \text { Global cognitive functioning impaired } \\
\text { - } & \text { Higher-order cognitive functioning not impaired } \\
& \text { Flitive functioning impaired }\end{array}$ & $1 / 0$ \\
\hline 4 & $\begin{array}{ll}-\quad \text { Global cognitive functioning impaired } \\
\text { - } & \text { Higher-order cognitive functioning not impaired } \\
& \text { Flugnitive functioning not impaired }\end{array}$ & $6 / 2$ \\
\hline 5 & $\begin{array}{l}\text { - } \quad \text { Global cognitive functioning not impaired } \\
\text { - }\end{array}$ & $0 / 0$ \\
\hline 6 & $\begin{array}{l}\text { - Global cognitive functioning not impaired } \\
\text { - }\end{array}$ & $6 / 3$ \\
\hline 7 & $\begin{array}{l}\text { Global cognitive functioning not impaired } \\
\text { - }\end{array}$ & $1 / 2$ \\
\hline 8 & $\begin{array}{ll}- & \text { Global cognitive functioning not impaired } \\
& \text { Higher-order cognitive functioning not impaired } \\
& \text { Fluid cognitive functioning not impaired }\end{array}$ & $9 / 33$ \\
\hline
\end{tabular}


Appendix 3. Flowchart of inclusion.

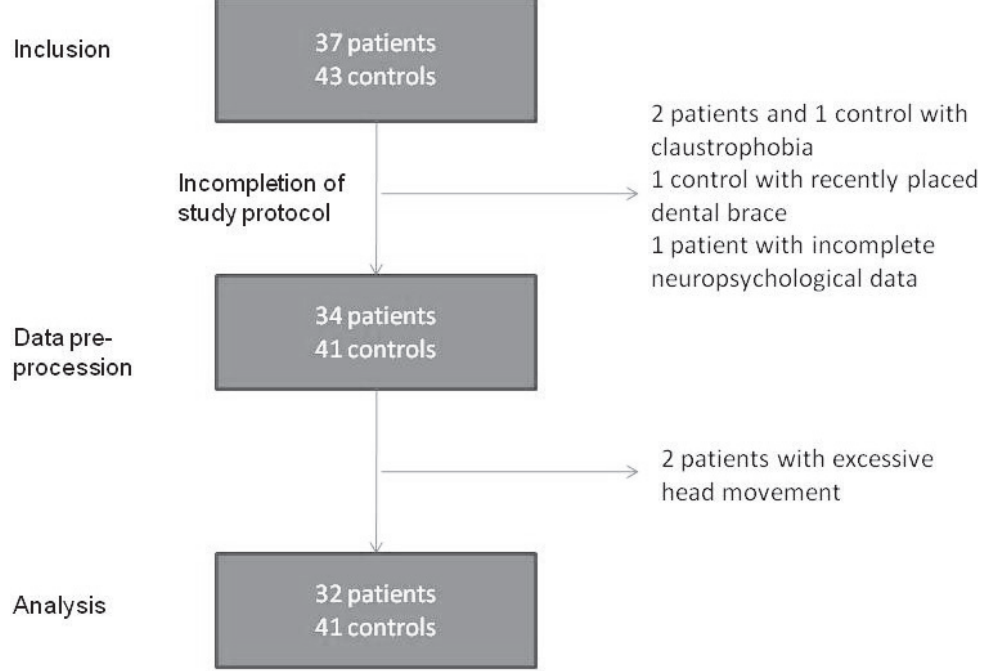

Appendix 4. Neuropsychological test results.

Patients, Controls,

Mean \pm SD $\quad$ Mean \pm SD

Global cognitive functioning

Central information processing speed

$4 \pm 3^{\mathrm{a}} \quad 7 \pm 3^{\mathrm{a}}$

(Computerized Visual Searching Task; CVST)

$\begin{array}{ll} & \\ 82 \pm 35^{\mathrm{b}} & 108 \pm 46^{\mathrm{b}} \\ 76 \pm 36^{\mathrm{b}} & 118 \pm 58^{\mathrm{b}}\end{array}$

Educational achievement (learning efficiency quotients; LEQ)

Reading words

$76 \pm 36^{\mathrm{b}} \quad 118 \pm 58^{\mathrm{b}}$

Reading sentences

$76 \pm 45^{\mathrm{b}}$

Mathematics

$87 \pm 11^{\mathrm{c}} \quad-$

Higher-order cognitive functioning

Recognition words score

'Digit Span' subtest score of the WISC-III

$5 \pm 3^{\mathrm{a}} \quad 7 \pm 3^{\mathrm{a}}$

Fluid cognitive functioning

STROOP Colour Word Test Interference score

Auditory reaction times

$8 \pm 3^{\mathrm{d}}-$

'Coding' subtest score of the WISC-III

$\begin{array}{ll}-0.1 \pm 1.1^{\mathrm{e}} & 0.4 \pm 0.7^{\mathrm{e}} \\ 5 \pm 3^{\mathrm{a}} & 6 \pm 3^{\mathrm{a}} \\ 8 \pm 3^{\mathrm{f}} & -\end{array}$

a: An age-corrected cognitive performance score was generated, expressed in decile scores. Scores $\leq 3$ represent impairment. ${ }^{35}$

b: A score of $<80 \%$ indicates educational delay. ${ }^{41-43}$

c: Full scale IQ scores $<85$ indicate impairment.

d: If performance scores were below normative values (standard score $<8$ ), higherorder cognition was considered impaired. ${ }^{34}$

e: A Z-score of 0 or 1 indicated normal or good performance, whereas a Z- score of $\leq$ -1 indicated impaired performance..$^{38}$

f: If performance scores were below normative values (standard score $<8$ ), fluid cognitive functioning was considered impaired. 
Appendix 5. Demographic and clinical characteristics of the epilepsy group.

\begin{tabular}{|c|c|c|}
\hline & $\begin{array}{l}\text { Cognitively } \\
\text { unimpaired patient } \\
\text { group }(n=16)\end{array}$ & $\begin{array}{l}\text { Cognitively impaired } \\
\text { patient group }(n=16)\end{array}$ \\
\hline Gender (male : female) & $11: 5$ & $7: 9$ \\
\hline $\begin{array}{l}\text { Age } \\
\text { Mean age }( \pm \text { SD }) \text { at assessment } \\
\text { Mean age }( \pm \text { SD }) \text { at seizure onset }\end{array}$ & $\begin{array}{l}11.1 \pm 1.6 \text { years } \\
5.3 \pm 3.0 \text { years }\end{array}$ & $\begin{array}{l}11.4 \pm 1.2 \text { years } \\
4.5 \pm 2.8 \text { years }\end{array}$ \\
\hline $\begin{array}{l}\text { Duration of epilepsy } \\
\text { Mean duration }( \pm S D) \text { of epilepsy }\end{array}$ & $5.8 \pm 2.8$ years & $6.4 \pm 3.1$ years \\
\hline $\begin{array}{l}\text { Seizure type } \\
\text { Complex partial seizures only } \\
\text { Atypical absence seizures only } \\
\text { Atypical absences and complex partial seizures } \\
\text { Secondary generalized tonic-clonic seizures }\end{array}$ & $\begin{array}{l}2 \\
5 \\
5 \\
4\end{array}$ & $\begin{array}{l}4 \\
8 \\
3 \\
1\end{array}$ \\
\hline $\begin{array}{l}\text { History } \\
\text { Febrile seizures } \\
\text { Status epilepticus }\end{array}$ & $\begin{array}{l}5 \\
1\end{array}$ & $\begin{array}{l}4 \\
1\end{array}$ \\
\hline $\begin{array}{l}\text { Seizure occurrence } \\
\text { Seizure free } \\
\text { Nocturnal seizures only } \\
\text { Diurnal seizures only } \\
\text { Both nocturnal and diurnal seizures }\end{array}$ & $\begin{array}{l}2 \\
1 \\
7 \\
6\end{array}$ & $\begin{array}{l}2 \\
0 \\
5 \\
9\end{array}$ \\
\hline $\begin{array}{l}\text { Seizure frequency (in the past year) } \\
\text { Low seizure frequency ( } \leq 1 \text { seizure/week) } \\
\text { High seizure frequency (>1 seizure/week) } \\
\text { Refractory } \\
\text { Not-refractory }\end{array}$ & $\begin{array}{c}9 \\
7 \\
10 \\
6\end{array}$ & $\begin{array}{c}7 \\
9 \\
11 \\
5\end{array}$ \\
\hline $\begin{array}{l}\text { Seizure focus based on history and EEG } \\
\text { Focus left frontal } \\
\text { Focus right frontal } \\
\text { Focus bifrontal }\end{array}$ & $\begin{array}{l}3 \\
4 \\
9\end{array}$ & $\begin{array}{l}5 \\
3 \\
8\end{array}$ \\
\hline $\begin{array}{l}\text { AED treatment } \\
\text { No AED } \\
\text { Monotherapy } \\
\text { Polytherapy }\end{array}$ & $\begin{array}{c}1 \\
10 \\
5\end{array}$ & $\begin{array}{r}0 \\
11 \\
5\end{array}$ \\
\hline $\begin{array}{l}\text { Drug load } \\
\text { Low }<1.0 \\
\text { High } \geq 1.0\end{array}$ & $\begin{array}{r}13 \\
3\end{array}$ & $\begin{array}{r}13 \\
3\end{array}$ \\
\hline
\end{tabular}

EEG: electroencephalogram; AED: antiepileptic drug. 


\section{References}

1. Manford M, Hart YM, Sander JW, Shorvon SD. National General Practice Study of Epilepsy (NGPSE): partial seizure patterns in a general population. Neurology 1992;42:1911-1917.

2. Braakman HMH, Vaessen MJ, Hofman PA, Debeij-van Hall MH, Backes WH, Vles JS, Aldenkamp AP. Cognitive and behavioral complications of frontal lobe epilepsy in children: a review of the literature. Epilepsia 2011;52:849-856.

3. Prévost J, Lortie A, Nguyen D, Lassonde M, Carmant L. Nonlesional Frontal Lobe Epilepsy (FLE) of Childhood: Clinical Presentation, Response to Treatment and Comorbidity. Epilepsia 2006;47:2198-2201.

4. Braakman HM, IJff DM, Vaessen MJ, Debeij-van Hall MH, Hofman PA, Backes WH, Vles JS, Aldenkamp AP. Cognitive and behavioural findings in children with frontal lobe epilepsy. Eur J Paediatr Neurol 2012;16:707-715.

5. Vlooswijk MC, Jansen JF, Majoie HJ, Hofman PA, de Krom MC, Aldenkamp AP, Backes WH. Functional connectivity and language impairment in cryptogenic localization-related epilepsy. Neurology 2010;75:395-402.

6. Vaessen MJ, Braakman HM, Heerink JS, Jansen JF, Debeij-van Hall MH, Hofman PA, Aldenkamp AP, Backes WH. Abnormal Modular Organization of Functional Networks in Cognitively Impaired Children with Frontal Lobe Epilepsy. Cereb Cortex 2012;Jul 6. [Epub ahead of print]

7. Provini F, Plazzi G, Tinuper P, Vandi S, Lugaresi E, Montagna P. Nocturnal frontal lobe epilepsy. A clinical and polygraphic overview of 100 consecutive cases. Brain 1999;122:1017-1031.

8. World Health Organization Collaborating Centre for Drug Statistics Methodology. About the ATC/ DDD system, 2008. Available on http://www.whocc.no/atcddd/.

9. Sternberg S. High-speed scanning in human memory. Science 1966;153:652-654.

10. Hillary FG, Chiaravalloti ND, Ricker JH, Steffener J, Bly BM, Lange G, Liu WC, Kalnin AJ, DeLuca J. An investigation of working memory rehearsal in multiple sclerosis using fMRI. J Clin Exp Neuropsychol 2003;25:965-978.

11. Deblaere K, Backes WH, Tieleman A, Vandemaele P, Defreyne L, Vonck K, Hofman P, Boon P, Vermeulen J, Wilmink J, Aldenkamp A, Boon PA, Vingerhoets G, Achten E. Lateralized anterior mesiotemporal lobe activation: semirandom functional MR imaging encoding paradigm in patients with temporal lobe epilepsy-initial experience. Radiology 2005;236:996-1003.

12. Vlooswijk MC, Jansen JF, Reijs RP, de Krom MC, Kooi ME, Majoie HJ, Hofman PA, Backes WH, Aldenkamp AP. Cognitive fMRI and neuropsychological assessment in patients with secondarily generalized seizures. Clin Neurol Neurosurg 2008;110:441-450.

13. Ashburner J, Friston KJ. Unified segmentation. Neuroimage 2005;26:839-851.

14. Nichols TE, Holmes AP. Nonparametric permutation tests for functional neuroimaging: a primer with examples. Hum Brain Mapp 2002;15:1-25.

15. Zar JH. Biostatistical Analysis. Prentice-Hall, Upper Saddle River, New Jersey, 1996.

16. Vollmar C, O’Muircheartaigh J, Barker GJ, Symms MR, Thompson P, Kumari V, Duncan JS, Janz D, Richardson MP, Koepp MJ. Motor system hyperconnectivity in juvenile myoclonic epilepsy: a cognitive functional magnetic resonance imaging study. Brain 2011;134:1710-1719.

17. Stretton J, Winston G, Sidhu M, Centeno M, Vollmar C, Bonelli S, Symms M, Koepp M, Duncan JS, Thompson PJ. Neural correlates of working memory in Temporal Lobe Epilepsy--an fMRI study. Neuroimage 2012;60:1696-1703.

18. Stretton J, Thompson PJ. Frontal lobe function in temporal lobe epilepsy. Epilepsy Res 2012;98:113. 
19. Powell HW, Richardson MP, Symms MR, Boulby PA, Thompson PJ, Duncan JS, Koepp MJ. Reorganization of verbal and nonverbal memory in temporal lobe epilepsy due to unilateral hippocampal sclerosis. Epilepsia 2007;48:1512-1525.

20. Vannest J, Szaflarski JP, Privitera MD, Schefft BK, Holland S. Medial temporal fMRI activation reflects memory lateralization and memory performance in patients with epilepsy. Epilepsy Behav 2008;12:410-418.

21. Wagner K, Frings L, Spreer J, Buller A, Everts R, Halsband U, Schulze-Bonhage A. Differential effect of side of temporal lobe epilepsy on lateralization of hippocampal, temporolateral, and inferior frontal activation patterns during a verbal episodic memory task. Epilepsy Behav 2008;12:382-387.

22. Dupont S, Van de Moortele PF, Samson S, Hasboun D, Poline JB, Adam C, Lehéricy S, Le Bihan D, Samsom Y, Baulac M. Episodic memory in left temporal lobe epilepsy: a functional MRI study. Brain 2000;123:1722-1732.

23. Weber W, Wellmer J, Schür S, Dinkelacker V, Ruhlmann J, Mormann F, Axmacher N, Elger CE, Fernández G. Presurgical language fMRI in patients with drug-resistant epilepsy: effects of task performance. Epilepsia 2006;47:880-886.

24. Roebling R, Scheerer N, Uttner I, Gruber O, Kraft E, Lerche H. Evaluation of cognition, structural, and functional MRI in juvenile myoclonic epilepsy. Epilepsia 2009;50:2456-2465.

25. Bettus G, Guedj E, Joyeux F, Confort-Gouny S, Soulier E, Laguitton V, Cozzone PJ, Chauvel P, Ranjeva JP, Bartolomei F, Guye M. Decreased basal fMRI functional connectivity in epileptogenic networks and contralateral compensatory mechanisms. Hum Brain Mapp 2009;30:1580-1591.

26. Waites AB, Briellmann RS, Saling MM, Abbott DF, Jackson GD. Functional connectivity networks are disrupted in left temporal lobe epilepsy. Ann Neurol 2006;59:335-343.

27. Voets NL, Adcock JE, Stacey R, Hart Y, Carpenter K, Matthews PM, Beckmann CF. Functional and structural changes in the memory network associated with left temporal lobe epilepsy. Hum Brain Mapp 2009;30:4070-4081.

28. Liao W, Zhang Z, Pan Z, Mantini D, Ding J, Duan X, Luo C, Lu G, Chen H. Altered functional connectivity and small-world in mesial temporal lobe epilepsy. PLoS One 2010;5:e8525.

29. Zhang Z, Lu G, Zhong Y, Tan Q, Liao W, Wang Z, Li K, Chen H, Liu Y. Altered spontaneous neuronal activity of the default-mode network in mesial temporal lobe epilepsy. Brain Res 2010;1323:152-160.

30. Luo C, Li Q, Lai Y, Xia Y, Qin Y, Liao W, Li S, Zhou D, Yao D, Gong Q. Altered functional connectivity in default mode network in absence epilepsy: a resting-state fMRI study. Hum Brain Mapp 2011;32:438-449.

31. Holm S. A simple sequentially rejective multiple test procedure. Scand J Stat 1979;6:65-70.

32. Benjamini Y, Hochberg Y. Controlling the false discovery rate: a practical and powerful approach to multiple testing. J R Statist Soc B 1995;57:289-300.

33. Zalesky A, Fornito A, Bullmore ET. Network-based statistic: identifying differences in brain networks. Neuroimage 2010;53:1197-1207.

34. Wechsler D. Wechsler Intelligence Scale for Children derde editie NL, Handleiding en verantwoording. Harcourt, London; 2005.

35. Alpherts WCJ, Aldenkamp AP. FePSY: 'The Iron Psyche'. Instituut voor epilepsiebestrijding, Heemstede, the Netherlands; 1995.

36. Kalverboer AF, Deelman BG. De 15-woorden tests A en B: (een voorlopige handleiding) (15WT/ VWT). Groningen: Academisch Ziekenhuis Groningen, afd. Neuropsychologie; 1986.

37. Meyers JE, Meyers KR. Rey Complex Figure Test and Recognition Trial: Professional manual. Odessa Florida: Psychological Assessment Resources; 1995. 
38. Beery KE, Buktenica NA, Beery NA. The Beery-Buktenica development test of visual-motor integration. $5^{\text {th }}$ edition. Minneapolis, MN: Pearson Assessments; 2003.

39. Hammes JGW. De Stroop Kleur-Woord Test. Handleiding. Lisse: Swets \& Zeitlinger; 1971.

40. Vos PG. Bourdon-Vos: Handleiding. Lisse: Swets \& Zeitlinger; 1988.

41. Vos T. Handleiding tempo-test-lezen (zinnen). Lisse: Swets \& Zeitlinger; 2000.

42. Vos T. Handleiding tempo-test-lezen (woorden). Lisse: Swets \& Zeitlinger; 2002.

43. Vos T. Handleiding tempo-test-rekenen. Harcourt Assessment bv, Amsterdam; 2004. 


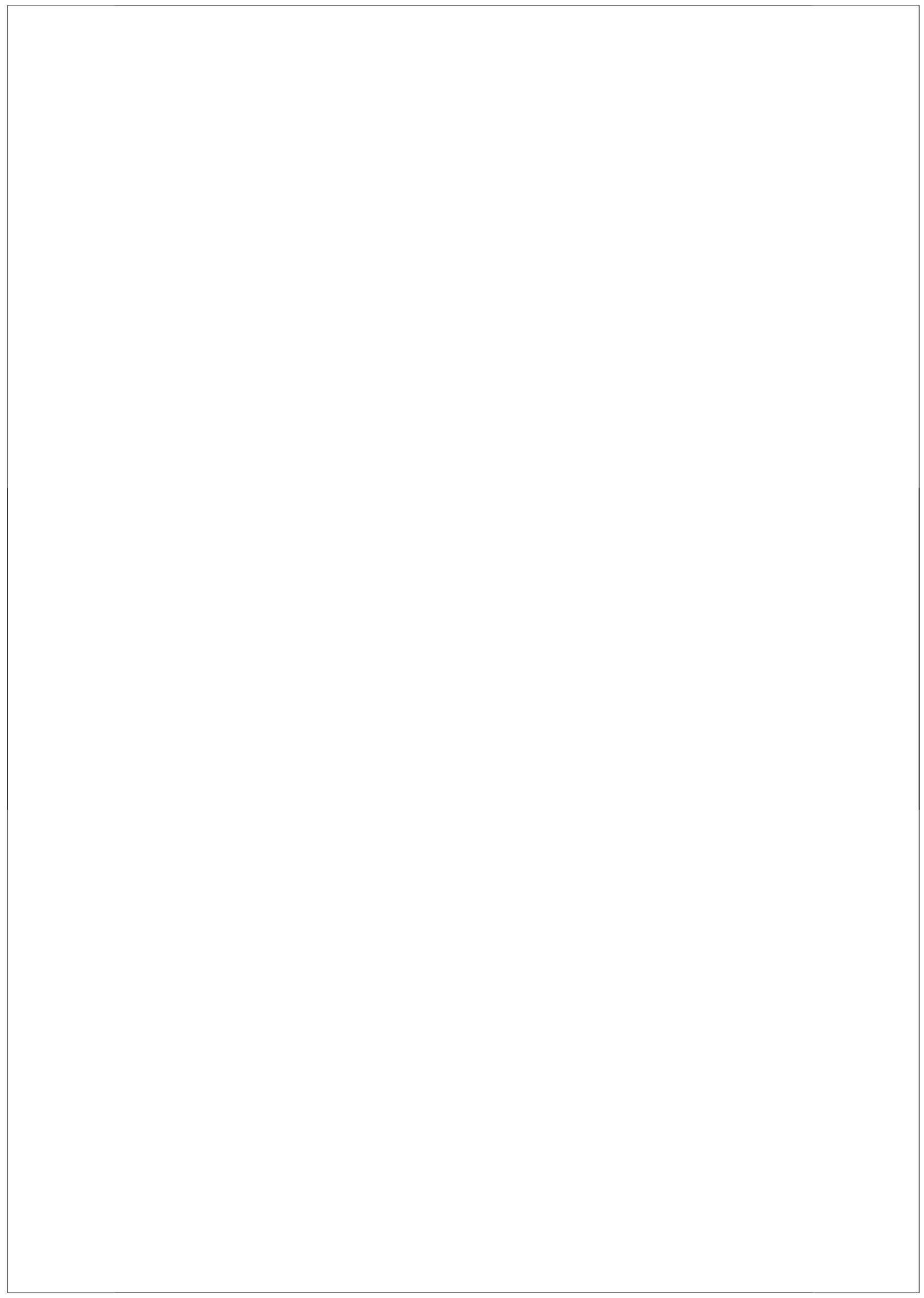




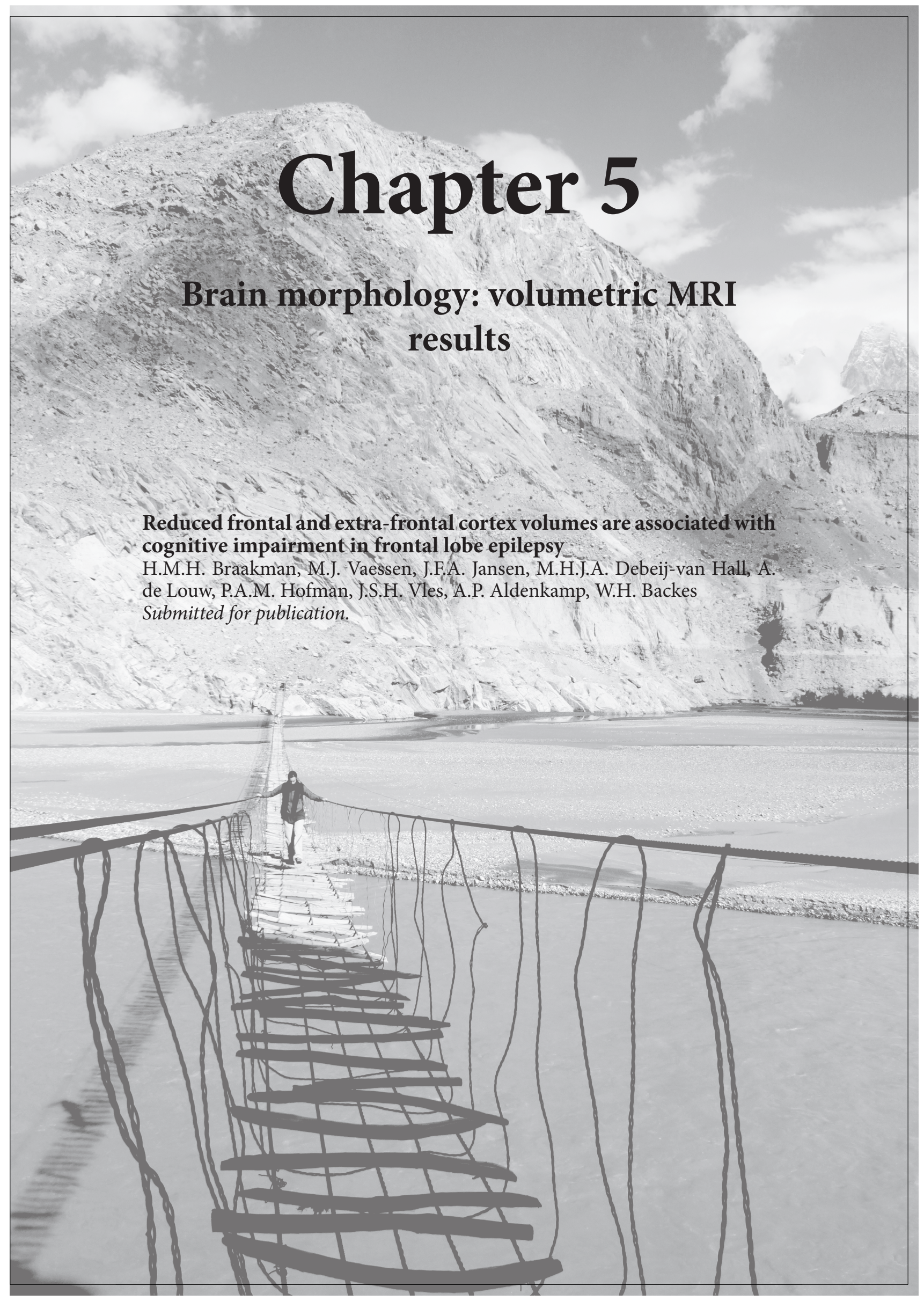




\begin{abstract}
Introduction: Cognitive impairment is frequent in children with frontal lobe epilepsy (FLE), but its etiology is unknown. MRI scans often reveal no structural brain abnormalities that could explain the cognitive impairment. This does not exclude more subtle morphological abnormalities that can only be detected by automated morphometric techniques. With these techniques, we investigate the relationship between cortical brain morphology and cognitive functioning in a cohort of children with FLE and healthy controls.
\end{abstract}

Materials and Methods: Thirty-four children aged 8 to 13 years with FLE of unknown cause and 41 healthy age-matched controls underwent neuropsychological assessment and structural brain MRI. Patients were grouped as cognitively impaired or unimpaired. Intracranial volume, white matter volume, lobular cortical volume, cortical thickness, and volumes of cortex structures were compared between patients and controls and potential correlations with cognitive status were determined.

Results: The group of cognitively impaired children with FLE had significantly smaller left temporal cortex volumes, specifically middle temporal grey matter volume and entorhinal cortex thickness. In addition, cognitively impaired children with FLE had smaller volumes of structures in the left and right frontal cortex, right temporal cortex, and the left subcortical area.

Conclusion: Cognitively impaired children with FLE have smaller volumes of various cortex structures within the frontal lobes and in extra-frontal regions, most notably temporal cortex volumes. These findings might well explain the broad scale of cognitive domains affected in children with FLE complicated by cognitive impairment and highlights that FLE impacts on areas beyond the frontal lobe. 


\section{Reduced frontal and extra-frontal cortex volumes are associated with cognitive impairment in frontal lobe epilepsy}

\section{Introduction}

Frontal lobe epilepsy (FLE) is considered the second most common type of the localization-related epilepsies and its average age at onset ranges from four to eight years. ${ }^{1,2} \mathrm{FLE}$ in children is frequently complicated by cognitive impairment, but this cognitive impairment shows strong inter-individual variability. ${ }^{2}$ Cognitive impairment generally comprises attention deficits and impaired executive functioning. In addition, a decline in intelligence quotient scores, language impairment and memory deficits have been described in children with FLE. ${ }^{2}$ Thus, FLE does not impact on one specific function but on a broad range of cognitive domains, which frequently results in educational problems and the need for special education. ${ }^{3}$

Theetiologyof cognitivedeficitsin children withFLEisunknownand correlations with clinical epilepsy characteristics, including age at seizure onset and seizure frequency, remain inconclusive. ${ }^{2}$ MRI scans often reveal no structural brain abnormalities that may explain the cognitive impairment, as FLE in childhood is usually of unknown cause. ${ }^{2}$ However, the cognitive impairment may still be related to more subtle morphological abnormalities that remain unnoticed on a visual MRI assessment. With sophisticated software programs to analyze brain morphology this relationship can be investigated. In previous studies, atrophy of various brain structures, including the hippocampus, thalamus, amygdala, and mammillary bodies, has for example been associated with impaired memory performance in adult patients with temporal lobe epilepsy (TLE).$^{4-9}$ The impact of seizures during brain development might be even more important in children with FLE, as the frontal lobe continues to develop until late adolescence and epilepsy can interfere with normal brain development. ${ }^{10}$ Our primary research questions were: are abnormalities in cortical volumes and cortical thickness detectable in children with FLE? And if so, are these abnormalities related to the cognitive impairment? Secondly, we investigated whether in our patient cohort clinical epilepsy characteristics were related to morphologic changes associated with cognitive impairment. 


\section{Material and methods}

\section{Ethics Statement}

The Medical Ethical Committees of Kempenhaeghe and the Maastricht University Medical Centre approved this study, which is registered by the Dutch Trial Register (NTR1749). All participants' parents gave written informed consent prior to study participation.

\section{Participants}

We performed this cohort study at the Epilepsy Centre Kempenhaeghe, Heeze, The Netherlands. Inclusion criteria for the patients were: confirmed FLE of unknown cause, age between eight and 13 years (children above the age of eight years were considered capable to undergo MRI scanning without sedation), no other disease that could cause cognitive decline, and no history of brain injury. All patients had a normal structural brain MRI (Epilepsy Protocol) prior to inclusion, reconfirmed by a board certified neuroradiologist. The diagnosis FLE was made when patients have had one or more clinical seizures associated with frontal focal epileptic EEG discharges. When no EEG is available during a clinical seizure, the video-recording of more than one seizure with clinical evidence of a frontal lobe origin is required to confirm the diagnosis. ${ }^{11} \mathrm{We}$ excluded patients with frontal lobe seizures resulting from spread to the frontal lobes or with interictal epileptiform EEG abnormalities outside the frontal lobes.

Healthy age-matched controls were recruited by advertisements in local newspapers. All controls followed regular education. Exclusion criteria were: medical history of head trauma or other diseases that may cause cognitive impairment.

Exclusion criteria for both groups were: contra-indications for MRI such as metal implants or (one of the) parents unwilling to provide informed consent.

We collected the following data for all subjects: gender, age, education level, medical history, family history, and dominant handedness.

For the FLE patients, the following clinical epilepsy characteristics were collected via chart review: age at onset, seizure duration, seizure type, seizure frequency, seizure occurrence, history of febrile seizures, history of status epilepticus, anti-epileptic drug treatment, drug load, response to anti-epileptic drug (AED) treatment, and localization of epileptic discharges on EEG (left frontal, right frontal, or bifrontal). We computed drug load as previously described. ${ }^{12,13}$ In children using two or more AEDs, cumulative drug loads were calculated. 


\section{Neuropsychological assessment}

We performed a neuropsychological assessment of all patients prior to inclusion (see Appendix 1 for neuropsychological test details). If neuropsychological assessment had been performed within one year prior to inclusion, and the assessment involved all necessary tests for this study then those test results were used. If neuropsychological assessment had been performed more than one year earlier, we repeated part of the neuropsychological assessment (see Appendix 1). The healthy control group underwent this same neuropsychological assessment. For each participant, we evaluated test performance on three different cognitive domains, i.e. global cognitive functioning, high-order cognitive functioning and fluid cognitive functioning to assess cognitive functioning. Global cognitive functioning reflects a trait-dependent ability. This ability shows only minor fluctuations over time (e.g. intelligence). Higher-order cognitive functioning consists of central functions modulating and controlling more routine or fundamental skills (e.g. memory and verbal comprehension). Fluid cognitive functioning consists of fluctuating or state-dependent functions (e.g. attention or psychomotor speed).

Individual cognitive functioning was transformed into an impairment index which reflects performance in the three above mentioned cognitive domains, on a scale of 1 (severe impairment) to 8 (no impairment); see Appendix 2 for details.

Participants were grouped as cognitively impaired (i.e. an impairment index of $\leq 4$; which means that at least global cognitive functioning is impaired) or cognitively minimal or unimpaired (impairment index $>4$ ).

\section{MRI procedure \\ Image acquisition}

MR imaging was performed on a 3.0-Tesla unit equipped with an 8-channel head coil (Philips Achieva, Philips Medical Systems, Best, The Netherlands). For anatomic reference, a T1-weigthed 3D turbo field echo was acquired with the following parameters: repetition time $8.1 \mathrm{~ms}$, inversion time $1022 \mathrm{~ms}$, echo time $3.7 \mathrm{~ms}$, flip angle 8 degrees, field of view $256 \times 256 \times 180 \mathrm{~mm}^{3}$, and voxel size $1 \times 1 \times 1 \mathrm{~mm}^{3}$.

\section{Data analysis}

Image preprocessing and image analysis

FreeSurfer (Martinos Centre of Biomedical Imaging, Boston, US) software was used to segment the T1-weighted images of each subject into grey and white matter, cortical and subcortical regions. FreeSurfer uses a surface based alignment procedure, which might be more accurate than a volume based alignment of a cortical atlas. ${ }^{24}$ Subsequently, all alignments were manually 
Table 1. Demographic and clinical characteristics of the (A) control group and (B) epilepsy groups.

\begin{tabular}{|c|c|}
\hline Characteristic & Number of subjects (\%) \\
\hline A & \\
\hline Gender (male : female) & $19: 22$ \\
\hline $\begin{array}{l}\text { Age } \\
\text { Mean age }( \pm \mathrm{SD}) \text { at assessment }\end{array}$ & $10.5 \pm 1.5$ years \\
\hline B & \\
\hline Gender (male : female) & $20: 14$ \\
\hline $\begin{array}{l}\text { Age } \\
\text { Mean age }( \pm \text { SD) at assessment } \\
\text { Mean age }( \pm \text { SD) at seizure onset }\end{array}$ & $\begin{array}{l}11.1 \pm 1.4 \text { years } \\
4.8 \pm 2.9 \text { years }\end{array}$ \\
\hline $\begin{array}{l}\text { Duration of epilepsy } \\
\text { Mean duration }( \pm S D) \text { of epilepsy }\end{array}$ & $6.1 \pm 2.9$ years \\
\hline $\begin{array}{l}\text { Seizure type } \\
\text { Complex partial seizures only } \\
\text { Atypical absence seizures only } \\
\text { Atypical absences and other complex partial seizures } \\
\text { Secondary generalized tonic-clonic seizures }\end{array}$ & $\begin{array}{l}6(18 \%) \\
14(41 \%) \\
9(26 \%) \\
5(15 \%)\end{array}$ \\
\hline $\begin{array}{l}\text { History } \\
\text { Febrile seizures } \\
\text { Status epilepticus }\end{array}$ & $\begin{array}{l}9(26 \%) \\
3(9 \%)\end{array}$ \\
\hline $\begin{array}{l}\text { Seizure occurrence } \\
\text { Seizure free } \\
\text { Nocturnal seizures only } \\
\text { Diurnal seizures only } \\
\text { Both nocturnal and diurnal seizures }\end{array}$ & $\begin{array}{l}4(12 \%) \\
1(3 \%) \\
13(38 \%) \\
16(47 \%)\end{array}$ \\
\hline $\begin{array}{l}\text { Seizure frequency (in the past year) } \\
\text { Low seizure frequency ( } \leq 1 \text { seizure/week) } \\
\text { High seizure frequency ( }>1 \text { seizure/week }) \\
\text { Refractory } \\
\text { Not-refractory }\end{array}$ & $\begin{array}{l}16(47 \%) \\
18(53 \%) \\
23(68 \%) \\
11(32 \%)\end{array}$ \\
\hline $\begin{array}{l}\text { Seizure focus based on history and EEG } \\
\text { Focus left frontal } \\
\text { Focus right frontal } \\
\text { Focus bifrontal }\end{array}$ & $\begin{array}{l}8(23 \%) \\
7(21 \%) \\
19(56 \%)\end{array}$ \\
\hline $\begin{array}{l}\text { AED }^{\mathrm{b}} \text { treatment } \\
\text { No AED } \\
\text { Monotherapy } \\
\text { Polytherapy }\end{array}$ & $\begin{array}{l}1(3 \%) \\
21(62 \%) \\
12(35 \%)\end{array}$ \\
\hline $\begin{array}{l}\text { Drugload } \\
\text { Low } \leq 1.0 \\
\text { High }>1.0\end{array}$ & $\begin{array}{l}27(79 \%) \\
7(21 \%)\end{array}$ \\
\hline
\end{tabular}

EEG: electroencephalogram; AED: antiepileptic drug.

checked on their accuracy of grey and white matter parcelation. The whole analysis was conducted on one computer, always with the same Freesurfer/ linux version within a time period of several weeks.

For the analysis of the structural brain imaging data the following morphological measures were used: total intracranial volume, cerebrospinal fluid volume, grey and white matter volumes, cortex volumes of the lobes, volumes of individual grey matter brain regions, cortical thickness, and volumes of cortex structures. 


\section{Statistical analysis}

Statistical data analysis was performed using the SPSS 16.0 software package (SPSS Inc., Chicago, IL). Because of substantial brain maturation processes in this age category, cortex volumes were corrected for gender, age and total intracranial volume using General Linear Model's multivariate analysis. Demographical and clinical characteristics were reported using descriptive statistics, i.e. values were expressed as mean value \pm standard deviation. Between-group differences in demographical and clinical characteristics were assessed using ANOVA's. To test for differences in brain volumes between cognitively unimpaired patients, cognitively impaired patients and controls, with General Linear Model, a multivariate analysis with group and gender as fixed factor and age and total intracranial volume as covariates was used. $\mathrm{P}$-values $<0.05$ were considered statistically significant.

Finally, the influence of clinical epilepsy characteristics on morphological measures that differed between cognitively impaired patients and cognitively unimpaired patients was investigated. For statistical analysis, we categorized patients into short ( $\leq 5$ years) versus long ( $>5$ years) seizure duration, young ( $\leq 5$ years) versus old ( $>5$ years) age at seizure onset, low ( $\leq 1$ seizure per week) versus high ( $>1$ seizure per week) seizure frequency, low $(\leq 1.0)$ versus high (>1.0) drug load, and left versus right versus bifrontal focus, based on seizure semiology and EEG.

\section{Results}

\section{Inclusion}

We included 37 patients and 43 controls. Three patients were excluded because of failure to finish either the MRI scanning or the neuropsychological assessment. Two controls were excluded; one because of failure to finish the scanning and another because of a recently placed dental brace. Eventually, 34 patients and 41 controls were included. Their demographical and clinical characteristics are recorded in Table 1.

\section{Cognitive performance}

We identified cognitive impairment in 17 children with FLE (50\%). Neuropsychological test results are recorded in Appendix 3. Demographical and clinical characteristics in the cognitively unimpaired and impaired patient groups were similar (data not shown). 
Table 2. Results of the between group analysis.

\begin{tabular}{|c|c|c|c|c|}
\hline & $\begin{array}{l}\text { Cognitively } \\
\text { impaired } \\
\text { patients, } \\
\text { mean } \pm \text { SD }\end{array}$ & $\begin{array}{l}\text { Cognitively } \\
\text { unimpaired } \\
\text { patients, } \\
\text { mean } \pm \text { SD }\end{array}$ & $\begin{array}{l}\text { Controls, } \\
\text { mean } \pm S D\end{array}$ & p-value \\
\hline \multicolumn{5}{|l|}{ Volumes $\left(\mathrm{cm}^{3}\right)$} \\
\hline Total intracranial volume & $1305 \pm 113$ & $1305 \pm 125$ & $1307 \pm 133$ & $\mathrm{p}=.998$ \\
\hline Cerebrospinal fluid & $1039 \pm 239$ & $1140 \pm 312$ & $1021 \pm 211$ & $\mathrm{p}=.240$ \\
\hline Cerebral white matter volume $\mathrm{a}^{\mathrm{a}}$ & $481 \pm 55$ & $484 \pm 55$ & $471 \pm 60$ & $\mathrm{p}=.047$ \\
\hline Cerebral grey matter volume ${ }^{\mathrm{a}}$ & $742 \pm 63$ & $738 \pm 68$ & $754 \pm 75$ & $\mathrm{p}=.056$ \\
\hline \multicolumn{5}{|l|}{ Cortical volumes $\left(\mathrm{cm}^{3}\right)$} \\
\hline $\begin{array}{l}\text { Frontal lobe }{ }^{\mathrm{a}} \\
\text { Left } \\
\text { Right }\end{array}$ & $\begin{array}{l}111 \pm 11 \\
113 \pm 11\end{array}$ & $\begin{array}{l}112 \pm 8 \\
114 \pm 9\end{array}$ & $\begin{array}{l}113 \pm 12 \\
115 \pm 13\end{array}$ & $\begin{array}{l}\mathrm{p}=.653 \\
\mathrm{p}=.337\end{array}$ \\
\hline $\begin{array}{l}\text { Temporal lobe } \\
\text { Left } \\
\text { Right }\end{array}$ & $\begin{array}{l}79 \pm 7 \\
79 \pm 6\end{array}$ & $\begin{array}{l}81 \pm 7 \\
80 \pm 7\end{array}$ & $\begin{array}{l}82 \pm 9 \\
81 \pm 9\end{array}$ & $\begin{array}{l}\mathrm{p}=.018 \\
\mathrm{p}=.140\end{array}$ \\
\hline $\begin{array}{l}\text { Parietal lobe } \\
\text { Left } \\
\text { Right }\end{array}$ & $\begin{array}{l}75 \pm 7 \\
76 \pm 7\end{array}$ & $\begin{array}{l}75 \pm 6 \\
77 \pm 8\end{array}$ & $\begin{array}{l}77 \pm 9 \\
78 \pm 9\end{array}$ & $\begin{array}{l}\mathrm{p}=.500 \\
\mathrm{p}=.559\end{array}$ \\
\hline $\begin{array}{l}\text { Occipital lobe }^{\text {a }} \\
\text { Left } \\
\text { Right }\end{array}$ & $\begin{array}{l}20 \pm 3 \\
20 \pm 2\end{array}$ & $\begin{array}{l}19 \pm 3 \\
20 \pm 3\end{array}$ & $\begin{array}{l}20 \pm 3 \\
20 \pm 3\end{array}$ & $\begin{array}{l}\mathrm{p}=.542 \\
\mathrm{p}=.860\end{array}$ \\
\hline $\begin{array}{l}\text { Cerebellum } \\
\text { Left } \\
\text { Right }\end{array}$ & $\begin{array}{l}75 \pm 8 \\
75 \pm 9\end{array}$ & $\begin{array}{l}74 \pm 9 \\
74 \pm 9\end{array}$ & $\begin{array}{l}75 \pm 7 \\
76 \pm 7\end{array}$ & $\begin{array}{l}\mathrm{p}=.748 \\
\mathrm{p}=.426\end{array}$ \\
\hline Cortical thickness (mm) & & & & \\
\hline $\begin{array}{l}\text { Frontal lobe thickness }{ }^{\mathrm{b}} \\
\text { Left } \\
\text { Right }\end{array}$ & $\begin{array}{l}4.54 \pm 0.22 \\
4.58 \pm 0.17\end{array}$ & $\begin{array}{l}4.54 \pm 0.18 \\
4.57 \pm 0.21\end{array}$ & $\begin{array}{l}4.60 \pm 0.18 \\
4.66 \pm 0.18\end{array}$ & $\begin{array}{l}\mathrm{p}=.719 \\
\mathrm{p}=.193\end{array}$ \\
\hline $\begin{array}{l}\text { Temporal lobe } \\
\text { Left } \\
\text { Right }\end{array}$ & $\begin{array}{l}4.63 \pm 0.22 \\
4.55 \pm 0.15\end{array}$ & $\begin{array}{l}4.59 \pm 0.24 \\
4.59 \pm 0.22\end{array}$ & $\begin{array}{l}4.66 \pm 0.16 \\
4.59 \pm 0.16\end{array}$ & $\begin{array}{l}\mathrm{p}=.859 \\
\mathrm{p}=.309\end{array}$ \\
\hline $\begin{array}{l}\text { Parietal lobe } \\
\text { Left } \\
\text { Right }\end{array}$ & $\begin{array}{l}2.62 \pm 0.13 \\
2.54 \pm 0.11\end{array}$ & $\begin{array}{l}2.59 \pm 0.13 \\
2.52 \pm 0.16\end{array}$ & $\begin{array}{l}2.63 \pm 0.12 \\
2.58 \pm 0.17\end{array}$ & $\begin{array}{l}\mathrm{p}=.677 \\
\mathrm{p}=.733\end{array}$ \\
\hline $\begin{array}{l}\text { Occipital lobe }^{b} \\
\text { Left } \\
\text { Right }\end{array}$ & $\begin{array}{l}2.12 \pm 0.14 \\
2.09 \pm 0.10\end{array}$ & $\begin{array}{l}2.09 \pm 0.15 \\
2.04 \pm 0.13\end{array}$ & $\begin{array}{l}2.10 \pm 0.13 \\
2.08 \pm 0.12\end{array}$ & $\begin{array}{l}\mathrm{p}=.272 \\
\mathrm{p}=.272\end{array}$ \\
\hline
\end{tabular}

a: Corrected for total intracranial volume; b: Corrected for mean cortex thickness.

\section{MRI morphometry}

First, we compared the total intracranial volume and total cerebrospinal fluid (CSF) volume between the cognitively unimpaired and impaired patients and controls. No significant differences were found between these groups (see Table 2).

Focusing on individual brain lobes, for the left temporal cortex we found that patients had smaller cortex volumes than controls (see Table 2). Here, the cognitively impaired patient group revealed significantly smaller left temporal cortex volumes than controls $\left(79 \pm 7 \mathrm{~cm}^{3}\right.$ vs. $\left.82 \pm 9 \mathrm{~cm}^{3} ; \mathrm{p}=0.01\right)$. This left 
temporal cortex volume remained significantly smaller after correction for total intracranial volume, gender, and age $(\mathrm{p}=0.02)$. Left temporal cortex volumes of the cognitively unimpaired patient group and those of the control group proved not different ( $81 \pm 7 \mathrm{~cm}^{3}$ vs. $82 \pm 9 \mathrm{~cm}^{3} ; \mathrm{p}=0.39$ ), whereas those of the cognitively impaired group showed a trend towards smaller volumes than those of the unimpaired patient group $\left(81 \pm 7 \mathrm{~cm}^{3}\right.$ vs. $79 \pm 7 \mathrm{~cm}^{3} ; \mathrm{p}=$ $0.08)$.

Right temporal cortex volumes were also smaller in the cognitively impaired patient group compared to the control group at the borderline significance level $\left(79 \pm 6 \mathrm{~cm}^{3}\right.$ vs. $\left.81 \pm 9 \mathrm{~mm}^{3} ; \mathrm{p}=0.05\right)$.

Although not statistically significant, on average the cortical volumes of the frontal, temporal, and parietal lobes were smaller in patients compared to controls (see Table 2).

Patients demonstrated larger total cerebral white matter volumes than controls, whereas total grey matter volumes showed a trend towards smaller volumes in patients than in controls (see Table 2). This difference in total cerebral white matter volume highly results from increased volumes particularly in the cognitively unimpaired group. This patient group had significantly larger total cerebral white matter volumes than the control group $\left(484 \pm 55 \mathrm{~cm}^{3} \mathrm{vs} .471 \pm 60\right.$ $\mathrm{cm}^{3} ; \mathrm{p}=0.02$ ), for which the cognitively impaired group showed a comparable trend (481 $\pm 55 \mathrm{~cm}^{3}$ vs. $\left.471 \pm 60 \mathrm{~cm}^{3} ; \mathrm{p}=0.07\right)$. Cognitively unimpaired and impaired patients had no significant differences in total cerebral white matter volumes ( $484 \pm 55 \mathrm{~cm}^{3}$ vs. $481 \pm 55 \mathrm{~cm}^{3} ; \mathrm{p}=0.66$ ).

No significant differences in cortex thicknesses of the individual brain lobes were measured between the control group and both patient groups (see Table 2).

\section{Cognitive impairment and left temporal cortex volume Left temporal grey matter volumes}

The volume of the middle temporal grey matter was significantly smaller in the cognitively impaired than in the unimpaired patient group $(\mathrm{p}=0.02)$, which remained significant after correction for total grey matter volume, gender and age $\left(13 \pm 2 \mathrm{~cm}^{3}\right.$ vs. $\left.15 \pm 1 \mathrm{~cm}^{3} ; \mathrm{p}=0.01\right)$. The volumes of other temporal grey matter areas did not significantly differ between the two patient groups (see Appendix 4).

\section{Left hippocampus and amygdala volumes}

Volumes of the hippocampus and amygdala did not differ significantly between the cognitively impaired and unimpaired patient groups (see Appendix 4).

\section{Left temporal cortex thicknesses}

The entorhinal cortex was significantly thinner in the cognitively impaired patient group $(3.35 \pm 0.37 \mathrm{~mm}$ in the cognitively unimpaired patient group 
Table 3. Volumes of cortex structures which were significantly smaller in patients than in controls.

\begin{tabular}{llll} 
& Patients & Controls & P-value \\
\hline $\begin{array}{l}\text { Left frontal lobe cortex } \\
\text { Thickness of the left pars opercularis }\end{array}$ & $2.86 \pm 0.19 \mathrm{~mm}$ & $2.96 \pm 0.15 \mathrm{~mm}$ & 0.033 \\
$\begin{array}{l}\text { Right frontal lobe cortex } \\
\text { Thickness of the right pars opercularis }\end{array}$ & $2.94 \pm 0.15 \mathrm{~mm}$ & $3.06 \pm 0.16 \mathrm{~mm}$ & 0.003 \\
$\quad \begin{array}{l}\text { Thickness of the right superior frontal gyrus } \\
\text { Right parietal lobe cortex }\end{array}$ & $3.04 \pm 0.17 \mathrm{~mm}$ & $3.15 \pm 0.19 \mathrm{~mm}$ & 0.041 \\
$\quad \begin{array}{l}\text { Thickness of the right pars postcentralis } \\
\text { Right temporal lobe cortex }\end{array}$ & $2.18 \pm 0.14 \mathrm{~mm}$ & $2.25 \pm 0.11 \mathrm{~mm}$ & 0.047 \\
$\quad \begin{array}{l}\text { Right parahippocampal grey matter volume } \\
\text { Right subcortical area }\end{array}$ & $2.64 \pm 0.35 \mathrm{~cm}^{3}$ & $2.92 \pm 0.52 \mathrm{~cm}^{3}$ & 0.023 \\
$\quad \begin{array}{l}\text { Right putamen volume } \\
\text { Right accumbens area volume }\end{array}$ & $6.18 \pm 0.72 \mathrm{~cm}^{3}$ & $6.42 \pm 0.78 \mathrm{~cm}^{3}$ & 0.049 \\
& $0.80 \pm 0.11 \mathrm{~cm}^{3}$ & $0.85 \pm 0.12 \mathrm{~cm}^{3}$ & 0.040 \\
\hline
\end{tabular}

Table 4. Volumes of cortex structures which were significantly larger in patients than in controls.

\begin{tabular}{llll} 
& Patients & Controls & P-value \\
\hline $\begin{array}{l}\text { Left frontal lobe cortex } \\
\text { Left pars triangularis grey matter volume }\end{array}$ & $4.79 \pm 0.73 \mathrm{~cm}^{3}$ & $4.43 \pm 0.76 \mathrm{~cm}^{3}$ & 0.019 \\
$\begin{array}{l}\text { Right frontal lobe cortex } \\
\text { Right lateral orbitofrontal grey matter volume }\end{array}$ & $9.29 \pm 1.17 \mathrm{~cm}^{3}$ & $8.96 \pm 1.05 \mathrm{~cm}^{3}$ & 0.009 \\
$\begin{array}{l}\text { Left temporal lobe cortex } \\
\text { Left transverse temporal grey matter volume }\end{array}$ & $1.64 \pm 0.29 \mathrm{~cm}^{3}$ & $1.52 \pm 0.29 \mathrm{~cm}^{3}$ & 0.021 \\
$\begin{array}{l}\text { Left parietal lobe cortex } \\
\text { Left cuneus grey matter volume }\end{array}$ & $3.56 \pm 0.73 \mathrm{~cm}^{3}$ & $3.31 \pm 0.69 \mathrm{~cm}^{3}$ & 0.044 \\
$\begin{array}{l}\text { Right parietal lobe cortex } \\
\text { Right precuneus grey matter volume } \\
\text { Left occipital lobe cortex } \\
\text { Left lingual grey matter volume }\end{array}$ & $12.88 \pm 1.81 \mathrm{~cm}^{3}$ & $12.5 \pm 2.13 \mathrm{~cm}^{3}$ & 0.015 \\
\hline
\end{tabular}

vs. $3.12 \pm 0.40 \mathrm{~mm}$ in the cognitively impaired patient group, corrected for mean cortex thickness, gender and age; $p=0.04$ ). The thicknesses of the other temporal cortex regions did not differ between both patient groups (see Appendix 4).

\section{Influence of clinical epilepsy characteristics}

The left temporal cortex volume in patients was not associated with age at seizure onset, duration of epilepsy, seizure type, history of febrile seizures or status epilepticus, seizure occurrence, seizure frequency, localization of the seizure focus, use of monotherapy versus polytherapy, or drug load (see Appendix 5). 


\section{Additional volumetric findings}

The findings reported so far provide an overview of the most prominent findings, decreased temporal lobe cortex volumes. When taking all different cortex structure volumes into account, patients did not only have smaller volumes of left temporal lobe cortex structures than controls, but have also smaller volumes of left and right frontal lobe cortex, right parietal lobe cortex, right temporal lobe cortex, and smaller volumes of right subcortical structures than controls (see Table 3). Not only smaller, but also larger cortex volumes were seen in patients than in controls. These larger volumes were present in the left and right frontal lobe cortex, left temporal lobe cortex, left and right parietal lobe cortex and left occipital lobe cortex structures (see Table 4).

More importantly, we also observed differences between cognitively impaired and unimpaired patients in structures outside the left temporal lobe. The cognitively impaired patient group also had significantly smaller volumes of structures in the left and right frontal cortex, right temporal cortex, and structures of the left subcortical area (see Table 5). Not only smaller, but also larger cortex volumes were seen in cognitively impaired patients than in cognitively unimpaired patients. These larger volumes were present in the right temporal lobe cortex, right parietal lobe cortex, and the right occipital lobe cortex (see Table 6).

\section{Discussion}

Localization of the cortical abnormalities and associations with cognitive impairment

The cortex volume of the temporal lobe, specifically the left temporal lobe, was significantly smaller in patients with FLE than in controls. In addition, temporal cortex volumes, specifically middle temporal grey matter volume and entorhinal cortex thickness, were smaller in patients with cognitive impairment than in the cognitively unimpaired patients. This suggests that volume loss in these temporal structures is part of the etiology of cognitive impairment in children with FLE. In addition, smaller volumes of the left and right frontal cortex, right temporal cortex and left subcortical areas, as well as larger volumes of the right temporal cortex, right parietal cortex and right occipital cortex were associated with cognitive impairment in children with FLE. These results imply that FLE impacts on areas outside the frontal lobe, which, in turn, may partly explain the broad-range of cognitive impairments frequently seen in children with FLE. ${ }^{2}$ 
Table 5. Volumes of different cortex structures which were significantly smaller in cognitively impaired patients than in cognitively unimpaired patients.

\begin{tabular}{|c|c|c|c|}
\hline & $\begin{array}{l}\text { Cognitively } \\
\text { impaired } \\
\text { patients }\end{array}$ & $\begin{array}{l}\text { Cognitively } \\
\text { unimpaired } \\
\text { patients }\end{array}$ & P-value \\
\hline \multicolumn{4}{|l|}{ Left frontal lobe cortex } \\
\hline Left lateral orbitofrontal grey matter volume & $8.79 \pm 1.23 \mathrm{~cm}^{3}$ & $9.36 \pm 1.02 \mathrm{~cm}^{3}$ & 0.005 \\
\hline \multicolumn{4}{|l|}{ Right frontal lobe cortex } \\
\hline Right lateral orbitofrontal grey matter volume & $9.02 \pm 1.11 \mathrm{~cm}^{3}$ & $9.56 \pm 1.20 \mathrm{~cm}^{3}$ & 0.030 \\
\hline Thickness of the right lateral orbitofrontal cortex & $2.91 \pm 0.16 \mathrm{~mm}$ & $3.00 \pm 0.17 \mathrm{~mm}$ & 0.038 \\
\hline Thickness of the right pars orbitalis & $3.08 \pm 0.22 \mathrm{~mm}$ & $3.19 \pm 0.29 \mathrm{~mm}$ & 0.023 \\
\hline \multicolumn{4}{|l|}{ Right temporal lobe cortex } \\
\hline Right middle temporal grey matter volume & $15.28 \pm 1.93 \mathrm{~cm}^{3}$ & $16.51 \pm 2.44 \mathrm{~cm}^{3}$ & 0.029 \\
\hline \multicolumn{4}{|l|}{ Left subcortical area } \\
\hline Left thalamus volume & $7.74 \pm 0.77 \mathrm{~cm}^{3}$ & $8.12 \pm 1.09 \mathrm{~cm}^{3}$ & 0.043 \\
\hline
\end{tabular}

Table 6. Volumes of different cortex structures which were significantly larger in cognitively impaired patients than in cognitively unimpaired patients.

\begin{tabular}{lllc} 
& $\begin{array}{l}\text { Cognitively } \\
\text { impaired } \\
\text { patients }\end{array}$ & $\begin{array}{l}\text { Cognitively } \\
\text { unimpaired } \\
\text { patients }\end{array}$ & P-value \\
\hline $\begin{array}{l}\text { Right temporal lobe cortex } \\
\text { Right amygdala volume } \\
\begin{array}{l}\text { Right parietal lobe cortex } \\
\text { Right cuneus grey matter volume }\end{array}\end{array}$ & $1.78 \pm 0.29 \mathrm{~cm}^{3}$ & $1.66 \pm 0.25 \mathrm{~cm}^{3}$ & 0.047 \\
$\begin{array}{l}\text { Right occipital lobe cortex } \\
\text { Thickness of the right lateral occipital cortex }\end{array}$ & $3.85 \pm 0.61 \mathrm{~cm}^{3}$ & $3.26 \pm 0.69 \mathrm{~cm}^{3}$ & 0.007 \\
\hline
\end{tabular}

\section{Role of the entorhinal cortex}

The affected left temporal structures are both situated in the medial temporal lobe (see Figure 1). The entorhinal cortex has connections with a wide array of subcortical and cortical areas, in particular the hippocampus, but also the medial and lateral frontal lobes, and modulates the interactions between these areas. ${ }^{25-27}$ Atrophy of the entorhinal cortex has been related to epilepsy duration and drug-refractoriness in TLE patients. ${ }^{28,29}$ It has not previously been associated with cognitive impairment in either TLE or FLE, as observed in the current study. The importance of the entorhinal cortex in cognitive functioning has previously been demonstrated in patients with neurodegenerative brain disease and in patients with schizophrenia. In Alzheimer's disease and mild cognitive impairment a decrease in entorhinal cortex volume has been associated with a decline in memory performance. ${ }^{30}$ In schizophrenia, atrophy of the entorhinal cortex has been associated with psychotic symptoms. ${ }^{31}$ 

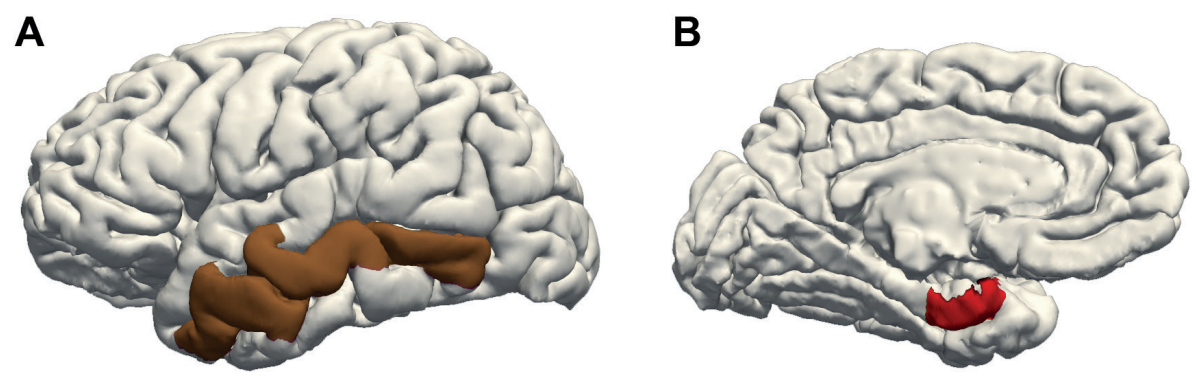

Figure 1. The volume of the middle temporal grey matter was significantly smaller in the cognitively impaired patient group (A). The entorhinal cortex was significantly thinner in the cognitively impaired patient group (B).

\section{Previous volumetric MRI studies in adult patients with epilepsy}

Contrary to our findings, volume loss within the medial temporal lobe of adult TLE patients typically affects the hippocampus and amygdala instead of the entorhinal cortex and middle temporal grey matter. ${ }^{28,29}$ In TLE, hippocampal and amygdala volume loss was associated with cognitive impairment in many studies. $^{4-8}$ Our results imply that medial temporal lobe volumes may be as important in FLE as they are in TLE and may play a general role in the etiology of cognitive impairment complicating epilepsy.

Two other volumetric MRI studies have been performed in patients with FLE, but none of them related the results to cognitive functioning. The first study investigated subcortical volumes, i.e., volumes of the bilateral caudate nucleus, putamen, pallidum, and thalamus in adult patients with extra-temporal lobe epilepsy, including FLE. They found that extra-temporal lobe epilepsy was not associated with smaller volumes in the studied subcortical structures. ${ }^{32}$ The second study investigated cortical thickness in children with therapy resistant FLE. Children with FLE with a left sided seizure focus demonstrated low cortical thickness in multiple left frontal, left parietal, left temporal, as well as in right frontal, right parietal, and right temporal cortex structures. In children with FLE with a right sided seizure focus, low cortical thickness was measured in right frontal, right temporal, right occipital, as well as in left frontal, left parietal, and left temporal cortex structures. ${ }^{33}$ We also found that cortical changes in children with FLE were present both in the frontal lobe as well as in extra-frontal lobes.

\section{Determinants of morphological brain abnormalities}

The observed smaller left temporal lobe cortex volumes may either reflect atrophy or a disturbed maturation process. In addition, we don't know whether the larger cortical volumes in patients with FLE compared to controls and in 
cognitively impaired compared to unimpaired patients reflect a (temporary) compensatory mechanism. Repetition of this volumetric MRI study in these patients and controls in the future might shed more light on the etiology of these smaller and larger volumes, and the smaller and larger cortex volumes. Clinical epilepsy characteristics did not influence these left temporal cortex volumes. In the current study, cortex volume measurement appears to be a more sensitive tool to uncover morphological abnormalities than cortex thickness measurement; this contrasts with the study by Widjaja et al. who found abnormalities of cortical thickness in children with FLE who had no structural abnormalities at the neuroradiological reading. ${ }^{33}$

\section{White matter volume}

The children with FLE in this study had larger cerebral white matter volumes than is normal for their age. Previous volumetric MRI studies in children as well as adults with TLE found either no differences in cerebral white matter volumes between patients and controls, ${ }^{34,35}$ or decreased white matter volumes in patients. ${ }^{36-38}$ This decreased white matter volume was more prominent in patients with idiopathic generalized epilepsy than in patients with localizationrelated epilepsy, and might therefore differ between different epilepsy types. ${ }^{37}$ This could be one reason why our volumetric findings in children with FLE differ from the findings in other epilepsy types. The mechanism behind the larger white matter volumes in children with FLE are unknown, but could include sprouting of white matter fibers in response to white matter damage or may reflect an accelerated myelination process. This etiology and resulting differences in white matter structure between patients and controls could be studied using diffusion tensor imaging to provide more insight in the organization of the white matter tissue. 


\section{Conclusion}

Cognitively impaired children with FLE have smaller volumes of various cortex structures within the frontal lobes and in extra-frontal regions, most notably temporal cortex volumes. These findings might well explain the broad scale of cognitive domains affected in children with FLE complicated by cognitive impairment and highlights that FLE impacts on areas beyond the frontal lobe. These cortex abnormalities reflect a neurodegenerative process or a disturbed maturation, and may have a predictive value for long-term persistence of cognitive impairment or seizures, which warrants further study. 


\section{Appendix 1. Neuropsychological test details.}

\section{Cognitive domain Test}

General intelligence

Memory

Short-term memory Recognition of words and figures. ${ }^{15 *}$
Wechsler Intelligence (WISC-III). ${ }^{14}$ Scale for Children-III

\section{Description}

The WISC consists of 13 subtests:

Picture Completion - artwork of common objects with a missing part are shown, and the patient is asked to identify the missing part by pointing and/or naming.

Information - general knowledge questions. Coding - patients transcribe a digit-symbol code which is time-limited.

Similarities - the patient has to explain the similarity between two words.

Picture arrangement - sequencing cartoon pictures to make sensible stories.

Arithmetic - orally administered arithmetic questions which are timed.

Block Design - patients put together red-and-white blocks in a pattern according to a displayed model which is timed.

Vocabulary - the patient has to explain the meaning of several words.

Object assembly - puzzles of cut-apart silhouette objects with no outline pieces.

Comprehension - questions about social situations or common concepts.

Symbol Search - patients are given rows of symbols and target symbols, and asked to mark whether or not the target symbols appear in each row.

Digit Span - patients are orally given sequences of numbers and asked to repeat them, either as heard or in reverse order.

Mazes - patient has to find a route to get out of the maze.

Intellectual ability is expressed in Full Scale IQ, Verba IQ, Performance IQ, Verbal Reasoning, Perceptual Organization and Mental Processing Speed score.

Stimuli (six words or four figures) are presented simultaneously during a learning phase with a presentation time of 1 second per item. After a delay of 2 seconds the screen shows one of these words figures between distracters. The target item has to be recognized. The number of correct items is scored, with a maximum of 24 .

Long-term memory The 15 word test (15

A list of 15 words is orally presented five times. After woordentest Kalverboer the Dutch version of the Rey Auditory Verbal Learning Test). ${ }^{16}$

The 15 word test
(15 woordentest Kalverboer). ${ }^{16}$

After five consecutive trials with direct recall, a delaved recall is requested after a 20 minutes interval. The number of correct words is scored. Thereafter the patient is asked if he/she recognized the words. Number of correct recognized items is scored, with a maximum of 30 .

Complex Figure test Twenty minutes after copying a complex figure, the same (Rey-Osterrieth figure). ${ }^{17}$ figure has to been drawn from memory. 


\begin{tabular}{|c|c|c|}
\hline Cognitive domain & Test & Description \\
\hline \multirow[t]{4}{*}{$\begin{array}{l}\text { Visual-spatial } \\
\text { functions }\end{array}$} & $\begin{array}{l}\text { Complex Figure test } \\
\text { (Rey-Osterrieth figure). }{ }^{17}\end{array}$ & $\begin{array}{l}\text { Twenty minutes after copying a complex figure, the same } \\
\text { figure has to been drawn from memory. }\end{array}$ \\
\hline & $\begin{array}{l}\text { Beery Buktenica } \\
\text { Developmental Test } \\
\text { of Visual-Motor } \\
\text { Integration. }{ }^{19}\end{array}$ & $\begin{array}{l}\text { The patient has to copy a sequence of geometric forms of } \\
\text { increasing difficulty. }\end{array}$ \\
\hline & $\begin{array}{l}\text { The Visual Perception } \\
\text { Test. }{ }^{18}\end{array}$ & The patient has to match given geometric forms. \\
\hline & $\begin{array}{l}\text { The Motor Coordination } \\
\text { Test. }^{18}\end{array}$ & $\begin{array}{l}\text { The patient traces shapes while remaining inside a double } \\
\text { lined path. Raw scores are converted into standard } \\
\text { scores. }\end{array}$ \\
\hline \multirow[t]{4}{*}{$\begin{array}{l}\text { Psychomotor speed } \\
\text { and alertness }\end{array}$} & Finger tapping task. ${ }^{15}$ & $\begin{array}{l}\text { Five consecutive trials for the index finger of the dominant } \\
\text { and separately the non-dominant hand. Number of taps } \\
\text { is recorded. }\end{array}$ \\
\hline & $\begin{array}{l}\text { Simple reaction time } \\
\text { measurements. }{ }^{15 *}\end{array}$ & $\begin{array}{l}\text { The patient has to react as quickly as possible on either } \\
\text { auditory* }(800 \mathrm{~Hz} \text { tone) or visual (square on the screen) } \\
\text { stimuli that were presented at random intervals by the } \\
\text { computer. }\end{array}$ \\
\hline & $\begin{array}{l}\text { Binary choice reaction- } \\
\text { time measurement. }\end{array}$ & $\begin{array}{l}\text { A reaction time test with a decision component. The } \\
\text { patient has to react differentially to a red square on the } \\
\text { left side of the screen and to a green square at the right } \\
\text { side of the screen. }\end{array}$ \\
\hline & $\begin{array}{l}\text { Computerized visual } \\
\text { searching task (CVST) } \\
\text { (an adaptation of } \\
\text { Goldstein's Visual } \\
\text { Searching Task). }{ }^{15 *}\end{array}$ & $\begin{array}{l}\text { A centered grid pattern has to be compared with } 24 \\
\text { surrounding patterns. Only one of them is identical to } \\
\text { the target pattern. The test consists of } 24 \text { trails. Reaction } \\
\text { time is recorded (CVST) as well as the total number of } \\
\text { errors (CVST errors). }\end{array}$ \\
\hline \multirow{2}{*}{$\begin{array}{l}\text { Attention } \\
\text { Selective attention }\end{array}$} & & \\
\hline & $\begin{array}{l}\text { The Stroop Colour Word } \\
\text { Test. }{ }^{19 *}\end{array}$ & $\begin{array}{l}\text { The test consists of } 3 \text { cards: color naming (the patient had } \\
\text { to name color blocks), word reading (the patient had to } \\
\text { read words printed in black ink) and interference (the } \\
\text { patient has to name the color of a word printed in an } \\
\text { incongruent color; e.g., the word red written in blue ink). } \\
\text { By comparing the speed of the last card with the speed of } \\
\text { the second card, interference of cognitive functioning can } \\
\text { be measured. Increased interference can be interpreted as } \\
\text { a disturbance in the concentration process. }\end{array}$ \\
\hline Sustained attention & Bourdon-Vos Test. ${ }^{18}$ & $\begin{array}{l}\text { A cancellation test requiring high-speed visual selectivity } \\
\text { and a repetitive motor response. Patients are instructed } \\
\text { to cross out the target items, i.e. the dot patterns with } \\
\text { four dots on a sheet of paper covered in three- four-, and } \\
\text { five-dot patterns. The mean reaction time of the patient } \\
\text { is scored. }\end{array}$ \\
\hline $\begin{array}{l}\text { Educational } \\
\text { achievement }\end{array}$ & Tempotest. ${ }^{21-23 *}$ & $\begin{array}{l}\text { The performance on school tasks is assessed by arithmetic } \\
\text { and reading words and sentences. This gives a learning } \\
\text { efficiency quotient (LEQ) whereby } 100 \% \text { indicating no } \\
\text { delay. }\end{array}$ \\
\hline
\end{tabular}

${ }^{*}$ Neuropsychological assessment for the control group and for the patients who had neuropsychological assessment more than twelve months earlier. 
Appendix 2. Impairment index composition details.

\section{Global cognitive functioning}

For the healthy controls two functions were used to assess global cognitive function: central information processing speed (Computerized Visual Searching Task (CVST) $)^{15}$ and educational achievement (learning efficiency quotients (LEQ))..$^{21-23}$

By determining searching time (reaction time) and the errors made during the CVST task, an age-corrected cognitive performance score was generated, expressed in decile scores. Scores $\leq 3$ represent impairment. ${ }^{15}$

Learning efficiency quotients reflect someone's performance on school tasks (i.e. arithmetic and reading words and sentences). A score of $<80 \%$ indicates educational delay. ${ }^{21-23}$

If both tests are performed below normative values global cognitive functioning is impaired.

For the patients we used the Wechsler full scale IQ scores as a measure of global cognitive performance. FSIQ scores $<85$ indicate impairment. ${ }^{14}$

\section{Higher-order cognitive functioning}

The recognition words score was used to assess higher order cognitive functioning both for the controls as well as for the patients. ${ }^{15}$ After correction for age, a decile score was generated. Scores $\leq 3$ represent impairment. ${ }^{15}$

For the 9 patients who had been neuropsychologically tested within one year prior to inclusion we used the 'Digit Span' subtest score of the WISC-III. ${ }^{14}$

If performance scores were below normative values (standard score $<8$ ), higher-order cognition was considered impaired.

\section{Fluid cognitive functioning}

The STROOP Colour Word Test Interference score ${ }^{20}$ as well as the auditory reaction times ${ }^{15}$ were used to assess fluid cognitive functioning. STROOP interference scores were converted into Z-scores. A Z-score of 0 or 1 indicated normal or good performance, whereas a $Z$ - score of $\leq-1$ indicated impaired performance. ${ }^{19}$

For auditory reaction time measurements, after correction for age, decile scores were used. Scores $\leq 3$ represent impairment.

If both the STROOP interference scores as well as the auditory reaction times were performed below normative values, fluid cognitive functioning was considered impaired.

For the patients who had recently been neuropsychologically assessed $(n=6)$ we used the 'Coding' subtest score of the WISC-III. ${ }^{14}$ If performance scores 
were below normative values (standard score $<8$ ), fluid cognitive functioning was considered impaired.

The neuropsychological test results were subsequently converted into eight different impairment index scores.

An impairment index of 1 indicated most severe impairment as both global cognitive functioning, higher-order cognitive functioning, as well as fluid cognitive functioning are impaired. An impairment index of 8 indicates no impairment.

Children were grouped into 2 groups; one cognitively impaired group (i.e. an impairment index of $\leq 4$; which means that at least global cognitive functioning is impaired) and one cognitively minimal or unimpaired group (impairment index $>4)$.

\begin{tabular}{|c|c|c|}
\hline $\begin{array}{l}\text { Impairment } \\
\text { index }\end{array}$ & Impairment index details & $\begin{array}{l}\text { Number of } \\
\text { patients/controls }\end{array}$ \\
\hline 1 & $\begin{array}{l}\text { - } \quad \text { Global cognitive functioning impaired } \\
\text { - } \quad \text { Fligher-order cognitive functioning impaired } \\
\text { cognitive functioning impaired }\end{array}$ & $5 / 0$ \\
\hline 2 & $\begin{array}{ll}\text { - } & \text { Global cognitive functioning impaired } \\
\text { - } & \text { Higher-order cognitive functioning impaired } \\
\text { cognitive functioning not impaired }\end{array}$ & $4 / 1$ \\
\hline 3 & $\begin{array}{l}\text { - } \quad \text { Global cognitive functioning impaired } \\
\text { - } \quad \text { Higher-order cognitive functioning not impaired } \\
\quad \text { Fluid cognitive functioning impaired }\end{array}$ & $1 / 0$ \\
\hline 4 & $\begin{array}{ll} & \text { Global cognitive functioning impaired } \\
\text { - } & \text { Higher-order cognitive functioning not impaired } \\
& \text { Fluid cognitive functioning not impaired }\end{array}$ & $7 / 2$ \\
\hline 5 & $\begin{array}{ll}\text { - } & \text { Global cognitive functioning not impaired } \\
\text { - } & \text { Higher-order cognitive functioning impaired } \\
& \text { Flugnitive functioning impaired }\end{array}$ & $0 / 0$ \\
\hline 6 & $\begin{array}{ll}\text { - } & \text { Global cognitive functioning not impaired } \\
\text { - } & \text { Fligher-order cognitive functioning impaired } \\
& \text { cognitive functioning not impaired }\end{array}$ & $7 / 3$ \\
\hline 7 & $\begin{array}{l}\text { - } \quad \text { Global cognitive functioning not impaired } \\
\text { - } \quad \text { Higher-order cognitive functioning not impaired } \\
\text { Fluitive functioning impaired }\end{array}$ & $1 / 2$ \\
\hline 8 & $\begin{array}{ll}\text { - } & \text { Global cognitive functioning not impaired } \\
\text { - } & \text { Higher-order cognitive functioning not impaired } \\
& \text { cognitive functioning not impaired }\end{array}$ & $9 / 33$ \\
\hline
\end{tabular}


Appendix 3. Neuropsychological test results.

\begin{tabular}{lll} 
& $\begin{array}{c}\text { Patients, } \\
\text { Mean } \pm \text { SD }\end{array}$ & $\begin{array}{c}\text { Controls, } \\
\text { Mean } \pm \text { SD }\end{array}$ \\
\hline Global cognitive functioning & & \\
Central information processing speed & $4 \pm 3^{\mathrm{a}}$ & $7 \pm 3^{\mathrm{a}}$ \\
(Computerized Visual Searching Task; CVST) & \\
Educational achievement (learning efficiency quotients; LEQ) & $83 \pm 36^{\mathrm{b}}$ & $108 \pm 46^{\mathrm{b}}$ \\
Reading words & $76 \pm 36^{\mathrm{b}}$ & $118 \pm 58^{\mathrm{b}}$ \\
Reading sentences & $77 \pm 43^{\mathrm{b}}$ & $102 \pm 31^{\mathrm{b}}$ \\
Mathematics & $87 \pm 12^{\mathrm{c}}$ & - \\
Wechsler full scale IQ scores & & \\
Higher-order cognitive functioning & $5 \pm 3^{\mathrm{a}}$ & $7 \pm 3^{\mathrm{a}}$ \\
Recognition words score & $8 \pm 3^{\mathrm{d}}$ & - \\
'Digit Span' subtest score of the WISC-III & & \\
Fluid cognitive functioning & $-0.1 \pm 1.0^{\mathrm{e}}$ & $0.4 \pm 0.7^{\mathrm{e}}$ \\
STROOP Colour Word Test Interference score & $5 \pm 3^{\mathrm{a}}$ & $6 \pm 3^{\mathrm{a}}$ \\
Auditory reaction times & $8 \pm 3^{\mathrm{f}}$ & - \\
\hline 'Coding' subtest score of the WISC-III & & \\
\hline
\end{tabular}

a: An age-corrected cognitive performance score was generated, expressed in decile scores. Scores $\leq 3$ represent impairment. ${ }^{15}$

b: A score of $<80 \%$ indicates educational delay. ${ }^{21-23}$

c: Full scale IQ scores $<85$ indicate impairment.

d: If performance scores were below normative values (standard score $<8$ ), higherorder cognition was considered impaired..$^{14}$

e: A Z-score of 0 or 1 indicated normal or good performance, whereas a Z- score of $\leq$ -1 indicated impaired performance. ${ }^{19}$

f: If performance scores were below normative values (standard score $<8$ ), fluid cognitive functioning was considered impaired. ${ }^{14}$ 
Appendix 4. Left temporal lobe volumes.

\begin{tabular}{|c|c|c|c|}
\hline & $\begin{array}{l}\text { Cognitively unimpaired } \\
\text { patient group, } \\
\text { mean } \pm \text { SD }\end{array}$ & $\begin{array}{l}\text { Cognitively impaired } \\
\text { patient group, } \\
\text { mean } \pm \text { SD }\end{array}$ & p-value \\
\hline Grey bankssts ${ }^{\mathrm{a}^{*}}$ & $3.9 \pm 0.7$ & $3.3 \pm 1.1$ & 0.13 \\
\hline Grey entorhinal ${ }^{\mathrm{a}}$ & $1.9 \pm 0.5$ & $1.8 \pm 0.4$ & 0.58 \\
\hline Grey fusiform ${ }^{\mathrm{a}}$ & $12.2 \pm 2.2$ & $11.8 \pm 2.2$ & 0.85 \\
\hline Grey inferior temporal ${ }^{a}$ & $13.6 \pm 2.6$ & $13.9 \pm 2.1$ & 0.79 \\
\hline Grey lingual $^{\mathrm{a}}$ & $7.9 \pm 1.6$ & $8.2 \pm 1.3$ & 0.52 \\
\hline Grey middle temporal $^{a}$ & $14.6 \pm 1.5$ & $13.2 \pm 2.0$ & 0.01 \\
\hline Grey parahippocampal $^{\mathrm{a}}$ & $3.0 \pm 0.5$ & $2.9 \pm 0.4$ & 0.28 \\
\hline Grey superior temporal $^{a}$ & $14.6 \pm 1.4$ & $14.0 \pm 2.0$ & 0.09 \\
\hline Grey temporal pole ${ }^{\mathrm{a}}$ & $1.8 \pm 0.4$ & $2.1 \pm 0.6$ & 0.11 \\
\hline Grey transverse temporal ${ }^{a}$ & $1.6 \pm 0.2$ & $1.7 \pm 0.4$ & 0.23 \\
\hline Bankssts thickness ${ }^{\mathrm{b}^{*}}$ & $2.92 \pm 0.19$ & $2.97 \pm 0.24$ & 0.69 \\
\hline Entorhinal thickness $^{\mathrm{b}}$ & $3.35 \pm 0.37$ & $3.12 \pm 0.40$ & 0.04 \\
\hline Fusiform thickness ${ }^{\mathrm{b}}$ & $2.97 \pm 0.15$ & $2.96 \pm 0.15$ & 0.65 \\
\hline Inferior temporal thickness ${ }^{\mathrm{b}}$ & $3.01 \pm 0.25$ & $3.00 \pm 0.13$ & 0.44 \\
\hline Lingual thickness ${ }^{\mathrm{b}}$ & $2.26 \pm 0.14$ & $2.29 \pm 0.13$ & 0.87 \\
\hline Middle temporal thickness ${ }^{\mathrm{b}}$ & $3.24 \pm 0.21$ & $3.25 \pm 0.17$ & 0.58 \\
\hline Parahippocampal thickness ${ }^{\mathrm{b}}$ & $3.09 \pm 0.37$ & $3.10 \pm 0.28$ & 0.63 \\
\hline Superior temporal thickness ${ }^{\mathrm{b}}$ & $3.13 \pm 0.23$ & $3.07 \pm 0.20$ & 0.09 \\
\hline Temporal pole thickness ${ }^{\mathrm{b}}$ & $3.31 \pm 0.54$ & $3.51 \pm 0.64$ & 0.26 \\
\hline Transverse temporal thickness ${ }^{\mathrm{b}}$ & $2.83 \pm 0.21$ & $2.80 \pm 0.23$ & 0.79 \\
\hline Left hippocampus volume ${ }^{c}$ & $4.5 \pm 0.9$ & $4.4 \pm 0.5$ & 0.79 \\
\hline Left amygdala volume ${ }^{c}$ & $1.7 \pm 0.2$ & $1.7 \pm 0.2$ & 0.67 \\
\hline
\end{tabular}

a: Left temporal grey matter volumes in $\mathrm{cm}^{3}$ corrected for total grey matter volume, gender and age.

b: Left temporal cortex thicknesses in mm corrected for mean cortex thickness, gender and age.

c: Volumes in $\mathrm{cm}^{3}$ corrected for gender and age.

*: posterior banks of the superior temporal sulcus. 
Appendix 5. Influence of clinical epilepsy characteristics on left temporal lobe volume.

Left temporal lobe volume ${ }^{*}, \quad$-value Mean \pm SD $\left(\mathrm{cm}^{3}\right)$

\begin{tabular}{|c|c|c|}
\hline $\begin{array}{l}\text { Age at seizure onset } \\
\text { Young age } \\
\text { Old age }\end{array}$ & $\begin{array}{l}78 \pm 6 \\
82 \pm 8\end{array}$ & 0.09 \\
\hline $\begin{array}{l}\text { Epilepsy duration } \\
\text { Short epilepsy duration } \\
\text { Long epilepsy duration }\end{array}$ & $\begin{array}{l}82 \pm 7 \\
78 \pm 7\end{array}$ & 0.61 \\
\hline $\begin{array}{l}\text { Seizure type } \\
\text { Complex partial seizures only } \\
\text { Atypical absence seizures only } \\
\text { Atypical absences and other complex partial seizures } \\
\text { Secondary generalized tonic-clonic seizures }\end{array}$ & $\begin{array}{l}81 \pm 7 \\
81 \pm 9 \\
79 \pm 3 \\
78 \pm 5\end{array}$ & 0.43 \\
\hline $\begin{array}{l}\text { History of febrile seizures } \\
\text { Yes } \\
\text { No }\end{array}$ & $\begin{array}{l}80 \pm 8 \\
80 \pm 7\end{array}$ & 0.31 \\
\hline $\begin{array}{l}\text { History of status epilepticus } \\
\text { Yes } \\
\text { No }\end{array}$ & $\begin{array}{l}79 \pm 5 \\
80 \pm 7\end{array}$ & 0.93 \\
\hline $\begin{array}{l}\text { Seizure occurrence } \\
\text { Seizure free }[\mathrm{n}=4] \\
\text { Nocturnal seizures only }[\mathrm{n}=1] \\
\text { Diurnal seizure only }[\mathrm{n}=13] \\
\text { Nocturnal and diurnal seizures }[\mathrm{n}=16]\end{array}$ & $\begin{array}{l}80 \pm 5 \\
80 \\
82 \pm 7 \\
78 \pm 7\end{array}$ & 0.98 \\
\hline $\begin{array}{l}\text { Seizure focus } \\
\text { Left frontal } \\
\text { Right frontal } \\
\text { Bifrontal }\end{array}$ & $\begin{array}{l}81 \pm 5 \\
78 \pm 7 \\
80 \pm 8\end{array}$ & 0.98 \\
\hline $\begin{array}{l}\text { Seizure frequency } \\
\text { Low } \\
\text { High }\end{array}$ & $\begin{array}{l}78 \pm 7 \\
82 \pm 7\end{array}$ & 0.97 \\
\hline $\begin{array}{l}\text { Refractory } \\
\text { Yes } \\
\text { No }\end{array}$ & $\begin{array}{l}82 \pm 7 \\
76 \pm 6\end{array}$ & 0.86 \\
\hline $\begin{array}{l}\text { AED treatment } \\
\text { No medication }[n=1] \\
\text { Monotherapy }[n=21] \\
\text { Polytherapy }[n=12]\end{array}$ & $\begin{array}{l}79 \\
80 \pm 8 \\
80 \pm 7\end{array}$ & 0.42 \\
\hline $\begin{array}{l}\text { Drug load } \\
\text { Low } \\
\text { High }\end{array}$ & $\begin{array}{l}80 \pm 8 \\
80 \pm 4\end{array}$ & 0.27 \\
\hline
\end{tabular}

${ }^{*}$ Corrected for total intracranial volume, gender and age. 


\section{References}

1. Manford M, Hart YM, Sander JW, Shorvon SD. National General Practice Study of Epilepsy (NGPSE): partial seizure patterns in a general population. Neurology 1992;42:1911-1917.

2. Braakman HM, Vaessen MJ, Hofman PA, Debeij-van Hall MH, Backes WH, Vles JS, Aldenkamp AP. Cognitive and behavioral complications of frontal lobe epilepsy in children: a review of the literature. Epilepsia 2011;52:849-856.

3. Braakman HM, IJff DM, Vaessen MJ, Debeij-van Hall MH, Hofman PA, Backes WH, Vles JS, Aldenkamp AP. Cognitive and behavioural findings in children with frontal lobe epilepsy. Eur J Paediatr Neurol 2012;16:707-715.

4. Trenerry MR, Jack CR Jr, Ivnik RJ, Sharbrough FW, Cascino GD, Hirschorn KA, Marsh WR, Kelly PJ, Meyer FB. MRI hippocampal volumes and memory function before and after temporal lobectomy. Neurology 1993;43:1800-1805.

5. Kilpatrick C, Murrie V, Cook M, Andrewes D, Desmond P, Hopper J. Degree of left hippocampal atrophy correlates with severity of neuropsychological deficits. Seizure 1997;6:213-218.

6. Kälviäinen R, Salmenperä T, Partanen K, Vainio P, Riekkinen P, Pitkänen A. Recurrent seizures may cause hippocampal damage in temporal lobe epilepsy. Neurology 1998;50:1377-1382.

7. Baxendale SA, Van Paesschen W, Thompson PJ, Connelly A, Duncan JS, Harkness WF, Shorvon SD. The relationship between quantitative MRI and neuropsychological functioning in temporal lobe epilepsy. Epilepsia 1998;39:158-166.

8. Martin RC, Hugg JW, Roth DL, Bilir E, Gilliam FG, Faught E, Kuzniecky RI. MRI extrahippocampal volumes and visual memory: correlations independent of MRI hippocampal volumes in temporal lobe epilepsy patients. J Int Neuropsychol Soc 1999;5:540-548.

9. Seidenberg M, Hermann B, Pulsipher D, Morton J, Parrish J, Geary E, Guidotti L. Thalamic atrophy and cognition in unilateral temporal lobe epilepsy. J Int Neuropsychol Soc 2008;14:384-393.

10. Hernandez MT, Sauerwein HC, Jambaqué I, De Guise E, Lussier F, Lortie A, Dulac O, Lassonde M. Deficits in executive functions and motor coordination in children with frontal lobe epilepsy. Neuropsychologia 2002;40:384-400.

11. Provini F, Plazzi G, Tinuper P, Vandi S, Lugaresi E, Montagna P. Nocturnal frontal lobe epilepsy. A clinical and polygraphic overview of 100 consecutive cases. Brain 1999;122:1017-1031.

12. World Health Organization Collaborating Centre for Drug Statistics Methodology. About the ATC/ DDD system, 2008. Available on http://www.whocc.no/atcddd/.

13. Canevini MP, De Sarro G, Galimberti CA, Gatti G, Licchetta L, Malerba A, Muscas G, La Neve A. Relationship between adverse effects of antiepileptic drugs, number of coprescribed drugs, and drug load in a large cohort of consecutive patients with drug-refractory epilepsy. Epilepsia 2010;51:797804.

14. Wechsler D. Wechsler Intelligence Scale for Children (3rd ed.). NL. Handleiding en verantwoording. Harcourt, London, 2005

15. Alpherts WCJ, Aldenkamp AP. FePSY: 'The Iron Psyche'. Instituut voor epilepsiebestrijding, Heemstede, the Netherlands, 1995.

16. Kalverboer AF, Deelman BG. De 15-woorden tests A en B: (een voorlopige handleiding) (15WT/ VWT). Groningen: Academisch Ziekenhuis Groningen, afd. Neuropsychologie, 1986.

17. Meyers JE, Meyers KR. Rey Complex Figure Test and Recognition Trial: Professional manual. Odessa Florida: Psychological Assessment Resources, 1995.

18. Vos PG. Bourdon-Vos: Handleiding. Lisse: Swets \& Zeitlinger, 1988.

19. Beery KE, Buktenica NA, Beery NA. The Beery-Buktenica development test of visual-motor integration. (5th ed.) Minneapolis, MN: Pearson Assessments, 2003. 
20. Hammes JGW. De Stroop Kleur-Woord Test. Handleiding. Lisse: Swets \& Zeitlinger, 1971.

21. Vos T. Handleiding tempo-test-lezen (zinnen). Lisse: Swets \& Zeitlinger, 2000.

22. Vos T. Handleiding tempo-test-lezen (woorden). Lisse: Swets \& Zeitlinger, 2002.

23. Vos T. Handleiding tempo-test-rekenen. Harcourt Assessment bv, Amsterdam, 2004.

24. Ghosh SS, Kakunoori S, Augustinack J, Nieto-Castanon A, Kovelman I, Gaab N, Christodoulou JA, Triantafyllou C, Gabrieli JD, Fischl B. Evaluating the validity of volume-based and surface-based brain image registration for developmental cognitive neuroscience studies in children 4 to 11 years of age. Neuroimage 2010;53:85-93.

25. Du F, Whetsell WO Jr, Abou-Khalil B, Blumenkopf B, Lothman EW, Schwarcz R. Preferential neuronal loss in layer III of the entorhinal cortex in patients with temporal lobe epilepsy. Epilepsy Res 1993;16:223-233.

26. Sim K, DeWitt I, Ditman T, Zalesak M, Greenhouse I, Goff D, Weiss AP, Heckers S. Hippocampal and parahippocampal volumes in schizophrenia: a structural MRI study. Schizophr Bull 2006;32:332340 .

27. Trivedi MA, Stoub TR, Murphy CM, George S, deToledo-Morerrell L, Shah RC, Whitfield-Gabrieli S, Gabrieli JD, Stebbins GT. Entorhinal cortex volume is associated with episodic memory related brain activation in normal aging and amnestic mild cognitive impairment. Brain Imaging Behav 2011;5:126-136.

28. Salmenperä T, Kälviäinen R, Partanen K, Pitkänen A. Quantitative MRI volume of the entorhinal cortex in temporal lobe epilepsy. Seizure 2000;9:208-215.

29. Bernasconi N, Natsume J, Bernasconi A. Progression in temporal lobe epilepsy: differential atrophy in mesial temporal structures. Neurology 2005;65:223-228.

30. Stoub TR, Rogalski EJ, Leurgans S, Bennett DA, deToledo-Morrell L. Rate of entorhinal and hippocampal atrophy in incipient and mild AD: relation to memory function. Neurobiol Aging 2010;31:1089-1098.

31. Schultz CC, Koch K, Wagner G, Roebel M, Schachtzabel C, Nenadic I, Albrecht C, Reichenbach JR, Sauer H, Schlösser RG. Psychopathological correlates of the entorhinal cortical shape in schizophrenia. Eur Arch of Psychiatry Clin Neurosci 2010;260:351-358.

32. Gärtner B, Seeck M, Michel CM, Delavelle J, Lazeyras F. Patients with extratemporal lobe epilepsy do not differ from healthy subjects with respect to subcortical volumes. J Neurol Neurosurg Psychiatry 2004;75:588-592.

33. Widjaja E, Mahmoodabadi SZ, Snead OC 3rd, Almehdar A, Smith ML. Widespread cortical thinning in children with frontal lobe epilepsy. Epilepsia 2011;52:1685-1691.

34. McDonald CR, Ahmadi ME, Hagler DJ, Tecoma ES, Iragui VJ, Gharapetian L, Dale AM, Halgren E. Diffusion tensor imaging correlates of memory and language impairments in temporal lobe epilepsy. Neurology 2008;71:1869-1876.

35. Hermann B, Jones J, Sheth R, Dow C, Koehn M, Seidenberg M. Children with new-onset epilepsy: neuropsychological status and brain structure. Brain 2006;129:2609-2619.

36. Hermann B, Seidenberg M, Bell B, Rutecki P, Sheth R, Ruggles K, Wendt G, O'Leary D, Magnotta V. The neurodevelopmental impact of childhood-onset temporal lobe epilepsy on brain structure and function. Epilepsia 2002;43:1062-1071.

37. Hermann BP, Seidenberg M, Dow C, Jones J, Rutecki P, Bhattacharya A, Bell B. Cognitive prognosis in chronic temporal lobe epilepsy. Ann Neurol 2006;60:80-87.

38. Hermann BP, Dabbs K, Becker T, Jones JE, Myers y Gutierrez A, Wendt G, Koehn MA, Sheth R, Seidenberg M. Brain development in children with new onset epilepsy: a prospective controlled cohort investigation. Epilepsia 2010;51:2038-2046. 


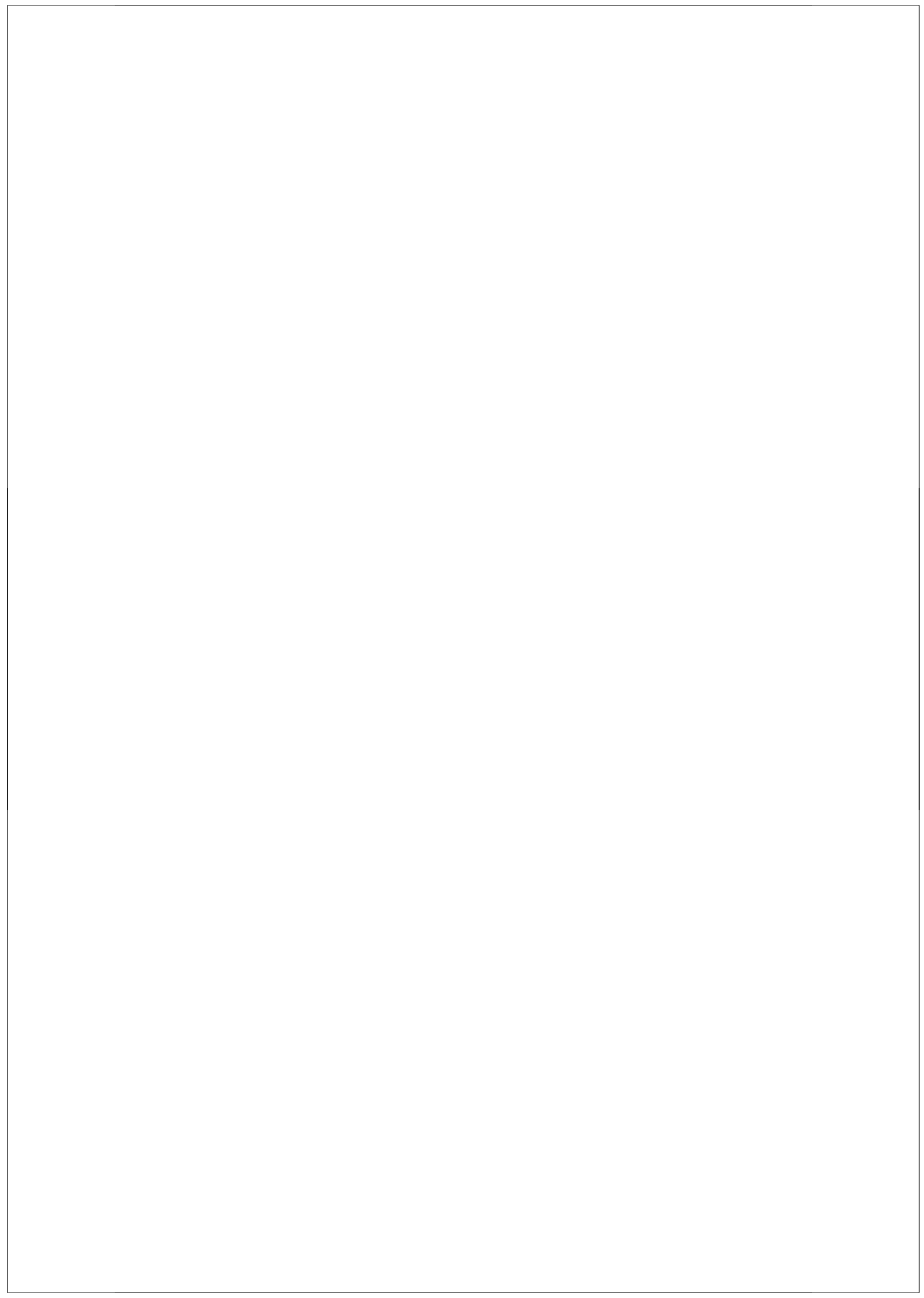




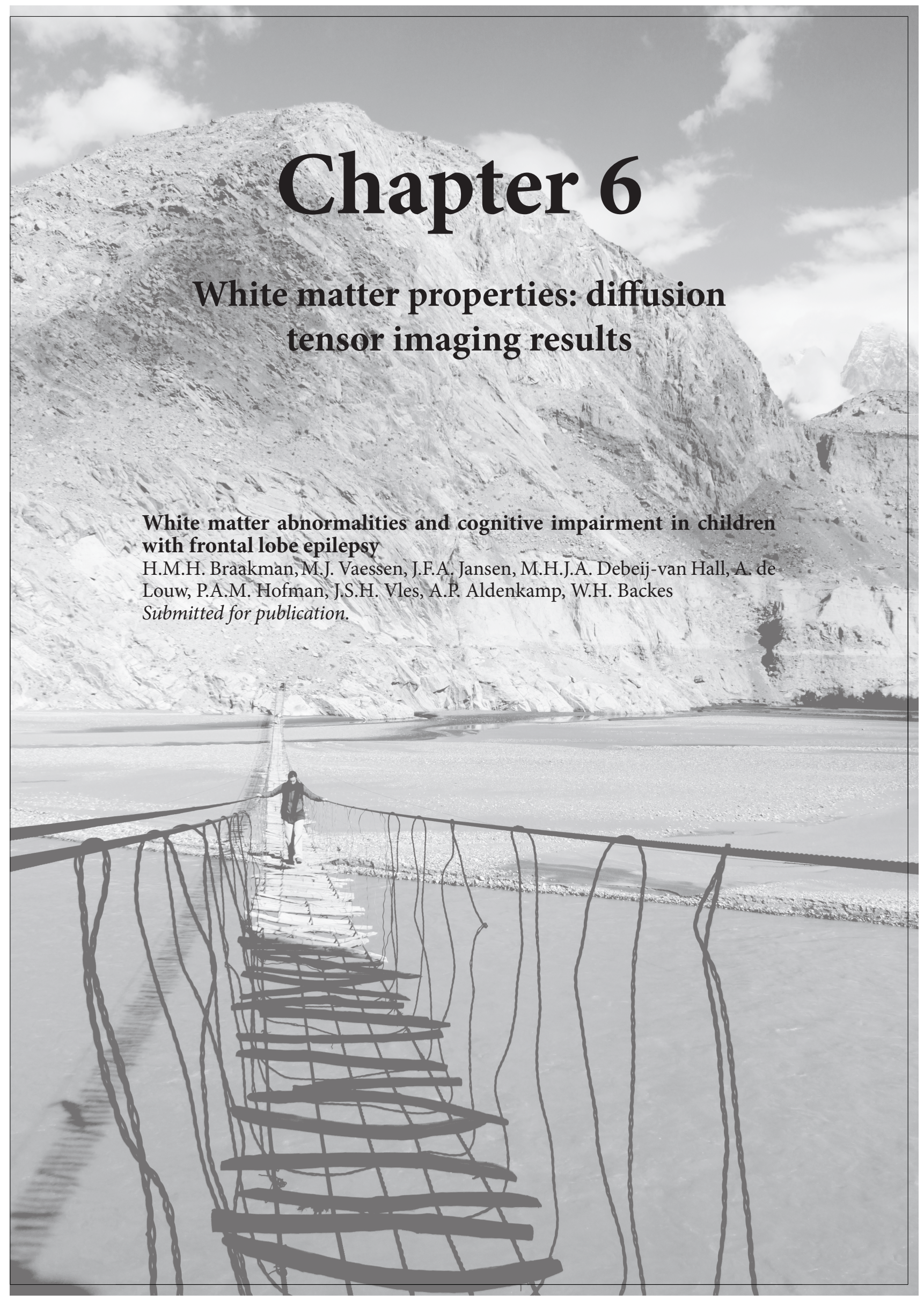




\section{Abstract}

Objectives: Cognitive impairment is frequent in children with frontal lobe epilepsy (FLE). Its etiology remains unknown. With diffusion tensor imaging, we have studied cerebral white matter properties and associations with cognitive functioning in children with FLE and healthy controls.

Methods: Thirty children aged 8 to 13 years with FLE of unknown cause and 39 healthy age-matched controls underwent neuropsychological assessment, structural and diffusion weighted brain MRI. Patients were grouped as cognitively impaired or unimpaired and their white matter diffusion properties were compared to the controls.

Results: Children with FLE had reduced apparent diffusion coefficients in various posteriorly located tract bundles, a reduced fractional anisotropy (FA) of the white matter tract between the right frontal and right occipital lobe, and smaller volumes of several collections of interlobar bundle tracts, compared to controls. The cognitively impaired patient group demonstrated significant increases in FA of the white matter of both occipital lobes, a reduced FA of white matter tract bundles between the right frontal and left occipital lobe and smaller volumes of two collection of tract bundles connecting the frontal lobe with the temporal and parietal lobes, compared to controls; these differences were not significant for the patient group as a whole.

Conclusions: Children with FLE had white matter abnormalities mainly in posterior brain regions, not confined to the area of the seizure focus. Cognitively impaired children with FLE showed the most pronounced white matter abnormalities. These possibly reflect disturbed maturation and might be part of the etiology of the cognitive impairment. 


\section{White matter properties: diffusion tensor imaging results}

\section{Introduction}

Frontal lobe epilepsy (FLE) in childhood is frequently complicated by cognitive impairment. These cognitive impairments often cover a broad range of cognitive domains, and frequently result in a need for special education. ${ }^{1,2}$ The etiology of cognitive impairment in children with FLE is unknown and correlations with clinical epilepsy characteristics remain inconclusive. ${ }^{1,2}$ Our previous functional and morphological MRI studies in children with FLE of unknown cause revealed disturbances extending beyond the frontal lobe. These disturbances were most pronounced in children with FLE with cognitive impairment, compatible with the broad range of cognitive impairments seen in this patient group. ${ }^{1,3}$

With diffusion tensor imaging (DTI) abnormalities of the microstructure of cerebral white matter can be assessed through the measurement of water diffusion. The two main parameters that can be determined by DTI are fractional anisotropy (FA) and diffusivity or apparent diffusion co-efficient (ADC). FA is a measure of anisotropy, the tendency of water to diffuse in one direction as opposed to randomly in any direction. ADC is a measurement of the water diffusion (i.e. motility) without reference to a preferred direction. Motion of the fluid in the white matter of the brain is normally restricted to movement along the same direction as the axon or myelin sheath. When there is damage to the neurons or myelin sheaths, FA decreases and ADC increases because the fluid can move freely in any direction. ${ }^{4,5}$ With diffusion tractography, the three-dimensional location of specific white matter tracts can be assessed, which provides the opportunity to study specific connections. ${ }^{6}$ In the current study, we have used DTI to investigate correlations between FLE, cognitive impairment and microstructural brain organization in a cohort of children with FLE and healthy age-matched controls.

\section{Methods}

\section{Participants}

We performed this cohort study at the Epilepsy Centre Kempenhaeghe, Heeze, The Netherlands. The Medical Ethical Committees of Kempenhaeghe and the 
Maastricht University Medical Centre approved this study, which is registered by the Dutch Trial Register (NTR1749).

Inclusion criteria for the patients were: confirmed FLE of unknown cause, age between eight and 13 years (children above the age of eight years were considered capable to undergo MRI scanning without sedation), no other disease that could cause cognitive decline, and no history of brain injury. All patients had a normal structural brain MRI (epilepsy protocol) prior to inclusion, reconfirmed by a board certified neuroradiologist. The diagnosis FLE was made when patients had one or more clinical seizures associated with frontal focal epileptic EEG discharges. When no EEG is available during a clinical seizure, the video-recording of more than one seizure with clinical evidence of a frontal lobe origin is required to confirm the diagnosis. ${ }^{7}$ We excluded patients with frontal lobe seizures resulting from spread to the frontal lobes or with interictal epileptiform EEG abnormalities outside the frontal lobes.

Healthy age-matched controls were recruited by advertisements in local newspapers. All controls followed regular education. Exclusion criteria were: history of head trauma or other diseases that may cause cognitive impairment.

Exclusion criteria for both groups were: contra-indications for MRI such as metal implants or (one of the) parents unwilling to provide informed consent.

We collected the following data for all subjects: gender, age, education level, medical history, family history, and dominant handedness.

For the FLE patients, the following clinical epilepsy characteristics were collected via chart review: age at onset, seizure duration, seizure type, seizure frequency, seizure occurrence, history of febrile seizures, history of status epilepticus, anti-epileptic drug treatment, drug load, response to anti-epileptic drug (AED) treatment, and localization of epileptic discharges on EEG (left frontal, right frontal, or bifrontal). We computed drug load as previously described. ${ }^{8}$ In children using two or more AEDs, cumulative drug loads were calculated.

\section{Neuropsychological testing}

We performed a neuropsychological assessment of all patients prior to inclusion (see Appendix 1 for neuropsychological test details). If neuropsychological assessment had been performed within one year prior to inclusion, and the assessment involved all necessary tests for this study then those test results were used. If neuropsychological assessment had been performed more than one year earlier, we repeated part of the neuropsychological assessment (see Appendix 1). 
The healthy control group underwent identical neuropsychological assessment.

For each participant, we evaluated test performance on three different cognitive domains: global cognitive functioning, high-order cognitive functioning and fluid cognitive functioning. ${ }^{3}$ (Global cognitive functioning reflects a traitdependent ability. This ability shows only minor fluctuations over time (e.g. intelligence). Higher-order cognitive functioning consists of central functions modulating and controlling more routine or fundamental skills (e.g. memory and verbal comprehension). Fluid cognitive functioning consists of fluctuating or state-dependent functions (e.g. attention or psychomotor speed))

Individual cognitive functioning was transformed into an impairment index which reflects performance in the three above mentioned cognitive domains, on a scale of 1 (severe impairment) to 8 (no impairment); see Appendix 2 for details.

Participants were grouped as cognitively impaired (i.e. an impairment index of $\leq 4$; which means that at least global cognitive functioning is impaired) or cognitively unimpaired (impairment index $>4$ ).

\section{MRI procedure}

\section{Image acquisition}

MR imaging was performed on a 3.0-Tesla unit equipped with an 8-channel head coil (Philips Achieva, Philips Medical Systems, Best, The Netherlands). For anatomic reference, a T1-weigthed 3D turbo field echo (TFE) was acquired with the following parameters: repetition time (TR) $8.1 \mathrm{msec}$, inversion time (TI) $1022 \mathrm{msec}$, echo time (TE) $3.7 \mathrm{msec}$, flip angle 8 degrees, field of view (FOV) $256 \times 256 \times 180 \mathrm{~mm}^{3}$, and voxel size $1 \times 1 \times 1 \mathrm{~mm}^{3}$.

\section{DWI acquisition}

Diffusion Weighted Imaging (DWI) was performed with a pixel size of $2 \mathrm{x}$ $2 \mathrm{~mm}^{2}$, slice thickness $2 \mathrm{~mm}$, and a b-value of $1200 \mathrm{~s} / \mathrm{mm}^{2}$. An echo planar imaging sequence was used with TE $72 \mathrm{msec}$, TR $6584 \mathrm{msec}$, and parallel imaging acceleration factor of 2. A set of 61 gradient directions was used, optimized via electrostatic repulsion to ensure homogenous distribution over the sphere. ${ }^{9}$ In addition, a single non-diffusion weighted scan (b0-scan) was obtained. The DWI acquisition time was 8 minutes.

\section{Image preprocessing}

Freesurfer (Martinos Centre of Biomedical Imaging, Boston, US) software was used to segment the T1 images of each subject into cortical and subcortical regions using a surface based alignment procedure. ${ }^{10}$ The cortical regions were 
grouped by lobe and merged to represent a lobe separately for the left and right hemisphere. This resulted in 8 cortical regions of interest (ROIs) representing the lobes of the left and right hemispheres.

The cortical and subcortical parcellation of each individual in native T1 space was transformed to the native DWI or fMRI space by applying a rigid body transformation.

Each data set was spatially co-registered to the $b=0$ image with an affine transformation to correct for head motion and eddy-current distortions utilizing CATNAP (Co-registration, Adjustment, and Tensor-solving, a Nicely Automated Program, version 1.3) software. ${ }^{11}$ The set of gradient vectors was adjusted according to the rotation of the individual images.

All DWI analyses, the tractography and tract segmentations were performed using the MRtrix software package. ${ }^{12}$ Diffusion tensor fits were performed to calculate FA and ADC maps. In addition, fiber orientation distributions, representing local fiber orientation, were estimated using constrained spherical deconvolution (CSD). In CSD, the diffusion profile is converted to the underlying fiber orientations by a constrained deconvolution method. ${ }^{12}$ The CSD response function was estimated from data with high FA voxels values $(\mathrm{FA}>0.7)$.

Within the white matter, five million evenly distributed seeds were placed and a streamline was started from each seed.

For each participant, we divided total cerebral white matter into 10 bilateral ROIs: frontal, temporal, parietal, occipital lobe and subcortical white matter. The division was based on the fiber tracts connecting regions within one ROI. We calculated mean FA and ADC of the white matter of these 10 brain ROIs. Subsequently, mean FA, ADC and volumes of the inter-regional white matter tract bundles (90 bundle tracts) were calculated.

\section{Statistical analysis}

Statistical data analysis was performed using the SPSS 16.0 software package (SPSS Inc., Chicago, IL). Demographical and clinical characteristics were assessed using descriptive statistics. Values were expressed as mean value \pm standard deviation.

Differences in mean FA and ADC of the brain ROIs and of the tract bundles between these different brain ROIs as well as differences in tract bundle volumes between the patient and control group, the cognitively impaired patient and control group, and the cognitively impaired and unimpaired patient group were assessed using analysis of variance (ANOVAs).

Because of substantial brain maturation processes in this age category, ${ }^{13}$ all results were corrected for gender and age, with group and gender as fixed 
Table 1. Demographic and clinical characteristics of the (A) control group and (B) epilepsy groups.

\begin{tabular}{|c|c|}
\hline Characteristic & Number of subjects (\%) \\
\hline \multicolumn{2}{|l|}{ A } \\
\hline Gender (male : female) & $19: 20$ \\
\hline $\begin{array}{l}\text { Age } \\
\text { Mean age }( \pm S D) \text { at assessment }\end{array}$ & $10.5 \pm 1.4$ years \\
\hline $\begin{array}{l}\text { Cognition } \\
\text { Impaired (impairment index } \leq 4 \text { ) } \\
\text { Unimpaired }\end{array}$ & $\begin{array}{l}3(8 \%) \\
36(92 \%)\end{array}$ \\
\hline \multicolumn{2}{|l|}{ B } \\
\hline Gender (male :female) & $17: 13$ \\
\hline $\begin{array}{l}\text { Age } \\
\text { Mean age }( \pm \text { SD }) \text { at assessment } \\
\text { Mean age }( \pm \text { SD) at seizure onset }\end{array}$ & $\begin{array}{l}11.2 \pm 1.5 \text { years } \\
4.6 \pm 2.7 \text { years }\end{array}$ \\
\hline $\begin{array}{l}\text { Duration of epilepsy } \\
\text { Mean duration }( \pm S D) \text { of epilepsy }\end{array}$ & $6.3 \pm 2.8$ years \\
\hline $\begin{array}{l}\text { Seizure type } \\
\text { Complex partial seizures only } \\
\text { Atypical absence seizures only } \\
\text { Atypical absences and other complex partial seizures } \\
\text { Secondary generalized tonic-clonic seizures }\end{array}$ & $\begin{array}{l}5(17) \\
14(46) \\
8(27) \\
3(10)\end{array}$ \\
\hline $\begin{array}{l}\text { History } \\
\text { Febrile seizures } \\
\text { Status epilepticus }\end{array}$ & $\begin{array}{l}8(27) \\
2(7)\end{array}$ \\
\hline $\begin{array}{l}\text { Seizure occurrence } \\
\text { Seizure free } \\
\text { Nocturnal seizures only } \\
\text { Diurnal seizures only } \\
\text { Both nocturnal and diurnal seizures }\end{array}$ & $\begin{array}{l}4(13) \\
1(3) \\
11(37) \\
14(47)\end{array}$ \\
\hline $\begin{array}{l}\text { Seizure frequency (in the past year) } \\
\text { Low seizure frequency }(\leq 1 \text { seizure/week }) \\
\text { High seizure frequency (>1 seizure/week) } \\
\text { Refractory } \\
\text { Not-refractory }\end{array}$ & $\begin{array}{l}13(43) \\
17(57) \\
20(67) \\
10(33)\end{array}$ \\
\hline $\begin{array}{l}\text { Seizure focus based on history and EEG } \\
\text { Focus left frontal } \\
\text { Focus right frontal } \\
\text { Focus bifrontal }\end{array}$ & $\begin{array}{l}8(27) \\
6(20) \\
16(53)\end{array}$ \\
\hline $\begin{array}{l}\text { AED treatment } \\
\text { No AED } \\
\text { Monotherapy } \\
\text { Polytherapy }\end{array}$ & $\begin{array}{l}1(3) \\
18(60) \\
11(37)\end{array}$ \\
\hline $\begin{array}{l}\text { Drug load } \\
\text { Low }<1.0 \\
\text { High } \geq 1.0\end{array}$ & $\begin{array}{l}24(80) \\
6(20)\end{array}$ \\
\hline $\begin{array}{l}\text { Cognition } \\
\text { Impaired (impairment index } \leq 4 \text { ) } \\
\text { Unimpaired }\end{array}$ & $\begin{array}{l}14(47 \%) \\
16(53 \%)\end{array}$ \\
\hline $\begin{array}{l}\text { Education } \\
\text { Regular } \\
\text { Special }\end{array}$ & $\begin{array}{l}19(63 \%) \\
11(37 \%)\end{array}$ \\
\hline
\end{tabular}

EEG: electroencephalogram; AED: antiepileptic drug.

factors and age as covariate. For all results, the statistical significance level was set to $\mathrm{p}<0.05$. 
Table 2. (A) Mean FA values of the individual brain lobes' white matter corrected for gender and age. (B) Mean ADC values of the individual brain lobes' white matter corrected for gender and age $\left(10^{-3} \mathrm{~mm}^{2} / \mathrm{s}\right)$.

\begin{tabular}{|c|c|c|c|c|c|c|}
\hline A & $\begin{array}{c}\text { Cognitively } \\
\text { impaired } \\
\text { patients } \\
(\text { mean } \pm \text { SD) }\end{array}$ & $\begin{array}{c}\text { Cognitively } \\
\text { unimpaired } \\
\text { patients } \\
(\text { mean } \pm S D)\end{array}$ & $\begin{array}{c}\text { Controls } \\
(\text { mean } \pm S D)\end{array}$ & $\begin{array}{l}\text { p-value } \\
\text { patients } \\
\text { versus } \\
\text { controls }\end{array}$ & $\begin{array}{c}\text { p-value } \\
\text { cognitively } \\
\text { impaired } \\
\text { patients } \\
\text { versus } \\
\text { controls }\end{array}$ & $\begin{array}{c}\text { p-value } \\
\text { cognitively } \\
\text { impaired } \\
\text { versus } \\
\text { cognitively } \\
\text { unimpaired } \\
\text { patients }\end{array}$ \\
\hline $\begin{array}{l}\text { Left frontal } \\
\text { lobe }\end{array}$ & $0.324 \pm 0.019$ & $0.321 \pm 0.016$ & $0.325 \pm 0.010$ & 0.27 & 0.58 & 0.84 \\
\hline $\begin{array}{l}\text { Right frontal } \\
\text { lobe }\end{array}$ & $0.318 \pm 0.014$ & $0.316 \pm 0.013$ & $0.319 \pm 0.011$ & 0.18 & 0.42 & 0.81 \\
\hline $\begin{array}{l}\text { Left temporal } \\
\text { lobe }\end{array}$ & $0.285 \pm 0.024$ & $0.283 \pm 0.016$ & $0.282 \pm 0.011$ & 0.92 & 0.48 & 0.99 \\
\hline $\begin{array}{l}\text { Right temporal } \\
\text { lobe }\end{array}$ & $0.279 \pm 0.026$ & $0.278 \pm 0.012$ & $0.273 \pm 0.011$ & 0.27 & 0.34 & 0.85 \\
\hline $\begin{array}{l}\text { Left parietal } \\
\text { lobe }\end{array}$ & $0.320 \pm 0.023$ & $0.320 \pm 0.018$ & $0.315 \pm 0.015$ & 0.51 & 0.55 & 0.77 \\
\hline $\begin{array}{l}\text { Right parietal } \\
\text { lobe }\end{array}$ & $0.316 \pm 0.019$ & $0.309 \pm 0.016$ & $0.309 \pm 0.014$ & 0.62 & 0.27 & 0.49 \\
\hline $\begin{array}{l}\text { Left occipital } \\
\text { lobe }\end{array}$ & $0.218 \pm 0.036$ & $0.208 \pm 0.026$ & $0.199 \pm 0.016$ & 0.06 & 0.00 & 0.48 \\
\hline $\begin{array}{l}\text { Right occipital } \\
\text { lobe }\end{array}$ & $0.216 \pm 0.023$ & $0.206 \pm 0.021$ & $0.202 \pm 0.015$ & 0.20 & 0.02 & 0.32 \\
\hline $\begin{array}{l}\text { Left } \\
\text { subcortical }\end{array}$ & $0.272 \pm 0.016$ & $0.273 \pm 0.014$ & $0.272 \pm 0.012$ & 0.92 & 0.97 & 0.40 \\
\hline $\begin{array}{l}\text { Right } \\
\text { subcortical }\end{array}$ & $0.264 \pm 0.018$ & $0.264 \pm 0.015$ & $0.261 \pm 0.011$ & 0.68 & 0.51 & 0.64 \\
\hline $\mathbf{B}$ & $\begin{array}{c}\text { Cognitively } \\
\text { impaired } \\
\text { patients } \\
(\text { mean } \pm \text { SD) }\end{array}$ & $\begin{array}{c}\text { Cognitively } \\
\text { unimpaired } \\
\text { patients } \\
(\text { mean } \pm S D)\end{array}$ & $\begin{array}{c}\text { Controls } \\
(\text { mean } \pm S D)\end{array}$ & $\begin{array}{l}\text { p-value } \\
\text { patients } \\
\text { versus } \\
\text { controls }\end{array}$ & $\begin{array}{c}\text { p-value } \\
\text { cognitively } \\
\text { impaired } \\
\text { patients } \\
\text { versus } \\
\text { controls }\end{array}$ & $\begin{array}{l}\text { p-value } \\
\text { cognitively } \\
\text { impaired } \\
\text { versus } \\
\text { cognitively } \\
\text { unimpaired } \\
\text { patients }\end{array}$ \\
\hline $\begin{array}{l}\text { Left frontal } \\
\text { lobe }\end{array}$ & $0.761 \pm 0.033$ & $0.759 \pm 0.033$ & $0.757 \pm 0.017$ & 0.27 & 0.12 & 0.31 \\
\hline $\begin{array}{l}\text { Right frontal } \\
\text { lobe }\end{array}$ & $0.779 \pm 0.034$ & $0.781 \pm 0.028$ & $0.775 \pm 0.019$ & 0.14 & 0.09 & 0.39 \\
\hline $\begin{array}{l}\text { Left temporal } \\
\text { lobe }\end{array}$ & $0.801 \pm 0.033$ & $0.794 \pm 0.028$ & $0.805 \pm 0.017$ & 0.48 & 0.71 & 0.10 \\
\hline $\begin{array}{l}\text { Right temporal } \\
\text { lobe }\end{array}$ & $0.816 \pm 0.037$ & $0.811 \pm 0.028$ & $0.820 \pm 0.020$ & 0.78 & 0.54 & 0.23 \\
\hline $\begin{array}{l}\text { Left parietal } \\
\text { lobe }\end{array}$ & $0.763 \pm 0.034$ & $0.754 \pm 0.037$ & $0.763 \pm 0.022$ & 0.81 & 0.44 & 0.08 \\
\hline $\begin{array}{l}\text { Right parietal } \\
\text { lobe }\end{array}$ & $0.776 \pm 0.035$ & $0.772 \pm 0.034$ & $0.776 \pm 0.021$ & 0.74 & 0.40 & 0.22 \\
\hline $\begin{array}{l}\text { Left occipital } \\
\text { lobe }\end{array}$ & $0.694 \pm 0.030$ & $0.693 \pm 0.025$ & $0.702 \pm 0.016$ & 0.37 & 0.48 & 0.33 \\
\hline $\begin{array}{l}\text { Right occipital } \\
\text { lobe }\end{array}$ & $0.690 \pm 0.029$ & $0.679 \pm 0.031$ & $0.691 \pm 0.018$ & 0.72 & 0.40 & 0.06 \\
\hline $\begin{array}{l}\text { Left } \\
\text { subcortical }\end{array}$ & $0.791 \pm 0.021$ & $0.783 \pm 0.027$ & $0.784 \pm 0.020$ & 0.52 & 0.14 & 0.23 \\
\hline $\begin{array}{l}\text { Right } \\
\text { subcortical }\end{array}$ & $0.836 \pm 0.025$ & $0.843 \pm 0.029$ & $0.838 \pm 0.023$ & 0.59 & 0.71 & 0.85 \\
\hline
\end{tabular}


Finally, the influence of clinical epilepsy characteristics was investigated. For statistical analysis, we categorized patients into short ( $\leq 5$ years) versus long ( $>$ 5 years) seizure duration, young ( $\leq 5$ years) versus old ( $>5$ years) age at seizure onset, low ( $\leq 1$ seizure per week) versus high ( $>1$ seizure per week) seizure frequency, low $(\leq 1.0)$ versus high $(>1.0)$ drug load, and left versus right versus bifrontal focus, based on seizure semiology and EEG.

\section{Results}

\section{Inclusion}

We enrolled 37 patients and 42 controls. Seven patients and three controls were excluded because of excessive head movements during the scanning $(\mathrm{n}=7)$ or claustrophobia $(n=3)$. Eventually, 30 patients and 39 controls were included. Their demographic and clinical characteristics are recorded in Table 1.

\section{Cognitive performance}

We identified cognitive impairment in 14 children with FLE (47\%). Neuropsychological test results are recorded in Appendix 3. Demographic and clinical characteristics did not differ between the cognitively unimpaired and impaired patient groups (data not shown).

\section{DTI}

\section{Regional FA}

FA values of the individual white matter ROIs are listed in Table $2 \mathrm{~A}$.

The cognitively impaired patient group demonstrated significantly higher FA values of the left and right occipital lobe white matter than the control group $(\mathrm{p}=0.004$ and $\mathrm{p}=0.022)$.

\section{Regional ADC}

$\mathrm{ADC}$ values of the individual white matter ROIs are listed in Table 2B.

ADC values did not significantly differ between patients and controls, cognitively impaired patients and controls, or between cognitively impaired and unimpaired patients.

\section{Tract FA}

In the total patient group, the FA of the white matter tract bundles between the right frontal and right occipital lobe was significantly lower than in the control group $(0.414 \pm 0.016$ versus $0.420 \pm 0.015 ; \mathrm{p}=0.04)$ (see Figure 1A).

In the cognitively impaired patient group, the FA of the white matter tract 


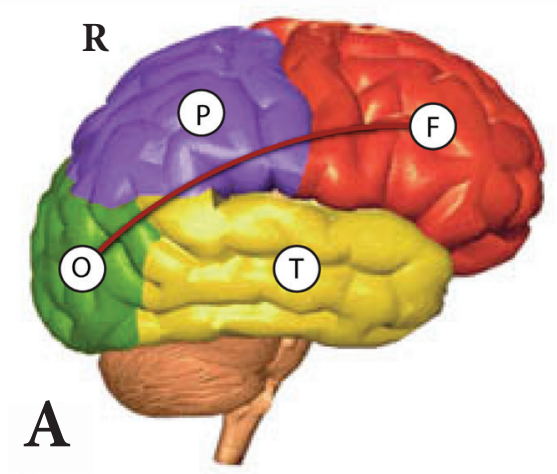

Figure 1. Significantly lower FA (A) and $\mathrm{ADC}$ (B) of the white matter tract bundles in the patient than in the control group. Significantly smaller (in red) and larger (in green) volumes of collections of white matter tract bundles in the patient than in the healthy control group (C). $\mathrm{L}=$ left; $\mathrm{R}=$ right; $\mathrm{F}=$ frontal lobe; $\mathrm{T}=$ temporal lobe; $\mathrm{P}=$ parietal lobe; $\mathrm{O}=$ occipital lobe; $\mathrm{S}=$ subcortical.
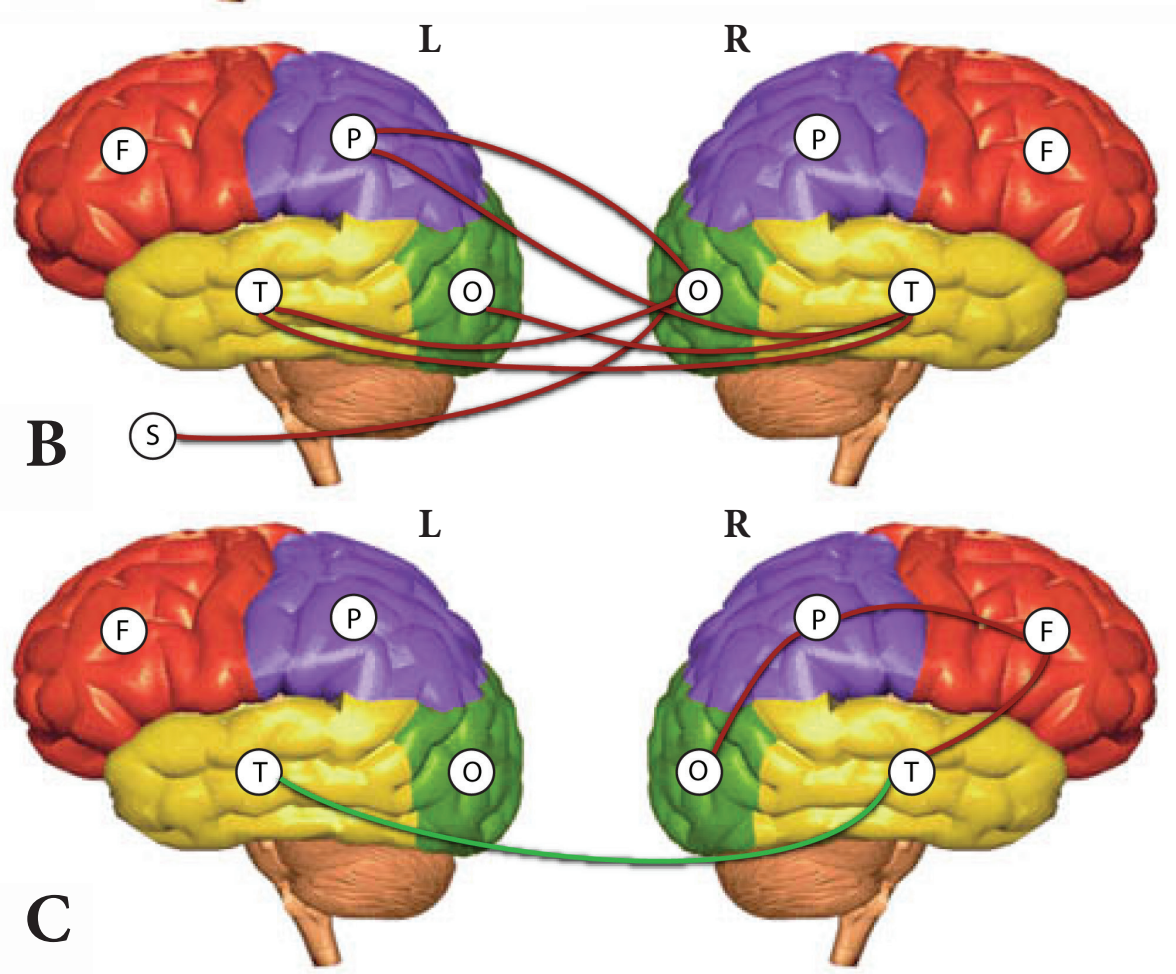

bundles between the right frontal and left occipital lobe was significantly lower than in the control group $(0.422 \pm 0.029$ versus $0.438 \pm 0.025 ; \mathrm{p}=0.02)$.

\section{Tract ADC}

The total patient group showed significantly lower ADC values of six white matter tract bundles compared to the control group (see Figure $1 \mathrm{~B}$ and the connectivity matrix in Figure 2A).

The cognitively impaired patient group showed no statistically significant 

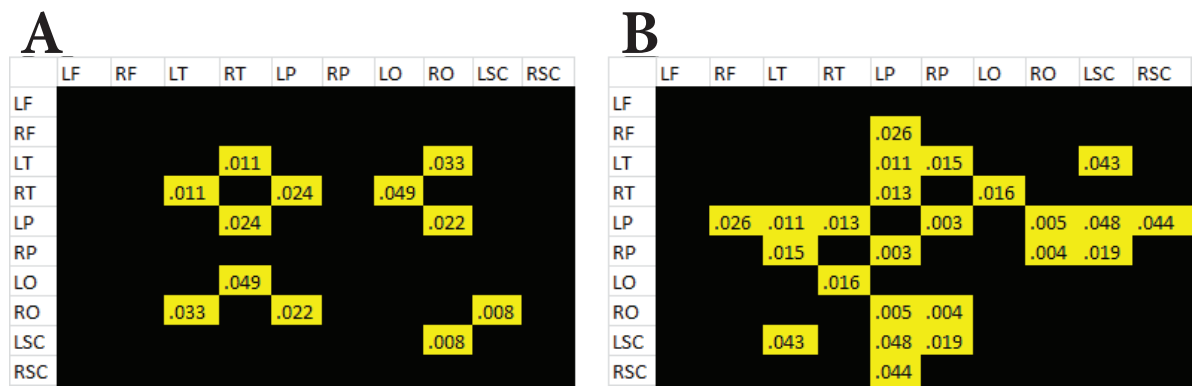

Figure 2. Connectivity matrix showing the statistically significant reduced mean ADC values of the white matter tract bundles of the patient group versus the control group (A) and the cognitively unimpaired patient group versus the cognitively impaired patient group (B), and their corresponding p-value (in yellow).

LF: left frontal; RF: right frontal; LT: left temporal; RT: right temporal; LP: left parietal; RP: right parietal; LO: left occipital; RO: right occipital; LSC: left subcortical; RSC: right subcortical.

differences in ADC values compared to the control group (results not shown). The cognitively unimpaired patient group showed significantly lower ADC values of 12 white matter tract bundles compared to the cognitively impaired patient group (see the connectivity matrix in Figure 2B).

\section{Tract volumes}

Three tract bundle collections had a significantly smaller volume in the patient than in the healthy control group, i.e. the bundles between the right frontal and right temporal lobe ( $105 \pm 19 \mathrm{~cm}^{3}$ vs. $\left.114 \pm 15 \mathrm{~cm}^{3} ; \mathrm{p}=0.01\right)$; right frontal and right parietal lobe (154 $\pm 27 \mathrm{~cm}^{3}$ vs. $\left.164 \pm 14 \mathrm{~cm}^{3} ; \mathrm{p}=0.02\right)$; and right parietal and right occipital lobe $\left(29 \pm 9 \mathrm{~cm}^{3}\right.$ vs. $\left.34 \pm 7 \mathrm{~cm}^{3} ; \mathrm{p}=0.01\right)$. The volume of the collection of tract bundles connecting the left temporal and right temporal lobe was significantly larger in the patient than in the control group (24 \pm 11 $\mathrm{cm}^{3}$ vs. $19 \pm 8 \mathrm{~cm}^{3} ; \mathrm{p}=0.02$ ) (see Figure $1 \mathrm{C}$ ).

The volume of the collection of tract bundles connecting the left frontal and left temporal lobe was significantly smaller in the cognitively impaired patient group than in the healthy control group $\left(120 \pm 20 \mathrm{~cm}^{3}\right.$ vs. $127 \pm 13 \mathrm{~cm}^{3} ; \mathrm{p}=$ 0.04 ) as well as the volume connecting the right frontal and right parietal lobe $\left(151 \pm 28 \mathrm{~cm}^{3}\right.$ vs. $\left.164 \pm 14 \mathrm{~cm}^{3} ; \mathrm{p}=0.01\right)$. The volume of the collection of tract bundles connecting the left temporal and right temporal lobe was larger in the cognitively impaired patient group than in the healthy control group (24 \pm 9 $\mathrm{cm}^{3}$ vs. $\left.19 \pm 8 \mathrm{~cm}^{3} ; \mathrm{p}=0.05\right)$.

Only one volume of the collection of tract bundles was smaller in the cognitively impaired than in the cognitively unimpaired patient group, i.e. the bundles 
connecting the left frontal and right occipital lobe $\left(2 \pm 1 \mathrm{~cm}^{3}\right.$ versus $3 \pm 3 \mathrm{~cm}^{3}$; $\mathrm{p}=0.049$ ).

\section{Associations with clinical epilepsy characteristics}

In the patient group, the lower FA of the right frontal to left occipital tract bundle and the lower ADC of the various tract bundles were not associated with any of the clinical epilepsy characteristics (i.e., age at epilepsy onset, epilepsy duration, history of febrile seizures or status epilepticus, seizure type, seizure occurrence, side of seizure focus, seizure frequency, anti-epileptic drug treatment, response to anti-epileptic drug treatment or drug load). Older age at seizure onset (i.e. $>5$ years) was associated with a larger volume of the collection of tract bundles between the left and right temporal lobe $(\mathrm{p}=0.02)$. No other clinical epilepsy characteristics were associated with the smaller or larger collection of tract bundle volumes in the patient group.

\section{Discussion}

\section{Major observations}

We found abnormalities of the white matter in children with FLE relative to a healthy control group. These differences were not restricted to the area of the seizure focus, but mainly located in the more posterior brain regions and in various more posteriorly located tract bundles. These bundles, with abnormal $\mathrm{FA}$ or $\mathrm{ADC}$ values, were all interhemispheric connections.

None of the abnormal FA or ADC values differed significantly between the cognitively impaired and unimpaired patient group. The observation that FA and bundle volumes differed significantly between cognitively impaired patients with FLE and controls, but not between the cognitively unimpaired patients and controls suggest a sliding scale, in which abnormalities are most pronounced in the patients with cognitive impairment (Table 3). These abnormalities might thus represent part of the etiology of cognitive impairment complicating FLE in children.

\section{Interpretation and determinants of microstructural abnormalities}

In the posterior brain regions, both reduced and increased FA values and reduced ADC values were seen in both patient subgroups, compared to healthy controls. A reduced FA is often interpreted as a marker of white matter degeneration. Explanations for a reduced FA include degeneration of axons, reduced packing density of axons, demyelination, dysmyelination, as well as an increased proportion of crossing fibers. ${ }^{14}$ Thus, reduced FA does 
Table 3. Significant differences between cognitively impaired patients and controls measured by DTI.

\begin{tabular}{lcccc} 
& Controls & $\begin{array}{c}\text { FLE cognitively } \\
\text { unimpaired }\end{array}$ & $\begin{array}{c}\text { FLE cognitively } \\
\text { impaired }\end{array}$ & Direction \\
\hline FA LO & $0.199 \pm 0.016$ & $0.208 \pm 0.026$ & $0.218 \pm 0.036$ & Increase \\
FA RO & $0.202 \pm 0.015$ & $0.206 \pm 0.021$ & $0.216 \pm 0.023$ & Increase \\
FA (RF-LO) & $0.438 \pm 0.025$ & $0.434 \pm 0.032$ & $0.422 \pm 0.029$ & Decrease \\
Volume (LF-LT) & $127 \pm 13 \mathrm{~cm}^{3}$ & $122 \pm 17 \mathrm{~cm}^{3}$ & $120 \pm 20 \mathrm{~cm}^{3}$ & Decrease \\
Volume (RF-RP) & $164 \pm 14 \mathrm{~cm}^{3}$ & $156 \pm 26 \mathrm{~cm}^{3}$ & $151 \pm 28 \mathrm{~cm}^{3}$ & Decrease \\
\hline
\end{tabular}

$\mathrm{FA}=$ fractional anisotropy; $(\mathrm{X}-\mathrm{Y})=$ bundles connecting $\mathrm{X}$ and $\mathrm{Y} ; \mathrm{RF}=$ right frontal; $\mathrm{LO}=$ left occipital lobe; $\mathrm{RO}=$ right occipital lobe; $\mathrm{LF}=$ left frontal lobe; $\mathrm{LT}=$ left temporal lobe; $\mathrm{RP}=$ right parietal lobe.

not necessarily imply loss of white matter integrity. We evaluated children in an age category in which FA increases and ADC decreases with age as part of normal maturation. ${ }^{15,16}$ These maturation processes follow a posterior to anterior direction, ${ }^{13}$ and our data suggests that FLE affects this posterior to anterior maturation process. The increased occipital white matter FA value and decreased ADC values in the cognitively impaired patient group compared to the control group could indicate an increase in myelination, thus earlier (preterm) maturation, or an increase in axonal packing. The abnormal FA and ADC values and smaller volumes of collections of tract bundles could be a direct result of epilepsy, causing damage to the axonal pathways involved in seizure spread or secondary white matter loss in connected areas. ${ }^{17}$ Other causes could include the effects of interictal discharges, the location of the epileptogenic zone, anticonvulsant drugs, or the presence of frontal lobe malformations not detected by 3 Tesla MRI. ${ }^{18}$ Last, the white matter abnormalities could predispose to the development of epilepsy. ${ }^{19}$ In our study group of children with FLE, these explanations do not seem appropriate; most white matter abnormalities were not located within the area in which the seizure focus resides and these abnormalities were not associated with clinical epilepsy factors, especially not with seizure frequency, localization of seizure focus, and antiepileptic drug use.

Seizure activity might boost myelination processes, as impulse conduction is a stimulus to myelination..$^{20}$ Frontal lobe seizures, with their rapid seizure propagation, ${ }^{21}$ may influence the maturation processes of the whole brain. Yet, in children with idiopathic generalized epilepsy these accelerations in maturation are not seen, despite widespread seizure activity. ${ }^{22}$ Moreover, we observed abnormalities in few regions and white matter tract bundles. Apparently, white matter abnormalities manifest in a specific distribution in and outside the area of the seizure focus. 
Previously reported white matter abnormalities in children with epilepsy Only seven DTI studies have been performed in children with epilepsy without macrostructural visible brain damage. ${ }^{22-28}$ These studies, too, observed alterations of the cerebral white matter that are not restricted to the area of the seizure focus, in various epilepsy types and even near to the time of diagnosis of epilepsy. ${ }^{22-27}$ Remarkable is that none of these studies found an accelerated maturation, and none of these studies related their findings to cognetive performance.

White matter abnormalities associated with cognitive impairment in adults with epilepsy

Seven studies have investigated the link between white matter abnormalities and cognition in adults with epilepsy. ${ }^{17,29-34}$ All these studies have demonstrated abnormalities of the white matter not restricted to the seizure focus and associated with cognitive performance in patients with TLE ${ }^{17,29-33}$ and FLE. ${ }^{34}$

In conclusion, children with FLE had abnormalities of the cerebral white matter which were mostly located in posterior brain regions thus not confined to the area of the seizure focus. The abnormalities were not associated with the children's clinical epilepsy characteristics. We did not observe differences in white matter properties directly between cognitively impaired and unimpaired children with FLE, but our data suggest a sliding scale in which the most pronounced alterations in the cerebral white matter were found in the cognitively impaired children with FLE. These white matter abnormalities possibly reflect disturbed maturation processes and might represent part of the etiology of cognitive impairment complicating FLE in children. 


\section{Appendix 1. Neuropsychological test details.}

\section{Cognitive domain Test}

General intelligence

Memory

Short-term memory Recognition of words and figures. ${ }^{15 *}$
Wechsler Intelligence (WISC-III). ${ }^{14}$ Scale for Children-III

\section{Description}

The WISC consists of 13 subtests:

Picture Completion - artwork of common objects with a missing part are shown, and the patient is asked to identify the missing part by pointing and/or naming.

Information - general knowledge questions. Coding - patients transcribe a digit-symbol code which is time-limited.

Similarities - the patient has to explain the similarity between two words.

Picture arrangement - sequencing cartoon pictures to make sensible stories.

Arithmetic - orally administered arithmetic questions which are timed.

Block Design - patients put together red-and-white blocks in a pattern according to a displayed model which is timed.

Vocabulary - the patient has to explain the meaning of several words.

Object assembly - puzzles of cut-apart silhouette objects with no outline pieces.

Comprehension - questions about social situations or common concepts.

Symbol Search - patients are given rows of symbols and target symbols, and asked to mark whether or not the target symbols appear in each row.

Digit Span - patients are orally given sequences of numbers and asked to repeat them, either as heard or in reverse order.

Mazes - patient has to find a route to get out of the maze.

Intellectual ability is expressed in Full Scale IQ, Verba IQ, Performance IQ, Verbal Reasoning, Perceptual Organization and Mental Processing Speed score.

Stimuli (six words or four figures) are presented simultaneously during a learning phase with a presentation time of 1 second per item. After a delay of 2 seconds the screen shows one of these words figures between distracters. The target item has to be recognized. The number of correct items is scored, with a maximum of 24 .

Long-term memory The 15 word test (15

A list of 15 words is orally presented five times. After woordentest Kalverboer the Dutch version of the Rey Auditory Verbal Learning Test). ${ }^{16}$

The 15 word test
(15 woordentest Kalverboer). ${ }^{16}$

After five consecutive trials with direct recall, a delayed recall is requested after a 20 minutes interval. The number of correct words is scored. Thereafter the patient is asked if he/she recognized the words. Number of correct recognized items is scored, with a maximum of 30 .

Complex Figure test Twenty minutes after copying a complex figure, the same (Rey-Osterrieth figure). ${ }^{17}$ figure has to been drawn from memory. 


\begin{tabular}{|c|c|c|}
\hline Cognitive domain & Test & Description \\
\hline \multirow[t]{4}{*}{$\begin{array}{l}\text { Visual-spatial } \\
\text { functions }\end{array}$} & $\begin{array}{l}\text { Complex Figure test } \\
\text { (Rey-Osterrieth figure). }{ }^{17}\end{array}$ & $\begin{array}{l}\text { Twenty minutes after copying a complex figure, the same } \\
\text { figure has to been drawn from memory. }\end{array}$ \\
\hline & $\begin{array}{l}\text { Beery Buktenica } \\
\text { Developmental Test } \\
\text { of Visual-Motor } \\
\text { Integration. }{ }^{19}\end{array}$ & $\begin{array}{l}\text { The patient has to copy a sequence of geometric forms of } \\
\text { increasing difficulty. }\end{array}$ \\
\hline & $\begin{array}{l}\text { The Visual Perception } \\
\text { Test. }{ }^{18}\end{array}$ & The patient has to match given geometric forms. \\
\hline & $\begin{array}{l}\text { The Motor Coordination } \\
\text { Test. }^{18}\end{array}$ & $\begin{array}{l}\text { The patient traces shapes while remaining inside a double } \\
\text { lined path. Raw scores are converted into standard } \\
\text { scores. }\end{array}$ \\
\hline \multirow[t]{4}{*}{$\begin{array}{l}\text { Psychomotor speed } \\
\text { and alertness }\end{array}$} & Finger tapping task. ${ }^{15}$ & $\begin{array}{l}\text { Five consecutive trials for the index finger of the dominant } \\
\text { and separately the non-dominant hand. Number of taps } \\
\text { is recorded. }\end{array}$ \\
\hline & $\begin{array}{l}\text { Simple reaction time } \\
\text { measurements. }{ }^{15 *}\end{array}$ & $\begin{array}{l}\text { The patient has to react as quickly as possible on either } \\
\text { auditory* }(800 \mathrm{~Hz} \text { tone) or visual (square on the screen) } \\
\text { stimuli that were presented at random intervals by the } \\
\text { computer. }\end{array}$ \\
\hline & $\begin{array}{l}\text { Binary choice reaction- } \\
\text { time measurement. }\end{array}$ & $\begin{array}{l}\text { A reaction time test with a decision component. The } \\
\text { patient has to react differentially to a red square on the } \\
\text { left side of the screen and to a green square at the right } \\
\text { side of the screen. }\end{array}$ \\
\hline & $\begin{array}{l}\text { Computerized visual } \\
\text { searching task (CVST) } \\
\text { (an adaptation of } \\
\text { Goldstein's Visual } \\
\text { Searching Task). }{ }^{15 *}\end{array}$ & $\begin{array}{l}\text { A centered grid pattern has to be compared with } 24 \\
\text { surrounding patterns. Only one of them is identical to } \\
\text { the target pattern. The test consists of } 24 \text { trails. Reaction } \\
\text { time is recorded (CVST) as well as the total number of } \\
\text { errors (CVST errors). }\end{array}$ \\
\hline \multicolumn{3}{|r|}{ 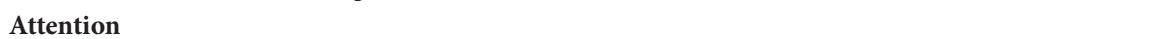 } \\
\hline Selective attention & $\begin{array}{l}\text { The Stroop Colour Word } \\
\text { Test. }^{19 *}\end{array}$ & $\begin{array}{l}\text { The test consists of } 3 \text { cards: color naming (the patient had } \\
\text { to name color blocks), word reading (the patient had to } \\
\text { read words printed in black ink) and interference (the } \\
\text { patient has to name the color of a word printed in an } \\
\text { incongruent color; e.g., the word red written in blue ink). } \\
\text { By comparing the speed of the last card with the speed of } \\
\text { the second card, interference of cognitive functioning can } \\
\text { be measured. Increased interference can be interpreted as } \\
\text { a disturbance in the concentration process. }\end{array}$ \\
\hline Sustained attention & Bourdon-Vos Test. ${ }^{18}$ & $\begin{array}{l}\text { A cancellation test requiring high-speed visual selectivity } \\
\text { and a repetitive motor response. Patients are instructed } \\
\text { to cross out the target items, i.e. the dot patterns with } \\
\text { four dots on a sheet of paper covered in three- four-, and } \\
\text { five-dot patterns. The mean reaction time of the patient } \\
\text { is scored. }\end{array}$ \\
\hline $\begin{array}{l}\text { Educational } \\
\text { achievement }\end{array}$ & Tempotest. ${ }^{21-23 *}$ & $\begin{array}{l}\text { The performance on school tasks is assessed by arithmetic } \\
\text { and reading words and sentences. This gives a learning } \\
\text { efficiency quotient (LEQ) whereby } 100 \% \text { indicating no } \\
\text { delay. }\end{array}$ \\
\hline
\end{tabular}

${ }^{*}$ Neuropsychological assessment for the control group and for the patients who had neuropsychological assessment more than twelve months earlier. 
Appendix 3. Neuropsychological test results.

\begin{tabular}{lll} 
& $\begin{array}{c}\text { Patients, } \\
\text { Mean } \pm \text { SD }\end{array}$ & $\begin{array}{c}\text { Controls, } \\
\text { Mean } \pm \text { SD }\end{array}$ \\
\hline Global cognitive functioning & & \\
Central information processing speed & $4 \pm 3^{\mathrm{a}}$ & $7 \pm 3^{\mathrm{a}}$ \\
(Computerized Visual Searching Task; CVST) & \\
Educational achievement (learning efficiency quotients; LEQ) & $89 \pm 34^{\mathrm{b}}$ & $108 \pm 47^{\mathrm{b}}$ \\
Reading words & $81 \pm 34^{\mathrm{b}}$ & $118 \pm 59^{\mathrm{b}}$ \\
Reading sentences & $79 \pm 43^{\mathrm{b}}$ & $102 \pm 31^{\mathrm{b}}$ \\
Mathematics & $88 \pm 12^{\mathrm{c}}$ & - \\
Wechsler full scale IQ scores & & \\
Higher-order cognitive functioning & $5 \pm 3^{\mathrm{a}}$ & $8 \pm 2^{\mathrm{a}}$ \\
Recognition words score & $8 \pm 3^{\mathrm{d}}$ & - \\
'Digit Span' subtest score of the WISC-III & & \\
Fluid cognitive functioning & $-0.1 \pm 1.0^{\mathrm{e}}$ & $0.4 \pm 0.7^{\mathrm{e}}$ \\
STROOP Colour Word Test Interference score & $5 \pm 3^{\mathrm{a}}$ & $6 \pm 3^{\mathrm{a}}$ \\
Auditory reaction times & $8 \pm 3^{\mathrm{f}}$ & - \\
\hline 'Coding' subtest score of the WISC-III & & \\
\hline
\end{tabular}

a: An age-corrected cognitive performance score was generated, expressed in decile scores. Scores $\leq 3$ represent impairment. ${ }^{36}$

b: A score of $<80 \%$ indicates educational delay. ${ }^{42-44}$

c: Full scale IQ scores $<85$ indicate impairment.

d: If performance scores were below normative values (standard score $<8$ ), higherorder cognition was considered impaired. ${ }^{35}$

e: A Z-score of 0 or 1 indicated normal or good performance, whereas a Z- score of $\leq$ -1 indicated impaired performance. ${ }^{39}$

f: If performance scores were below normative values (standard score $<8$ ), fluid cognitive functioning was considered impaired. ${ }^{35}$ 


\section{References}

1. Braakman HM, Vaessen MJ, Hofman PA, Debeij-van Hall MH, Backes WH, Vles JS, Aldenkamp AP. Cognitive and behavioral complications of frontal lobe epilepsy in children: a review of the literature. Epilepsia 2011;52:849-856.

2. Braakman HM, Ijff DM, Vaessen MJ, Debeij-van Hall MH, Hofman PA, Backes WH, Vles JS, Aldenkamp AP. Cognitive and behavioural findings in children with frontal lobe epilepsy. Eur J Paediatr Neurol 2012;16:707-715.

3. Braakman, HMH, Vaessen MJ, Jansen JFA, Debeij-van Hall MHJA, de Louw A, Hofman PAM, Vles JSH, Aldenkamp AP, Backes WH. Frontal lobe connectivity and cognitive impairment in pediatric frontal lobe epilepsy. Epilepsia 2013;54(3):446-454..

4. Eriksson SH, Rugg-Gunn FJ, Symms MR, Barker GJ, Duncan JS. Diffusion tensor imaging in patients with epilepsy and malformations of cortical development. Brain 2001;124:617-626.

5. Rugg-Gunn FJ, Eriksson SH, Symms MR, Barker GJ, Duncan JS. Diffusion tensor imaging of cryptogenic and acquired partial epilepsies. Brain 2001;124:627-636.

6. Gross DW. Diffusion tensor imaging in temporal lobe epilepsy. Epilepsia 2011;52:32-34.

7. Provini F, Plazzi G, Tinuper P, Vandi S, Lugaresi E, Montagna P. Nocturnal frontal lobe epilepsy. A clinical and polygraphic overview of 100 consecutive cases. Brain 1999;122:1017-1031.

8. World Health Organization Collaborating Centre for Drug Statistics Methodology. About the ATC/ DDD system, 2008. Available on http://www.whocc.no/atcddd/.

9. Jones DK, Horsfield MA, Simmons A (1999) Optimal strategies for measuring diffusion in anisotropic systems by magnetic resonance imaging. Magn Reson Med 1999;42:515-525.

10. Ghosh SS, Kakunoori S, Augustinack J, Nieto-Castanon A, Kovelman I, Gaab N, Christodoulou JA, Triantafyllou C, Gabrieli JD, Fischl B. Evaluating the validity of volume-based and surface-based brain image registration for developmental cognitive neuroscience studies in children 4 to 11 years of age. Neuroimage 2010;53:85-93.

11. Farrell JA, Landman BA, Jones CK, Smith SA, Prince JL, van Zijl PC, Mori S. Effects of signalto-noise ratio on the accuracy and reproducibility of diffusion tensor imaging-derived fractional anisotropy, mean diffusivity, and principal eigenvector measurements at 1.5 T. J Magn Reson Imaging 2007;26:756-767.

12. Tournier JD, Calamante F, Connelly A. Robust determination of the fibre orientation distribution in diffusion MRI: non-negativity constrained super-resolved spherical deconvolution. Neuroimage 2007;35:1459-1472.

13. Lebel C, Walker L, Leemans A, Phillips L, Beaulieu C. Microstructural maturation of the human brain from childhood to adulthood. Neuroimage 2008;40:1044-1055.

14. Concha L, Livy DJ, Beaulieu C, Wheatley BM, Gross DW. In vivo diffusion tensor imaging and histopathology of the fimbria-fornix in temporal lobe epilepsy. J Neurosci 2010;30:996-1002.

15. Jones DK, Knösche TR, Turner R. White matter integrity, fiber count, and other fallacies: The do's and don'ts of diffusion MRI. Neuroimage 2012; doi:pii: S1053-8119(12)00730-6.

16. Hagmann P, Sporns O, Madan N, Cammoun L, Pienaar R, Wedeen VJ, Meuli R, Thiran JP, Grant PE. White matter maturation reshapes structural connectivity in the late developing human brain. Proc Natl Acad Sci USA 2010;107:19067-19072.

17. Diehl B, Busch RM, Duncan JS, Piao Z, Tkach J, Lüders HO. Abnormalities in diffusion tensor imaging of the uncinate fasciculus relate to reduced memory in temporal lobe epilepsy. Epilepsia 2008;49:1409-1418.

18. Anneken K, Evers S, Mohammadi S, Schwindt W, Deppe M. Transient lesion in the splenium related to antiepileptic drug: case report and new pathophysiological insights. Seizure 2008;17:654-657. 
19. Concha L, Beaulieu C, Wheatley BM, Gross DW. Bilateral white matter diffusion changes persist after epilepsy surgery. Epilepsia 2007;48:931-940.

20. Van der Knaap MS, Valk J. Magnetic resonance of myelination and myelin disorders. Chapter 1. Myelin and White matter. $3^{\text {rd }}$ Edition. Springer Berlin Heidelberg New York, 2005, pp. 1-19.

21. Riva D, Avanzini G, Franceschetti S, Nichelli F, Saletti V, Vago C, Pantaleoni C, D’Arrigo S, Andreucci E, Aggio F, Paruta N, Bulgheroni S. Unilateral frontal lobe epilepsy affects executive functions in children. Neurol Sci 2005;26:263-270.

22. Hutchinson E, Pulsipher D, Dabbs K, Myers y Gutierrez A, Sheth R, Jones J, Seidenberg M, Meyerand E, Hermann B. Children with new-onset epilepsy exhibit diffusion abnormalities in cerebral white matter in the absence of volumetric differences. Epilepsy Res 2010;88:208-214.

23. Kimiwada T, Juhász C, Makki M, Muzik O, Chugani DC, Asano E, Chugani HT. Hippocampal and thalamic diffusion abnormalities in children with temporal lobe epilepsy. Epilepsia 2006;47:167175.

24. Govindan RM, Makki MI, Sundaram SK, Juhász C, Chugani HT. Diffusion tensor analysis of temporal and extra-temporal lobe tracts in temporal lobe epilepsy. Epilepsy Res 2008;80:30-41.

25. Nilsson D, Go C, Rutka JT, Rydenhag B, Mabbott DJ, Snead OC 3rd, Raybaud CR, Widjaja E. Bilateral diffusion tensor abnormalities of temporal lobe and cingulate gyrus white matter in children with temporal lobe epilepsy. Epilepsy Res 2008;81:128-135.

26. Holt RL, Provenzale JM, Veerapandiyan A, Moon WJ, De Bellis MD, Leonard S, Gallentine WB, Grant GA, Egger H, Song AW, Mikati MA. Structural connectivity of the frontal lobe in children with drug-resistant partial epilepsy. Epilepsy Behav 2011;21:65-70.

27. Meng L, Xiang J, Kotecha R, Rose D, Zhao H, Zhao D, Yang J, Degrauw T. White matter abnormalities in children and adolescents with temporal lobe epilepsy. Magn Reson Imaging 2010;28:1290-1298.

28. Bhardwaj RD, Mahmoodabadi SZ, Otsubo H, Snead OC 3rd, Rutka JT, Widjaja E. Diffusion tensor tractography detection of functional pathway for the spread of epileptiform activity between temporal lobe and Rolandic region. Childs Nerv Syst 2010;26:185-190.

29. Lui YW, Nusbaum AO, Barr WB, Johnson G, Babb JS, Orbach D, Kim A, Laliotis G, Devinsky O. Correlation of apparent diffusion coefficient with neuropsychological testing in temporal lobe epilepsy. AJNR Am J Neuroradiol 2005;26:1832-1839.

30. McDonald CR, Ahmadi ME, Hagler DJ, Tecoma ES, Iragui VJ, Gharapetian L, Dale AM, Halgren E. Diffusion tensor imaging correlates of memory and language impairments in temporal lobe epilepsy. Neurology 2008;71:1869-1876.

31. Yogarajah M, Powell HWR, Parker GJM, Alexander DC, Thompson PJ, Symms MR, Boulby P, Wheeler-Kingshott CA, Barker GJ, Koepp MJ, Duncan JS. Tractography of the parahippocampal gyrus and material specific memory impairment in unilateral temporal lobe epilepsy. Neuroimage 2008;40:1755-1764

32. Riley JD, Franklin DL, Choi V, Kim RC, Binder DK, Cramer SC, Lin JJ. Altered white matter integrity in temporal lobe epilepsy: association with cognitive and clinical profiles. Epilepsia 2010;51:536545.

33. Wang XQ, Lang SY, Hong LU, Lin MA, Yan-ling MA, Yang F. Changes in extratemporal integrity and cognition in temporal lobe epilepsy: a diffusion tensor imaging study. Neurol India 2010;58:891899.

34. Wang XQ, Lang SY, Hong LU, Lin MA, Yan-Ling MA, Yang F. Changes in extrafrontal integrity and cognition in frontal lobe epilepsy: a diffusion tensor imaging study. Epilepsy Behav 2011;20:471477.

35. Wechsler D. Wechsler Intelligence Scale for Children derde editie NL, Handleiding en verantwoording. Harcourt, London, 2005. 
36. Alpherts WCJ, Aldenkamp AP. FePSY: 'The Iron Psyche'. Instituut voor epilepsiebestrijding, Heemstede, the Netherlands, 1995.

37. Kalverboer AF, Deelman BG. De 15-woorden tests A en B: (een voorlopige handleiding) (15WT/ VWT). Groningen: Academisch Ziekenhuis Groningen, afd. Neuropsychologie, 1986.

38. Meyers JE, Meyers KR. Rey Complex Figure Test and Recognition Trial: Professional manual. Odessa Florida: Psychological Assessment Resources, 1995.

39. Beery KE, Buktenica NA, Beery NA. The Beery-Buktenica development test of visual-motor integration. $5^{\text {th }}$ edition. Minneapolis, MN: Pearson Assessments, 2003.

40. Vos PG. Bourdon-Vos: Handleiding. Lisse: Swets \& Zeitlinger, 1988.

41. Hammes JGW. De Stroop Kleur-Woord Test. Handleiding. Lisse: Swets \& Zeitlinger, 1971.

42. Vos T. Handleiding tempo-test-lezen (zinnen). Lisse: Swets \& Zeitlinger, 2000.

43. Vos T. Handleiding tempo-test-lezen (woorden). Lisse: Swets \& Zeitlinger, 2002.

44. Vos T. Handleiding tempo-test-rekenen. Harcourt Assessment bv, Amsterdam, 2004. 


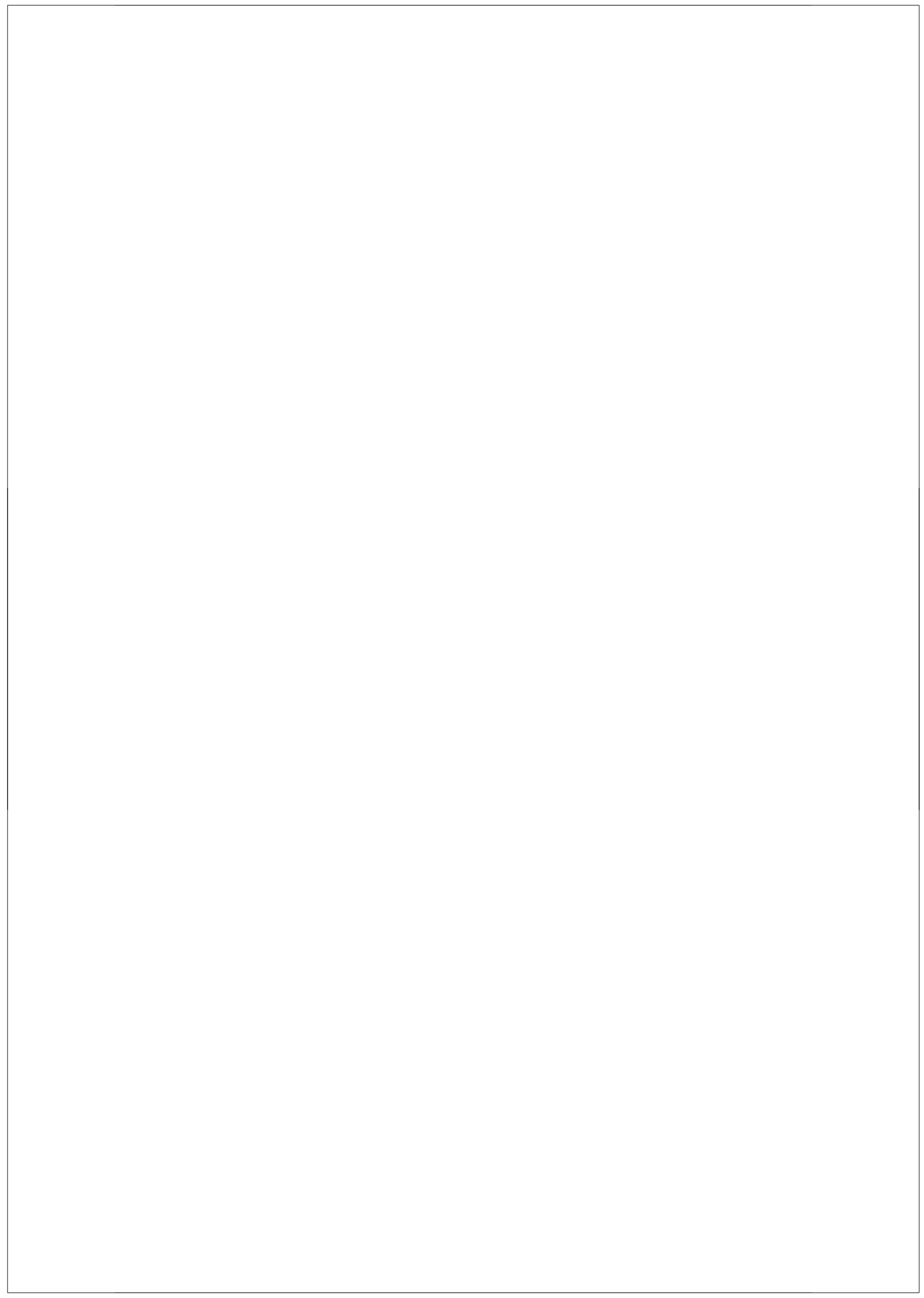




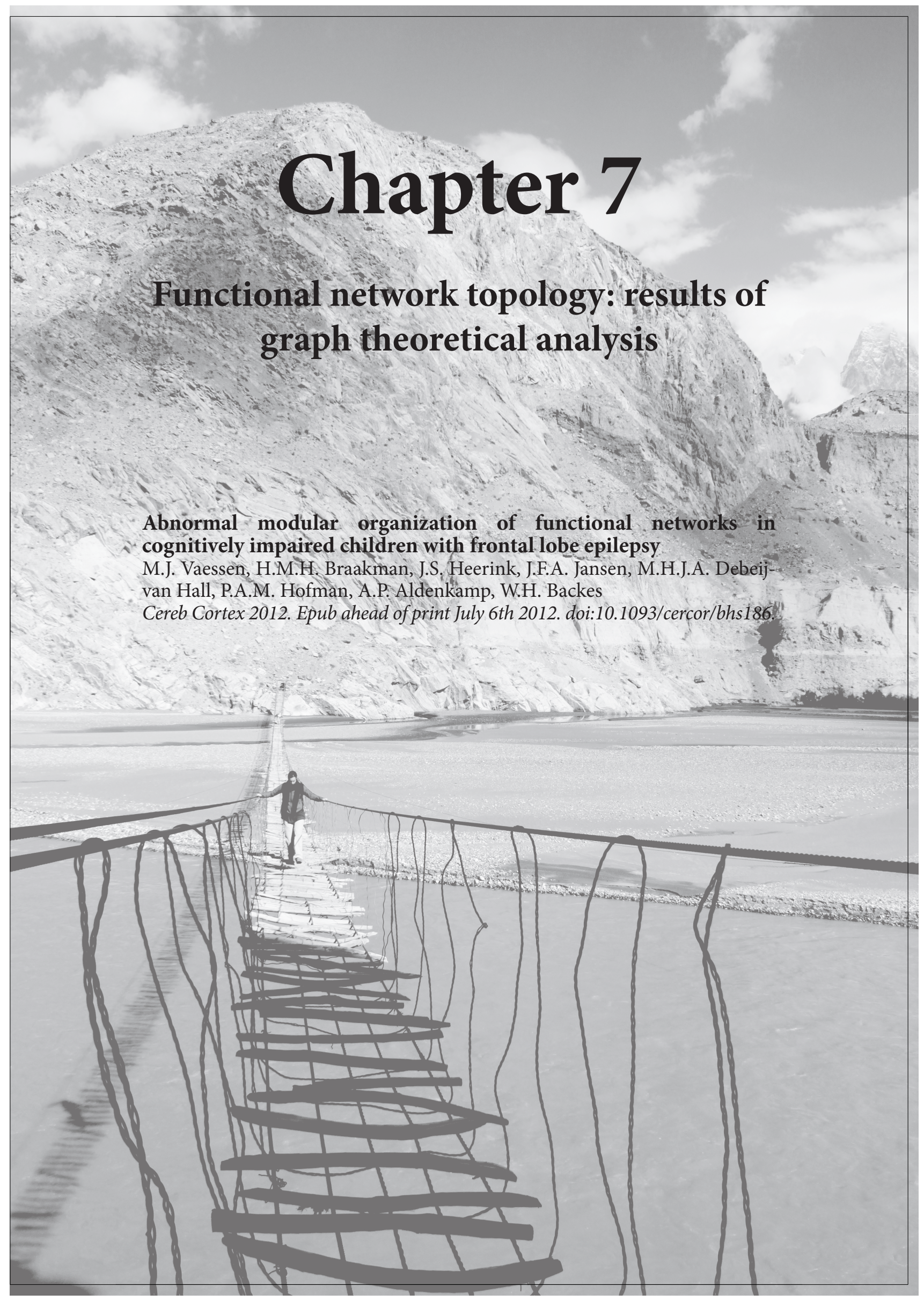




\begin{abstract}
Many children with frontal lobe epilepsy (FLE) have significant cognitive comorbidity, for which the underlying mechanism has not yet been unravelled, but is likely related to disturbed cerebral network integrity. Using resting-state fMRI we investigated whether cerebral network characteristics are associated with epilepsy and cognitive comorbidity.

We included 28 children with FLE and 37 healthy age-matched controls. Cognitive performance was determined by means of a computerized visual searching task. A connectivity matrix for 82 cortical and subcortical brain regions was generated for each subject by calculating the inter-regional correlation of the fMRI time signals. From the connectivity matrix, graph metrics were calculated and the anatomical configuration of aberrant connections and modular organization was investigated.

Both patients and controls displayed efficiently organized networks. However, patients with FLE displayed a higher modularity, implying that subnetworks are less interconnected. Impaired cognition was associated with higher modularity scores and abnormal modular organization of the brain, which was mainly expressed as a decrease in long-range and an increase in interhemispheric connectivity in patients. We showed that network modularity analysis provides a sensitive marker for cognitive impairment in FLE and suggest that abnormally interconnected functional subnetworks of the brain might underlie the cognitive problems in children with FLE.
\end{abstract}




\section{Abnormal modular organization of functional networks in cognitively impaired children with frontal lobe epilepsy}

\section{Introduction}

Frontal lobe epilepsy (FLE) is considered the second most common type of the localization-related (partial) epilepsies of childhood, after temporal lobe epilepsy, and accounts for $20-30 \%$ of partial epilepsies. ${ }^{1}$ Pediatric FLE is frequently complicated by cognitive impairment and behavioural disturbances. FLE impacts a broad scale of cognitive domains, broader than the typical frontal functions. ${ }^{2,3}$ In children with FLE, the learning difficulties may even precede seizure onset, suggesting a nontrivial relationship between seizures and cognitive problems, which has not been unravelled thus far. ${ }^{4,5}$

The broad scale of affected cognitive domains hints at a network disturbance, rather than disturbance of localized processes. In line with this suggestion, conventional structural MRI studies have not shown an anatomical substrate for the neuronal mechanisms leading to cognitive impairment in FLE. ${ }^{6-10}$ To resolve this, functional MRI techniques may prove novel and valuable insights. Resting-state fMRI (RS-fMRI) is a functional imaging technique that may be useful in understanding the neuronal mechanisms behind cognitive comorbidity in neurological disorders. ${ }^{11}$ RS-fMRI enables the investigation of the intrinsic functional organization of the brain, in contrast to the cerebral effect of tasks executed by subjects. This intrinsic functional organization is called "functional connectivity," which is defined by the temporal correlation of neuronal activity-induced patterns of anatomically different brain regions. ${ }^{12,13}$ Previous studies have demonstrated disturbances in functional connectivity networks in the brains of adult epilepsy patients. ${ }^{14-20}$ These studies focused on "local" connectivity abnormalities, that is, only a few regions of the brain were analyzed or considered as a reference. Given the heterogeneous expression of cognitive deficits in FLE, ${ }^{3}$ it is advantageous to investigate the whole-brain network. In mathematical terms, the brain can be modeled as a system consisting of nodes (brain regions) and edges (connections) between them. The strength of a connection is then quantified by the degree of correlation of the dynamic fluctuations between a pair of nodes, that is, brain regions. An elegant way to understand and quantify the organization of this system of nodes and edges is to calculate graph theoretical metrics of the whole-brain network..$^{21}$ The metrics that provide information 
on the amount of integration and segregation over the entire brain are path length and clustering. In addition to whole-brain network organization, graph theoretical metrics can also describe the interconnection of subnetworks in the whole-brain network by modularity analysis, ${ }^{22}$ see Table 1 for a detailed description. The modular structure of the brain network is thought to be important for cognitive abilities as increases in coherent activity between functional systems might facilitate information integration ${ }^{23}$ and adaptive behaviour. ${ }^{24}$

Based on the hypotheses that children with FLE have an abnormal brain organization caused by interference of epilepsy with normal development, and that this organization may affect cognitive function, we have analyzed cerebral functional connectivity of children with FLE in correlation to their cognitive performance using graph theoretical network parameters.

\section{Materials and Methods}

\section{Participants}

Patients with FLE were selected from our reference clinic database and were actively contacted. Inclusion criteria for the patients were a confirmed cryptogenic (i.e., presumed to be symptomatic, but with unknown etiology) localization-related epilepsy with an epileptic focus in the frontal lobe, aged between 8 and 13 years, no other disease that could cause cognitive impairment, and no history of brain injury. When patients displayed one or more episodes associated with clear ictal epileptic focal activity in the frontal lobe during EEG, the diagnosis FLE was based on EEG. When EEG was not informative, the recording of more than one seizure with clinical evidence of seizures originating from the frontal lobe was required to make the diagnosis. The EEGs of all children with epilepsy were assessed by experienced clinical neurophysiologists at the Epilepsy Centre Kempenhaeghe. All children with FLE had brain MRI before inclusion, which revealed no structural brain abnormalities, such as cortical dysplasia, according to the image reading of a specialized neuroradiologist.

Healthy age-matched controls were recruited by advertisements in local newspapers. Inclusion criteria were no history of brain injury or cognitive problems and visiting regular education. All subjects and parents gave written informed consent and approval for the study by the local Medical Ethical Committee was obtained. 


\section{Neuropsychological Assessment}

Neuropsychological assessment was generally performed on the same day as MRI, although a small number of patients $(N=3)$ had their neuropsychological assessment prior (within 1 year) to MRI. Cognitive performance was measured using a computerized visual searching task (CVST). ${ }^{25}$ This task consists of finding a grid pattern out of 24 patterns which matches the one in the centre of the screen. Grid patterns are displayed in a checkerboard fashion and are numbered from 1 to 24 . The target pattern is marked by an arrow on the right side and is selected by typing the correct number on the keyboard. Twenty different target patterns are presented. After 12 presentations, the surrounding grids change. The testee is asked to respond as fast as possible. The results show accuracy and speed of responses and are evaluated within the context of visual (complex) information processing and perceptual mental strategies. The most important variable indicating efficient information processing is the average reaction time.

By determining the average reaction time and the errors being made during the task, an age-corrected cognitive performance score was generated (decile score). After grouping these scores into numbers from 1 (worst score) to 10 (best score), the three worst performance scores (1,2 and 3) were considered a manifestation of impaired cognitive performance, whereas other scores were considered normal or good.

\section{Image acquisition}

MRI was performed on a 3.0-Tesla unit equipped with an 8-channel head coil (Philips Achieva, Philips Medical Systems). Functional MRI data were acquired using a whole-brain single-shot multislice echo-planar imaging (EPI) sequence sensitive to the blood oxygen level-dependent (BOLD) effect, with repetition time (TR) $2 \mathrm{~s}$, echo time (TE) $35 \mathrm{~ms}$, flip angle $90^{\circ}$, pixel size $2 \times 2 \mathrm{~mm}^{2}, 32$ contiguous 4 -mm thick slices per volume, 195 volumes per acquisition, and an acceleration factor (SENSE) of 1.5. For anatomic reference, a $T 1$-weigthed $3 \mathrm{D}$ fast field echo was acquired with the following parameters: TR $8.1 \mathrm{~ms}$, TE $3.7 \mathrm{~ms}$, flip angle $8^{\circ}$, field of view $256 \times 256 \times$ $180 \mathrm{~mm}^{3}$, and voxel size $1 \times 1 \times 1 \mathrm{~mm}^{3}$. For safety reasons, all participants were continuously video-monitored in the magnet and were asked after scanning if they thought any seizures had happened during the procedure. We saw no evidence on video of any seizure-like responses, nor did any of the patients report having experienced a seizure. However, potential confounding influences of interical EEG abnormalities could not be ruled out as simultaneous EEG was not performed. 


\section{Network construction}

As displayed in Figure 1, data analysis sequentially consisted of the following procedures:

1) preprocessing of the measured fMRI time series; 2) anatomical parcellation and connectivity matrix; 3) network analysis; and 4) statistical analysis.

\section{Preprocessing of Time-Series Data}

The BOLD images were corrected for motion artifacts using SPM5 (Wellcome Trust Centre for Neuroimaging, UCL) software. The images were then highpass filtered with a $\sigma$ of 25 scans $(50 \mathrm{~s})$ and spatially smoothed $(\sigma=1.7 \mathrm{~mm})$ using FSL 4.1.7 (Oxford University) software. Subsequently, the CSF and whole-brain signal time course were removed from the images using standard linear regression. The resulting residual time-series of the cerebrum were used for further analysis. Finally, the images were low-pass filtered ( $\sigma=2 \mathrm{~s}$, i.e., one dynamic scan interval) to remove high-frequency noise components. To assess possible confounding of motion parameters, these were compared between the groups.

\section{Anatomical Parcellation and Connectivity Matrix}

Freesurfer (Martinos Centre of Biomedical Imaging) software was used to segment the $T 1$ images of each subject into 82 cortical and subcortical regions. Freesurfer uses a surface-based alignment procedure, which might be more accurate than a volume-based alignment of a cortical atlas. ${ }^{26}$

Using Matlab 7.6.0 (The MathWorks Inc.), Pearson's linear correlation coefficients between the region-averaged time-series of all pairs of Freesurfer regions were computed. In this way, for each subject an $82 \times 82$ connectivity matrix was determined. This connectivity matrix included both negative and positive correlation values. The removal of the whole-brain average time-series signal tends to shift the correlation distribution to a mean value that is closer to zero, thereby creating negative correlations even if no such correlations are initially present in the data. ${ }^{27}$ Only positive correlations were used for further analysis. Additionally, low (absolute) correlation coefficients could adversely affect the results as they may either represent physiologically relevant signal fluctuations or just noise. To overcome this issue, only a prespecified number of connections with highest correlation coefficients were selected, and all other connections were set to zero. ${ }^{28}$ Conceptually, this thresholding procedure can be expressed as a sparsity value relating the connections maintained in the network to the total number of connections possible. ${ }^{19,29}$ In the remainder of this article, the results will either be presented for a particular sparsity value or as a function of sparsity. 

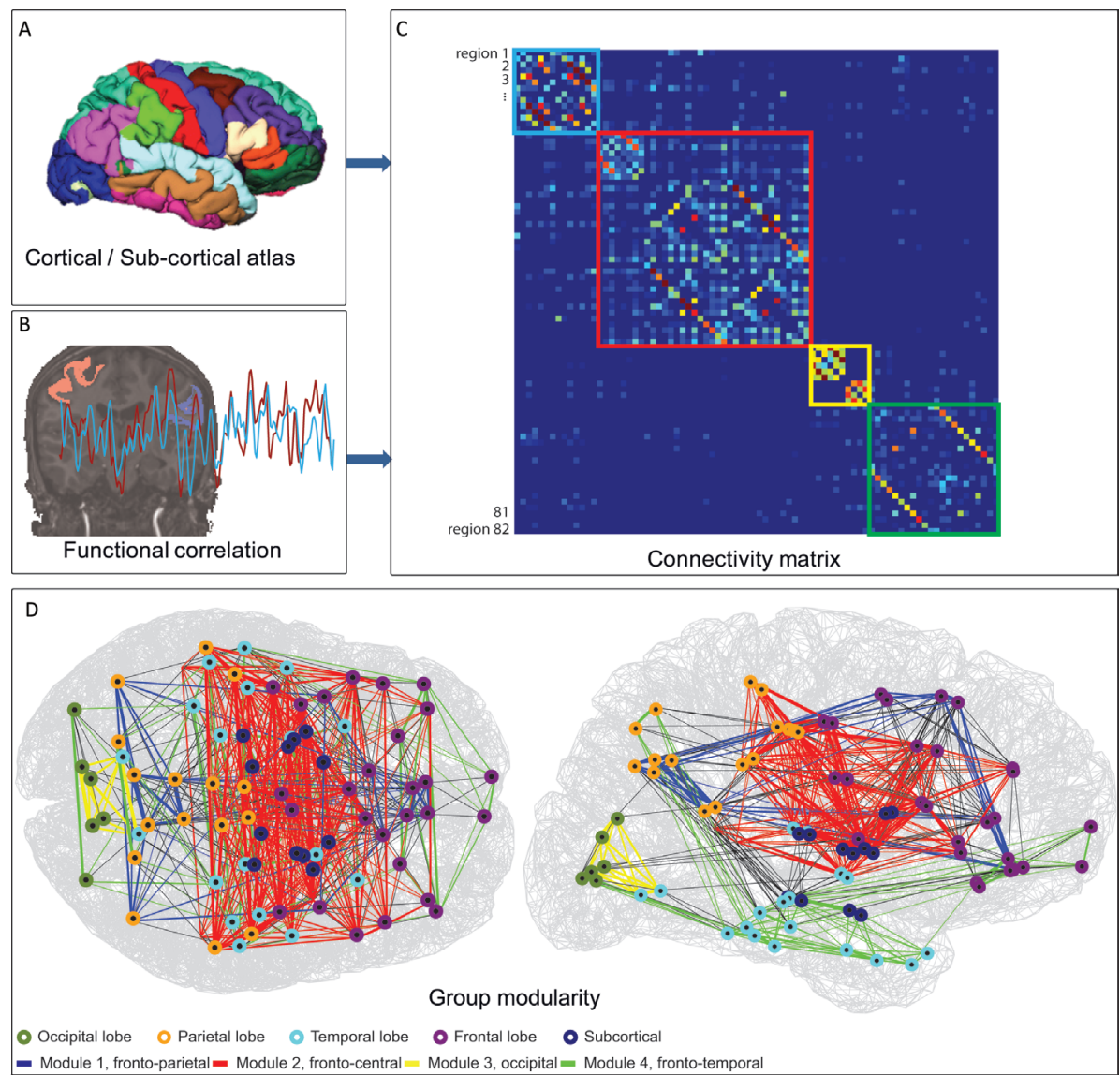

Figure 1. (A) $\mathrm{T}_{1}$-image-based subject-specific parcellation of the cortex and subcortical structures. $(B)$ Mean time signals of the 82 parcellated regions are extracted from the regional signal fluctuations of RS-fMRI. $(C)$ Correlation analysis is performed on each pair of time signals to construct a connectivity matrix for each subject. The colored squares indicate in which module the regions (nodes) and connections reside. $(D)$ Modular organization of the resting-state network in the control group. In this figure, the anatomical locations of the regions are indicated as black dots. The surrounding colored circles indicate in which lobe these regions reside. The color of the lines between regions display to what modules the connections belong. It is evident that some modules occupy several lobes, while other are mainly present within one lobe (the yellow occipital module for instance).

\section{Network Analysis}

\section{Network Characteristics}

For each subject, the values of network metrics were calculated from the individual connectivity matrix. We included three widely used network metrics: characteristic path length, clustering coefficient, and modularity, 
Table 1. Network parameters used in this study.

Measures

\begin{tabular}{|c|c|}
\hline$L=\frac{1}{N(N-1)} \sum_{i=1}^{N} \sum_{j=1, i \neq j}^{N} d_{i, j}$ & $\begin{array}{l}\text { Characteristic path length is defined as the average geodesic } \\
\text { distance, in number of edges, connecting any two nodes in the } \\
\text { graph, where } d_{i, j} \text { is the length of the shortest path between nodes } \\
i \text { and } j \text {. The characteristic path length is a measure of how well } \\
\text { connected a network is. Small characteristic path length indicates } \\
\text { an average short distance between any two nodes, that is, they can } \\
\text { be reached through a small number of steps. }\end{array}$ \\
\hline$L=\frac{1}{N(N-1)} \sum_{i, j \in G, i \neq j} w_{i, j}$ & $\begin{array}{l}\text { The weighted characteristic path length is defined as the average of } \\
\text { the shortest paths connecting any two nodes in the graph, where } w_{i, j} \\
\text { is the sum of weights of the shortest weighted path between nodes } \\
i \text { and } j . \text { The characteristic path length is a measure of how well } \\
\text { connected a network is. In the case of a weighted network higher } \\
\text { connectivity strength will decrease the distance between two nodes, } \\
\text { and thus a short path length indicates that, on average, any two } \\
\text { nodes are connected by one or several strong connections. }\end{array}$ \\
\hline$C=\frac{1}{N} \sum_{i} \frac{\sum_{j, m}\left(A_{i, j} A_{j, m} A_{m, i}\right)}{k_{i}\left(k_{i}-1\right)}$ & $\begin{array}{l}\text { The cluster coefficient is defined as the number of edges connecting } \\
\text { the neighbors of a node divided by the maximum number of } \\
\text { edges possible between neighboring nodes. The cluster coefficient } \\
\text { of a network is a measure of how many local clusters exist in the } \\
\text { network. A high cluster coefficient indicates that the neighbors of } \\
\text { a node are often also directly connected to each other, that is, they } \\
\text { form a cluster. }\end{array}$ \\
\hline$C=\frac{1}{N} \sum_{i} \frac{\sum_{j, m}\left(w_{i, j} w_{j, m} w_{m, i}\right)^{1 / 3}}{k_{i}\left(k_{i}-1\right)}$ & $\begin{array}{l}\text { For a weighted graph, the cluster coefficient is high when the direct } \\
\text { neighbors of a node are also interconnected and have relatively } \\
\text { high connectivity strengths. }\end{array}$ \\
\hline$Q=\frac{1}{2 K} \sum_{i, j}\left[A_{i, j}-\frac{k_{i} k_{j}}{2 K}\right] \delta\left(m_{i}, m_{j}\right)$ & $\begin{array}{l}\text { The modularity score } Q \text { quantifies the degree to which a network } \\
\text { can be divided in nonoverlapping groups. The membership of node } \\
i \text { with a module is } m_{i} \text {. Hence, } \delta\left(\mathrm{m}_{\mathrm{i}}, \mathrm{m}_{\mathrm{i}}\right)=1 \text { when two nodes } i \text { and } j \\
\text { are in the same module and } 0 \text { otherwise. }\end{array}$ \\
\hline
\end{tabular}

Note: Parameter names (first column) are accompanied by a short interpretation (second column). See Rubinov and Sporns for a more detailed explanation. ${ }^{21}$

by using algorithms implemented in the Brain Connectivity Toolbox. ${ }^{21}$ A description of these parameters can be found in Table 1 and in Rubinov and Sporns. ${ }^{21}$ For these metrics, both the binary and weighted variants were calculated. For the binary metrics, the sparsity thresholded connectivity matrix was binarized by setting all edges with a correlation coefficient $>0$ to the value of 1 . For the weighted networks, the connection matrices were divided by the mean connection weight (mean correlation coefficient over all connections), which was also evaluated separately, as this can potentially influence weighted network metrics. ${ }^{30}$ For the binary networks, equivalent random networks were generated. ${ }^{28,31}$ Clustering and path length from the random networks were compared with the measured networks to assess small-worldness. ${ }^{32}$

We compared the entire patient group with controls, the cognitively impaired patients with controls and the cognitively unimpaired with the impaired patients. Between-group effects in network parameters were assessed by a twosample (two-tailed) $t$-test. 


\section{Correlation Between Network Metrics and Cognitive Performance}

Pearson's (linear) correlation coefficients were calculated between cognitive performance (CVST reaction time, age and decile scores) and network parameters. We performed this analysis for the entire subject population, as well as for the patient and control groups separately.

\section{Group Modularity}

Modularity quantifies the degree to which a brain network is organized in isolated subnetworks. The more isolated the subnetworks are, the higher the modularity. We used an algorithm developed by Newman et al..$^{22}$ to visualize the "modular structure" of the brain. With this algorithm, the brain was automatically subdivided into a number of modules (i.e., groups of nodes) with maximal correlation within and minimal correlation between the modules, creating a so-called optimal community structure (OCS) of the cerebrum. It is difficult to assess OCS at the group level, because the resulting number and spatial locations of the modules varies between subjects. For group-level analysis, a group connectivity matrix was obtained by averaging all individual correlation matrices from a subgroup of subjects. ${ }^{33}$ Another option is to concatenate the time series from all subjects, as is often done in fMRI studies using group ICA, ${ }^{34}$ and to subsequently calculate group connectivity matrices and modularity. Both options were performed; however, interpretations of the results were similar. Therefore, only the results from the averaged connectivity matrices are reported here. The OCS for the group matrix was calculated and visualized for 1) the control group, 2) the entire patient group, and 3) the group of cognitively impaired patients.

\section{Analysis of Individual Connections}

The individual elements of the connectivity matrices were tested for group differences. Differences between the entire patient group and the control group as well as differences between the cognitively impaired patient group and the control group were assessed by mass univariate (two-sided) $t$-tests. Owing to the exploratory nature of this analysis, no stringent multiple comparisons methods were applied. Instead, a liberal significance threshold of $P<0.05$ was used to assess possible group differences.

Furthermore, we investigated whether any aberrant connections would show a particular relation with the modularity analysis or would reveal an effect with connection length. The relation with modularity was investigated by analyzing whether differences would manifest as inter- or intramodular connections. A possible difference in anatomical orientation was investigated by measuring the angle relative to a strict left-right orientation of connections. Hence, we 
quantified whether aberrant edges would be oriented in an anterior-posterior or left-right orientation, disregarding their anterior-superior orientation. A possible effect of connection length was assessed by the differences in Euclidian distance between connections that showed either an increase or decrease of connection strength in the entire patient group.

\section{Results}

\section{Preprocessing Results}

The motion correction procedure was able to adequately correct for movement in the majority of the cases. The control and patient group did not differ in the amount of head movement; no significant differences were found in the mean, standard deviation, and maximum of the movement parameters. Subjects were excluded when head movements exceeded $1.5 \mathrm{~mm} / \mathrm{s}$ or $1.5 \%$ in at least one direction. Data of nine patients and four controls were excluded from further analysis because of movement-related artifacts $(\mathrm{n}=8 ; 6$ patients and 2 controls) or EPI artifacts ( $n=5 ; 3$ patients and 2 controls). The final study population for analysis included 28 patients and 37 healthy controls.

\section{Cognition}

Six patients did not complete the neuropsychological assessment and had no CVST scores. These patients are included in the group analysis, but not in the correlation analysis. In total, 11 patients had a decile score below 4 and were considered cognitively impaired. The mean CVST reaction time was significantly higher in the patient group (controls: $17.3 \pm 6.4$ s, patients: 23.8 $\pm 9.5 \mathrm{~s}, \mathrm{P}<0.002)$.

\section{Between-Group Analysis of Network Parameters}

The mean matrix weight of the weighted connection matrices differ significantly neither between the control and patient group nor between the control and cognitively impaired patient group. Network parameters were assessed over a range of sparsity values $(0.35-0.75)$. Both patient and control networks showed small-world properties indicated by a high clustering compared with equivalent random networks (mean $C=1.82$, range 1.19-4.65) and a path length comparable to equivalent random networks (mean $L=1.02$, range $1.00-1.09){ }^{32}$ The binary cluster coefficient displayed significantly higher values in the cognitively impaired patient group compared with the control group for the relatively small sparsity range $0.67-0.74$. The binary path length was significantly higher in the cognitively impaired patient group compared with 

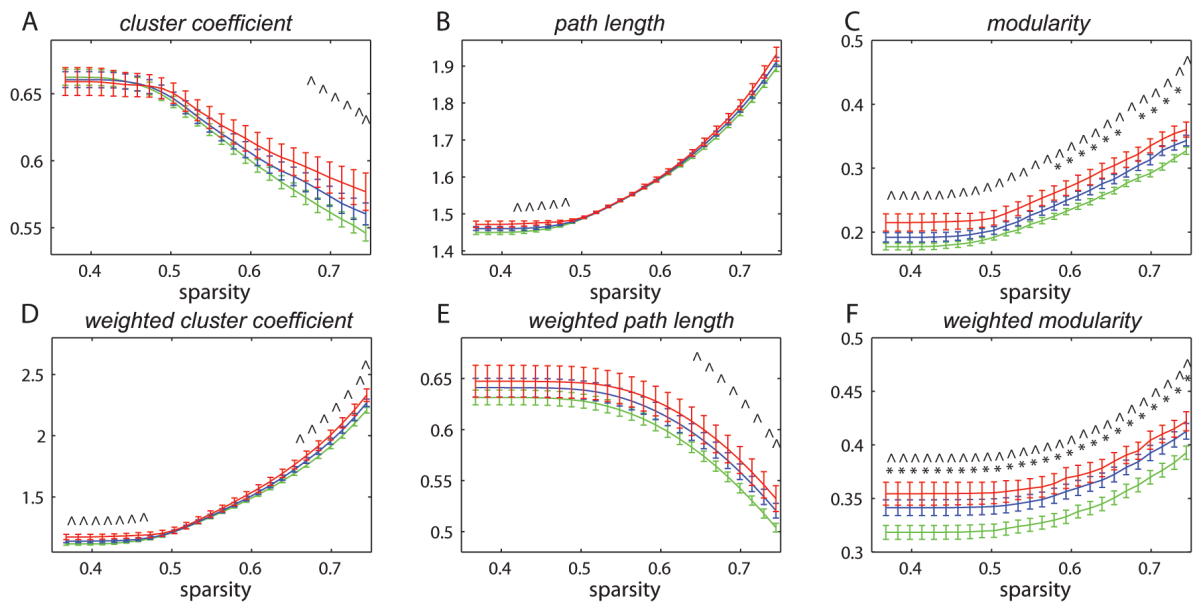

Figure 2. The mean \pm standard error (error bars) of the tested network parameters for the control group (green), the full patient group (blue), and the cognitively impaired patient group (red) as function of sparsity. An asterisk $\left(^{*}\right)$ indicates that the full patient group was significantly different from the control group. A hat $(\wedge)$ indicates that the cognitively impaired patient group was significantly different from the control group. As the sparsity increases, the number of edges in the network decreases, which causes a decrease in the binary cluster coefficient $(A)$ and an increase in the binary path length $(B)$ and binary and weighted modularity scores $(C$ and $F)$. The weighted cluster coefficient increases $(D)$ and the weighted path length increases $(E)$ because the remaining edges have high connection strengths and are strongly clustered $(D)$.

the control group for the narrow sparsity range 0.41-0.47. The weighted cluster coefficient was significantly higher for the cognitively impaired patient group compared with the healthy control group over the sparsity range 0.37-0.46 and $0.65-0.85$. The weighted path length was significantly higher for the cognitively impaired patient group compared with the healthy control group over the sparsity range $0.64-0.74$.

In contrast to $\mathrm{L}$ and $\mathrm{C}$, we found that modularity showed significant group differences over a much wider range of sparsity values. The modularity calculated from the binary networks was higher in the entire patient group compared to the control group for the sparsity range $0.58-0.73$. The cognitively impaired patient group displayed significantly higher modularity compared to the control group for the entire sparsity range. The cognitively impaired patient group also showed higher modularity scores compared to the unimpaired patient group over the sparsity range $0.37-0.70$. The weighted modularity scores were higher for both the entire patient group and the cognitively impaired patient group compared with the control group over the entire sparsity range. These results are visualized in Figure 2. 


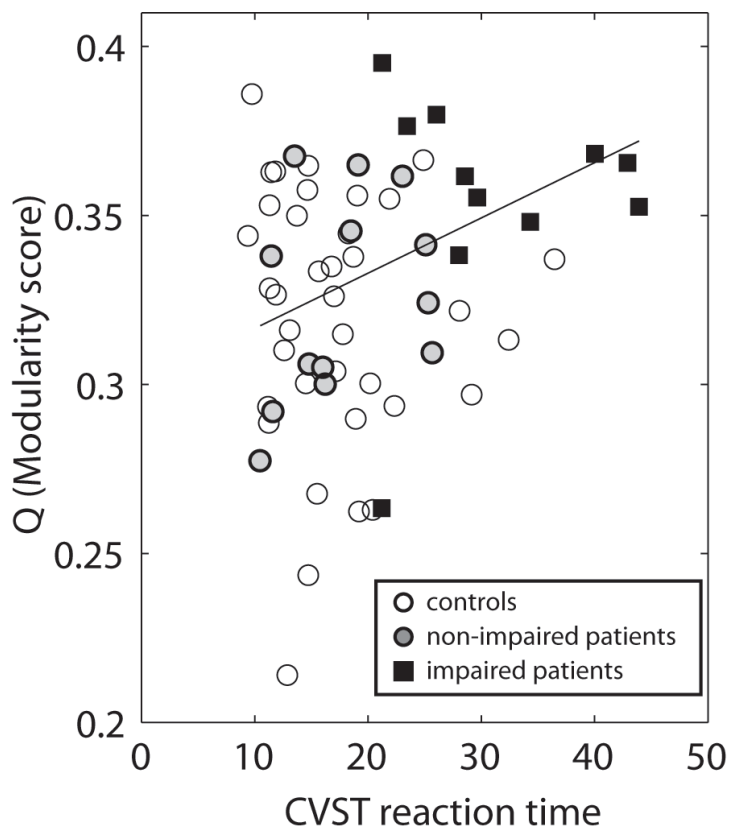

Figure 3. Scatter plot of the modularity scores against CVST scores for the control, the cognitively impaired and non-impaired patient groups. The regression line (black) of the correlation between modularity and CVST for the (full) patient group is displayed.

\section{Network Metrics, Age, and Cognitive Performance}

Within the patient group, we found that binary modularity scores significantly increased with decreased cognitive performance (i.e., increased CVST reaction time) for all sparsity values (mean $r=0.48$; range: $0.44-0.55$; all $P<0.03$ ). See Figure 3 for a plot of the correlation between CVST reaction times and modularity scores at sparsity $=0.48$. The same effect was found with the CVST decile scores, which is a normalized age- and gender-corrected score (mean $r=-0.55$; range: -0.63 to -0.47 ; all $P<0.02$ ). Higher modularity scores were associated with the longer reaction times and the lower decile scores (i.e., poor performance). The CVST reaction times positively correlated with the weighted modularity scores over the entire sparsity range (mean $r=0.47$; min-max: 0.43 - 0.54; all $P<0.05$ ). The CVST decile scores were negatively correlated with the weighted modularity scores over the entire sparsity range (mean $r=-0.45$; range -0.55 to -0.40 ; all $P<0.05$ ). No significant correlations were found in the control group. No significant correlation was found between age (range 8-13 years) and any of the network parameters. The CVST reaction times and decile scores were not significantly correlated with the binary or weighted cluster coefficient or path length in the patient or control groups.

\section{Visualization of Cerebral Modularity}

The OCS was calculated for networks thresholded at sparsity $=0.48$. About half of the possible number of edges (3500 of 6724) in the full matrix is included at 
this sparsity value, which reflects a good balance between the presence of noisy edges and an overly sparse matrix.

Four modules were found in all groups at this sparsity threshold. All modules were organized in a bilateral fashion. Figure 4 visualizes the organization of the OCS in the cerebrum, such that group differences in modules can be observed. Considering the control group, module 1 was located mainly in the frontal and parietal lobe (blue in Figure 4), module 2 was mainly located in the frontal lobe (red in Figure 4), module 3 was mainly located in the occipital lobe (yellow in Figure 4), whereas module 4 was mainly located in the frontal and temporal lobes (green in Figure 4). Both the patient group as a whole and the cognitively impaired patients displayed several differences in modular structure in both hemispheres in comparison to the control group. Module 4 (the green module) occupies occipital, parietal, temporal and prefrontal regions in the control group, whereas this module curtails only to temporal regions in the cognitively impaired patient group. Consequently, module 1 (blue) occupies most of the prefrontal regions, and therefore, the diversity of the modular composition in the frontal lobe decreases in the entire patient group, and even further decreases in the cognitively impaired patient group relative to the control group (see Supplementary Figure S1). Although the vast majority of modular differences were located in frontal regions $(n=21)$, as could be expected considering the frontal seizure focus in FLE, parietal $(n=8)$, temporal $(n=2)$, and occipital $(n=2)$ regions are also involved.

\section{Modular- and Distance-Based Characteristics of Aberrant Connections}

As shown in Figure 5A, a number of connections were found to be altered in the patient group, and a larger number of aberrant connections were found in the impaired patient group. These results were obtained at the same sparsity threshold as the one used for visualization of the modules (sparsity $=0.48$ ). Of the connections significantly different at the $P<0.05$ level, 52 (41\%) were intramodular connections, whereas 151 (59\%) were intermodular connections. Moreover, Figure $5 B$ indicates that most connections weaker in patients $(P<0.05)$ are oriented anterior-posteriorly, whereas the connections stronger in the patients are mainly oriented left-right and interhemispheric. This discrepancy in orientation was quantified by measuring the angle of the connections with respect to left-right axis (a $90^{\circ}$ angle would indicate a pure anterior-posterior orientation of an edge). This revealed that the connections weaker in patients had a significantly higher angle (hence were oriented more anterior-posteriorly) than the connections stronger in patients $\left(65.3 \pm 22.2^{\circ} \mathrm{vs}\right.$. $\left.38.8 \pm 27.5^{\circ}, P<0.001\right)$. We tested whether the anatomical distance between the connections that were either stronger or weaker would differ. We found 


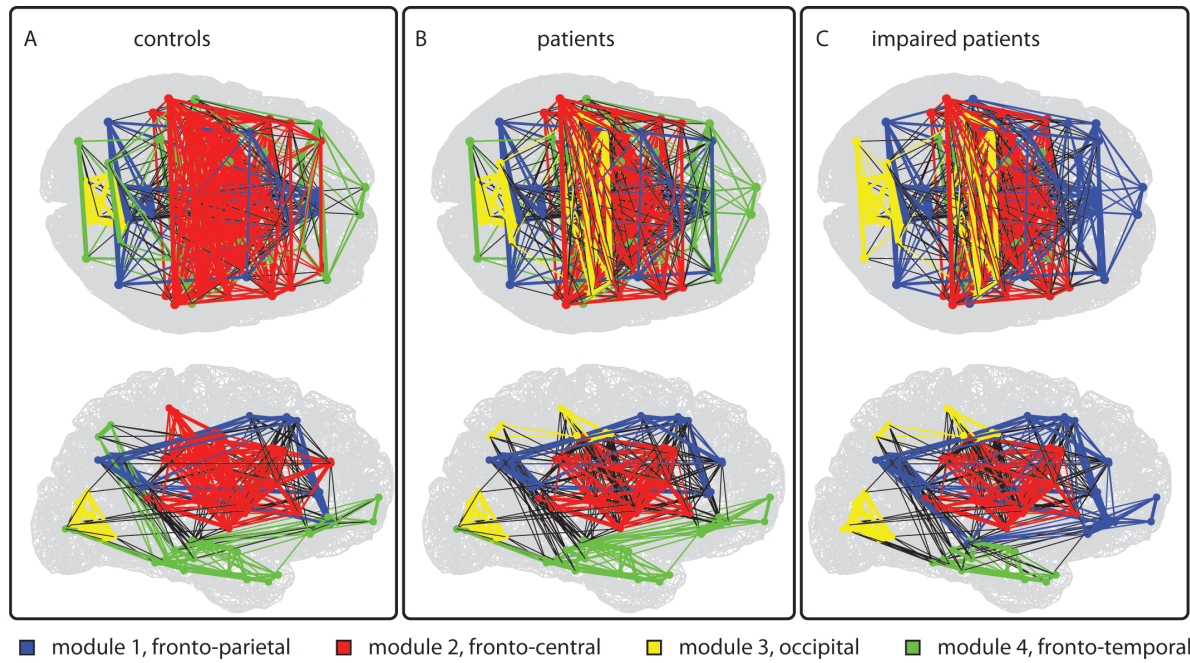

Figure 4. In the OCS, four distinct modules of the cerebrum are visualized by different colors (as in Figure1) for the healthy controls $(A)$, the full patient group (B), and the cognitively impaired patient group. Module 1 (blue) extends from frontoparietal regions in controls to more prefrontal and latero-frontal regions in patients, particularly for the cognitively impaired patients. Module 2 (red) reveals no apparent differences between patients and controls. Module 3 (yellow) extends from mere posterior occipital regions in controls to parietal and more latero-occipital regions in patients. Module 4 (green) curtails from occipital, parietal, temporal, and frontal regions to temporal and frontal regions.

that the connections that were weaker in the patient group were on average longer $(76.8 \pm 26.9 \mathrm{~mm})$ than those that were stronger in the patient group $(65.7 \pm 26.0 \mathrm{~mm}, P<0.003)$, see Figure $5 C$.

\section{Discussion}

Here, we have shown for the first time that a neuronal correlate for cognitive impairment exists in children with FLE. Our results suggest that functional networks in FLE are configured to have reduced connectivity between functional modules with a decline in long-range connectivity and an increase in interhemispheric connectivity. This was expressed by an increased modularity score in pediatric patients with epilepsy that was correlated with the cognitive impairment. Notably, in the cognitively impaired patients, the frontal lobe missed the characteristic module that functionally interacted with the temporal, parietal and occipital regions as seen in the healthy controls. Interestingly, the discrepancy in network organization found between the 


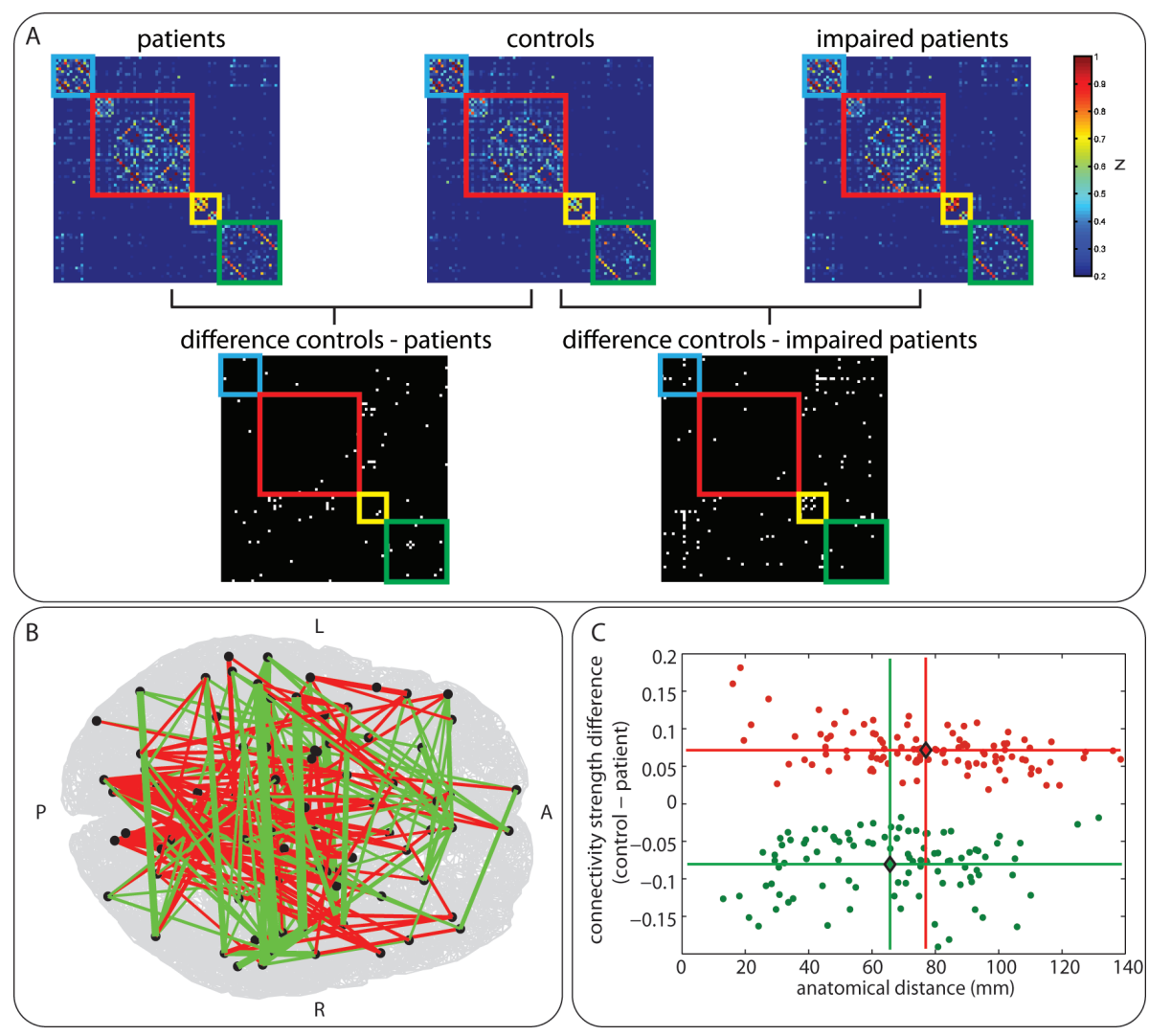

Figure 5. (A) Top row: connectivity matrices for all three groups; controls (middle), patients (left), and cognitively impaired patients (right). Colors of matrix elements indicate Fisher $z$-transformed correlation coefficients (truncated between 0.2 and 1). The rows and columns of the matrices are sorted by the modules found in the control group as indicated by the colored squares. Bottom row shows the connections that differed at the $P<0.01$ significance level (uncorrected) between the control and patient (left) and cognitively impaired patients (right). Note that most aberrant connections are intermodular. $(B)$ Location of abnormal connections at the $P<0.05$ level. Red and green lines indicate connections weaker and stronger, respectively, in patients. Red (weaker) connections are oriented in an anterior-posterior fashion, while green (stronger) connections have a left-right orientation $(C)$. Same set of connections as in $(B)$ versus anatomical distance. On average, the connections weaker in patients (red dots) are longer than the connections stronger in patients (green dots). Red and green diamonds and lines indicate the average (distance and difference) of the two classes of connections.

children with FLE (with cognitive impairments) and normal controls has previously been reported in healthy development, where a decrease in modularity and an increase in long-range connectivity was associated with normal brain maturation. ${ }^{33,35}$ 
Our results relate to a larger body of literature on the relation between cognitive performance and large-scale connectivity, where it is suggested that higher cognitive functions are the result of interactions between systems involving numerous brain regions, instead of a direct relation between cognitive functioning and single brain regions. ${ }^{36,37}$ This paradigm can also be extended to differences between healthy subjects and patients with FLE. The brain and especially the frontal lobe is a highly connected structure and thus regional abnormalities might extend beyond the seizure focus and affect distant regions and connectivity to such regions. Functional MRI measurements are ultimately dependent on the synaptic and axonal configuration of the underlying neuronal ensembles. However, it is thought that, by $\sim 9$ months of age, axonal connectivity is near complete ${ }^{38}$ but other mechanisms such as synaptic pruning ${ }^{39}$ and axonal myelination ${ }^{40}$ continue through young adulthood. How then do epileptic seizures ${ }^{41}$ and daily AED use ${ }^{42,43}$ interact with the mechanisms of normal development and how do they eventually affect development of large-scale brain connectivity as measured with fMRI? It is likely that disturbances early in life in any of these mechanisms may have profound influences on large parts of the brain, as indicated by the wholebrain network results presented here.

\section{Previous Findings}

Several studies found functional connectivity abnormalities in epilepsy by means of calculating correlation coefficients between pairs of brain regions, ${ }^{14,15,17,44-46}$ but in only one study an analysis of these correlations was performed in terms of network parameters. ${ }^{16}$ Moreover, most of these studies focused on local connectivity abnormalities (only a few regions of the brain were analyzed or considered as a reference), while here, we primarily analyzed "global" brain connectivity. Cognitive functioning depends on several cerebral networks instead of isolated brain regions. It is reasonable to assume that, in patients with epilepsy, a disruption of whole-brain networks is involved in the development of cognitive deficits, instead of a localized disruption at the site of seizure focus only. ${ }^{19}$

\section{Increased Modularity but Preserved Small-Worldness in FLE}

The means of both variants of the cluster coefficient were higher in the patients and further increased in the cognitively impaired patient group. For both variants of the path length, the same effect could be observed. The networks with high path length and high clustering are also known as regular networks: ${ }^{47}$ these are networks with high local clustering but few connections linking distant nodes. These findings are in line with the modularity analysis: high path length 
and high clustering are signs that the patient networks are organized in tightly clustered modules with only limited intermodular connectivity. However, the high clustering and comparable low path length, compared with equivalent random networks, indicate that the resting-state functional networks of both groups are still organized as an efficient small-world network. ${ }^{48}$ Previous studies have found altered small-world networks in epilepsy patients. ${ }^{16,19}$ It remains to be elucidated why these parameters only showed limited effects in this study. The network parameter modularity did show ample significant group differences. Patients, especially the cognitively impaired patients, showed higher modularity scores than controls, suggesting the presence of more functionally isolated brain modules. In line with these findings, longer reaction times (greater cognitive impairment) correlated with higher modularity scores within the patient group. It is possible that increases in coherent activity between functional systems (integration) might facilitate particular cognitive abilities. Therefore, a reduced amount of integration could lead to an impairment of cognitive functions.

When we visualized the modular structures of different subject groups (Figure 4) we observed a rearrangement of modular structures between controls and patients, which was more pronounced in the cognitively impaired subgroup. These findings suggest that disruptions of functional brain network modularity in children with cryptogenic FLE are related to their cognitive impairment. Furthermore, the vast majority of modular differences were located in frontal lobe, as could be expected considering the frontal seizure focus in FLE. Importantly, module 4 (green) comprised prefrontal, temporal, parietal and occipital regions and might thus facilitate information integration over spatially distributed regions of the brain. Especially, this module curtailed to mere temporal regions in the cognitively impaired patient group. The functional significance of this module remains to be elucidated, but the corresponding connections to the frontal lobe might be an interesting target for future studies. The finding that modular abnormalities did not seem to be restricted exclusively to the frontal lobe might imply that regions of other parts of the brain are also involved in the process that hinder some individuals with FLE to successfully perform complex cognitive tasks such as the CVST. This could also be an explanation for the broad variety of cognitive impairment seen in children with FLE.

\section{Aberrant Connections and Anatomical Distance}

We found both decreases and increases in connection strengths in the patient group (Figure 5B), although given the large number of connections tested, these findings should be interpreted with care. A further analysis on 
the anatomical length and orientation of these connections did reveal an interesting effect. Connections with decreased strength in the patients were on average longer than the connections that were increased in the patients, compared with the healthy controls. Furthermore, a predominantly anteriorposterior orientation of the connections with decreased strength and a leftright (and thus interhemispheric) orientation of connections with increased strength in the patients was found. This is in agreement with prior studies that showed that in early (normal) development mainly the long-range connections increase in strength, whereas the strength of the short-range connections decreased. ${ }^{33,35,49}$ This raises the question of whether FLE interferes with the normal development of functional brain networks. ${ }^{24,50}$ However, due to the narrow age range of our study population, network metrics could not be related to age. Future studies should include FLE patients with various, but well-defined, types of cognitive impairments, and age-matched healthy controls with a much wider age range to investigate whether cognitive impairment in FLE can be modeled as a developmental delay. ${ }^{51}$ Furthermore, the nature of network abnormalities in different childhood neurological diseases such as epilepsy, $\mathrm{ADHD}$, and autism, where cognitive impairments play a major role, should be compared. This might shed light on the commonalities and differences of network abnormalities in relation to developmental trajectories and cognitive profiles. Whether the observed changes in network organization are driven by altered developmental trajectories or by functional abnormalities in epileptic networks remain elusive. Studies using the combined EEG/fMRI analysis with well-defined epileptic zones might be able to differentiate the effects of epileptic networks on whole-brain connectivity from brain-wide abnormalities related to abnormal development.

Most connections that showed significant differences between the healthy controls and patients were intermodular connections. These are connections that contribute to the overall integration of functional systems in the brain. These findings indicate that the higher modularity scores found in the patient and cognitively impaired patient group can be mainly attributed to connectional differences in those regions that connect different modules.

\section{Clinical Significance and Future Research}

Follow-up research is needed to investigate the relationship between cognition and measures of network topology, particularly for determining the prognostic value of these measures that predict cognitive progress or delay in time. Currently, no clinical tools are available that can reliably predict the long-term cognitive outcome and drug response in children with FLE. Individual connectivity maps and network analysis might eventually serve as 
an additional tool for the neurologist to tailor the therapeutic decision-making to the network characteristics of the impaired brain, and to balance this to seizure treatment.

\section{Methodological Considerations}

Several considerations in the choice of methodology for the current study should be discussed. First, the use of resting-state fMRI has advantages over task fMRI because the experiment is not dependent on subject compliance and ability to perform a task. This can especially be relevant in pediatric studies, where differences in developmental status and task performance are present. Here, all included subjects were video-monitored during scanning and were able to lie still with their eyes closed.

Second, the current study correlated functional connectivity to performance scores of a single cognitive task. The CVST is a computerized version of Goldstein's visual search task ${ }^{52}$ and is recognized as a valid measurement for information processing speed.Information processing is akey cognitivefunction and is demonstrated to be a measurement that is sensitive to brain damage in general ${ }^{53}$ seizure effects, ${ }^{25}$ and even effects of epileptiform discharges. ${ }^{54,55}$ Despite these considerations in favor of the CVST, the assessment of other cognitive domains or global cognitive functioning is needed as well to reveal more specific neurocognitive correlates of functional reorganization.

Third, there are many algorithms designed to calculate the OCS. ${ }^{56}$ Although we applied a widely used algorithm, ${ }^{22}$ novel approaches for comparing the OCS between several different individual networks ${ }^{57}$ or groups of networks ${ }^{58}$ have also been proposed. Other authors have suggested that future algorithms might include the concept of persistence of information flowing within modules over time, ${ }^{59}$ or use the concept of hierarchy, subdividing the modules into smaller modules, which can be further subdivided into smaller modules, and so on. ${ }^{56}$ In the latter method, large modules have been described to represent consciously demanding tasks (i.e., working memory or the cognitive task from the current study), because they demand access to a more globally integrated processing system. ${ }^{60}$ Smaller modules are supposed to represent automated, anatomically localized tasks (i.e., color vision or visual motion detection). Because consciously demanding tasks usually include a combination of automated tasks, algorithms that determine the modular structure on different levels might be useful in future research relating cerebral connectivity data to cognition.

In conclusion, our results show that network modularity analysis of wholebrain resting-state fMRI connectivity provides a sensitive marker for cognitive impairment in FLE. We found that the more cognitively impaired 
the patient with FLE is, the more isolated brain subnetworks appeared to function. Cognitively impaired patients seem to have a less efficient interregional transfer of information between functional networks. We suggest that abnormally interconnected functional subnetworks of the brain might underlie the cognitive problems in children with FLE. 


\section{Supplementary Data}

A
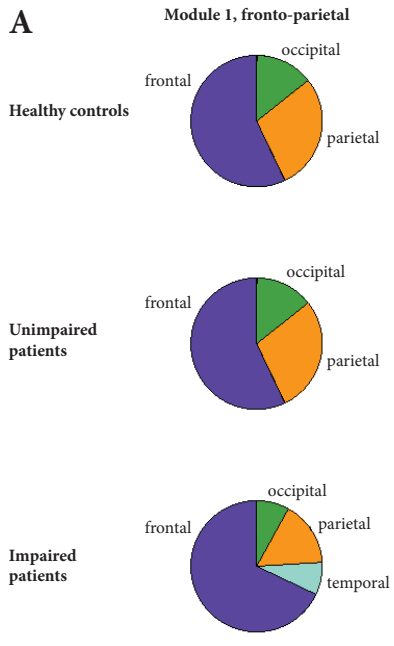
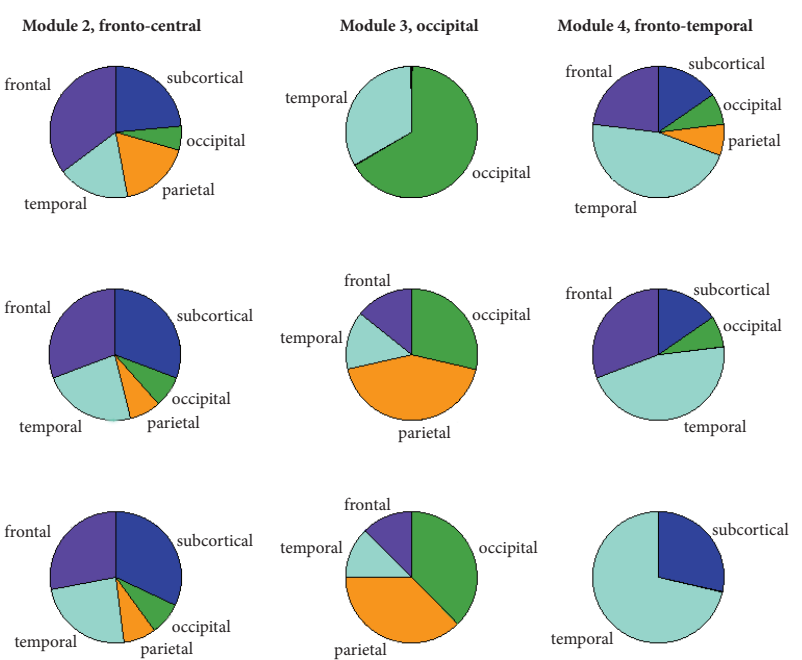

B Frontal lobe Temporal lobe Parietal lobe Occipital lobe Subcortical Healthy controls
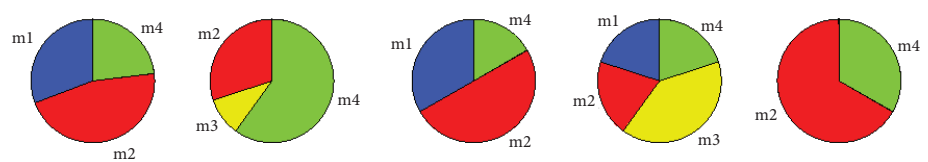
Unimpaired
patients
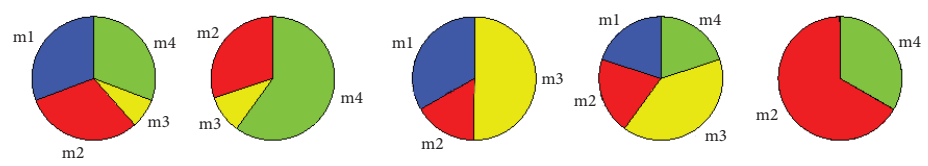

Impaired
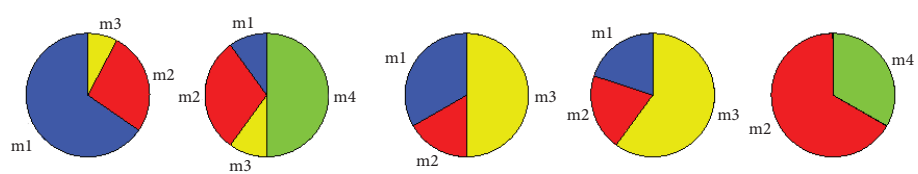

Figure S1. (A) The lobar composition of each module is depicted as a pie chart showing the relative number of regions (nodes) of each lobe to a module. For instance, module 3 is composed of only temporal and occipital regions in the control group, while parietal and frontal regions are also present in the patient groups. (B) The modular composition of each lobe is depicted here in the same fashion as in (A). The frontal lobe is occupied by regions from modules 1,2 and 4 in the control group, while in the cognitively impaired patient group, modules 1, 2 and 3 are found in the frontal lobe. The same color schemes as in Figure 1 (p.149) are used. 


\section{References}

1. Manford M, Hart YM, Sander JW, Shorvon SD. National General Practice Study of Epilepsy (NGPSE): partial seizure patterns in a general population. Neurology 1992;42:1911-1917.

2. Centeno M, Thompson PJ, Koepp MJ, Helmstaedter C, Duncan JS. Memory in frontal lobe epilepsy. Epilepsy Res 2010;91:123-132.

3. Braakman HM, Vaessen MJ, Hofman PA, Debeij-van Hall MH, Backes WH, Vles JS, Aldenkamp AP. Cognitive and behavioral complications of frontal lobe epilepsy in children: A review of the literature. Epilepsia 2011;52:849-856.

4. Prevost J, Lortie A, Nguyen D, Lassonde M, Carmant L. Nonlesional frontal lobe epilepsy (FLE) of childhood: clinical presentation, response to treatment and comorbidity. Epilepsia 2006;47:21982201.

5. Patrikelis P, Angelakis E, Gatzonis S. Neurocognitive and behavioral functioning in frontal lobe epilepsy: a review. Epilepsy Behav 2009;14:19-26.

6. Harvey AS, Hopkins IJ, Bowe JM, Cook DJ, Shield LK, Berkovic SF. Frontal lobe epilepsy: clinical seizure characteristics and localization with ictal 99mTc-HMPAO SPECT. Neurology 1993;43:19661980.

7. Laskowitz DT, Sperling MR, French JA, O'Connor MJ. The syndrome of frontal lobe epilepsy: characteristics and surgical management. Neurology 1995;45:780-787.

8. Lorenzo NY, Parisi JE, Cascino GD, Jack CR, Jr., Marsh WR, Hirschorn KA. Intractable frontal lobe epilepsy: pathological and MRI features. Epilepsy Res 1995;20:171-178.

9. Provini F, Plazzi G, Tinuper P, Vandi S, Lugaresi E, Montagna P. Nocturnal frontal lobe epilepsy. A clinical and polygraphic overview of 100 consecutive cases. Brain 1999;122 ( Pt 6):1017-1031.

10. Lawson JA, Cook MJ, Vogrin S, Litewka L, Strong D, Bleasel AF, Bye AM. Clinical, EEG, and quantitative MRI differences in pediatric frontal and temporal lobe epilepsy. Neurology 2002;58:723-729.

11. Fox MD, Raichle ME. Spontaneous fluctuations in brain activity observed with functional magnetic resonance imaging. Nat Rev Neurosci 2007;8:700-711.

12. Friston KJ. Functional and effective connectivity in neuroimaging: A synthesis. Hum Brain Mapp 1994;2:56-78.

13. Van den Heuvel MP, Hulshoff Pol HE. Exploring the brain network: a review on resting-state fMRI functional connectivity. Eur Neuropsychopharmacol 2010;20:519-534.

14. Waites AB, Briellmann RS, Saling MM, Abbott DF, Jackson GD. Functional connectivity networks are disrupted in left temporal lobe epilepsy. Ann Neurol 2006;59:335-343.

15. Bettus G, Guedj E, Joyeux F, Confort-Gouny S, Soulier E, Laguitton V, Cozzone PJ, Chauvel P, Ranjeva JP, Bartolomei F, Guye M. Decreased basal fMRI functional connectivity in epileptogenic networks and contralateral compensatory mechanisms. Hum Brain Mapp 2009;30:1580-1591.

16. Liao W, Zhang Z, Pan Z, Mantini D, Ding J, Duan X, Luo C, Lu G, Chen H. Altered functional connectivity and small-world in mesial temporal lobe epilepsy. PLoS One 2010;5:e8525.

17. Pereira FR, Alessio A, Sercheli MS, Pedro T, Bilevicius E, Rondina JM, Ozelo HF, Castellano G, Covolan RJ, Damasceno BP, Cendes F. Asymmetrical hippocampal connectivity in mesial temporal lobe epilepsy: evidence from resting state fMRI. BMC Neurosci 2010;11:66.

18. Vlooswijk MC, Jansen JF, Majoie HJ, Hofman PA, de Krom MC, Aldenkamp AP, Backes WH. Functional connectivity and language impairment in cryptogenic localization-related epilepsy. Neurology 2010;75:395-402.

19. Vlooswijk MC, Vaessen MJ, Jansen JF, de Krom MC, Majoie HJ, Hofman PA, Aldenkamp AP, Backes WH. Loss of network efficiency associated with cognitive decline in chronic epilepsy. Neurology 2011;77:938-944. 
20. Pravata E, Sestieri C, Mantini D, Briganti C, Colicchio G, Marra C, Colosimo C, Tartaro A, Romani GL, Caulo M. Functional connectivity MR imaging of the language network in patients with drugresistant epilepsy. AJNR Am J Neuroradiol 2011;32:532-540.

21. Rubinov M, Sporns O. Complex network measures of brain connectivity: uses and interpretations. Neuroimage 2010;52:1059-1069.

22. Newman ME. Modularity and community structure in networks. Proc Natl Acad Sci U S A 2006;103:8577-8582.

23. van den Heuvel MP, Stam CJ, Kahn RS, Hulshoff Pol HE. Efficiency of functional brain networks and intellectual performance. J Neurosci 2009;29:7619-7624.

24. Power JD, Fair DA, Schlaggar BL, Petersen SE. The development of human functional brain networks. Neuron $2010 ; 67: 735-748$.

25. Aldenkamp AP, Arends J, Verspeek S, Berting M. The cognitive impact of epileptiform EEGdischarges; relationship with type of cognitive task. Child Neuropsychol 2004;10:297-305.

26. Ghosh SS, Kakunoori S, Augustinack J, Nieto-Castanon A, Kovelman I, Gaab N, Christodoulou JA, Triantafyllou C, Gabrieli JD, Fischl B. Evaluating the validity of volume-based and surface-based brain image registration for developmental cognitive neuroscience studies in children 4 to 11 years of age. Neuroimage 2010;53:85-93.

27. Van Dijk KRA, Hedden T, Venkataraman A, Evans KC, Lazar SW, Buckner RL. Intrinsic Functional Connectivity As a Tool For Human Connectomics: Theory, Properties, and Optimization. J Neurophysiol 2010;103:297-321.

28. Vaessen MJ, Hofman PA, Tijssen HN, Aldenkamp AP, Jansen JF, Backes WH. The effect and reproducibility of different clinical DTI gradient sets on small world brain connectivity measures. Neuroimage 2010;51:1106-1116.

29. Achard S, Bullmore E. Efficiency and cost of economical brain functional networks. PLoS Comput Biol 2007;3:e17.

30. Ginestet CE, Nichols TE, Bullmore ET, Simmons A. Brain network analysis: separating cost from topology using cost-integration. PLoS One 2011;6:e21570.

31. Maslov S, Sneppen K. Specificity and stability in topology of protein networks. Science 2002;296:910913.

32. Watts DJ, Strogatz SH. Collective dynamics of ,small-world' networks. Nature 1998;393:440-442.

33. Fair DA, Cohen AL, Power JD, Dosenbach NU, Church JA, Miezin FM, Schlaggar BL, Petersen SE. Functional brain networks develop from a „local to distributed“ organization. PLoS Comput Biol 2009;5:e1000381.

34. Filippini N, MacIntosh BJ, Hough MG, Goodwin GM, Frisoni GB, Smith SM, Matthews PM, Beckmann CF, Mackay CE. Distinct patterns of brain activity in young carriers of the APOE-epsilon4 allele. Proc Natl Acad Sci U S A 2009;106:7209-7214.

35. Hagmann P, Sporns O, Madan N, Cammoun L, Pienaar R, Wedeen VJ, Meuli R, Thiran JP, Grant PE. White matter maturation reshapes structural connectivity in the late developing human brain. Proc Natl Acad Sci U S A 2010;107:19067-19072.

36. Bressler SL, Menon V. Large-scale brain networks in cognition: emerging methods and principles. Trends Cogn Sci 2010;14:277-290.

37. Menon V. Large-scale brain networks and psychopathology: a unifying triple network model. Trends Cogn Sci 2011;15:483-506.

38. Conel JLR. The postnatal development of the human cerebral cortex: The cortex of the three-month infant: Harvard University Press, 1947.

39. Huttenlocher PR. Synaptic density in human frontal cortex - developmental changes and effects of aging. Brain Res 1979;163:195-205. 
40. Fields RD. Myelination: an overlooked mechanism of synaptic plasticity? Neuroscientist 2005;11:528531.

41. Dodrill CB. Progressive cognitive decline in adolescents and adults with epilepsy. Prog Brain Res 2002;135:399-407.

42. Vermeulen J, Aldenkamp AP. Cognitive side-effects of chronic antiepileptic drug treatment: a review of 25 years of research. Epilepsy Res 1995;22:65-95.

43. Kuhnert MT, Elger CE, Lehnertz K. Long-term variability of global statistical properties of epileptic brain networks. Chaos 2010;20:043126.

44. Zhang Z, Lu G, Zhong Y, Tan Q, Liao W, Chen Z, Shi J, Liu Y. Impaired perceptual networks in temporal lobe epilepsy revealed by resting fMRI. J Neurol 2009;256:1705-1713.

45. Zhang Z, Lu G, Zhong Y, Tan Q, Yang Z, Liao W, Chen Z, Shi J, Liu Y. Impaired attention network in temporal lobe epilepsy: a resting FMRI study. Neurosci Lett 2009;458:97-101.

46. Wang Z, Lu G, Zhang Z, Zhong Y, Jiao Q, Tan Q, Tian L, Chen G, Liao W, Li K, Liu Y. Altered resting state networks in epileptic patients with generalized tonic-clonic seizures. Brain Res 2011;1374:134141.

47. Sanz-Arigita EJ, Schoonheim MM, Damoiseaux JS, Rombouts SA, Maris E, Barkhof F, Scheltens P, Stam CJ. Loss of 'small-world' networks in Alzheimer's disease: graph analysis of FMRI resting-state functional connectivity. PLoS One 2010;5:e13788.

48. Stam CJ, Jones BF, Nolte G, Breakspear M, Scheltens P. Small-world networks and functional connectivity in Alzheimer's disease. Cereb Cortex 2007;17:92-99.

49. Supekar K, Musen M, Menon V. Development of large-scale functional brain networks in children. PLoS Biol 2009; 7:e1000157.

50. Uddin LQ, Supekar K, Menon V. Typical and atypical development of functional human brain networks: insights from resting-state FMRI. Front Syst Neurosci 2010;4:21.

51. Church JA, Fair DA, Dosenbach NU, Cohen AL, Miezin FM, Petersen SE, Schlaggar BL. Control networks in paediatric Tourette syndrome show immature and anomalous patterns of functional connectivity. Brain 2009;132:225-238.

52. Goldstein G, Welch RB, Rennick PM, Shelly CH. The validity of a visual searching task as an indicator of brain damage. J Consult Clin Psychol 1973;41:434.

53. DeMita MA, Johnson JH, Hansen KE. The validity of a computerized visual searching task as an indicator of brain damage. Behav Res Methods 1981;13:592-594.

54. Aldenkamp AP, Beitler J, Arends J, van der Linden I, Diepman L. Acute effects of subclinical epileptiform EEG discharges on cognitive activation. Funct Neurol 2005;20:23-28.

55. Aldenkamp AP, Arends J, de la Parra NM, Migchelbrink EJ. The cognitive impact of epileptiform EEG discharges and short epileptic seizures: relationship to characteristics of the cognitive tasks. Epilepsy Behav 2010;17:205-209.

56. Meunier D, Lambiotte R, Bullmore ET. Modular and hierarchically modular organization of brain networks. Front Neurosci 2010;4:200.

57. Meunier D, Lambiotte R, Fornito A, Ersche KD, Bullmore ET. Hierarchical modularity in human brain functional networks. Front Neuroinformatics 2009;3:37.

58. Alexander-Bloch AF, Gogtay N, Meunier D, Birn R, Clasen L, Lalonde F, Lenroot R, Giedd J, Bullmore ET. Disrupted modularity and local connectivity of brain functional networks in childhood-onset schizophrenia. Front Syst Neurosci 2010;4:147.

59. Delvenne JC, Yaliraki SN, Barahona M. Stability of graph communities across time scales. Proc Natl Acad Sci U S A 2010;107:12755-12760.

60. Zeki S, Bartels A. The autonomy of the visual systems and the modularity of conscious vision. Philos Trans R Soc Lond B Biol Sci 1998;353:1911-1914. 


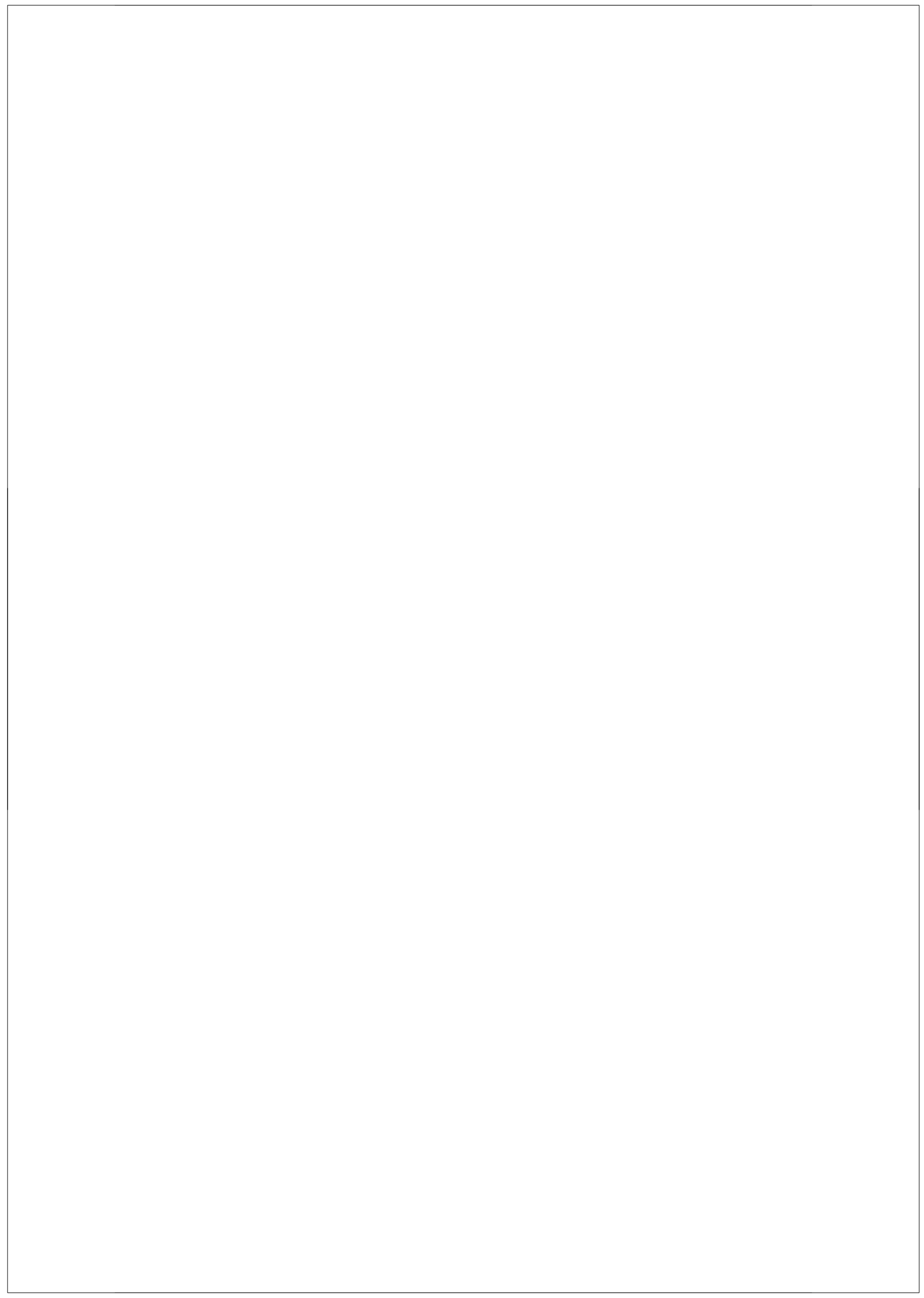




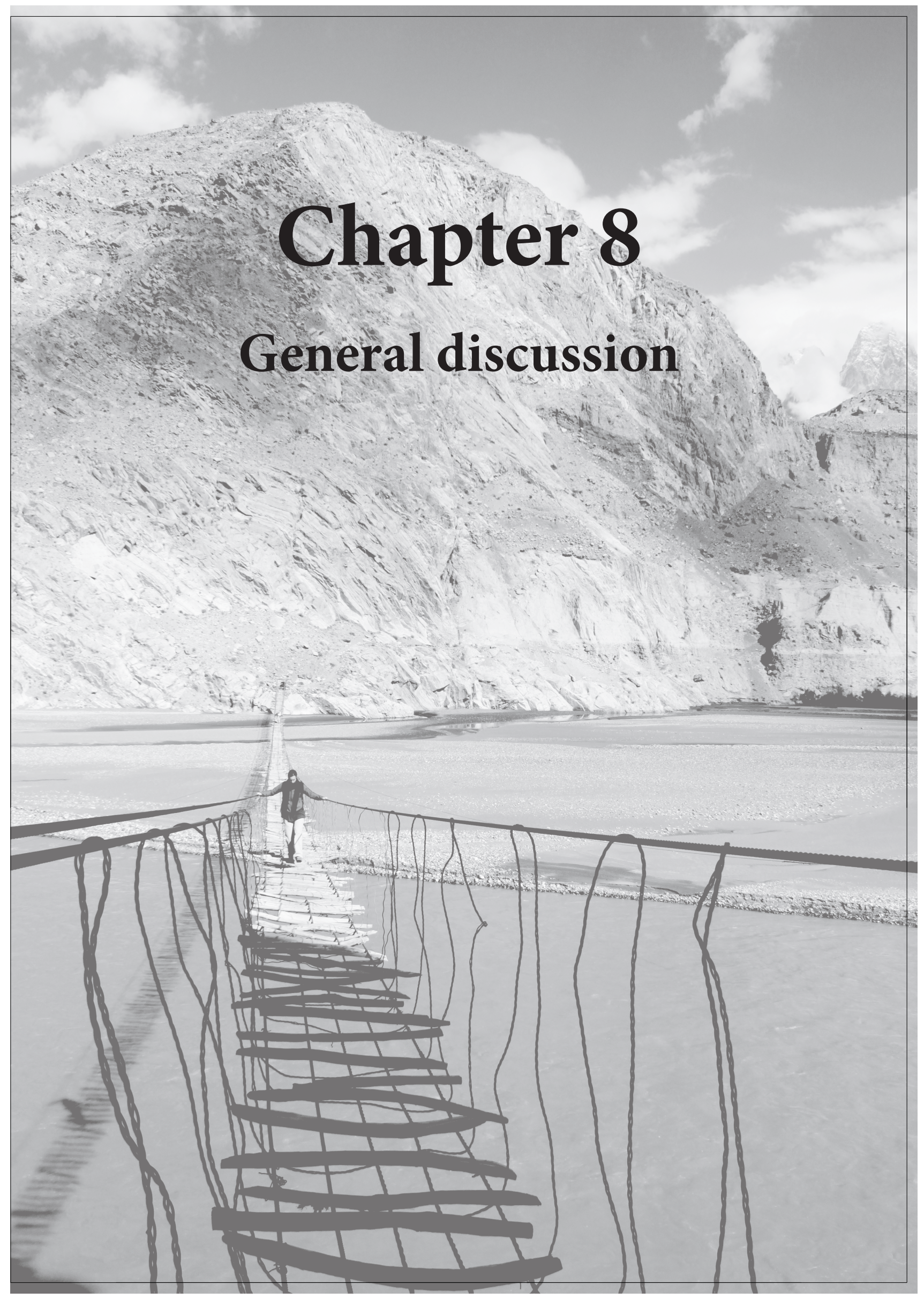




\section{General Discussion}

\section{Cognitive functioning in children with FLE}

The first aim of this thesis was to investigate whether cognitive impairment, one of the major comorbidities in children and adults with epilepsy, is also an important complication of FLE in childhood. In literature, the prevalence of cognitive impairment in children with FLE remains unclear. Very few epidemiologic and neuropsychological studies have been performed, and this is an area that warrants further research. Existing case series provide no data on the frequency of cognitive impairment in children with FLE. It is clear, though, that considerable intra- and inter-individual variation in cognitive performance exists (Chapter 2.1). Impaired attention and executive functions are the most frequently reported deficits. ${ }^{1-4}$ In addition, language impairment, ${ }^{1,5-8}$ memory deficits, ${ }^{6,9-11}$ and declines in intelligence scores have been described in children with FLE (Chapter 2.1). ${ }^{4,6,12}$

To gain more insight in the frequency and extent of cognitive impairment, we measured the performance of 71 children with FLE of unknown cause (previously named 'cryptogenic FLE') on intelligence tests, neuropsychological tests, and by behavioural questionnaires. Age-dependent normative values were used for reference. We found that children with FLE performed worse on intellectual and neuropsychological tests compared to reference values. Most children had impairments on a broad range of cognitive domains. These impairments were not restricted to the typical frontal lobe impairments but were widespread and often led to learning problems and a need for special education (Chapter 2.2). The performance of patients was typically worse on tasks measuring visual-spatial functions, memory, psychomotor speed and alertness. Behavioural problems included attention problems, anxiety and internalizing behaviour. Thirty percent of the children with FLE attended special education. Of the 70 percent of children who attended regular education, we performed school achievement tests in 46 of the 50 children (92\%). These tests revealed that $71 \%$ of the children had severe delays in school achievement (Chapter 2.2). Thus, cognitive impairment is an important complication of FLE in childhood.

This study and its design have important intrinsic limitations. First, the reference centre setting may lead to selection bias. Second, the use of a control group with other types of epilepsy may be superior to a normative reference. The cognitive and behavioural impairments measured may be characteristic of (childhood) epilepsy in general, rather than FLE specifically. Therefore, comparison with other epilepsy types would be necessary to sort out which of these impairments could be attributed to FLE. 


\section{Etiology of cognitive impairment in children with FLE}

FLE in childhood is mostly of unknown cause, i.e. no structural brain abnormalities are present on normal MRI scans. ${ }^{11-17}$ Accordingly, no such macrostructural brain abnormalities explain the cognitive impairment observed in children with FLE of unknown cause (Chapter 2.1). We found that clinical epilepsy factors such as seizure frequency, age at seizure onset or site of seizure focus, too, did not explain the cognitive impairments (Chapter 2.2). The cause of cognitive impairment therefore remains unclear.

Unravelling those underlying causes of cognitive impairment in children FLE of unknown cause was the second aim of this thesis. As gross structural brain abnormalities were lacking in these children with FLE, the underlying causes of these cognitive impairments could probably be found at the brain's functional or microstructural level. With advanced MRI techniques, including functional MRI (fMRI), volumetric MRI, diffusion tensor imaging (DTI) as well as sophisticated post-processing of MRI data, such as in graph theoretical analysis, we aimed to explore neuronal correlates of cognitive impairment in children with FLE. Literature research revealed that all of these MRI techniques were potentially capable to demonstrate at least part of the neuronal correlates of cognitive impairment in patients with all forms of epilepsy, although just two studies focused on FLE, albeit in adults (Chapter 3). ${ }^{18,19}$ None of these studies had applied both functional as well as (micro)structural imaging in the same patient cohort to investigate cognitive functioning, or focused only on one cerebral structure and therefore, no overall conclusions about the neuronal correlates of cognitive impairment in epilepsy could be made (Chapter 3).

\section{IMAGINE - The imaging studies, by technique}

As the cognitive impairments in children with FLE are diverse in nature and not limited to the typical frontal lobe functions, we focused on the whole brain to investigate the underlying causes of cognitive impairment in children with FLE. In the IMAGINE study (IMAGing study IN children with frontal lobe Epilepsy), a case-control design, we applied fMRI, volumetric MRI and DTI of the brain, as well as graph theoretical analysis, to explore functional and/or (micro)structural differences between patients and controls; moreover, among the patients, we investigated differences between those with and without cognitive impairment. We found such differences between children with FLE and controls! Such differences were detected by fMRI, volumetric MRI, DTI as well as by graph theoretical analysis. We found differences between patients and controls, i.e. related to the FLE itself, as well as differences between cognitively impaired and unimpaired patients, i.e. specifically associated with cognitive impairment (Chapters 4, 5, 6, 7). 


\section{Grey matter responses: functional MRI results}

First, we applied fMRI to explore possible functional neuronal correlates of cognitive impairment in children with FLE. During scanning, the patients and controls performed a Sternberg letter recognition task, which reflects working memory performance. We measured which brain areas showed activation induced by this task and to what extent. Similar regions were activated in the patient and the control group. Quantitatively, patients showed less cerebral activation in several regions during task performance than controls, although this did not reach statistical significance (Chapter 4). Similarly, no significant differences in cerebral activation between patients with epilepsy and controls were found during working memory task performance in adult patients with juvenile myoclonic epilepsy ${ }^{20}$ and during word-generation and text-reading performance in adult patients with localization-related epilepsy of unknown cause. ${ }^{21}$ Yet, other studies have reported significant differences in cerebral activation patterns in patients with epilepsy. In adult patients with TLE, these differences presented either as shifts of activation to the hemisphere contralateral to the seizure focus during memory task performance ${ }^{22-24}$ or as activation in areas that normally do not show activation during a particular task..$^{25}$ The only fMRI study performed in adult patients with FLE revealed the occurrence of both types of activation shifts: patients without memory impairment showed increased activation in frontal lobe areas contralateral to the seizure focus compared to patients with memory impairment, who had an absence of this increased frontal activation and showed a decreased activation in mesial temporal lobe areas during memory task performance. ${ }^{19}$

Two interpretations exist for this activation in areas that normally do not show activation during a particular task; the first is that this represents brain plasticity, an effective compensatory mechanism to maintain memory function, as only patients with FLE without memory impairment showed this activation pattern. ${ }^{19}$ The second interpretation also centres on brain plasticity; a cortical reorganization secondary to a functional reorganization of memory. However, memory performance in the studied cohort of patients with TLE was poor, suggesting that this reorganization was not efficient. Therefore this activation pattern reflects an inefficient reorganization. ${ }^{25}$

Compared to the previously mentioned studies, we used a rather stringent method to correct for multiple comparisons in our analysis of cerebral activation and therefore did not find differences in cerebral activation between children with FLE and healthy controls (Chapter 4). If we did not use this method and only corrected for gender and age, we also would have demonstrated significant differences in cerebral activation during working memory task performance in our patients with FLE, i.e. significantly decreased activation in 
the left and right superior temporal gyrus and the right middle temporal gyrus compared to the healthy control group. In addition, the cognitively impaired patients would have demonstrated a significantly increased activation of the right superior parietal lobe compared to the unimpaired patients. This can thus be interpreted as an ineffective cortical reorganization.

Second, we investigated to which extent the different brain regions were connected. We found that children with FLE, regardless of their cognitive functioning, showed a significantly decreased functional connectivity throughout the whole brain, compared to controls during working memory task performance. This implies that FLE in children is associated with a global network disorder. Importantly, cognitively impaired children with FLE had a decreased connectivity of a specific subset of frontal lobe connections compared to cognitively unimpaired children with FLE. This decreased frontal lobe connectivity comprised both connections within the frontal lobe as well as connections from the frontal lobe to the parietal lobe, temporal lobe, cerebellum, and basal ganglia (Chapter 4). This confirms that the frontal lobe network has a key role in cognitive functioning in children with FLE. The decreased connectivity between the frontal lobe and many other brain areas fits well with our observation that the cognitive impairments in children with FLE span multiple cognitive domains (Chapter 2) and implies that extensive coordinated networks are required for cognitive functioning. Based hereupon, FLE in children appears to be associated with a widespread cerebral network disruption and the cognitive impairment in children with FLE with a disruption of the frontal network specifically.

We performed the first study that assessed functional connectivity in a cohort of patients with FLE. As a result, there are no data to compare or confirm our findings. Functional connectivity studies have been performed in adult patients with mesial TLE: in line with our findings, these have shown that altered connectivity is observed not only in the network of mesiotemporal structures, i.e. structures in which the seizure focus resides, ${ }^{26}$ but also in network structures distant from the seizure focus. ${ }^{27-31}$

The exact abnormalities revealed by fMRI during a working memory task appear to depend largely on the underlying diseases and the way by which they interfere with the performance of the task. Functional MRI with working memory tasks has, for example, been applied to assess cerebral activation and/or functional connectivity in patients with schizophrenia. These patients had decreased activation in temporal and occipital lobe regions with normal frontal lobe activation, ${ }^{32}$ and decreased connectivity between the anterior cingulate cortex and temporal lobes, cerebellum and subcortical regions, and the occipital lobe and the cerebellum..$^{33}$ Both these studies concluded that 
patients with schizophrenia have abnormalities in visual processing pathways, which impair working memory performance.

Decreased frontal lobe connectivity during working memory task performance measured in our study is likely characteristic for children with FLE and cognitive impairment. Likely, the decreased connectivity of the specific frontal lobe connections are a reflection of the site in the information processing pathway applied in the working memory task that is affected by these children's FLE; working memory is an executive function and is regarded as a typical frontal lobe function. ${ }^{34,35}$ Conversely, in patients with schizophrenia, the visual information processing - a critical step in any visual working memory task - is altered and decreased connectivity is mainly measured in posterior lobes.

The question remains why the frontal lobe connectivity is decreased and which factors contribute to this decrease. A possible explanation is that altered frontal connectivity reflects degeneration of previously intact connections. This is supported by the fact that these connections are intact in the cognitively unimpaired children with FLE (Chapter 4).

One of the key limitations of our fMRI study was that it only provided insight in cerebral activation patterns and cerebral connectivity during performance of one specific task. The task that was performed in our fMRI study was a working memory task, which is a typical frontal lobe function. ${ }^{34,35}$ This may, in part, explain why we found frontal lobe networks to be specifically associated with cognitive impairment in patients with FLE. Disturbances in non-frontal networks may remain undetected if these networks are not challenged by the task performed during scanning. For example, in adult patients with localization-related epilepsy of unknown cause, decreased connectivity in the language networks was diagnosed by fMRI combined with a language task. ${ }^{21}$ Owing to the limitations inherent to fMRI in its current set-up, we do not know the exact direction in which the connectivity is decreased i.e., whether in cognitively impaired children with FLE, the frontal lobe impacts on the parietal lobe, temporal lobe, cerebellum, and basal ganglia or the other way around. Given the fact that we performed a single measurement for all participants, we cannot study the progression of the observed changes over time; such information could shed important light on the mechanisms underlying the cognitive impairment and possibly FLE itself.

\section{Brain morphology: volumetric MRI results}

Automated morphometric techniques such as volumetric MRI can detect more subtle morphological abnormalities than normal structural MRI. The four most important results of our volumetric MRI were that, first, children with FLE had 
larger total cerebral white matter volumes than controls; second, children with FLE had smaller volumes of several frontal and extra-frontal cortex structures than controls; third, the group of cognitively impaired children with FLE had significantly smaller volumes of various cortex structures within the frontal lobe and in extra-frontal regions, most notably temporal cortex volumes; last, within the temporal cortex, middle temporal grey matter volume and entorhinal cortex thickness were specifically smaller in patients with cognitive impairment than in the cognitively unimpaired patients.

These findings might well explain the broad scale of cognitive domains affected in children with FLE complicated by cognitive impairment and highlights that FLE impacts on areas beyond the frontal lobe (Chapter 2.2).

The smaller entorhinal cortex volumes have not previously been associated with cognitive impairment in either TLE or FLE. The importance of the entorhinal cortex in cognitive functioning has previously been demonstrated in patients with neurodegenerative brain disease and in patients with schizophrenia. In patients with Alzheimer's disease and mild cognitive impairment a decrease in entorhinal cortex volume has been associated with a decline in memory performance. ${ }^{36}$ In patients with schizophrenia, left entorhinal cortex volumes were significantly smaller in patients with schizophrenia than in healthy controls. Smaller entorhinal cortex volumes correlated with more severe psychotic symptoms in patients with schizophrenia. ${ }^{37}$

Two other volumetric MRI studies have been performed in patients with FLE, but none of them related the results to cognitive functioning. The first study investigated subcortical volumes, i.e., volumes of the bilateral caudate nucleus, putamen, pallidum, and thalamus in adult patients with extra-temporal lobe epilepsy, including FLE. They found that extra-temporal lobe epilepsy was not associated with smaller volumes in the studied subcortical structures. ${ }^{38}$ The fact that this study was performed in adults and investigated a limited number of subcortical structures limits comparisons with our findings. The second study investigated cortical thickness in children with therapy resistant FLE. Children with FLE with a left sided seizure focus demonstrated reduced cortical thickness in multiple left frontal, left parietal, left temporal, as well as in right frontal, right parietal, and right temporal cortex structures. In children with FLE with a right sided seizure focus, reduced cortical thickness was measured in right frontal, right temporal, right occipital, as well as in left frontal, left parietal, and left temporal cortex structures. ${ }^{39}$ We also found that cortical changes in children with FLE were present both in the frontal lobe as well as in extra-frontal lobes (Chapter 5). The results of our volumetric study in the cognitively impaired children with FLE are also in line with volumetric MRI studies in adults with TLE complicated by cognitive impairment, in 
which abnormal volumes are not only seen in the area in which the seizure focus resides but also in areas connected to or distant from the seizure focus (reviewed in Chapter 3). For example, both volume loss of the hippocampus as well as reduction of total white matter volume have been associated with memory impairment in TLE patients. ${ }^{40,41}$

Volumes of both frontal and extra-frontal cortex structures as well as subcortical structures differ between children with FLE and controls, as well as between cognitively impaired and unimpaired children with FLE. Thus FLE itself is associated with volumetric abnormalities of multiple cortical structures throughout the brain and volumetric abnormalities of particular structures lead to or are associated with the development of cognitive impairment.

The limitations of the volumetric MRI study are identical to those of the fMRI study: because we performed a single measurement for all participants, we do not know whether the smaller volumes reflect atrophy or a delay in growth or maturation. In addition, we do not know whether the larger cortical volumes in patients with FLE compared to controls and in cognitively impaired compared to unimpaired patients reflect a (temporary) compensatory mechanism.

\section{White matter properties: diffusion tensor imaging results}

Neuronal activity is transmitted via white matter tracts, bundles of huge number of axons. ${ }^{42}$ These white matter tract bundles form the structural brain network. In our search for neuronal correlates of cognitive impairment in children with FLE, we used DTI to investigate whether disturbances in this structural brain network were associated with cognitive impairment. With DTI abnormalities of the microstructure of cerebral white matter, both within brain regions and in the bundle tracts connecting these regions, can be assessed through the measurement of water diffusion. The two parameters that can be determined by DTI are fractional anisotropy (FA) and diffusivity or apparent diffusion co-efficient (ADC). FA is a measure of anisotropy, the tendency of water to diffuse in one direction as opposed to randomly in any direction. $\mathrm{ADC}$ is a measurement of the water diffusion (i.e. motility) without reference to a preferred direction. Motion of the fluid in the white matter of the brain is normally restricted to movement along the same direction as the axon or myelin sheath. When there is damage to the neurons or myelin sheaths, FA decreases and ADC increases because the fluid can move freely in any direction. ${ }^{43,44}$ With diffusion tractography, the three-dimensional location of specific white matter tracts can be assessed, which provides the opportunity to study specific connections. ${ }^{45}$ In addition, DTI allows measurement of white matter tract bundle volumes. 
We found that in children with FLE, the diffusional properties of the cerebral white matter were affected and that the abnormalities were not confined to the regions in which the seizure focus resided. Rather, the abnormalities were mostly located in posterior brain regions (Chapter 6). The differences in white matter diffusion properties between the patient and the control group included a significantly lower FA of the white matter tract bundles between the right frontal and right occipital lobe in the patient group, and significantly lower ADC values of six white matter tract bundles, mainly located in the more posterior brain regions, in the patient group. Three tract bundle collections had a significantly smaller volume in the patient than in the healthy control group, i.e. the bundles between the right frontal and right temporal lobe; right frontal and right parietal lobe; and right parietal and right occipital lobe. The volume of the collection of tract bundles connecting the left temporal and right temporal lobe was significantly larger in the patient than in the control group (Chapter 6).

None of the differences in white matter FA and ADC differed significantly between the cognitively impaired and unimpaired patient group. However, the cognitively impaired patient group demonstrated a significantly increase in FA of the white matter of the left and right occipital lobe, as well as a significantly lower FA of the white matter tract bundles between the right frontal and left occipital lobe than the control group, whereas these were not significantly different between the total patient group and controls. The volume of the collection of tract bundles connecting the left frontal and left temporal lobe, as well as those connecting the right frontal and right parietal lobe was significantly smaller in the cognitively impaired patient group than in the healthy control group, whereas these, too, were not significantly different between the total patient group and controls (Chapter 6). The observation that FA and bundle volumes differed significantly between cognitively impaired patients with FLE and controls, but not between the cognitively unimpaired patients and controls suggest a sliding scale, in which abnormalities are most pronounced in the patients with cognitive impairment (Chapter 6). These abnormalities might thus represent part of the etiology of cognitive impairment complicating FLE in children.

A reduced FA is often interpreted as a marker of white matter degeneration. Explanations for a reduced FA include degeneration of axons, reduced packing density of axons, demyelination, dysmyelination and an increased proportion of crossing fibers. ${ }^{46}$ The increased occipital white matter FA value in the cognitively impaired patient group compared to the control group could indicate an increase in myelination, thus earlier (pre-term) maturation possibly due to epileptiform activity, or an increase in axonal packing. In childhood, the white 
matter undergoes progressive increases in volume and changes in composition due to increases in axonal diameter and increasing myelination. ${ }^{47}$ Myelination processes follow a posterior to anterior direction..$^{48}$ Our data suggests that FLE affects this posterior to anterior maturation process.

It remains questionable whether this disturbance in the structural brain network is typical for FLE. Only seven DTI studies have been performed in children with epilepsy without macrostructural visible brain damage. ${ }^{49-55}$ These studies, too, observed alterations of the cerebral white matter that were not restricted to the area of the seizure focus, in various epilepsy types and even near to the time of diagnosis of epilepsy. ${ }^{49-55}$ Remarkable is that none of these studies found an accelerated maturation, and none of these studies related their findings to cognitive performance. ${ }^{49-55}$

Seven studies have investigated the link between white matter abnormalities and cognition in adults with epilepsy. ${ }^{18,56-61}$ All these studies have demonstrated abnormalities of the white matter not restricted to the seizure focus and associated with cognitive performance in patients with TLE ${ }^{56-61}$ and FLE. ${ }^{18}$

We did not observe differences in white matter properties directly between cognitively impaired and unimpaired children with FLE, which contrasts with the previously discussed findings in adult patients with epilepsy. A possible explanation of this difference could be that these abnormal diffusion properties reflect compensatory changes and reorganization and that this occurs only after a long epilepsy duration. For example, three studies in adult patients with TLE found a correlation between white matter abnormalities and duration of epilepsy. ${ }^{60,61,62}$ It could be that for our group of young children with FLE, duration of epilepsy is relatively short compared to adult patients with epilepsy since their childhood. Whether a high seizure frequency predisposes to cognitive impairments and alterations in white matter structure remains controversial. ${ }^{57,62}$ In our study the seizure frequency did not differ between cognitively impaired and unimpaired children with FLE (Chapter 6).

Another explanation for the differences in white matter structure between cognitively impaired and unimpaired patients might be that studies in adult patients with epilepsy have generally investigated specific white matter tracts known for their role in a particular cognitive task performance; for example the importance of the uncinate fasciculus in episodic memory function. ${ }^{58}$ We have investigated white matter tract bundles between the different brain lobes rather than specific task related white matter tracts. As a result, subtle abnormalities in such specific tracts may have remained undetected. Third, other MRI studies have revealed that among children with epilepsy, those with brain abnormalities (e.g. leukomalacia/gliosis) performed worse than children without MRI abnormalities on a range of cognitive tests. ${ }^{63}$ This argument is 
further strengthened by data from diseases mostly affecting white matter, such as multiple sclerosis, where the extent of white matter lesions and abnormal diffusivity measures correlated with reduced cognitive processing speed. ${ }^{64}$ The fact that we have only included children with FLE of unknown cause might explain the absence of significant differences in the white matter structure and its potential correlation with cognitive impairment.

Not only in adult patients with epilepsy, but also in adult patients with frontal lobe injury after head trauma, Alzheimer's disease and mild cognitive impairment, white matter abnormalities across multiple brain areas have been observed compared to controls. ${ }^{65,66}$ A DTI study in children with dyslexia demonstrated FA decreases in white matter bundles in the left temporo-parietal region compared to healthy controls. ${ }^{67}$ Similarly, children and adolescents with schizophrenia with linguistic impairment had increased ADC values in various, mainly parietal lobe regions in the left hemispheric compared to children and adolescents with schizophrenia without linguistic impairment and healthy controls. ${ }^{68}$

One of the main limitations of DTI and tractography is that it cannot differentiate afferents from efferents, and so the true nature of the white matter abnormalities cannot be directly elucidated. Moreover, DTI measurements are subject to inaccuracies due to crossing fibers, partial volume, noise, and limitations of the particular tracking algorithm applied ${ }^{69}$ In addition, we evaluated a group of children in an age category in which normal brain maturation, characterized by $\mathrm{FA}$ increases and ADC decreases ${ }^{70}$ is still in process. Therefore, it is unknown whether the differences in white matter structure between children with FLE and controls are a temporary phenomenon and reflect alterations in the pace of the maturation process only, or lead to permanent abnormalities. Follow-up measurements would allow to study the progression of the observed changes over time and their potential correlation with cognitive performance.

\section{Functional network topology: results of graph theoretical analysis}

With resting-state fMRI, we investigated whether cerebral network characteristics were associated with FLE and with cognitive impairment. Resting-state fMRI is a functional imaging technique that enables the investigation of the intrinsic functional organization of the brain, in contrast to the cerebral effect of tasks executed by patients. This intrinsic functional organization is called 'functional connectivity', which is defined by the temporal correlation of neuronal activity-induced patterns of anatomical different brain regions. ${ }^{71,72}$ In mathematical terms, the brain can be modeled as a system consisting of nodes (brain regions) and edges (connections) between them. The strength of a connection is then quantified by the degree of correlation 

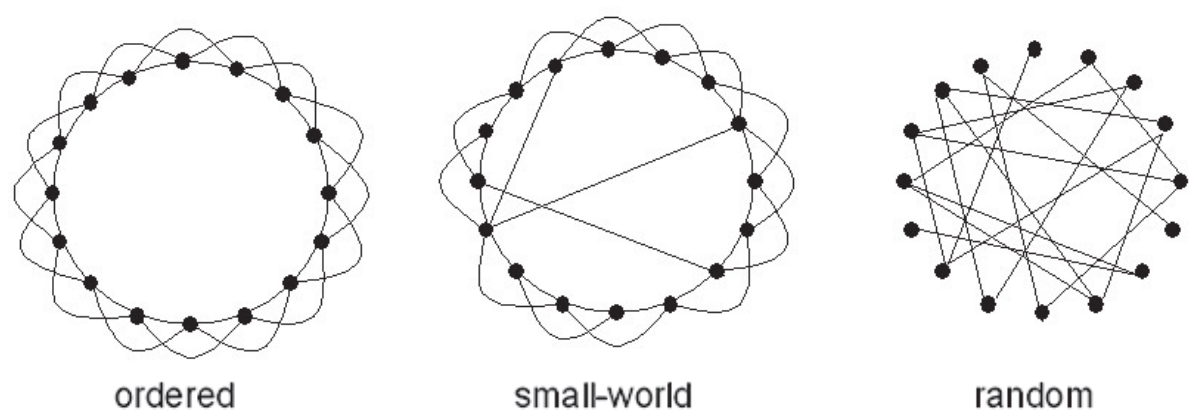

Figure 1. Three basic network types in the model of Watts and Strogatz.

of the dynamic fluctuations between a pair of nodes, that is, brain regions. An elegant way to understand and quantify the organization of this system of nodes and edges is to calculate graph theoretical metrics of the wholebrain network. ${ }^{73}$ In addition to the whole-brain network organization, graph theoretical metrics can also describe the interconnection of subnetworks in the whole-brain network by modularity analysis (Chapter 7). ${ }^{74}$ This modular structure of the brain network is thought to be important for cognitive abilities as increases in coherent activity between functional systems might facilitate information integration. ${ }^{75}$ Connectivity analysis can provide a framework for the expression and monitoring of brain development. In turn these frameworks may allow detection of early abnormalities in neuronal networks, including abnormalities that underlie cognitive impairment.

The optimum structure of a network is the one that maintains a balance between local and global structural characteristics which lead to an appropriate optimal balance between segregation and integration. Modern networks theory calls a network with such a structure a "small-world network." It is characterized by the coexistence of dense clustering of connections and short path lengths between the network units. In the small-world network, the highest synchronizability and the highest speed of information transition among the network functional units exist compared with other types of network structures such as random and ordered networks (See Figure 1) ${ }^{76}$

The left graph is a ring of 16 vertices, where each vertex is connected to four neighbors. This is an ordered graph which has a high clustering coefficient and a long path length. By choosing an edge at random, and reconnecting it to a randomly chosen vertex, graphs with increasingly random structure can be generated.

A completely random graph has a low clustering coefficient and a short path length. Small-world networks combine the high clustering coefficient of ordered networks with the short path length of random networks. 
Imaging experiments in humans have shown that functional networks reorganize significantly during the age period of 2 to 18 years, with short-range functional connectivity decreasing and long-range functional connectivity increasing, providing evidence that brain networks progressively refine to decrease segregation and increase integration. ${ }^{47}$

We have used graph theoretical analysis to study network characteristics of children with FLE and whether these differed between controls and children with and without cognitive impairment. For this specific study, cognitive performance was determined by means of a computerized visual searching task (CVST), a computerized version of Goldstein's visual search task. ${ }^{77}$ This test is recognized as a valid measurement for information processing speed. ${ }^{78}$ Functional networks in children with FLE demonstrated both reduced connectivity between functional modules with a decrease in long-range connectivity, thus a decrease in integration, and a higher modularity, implying that subnetworks are less interconnected, thus persistent segregation. This suggests a lack of the normal age-related reorganization into long-range functional connectivity. In the cognitively impaired patients specifically, the frontal lobe missed the characteristic module that functionally interacted with the temporal, parietal, and occipital regions as seen in the healthy control group. This suggests a delay in the functional development of the frontal lobe network in the cognitively impaired patients (Chapter 7). The finding that modular abnormalities were not restricted to the frontal lobe implies that other parts of the brain are also essential to perform complex cognitive tasks such as the CVST. The involvement of other brain regions could also explain the broad variety of cognitive impairment seen in children with FLE (Chapter 2).

In adults with epilepsy, three studies have used graph theoretical analysis of fMRI data, one in patients with TLE, ${ }^{29}$ one in patients with idiopathic generalized epilepsy, ${ }^{30}$ and one in patients with cryptogenic localizationrelated epilepsy with an epileptic focus in the frontal or temporal lobe. ${ }^{79}$ All three studies found disturbed local and global cerebral network connectivity, reflected by decreased path length or clustering..$^{29,30,79}$

Only one study has related results of measurements by this technique to cognitive performance in epilepsy. Cognitively impaired patients with chronic cryptogenic localization-related epilepsy displayed more pronounced disruptions in both local as well as global cerebral networks. ${ }^{79}$

Most of the graph theoretical analysis studies of functional connectivity networks in patients with epilepsy have used either electrophysiological recordings, ${ }^{80-84}$ magnetoencephalography recordings ${ }^{85}$ MRI-based cortical thickness correlations ${ }^{86}$ or corticography recordings. ${ }^{87}$ Regardless of the 
methodology, all have demonstrated that brain networks (both local and global dependent on the extent of measurement) are disturbed in patients with epilepsy. This was reflected by an increase in path length and a decrease in clustering, thus a less efficient brain network organization. This was seen in patients with different types of epilepsy, and in adults with epilepsy as well as in our group of children with FLE. Epilepsy duration may play a role in the extent of network disturbances. ${ }^{87}$

An altered brain network organization is not typical for epilepsy. In fact, it has been shown in several psychiatric and neurological diseases, including schizophrenia, ${ }^{88,89}$ Alzheimer's disease, ${ }^{90}$ and multiple sclerosis. ${ }^{91}$ Patients with schizophrenia had a reduced global efficiency of the structural network of mainly frontal, but also temporal, and occipital brain regions. ${ }^{88}$ To a lesser extent, local organization was affected ${ }^{88}$ or was not affected. ${ }^{89}$ In patients with Alzheimer's disease, a loss of global information integration (i.e., an affected long-distance connectivity) was demonstrated. ${ }^{90}$ In patients with multiple sclerosis, the extent of white matter lesions significantly impaired the efficiency of both local and global structural cortical networks. ${ }^{91}$

All studies that investigated global cerebral network organization in neurological or psychiatric illnesses found a loss of global efficiency. Differences between the various patient populations could be found in the localization of the network disturbances. For example, in our children with FLE and cognitive impairment, the frontal lobe missed the characteristic module that functionally interacted with the temporal, parietal, and occipital regions as seen in the healthy control group (Chapter 7). No other studies have investigated these modules in patients with epilepsy. The localization of the modular differences likely reflects disease-specific pathophysiologies. In our children with FLE, the lack of this characteristic module was strongly associated with cognitive impairment. This could perhaps be an interesting tool to identify patients at risk of, or in early phases of cognitive impairment as a complication of FLE. Brain network analysis may also provide a promising tool to elucidate the mechanisms responsible for the development of these cognitive impairments. Should future studies prove that cerebral network organization changes before the onset of cognitive impairment, its early identification may provide a ground for measures to prevent further deterioration.

An important limitation of our study is that we used the CVST alone, instead of the impairment index. CVST measures the performance within a single cognitive domain, the assessment of other cognitive domains or global cognitive functioning is needed to gain a more specific insight in the neuronal correlates of cognitive impairment. 
Table 1. Summary of the different MRI results obtained in this thesis.

\begin{tabular}{|c|c|c|c|c|c|c|}
\hline \multirow{3}{*}{ Left frontal lobe } & \multicolumn{2}{|c|}{ fMRI } & \multicolumn{2}{|c|}{ DTI } & \multicolumn{2}{|c|}{ Volumetric MRI } \\
\hline & FLE & $\begin{array}{c}\mathrm{FLE}+\operatorname{Cogn} \\
\text { Imp }\end{array}$ & FLE & $\begin{array}{c}\mathrm{FLE}+\operatorname{Cog} n \\
\text { Imp }\end{array}$ & FLE & $\begin{array}{c}\text { FLE + Cogn } \\
\text { Imp }\end{array}$ \\
\hline & + & + & - & - & $+\downarrow \uparrow$ & + \\
\hline Right frontal lobe & + & $+\downarrow$ & + & - & $+\downarrow \uparrow$ & + \\
\hline Left temporal lobe & + & + & + & - & $+\downarrow \uparrow$ & $+\downarrow$ \\
\hline Right temporal lobe & + & $+\downarrow$ & + & - & $+\downarrow$ & $+\downarrow \uparrow$ \\
\hline Left parietal lobe & + & + & + & - & $+\uparrow$ & - \\
\hline Right patietal lobe & + & $+\downarrow$ & - & - & $+\downarrow \uparrow$ & $+\uparrow$ \\
\hline Left occipital lobe & + & - & + & - & $+\uparrow$ & - \\
\hline Right occipital lobe & + & - & + & - & - & $+\uparrow$ \\
\hline Left subcortical & + & $+\downarrow$ & + & - & - & $+\downarrow$ \\
\hline Right subcortical & + & $+\downarrow$ & - & - & $+\downarrow$ & - \\
\hline
\end{tabular}

fMRI: functional MRI; all $+\downarrow$ signs indicate that functional connectivity is significantly decreased to the specific brain lobes, whereas all - signs indicate that the changes in functional connectivity to the specific brain lobes are not statistically significant.

DTI: diffusion tensor imaging; the diffusional properties of the white matter tract bundles between the specific brain lobes is either significantly decreased or increased (+) or not of statistically significance (-).

Volumetric MRI: cortex volumes within the specific brain lobes are either significantly smaller $(+\downarrow)$, larger $(+\uparrow)$, both smaller and larger $(+\uparrow \downarrow)$, or not of statistically significance $(-)$.

FLE: total group of children with frontal lobe epilepsy.

FLE + Cogn Imp: total group of cognitively impaired children with frontal lobe epilepsy.

CVST and impairment index are not well correlated. For the total group of 59 participants, 44 were concordantly designated as cognitively impaired or unimpaired by CVST and the impairment index (75\%). Of the remaining 15 participants, 8 were designated as cognitively impaired on basis of CVST but not by their impairment index and 7 participants were designated cognitively unimpaired by CVST but impaired by their impairment index.

\section{Summary of the different MRI results obtained in this thesis}

Table 1 provides an overview of MRI abnormalities specific for children with FLE compared to controls (the impact of FLE itself, explained in the next paragraph) and those specific for the cognitively impaired patient group compared to the cognitively unimpaired patient group (the neuronal correlates of cognitive impairment in children with FLE, explained in the next paragraph). 


\section{The impact of FLE itself}

Based on our neuroradiological data (Table 1), FLE presents as a cerebral network disorder characterized by functional, microstructural, and volumetric abnormalities in the majority of brain lobes, and not just the frontal lobe where the seizure foci reside. It is also apparent that functional connectivity is always impaired: no structural disturbances exist without functional disturbances. Sporadically, functional disturbances are observed in the absence of structural disturbances (see Table 1). It is therefore tempting to see the functional disturbances as a first phase, eventually leading to structural impairments. It remains unknown whether these widespread functional and structural network disturbances are a cause or an effect of FLE.

In theory, communication or function between neurons of different brain regions is impossible without structural connections. Therefore, structural connectivity is regarded as the substrate for functional connectivity. ${ }^{92-94}$ This relationship between structural and functional connectivity strengthens with age. ${ }^{47}$ Conversely, functional networks can modulate structural networks. During development and after brain damage, neuronal activity can modify the underlying brain networks. This is termed plasticity. Structural connections can either increase (e.g. generation of new axons) or decrease (e.g. degeneration of old axons) in strength, and functional connections can either increase (e.g. due to an increase in neuronal activity) or decrease (e.g. due to a decrease in neuronal activity) in strength.

This same modulation of structural networks by functional networks could be the cause of the diffusion and volumetric abnormalities seen in our children with FLE. For example, a decreased functional connectivity in left and right temporal lobe regions is associated with increased ADC values and smaller volumes of cortex structures within these regions.

This finding is in line with a study of Zhang et al., 2011 who found that the structural connectivity network was less affected in patients with idiopathic generalized epilepsy than the functional connectivity network. ${ }^{95}$ In general, the functional connectivity network is thought to be more flexible, while the structural network is relatively rigid. ${ }^{96}$

Longitudinal studies to assess alterations in the diffusion properties of these children with FLE would be needed to confirm this modulation of structural networks. This may explain why the abnormalities in cerebral white matter properties of adults or adolescents with epilepsy are more pronounced than in children. Some studies have reported that duration of epilepsy plays a role in this white matter damage. ${ }^{60,61}$ In our study cohort, duration of epilepsy had no influence, although duration of epilepsy was relatively short in our entire cohort of children with FLE, possibly too short to demonstrate white matter 
damage. The fact that we evaluated a group of children in an age category in which the white matter is subject to change due to maturation processes adds another layer of difficulty; ${ }^{70}$ here, too, longitudinal studies would allow to evaluate the course of the white matter abnormalities within the context of the maturation process. Moreover, follow-up after full brain maturation could resolve the question whether the white matter abnormalities are of a temporary, e.g. change in pace of maturation, or permanent nature.

\section{The neuronal correlates of cognitive impairment in children with FLE}

From the different MRI techniques alone, the following neuronal correlates of cognitive impairment in children with FLE were demonstrated:

1. Decreased functional frontal lobe connectivity that comprised both connections within the frontal lobe as well as connections between the frontal lobe and the parietal lobe, temporal lobe, cerebellum, and basal ganglia (fMRI).

2. Smaller volumes of left and right frontal and temporal lobe cortex structures and left subcortical area structures, as well as larger volumes of right temporal, right parietal, and right occipital lobe cortex structures (volumetric MRI).

3. Abnormal diffusional properties mostly located in the posterior brain regions/occipital lobes (DTI).

4. The loss of the characteristic frontal lobe module that functionally interacts with the temporal, parietal, and occipital regions (graph theoretical analysis).

For all techniques, we observed that clinical epilepsy characteristics such as localization of the seizure focus and age at seizure onset, did not impact on these neuronal correlates of cognitive impairment. Combining the results of the various techniques, we have observed that impaired functional connectivity is the predominant factor associated with cognitive impairment in children with FLE. In children with FLE with cognitive impairment, the functional connectivity between the frontal lobe and various other brain lobes is significantly decreased compared to cognitively unimpaired children with FLE, with the exception of the left and right occipital lobe. Yet, the diffusion properties of the white matter tract bundles between these different brain lobes have remained relatively intact, though there does seem to be a sliding scale in which the cognitively impaired children with FLE differ significantly from controls, but not from cognitively unimpaired children with FLE. In the majority of brain lobes, abnormal cortex structure volumes 
were demonstrated in the cognitively impaired children with FLE compared to cognitively unimpaired children with FLE (see Table 1). The decreased functional connectivity often results in, or goes hand in hand with, smaller volumes of cortical structures within these connected brain lobes (see Table 1). These smaller cortex volumes in cognitively impaired patients could thus be the result of decreased functional connectivity. We do not know whether the smaller volumes reflect atrophy or a delay in growth or maturation; a decrease in functional connectivity likely leads to less activity of the affected brain region, ultimately leading to atrophy or a delay in maturation - "if you don't use it, you lose it."

Not all abnormalities are losses of volume or diffusivity. The larger volumes of specific structures (e.g. right occipital lobe cortex structure volume) in cognitively impaired compared to unimpaired children with FLE may reflect a compensatory mechanism. Similarly, the increased FA in the occipital lobe of the cognitively impaired children with FLE could result from compensatory mechanisms, as in this group the functional connectivity had remained intact. Given that these children have cognitive impairments, this compensatory mechanism appears inadequate. This is also reflected in the decrease of the volume of white matter tract bundles connecting the left frontal and right occipital lobe in the cognitively impaired patient group compared to the cognitively unimpaired patient group, and the decreased FA of the bundle tracts connecting the left frontal and right occipital lobe which was most pronounced in the cognitively impaired patient group (Chapter 6). These observations may reflect a degeneration of white matter tracts to the occipital lobes as one of the neuronal correlates of cognitive impairment in children with FLE. This is the sole contradiction to the hypothesis that functional networks modulate structural networks.

It remains questionable whether a modulation of structural networks by functional networks could be the cause of the diffusion and volumetric abnormalities seen in our children with FLE, regardless of their cognitive performance. With fMRI we measured the functional connectivity between 27 different brain regions of interest, that is, 351 unique connections between these different brain regions. With volumetric MRI, the volumes of 30 individual cortical and subcortical structures, 67 grey matter structures, and thicknesses of 67 cortex regions were measured. With DTI, we investigated the properties of white matter connections between 10 different regions of interest only, that is, 90 bundle tracts. In other words, our fMRI and volumetric MRI data were far more detailed than the DTI data. Hence, diffusion abnormalities may be more pronounced if one measures the tract bundles in greater detail, rather than the collections of tract bundles 
as we have done. This is supported by studies that have examined specific white matter tracts involved in particular cognitive tasks in patients with epilepsy. ${ }^{57,58,62}$ These diffusion abnormalities may thus be more important as correlates of cognitive impairment in children with FLE than our current data can support.

There are no other studies in children with epilepsy that compared the results of various MRI techniques. Therefore comparison with other types of epilepsy is not yet possible. Moreover, we have only performed a single measurement for all participants. As a result, we cannot study the progression of the observed changes over time. Such data would be very helpful to determine the etiology of FLE and its associated cognitive impairment, as well as to determine the progression of the various abnormalities and their relation to cognitive development.

\section{Conclusions}

Cognitive impairment is frequent in children with FLE. These cognitive impairments proved not restricted to the typical frontal lobe functions as one would expect in patients with FLE, but were widespread. The clinical relevance of these impairments is that they often led to learning difficulties and a need for special education. FLE in childhood is generally of unknown cause thus without abnormalities on structural MRI that could explain the cognitive impairment. With advanced MRI techniques we have revealed significant differences between children with FLE and healthy controls as well as several neuronal correlates of cognitive impairment in children with FLE. Functional fMRI, volumetric MRI, DTI and graph theoretical analysis all revealed that the differences between children with FLE and healthy controls were not limited to the side of seizure focus in the frontal lobe, but that children with FLE have widespread functional and structural network disturbances and an abnormal cerebral network organization. Some of these abnormalities proved characteristic only for the cognitively impaired children with FLE These neuronal correlates of cognitive impairment, too, were not restricted to the frontal lobe, but rather affected multiple cortical and subcortical brain regions. This implicates that epileptiform activity in the frontal lobe interferes with extensive and coordinated networks, required for many cognitive functions and that specific abnormalities within this network lead to the development of cognitive impairment. Clinical epilepsy characteristics such as age at onset and localization of seizure focus had no significant impact on cognitive impairment and its neuronal correlates. Both FLE and cognitive impairment in children with FLE are network disorders. 


\section{Future perspective}

Longitudinal studies are warranted to assess whether the abnormalities we have observed are a temporary phenomenon and reflect alterations in the pace of the maturation process only, or lead to permanent abnormalities. Besides a healthy control group, such studies should preferably include patients with multiple types of epilepsy and cognitively impaired as well as unimpaired patients in each group. Moreover, such imaging studies should be of good quality, reliable, reproducible and safe, and specifically equipped for children. This means that short scan protocols should be used and the procedure must be non-invasive (thus no interventions such as sedation, contrast agents or ionizing radiation), and child-proof, thus for example not sensitive for excessive head movements. To increase the yield of such imaging studies, a higher scanning (spatiotemporal) resolution will be important. For fMRI, the temporal resolution should be such that the direction of the signal transduction (afferent/efferent) can also be studied, and for DTI the spatial resolution should be able to solve the issue of crossing fibers.

A disturbed network organization is the key neuronal correlate for FLE and for cognitive impairment in children with FLE. This cerebral network organization and its visualization have the potential to move into the clinical field and become prognostic markers of epilepsy and of cognitive functioning in patients with epilepsy. Currently, no clinical tools are available that can reliably predict the long-term cognitive outcome in children with FLE. Therefore, individual connectivity maps and network analysis might eventually serve as an additional tool for the neurologist to tailor the therapeutic decision-making to the network characteristics. For now, MRI remains the optimal technique to study this cerebral network organization in children. 


\section{References}

1. Lassonde M, Sauerwein HC, Jambaqué I, Smith ML, Helmstaedter C. Neuropsychology of childhood epilepsy: pre- and postsurgical assessment. Epileptic Disord 2000;2:3-12.

2. Culhane-Shelburne K, Chapieski L, Hiscock M, Glaze D. Executive functions in children with frontal and temporal lobe epilepsy. J Int Neuropsychol Soc 2002;8:623-632.

3. Hernandez MT, Sauerwein HC, Jambaqué I, de Guise E, Lussier F, Lortie A, Dulac O, Lassonde M. Attention, memory, and behavioral adjustment in children with frontal lobe epilepsy. Epilepsy Behav 2003;4:522-536.

4. Nolan MA, Redoblado MA, Lan S, Sabaz M, Lawson JA, Cunningham AM, Bleasel AF, Bye AM. Intelligence in childhood epilepsy syndromes. Epilepsy Res 2003;53:139-150.

5. Boone KB, Miller BL, Rosenberg L, Durazo A, McIntyre H, Weil M. Neuropsychological and behavioral abnormalities in an adolescent with frontal lobe seizures. Neurology 1988;38:583-586.

6. Prévost J, Lortie A, Nguyen D, Lassonde M, Carmant L. Nonlesional frontal lobe epilepsy (FLE) of childhood: clinical presentation, response to treatment and comorbidity. Epilepsia 2006;47:21982201.

7. Jambaqué I, Dulac O. Reversible frontal syndrome and epilepsy in a 8-year-old boy. Arch Fr Pediatr 1989;46:525-529.

8. Cohen H, Le Normand MT. Language development in children with simple-partial left-hemisphere epilepsy. Brain Lang 1998;64:409-422.

9. Jambaqué I, Dellatolas G, Dulac O, Ponsot G, Signoret JL. Verbal and visual impairment in children with epilepsy. Neuropsychologia 1993;31:1321-1337.

10. Lendt M, Gleissner U, Helmstaedter C, Sassen R, Clusmann H, Elger CE. Neuropsychological outcome in children after frontal lobe epilepsy surgery. Epilepsy Behav 2002;3:51-59.

11. Nolan MA, Redoblado MA, Lah S, Sabaz M, Lawson JA, Cunningham AM, Bleasel AF, Bye AM. Memory function in childhood epilepsy syndromes. J Paediatr Child Health 2004;40:20-27.

12. Sinclair DB, Wheatley M, Snyder T. Frontal lobe epilepsy in childhood. Pediatr Neurol 2004;30:169176 .

13. Lagae L, Pauwels J, Monté CP, Verhelle B, Vervisch J. Frontal absences in children. Eur J Paediatr Neurol 2001;5:243-251.

14. Lawson JA, Cook MJ, Vogrin S, Litewka L, Strong D, Bleasel AF, Bye AM. Clinical, EEG, and quantitative MRI differences in pediatric frontal and temporal lobe epilepsy. Neurology 2002;58:723729.

15. Aoyagi K, Masao A, Goldberg E, Nakazawa S. Lateralization of the frontal lobe functions elicited by a cognitive bias task is a fundamental process. Lesion study. Brain Dev 2005;27:419-423.

16. Auclair L, Jambaqué I, Dulac O, LaBerge D, Siéroff E. Deficit of preparatory attention in children with frontal lobe epilepsy. Neuropsychologia 2005;43:1701-1712.

17. Jocić-Jakubi B, Jovanović M, Janković DS, Lagae L. Frontal-onset absences in children: associated with worse outcome? A replication study. Seizure 2009;18:275-278.

18. Wang XQ, Lang SY, Hong LU, Lin MA, Yan-Ling MA, Yang F. Changes in extrafrontal integrity and cognition in frontal lobe epilepsy: a diffusion tensor imaging study. Epilepsy Behav 2011;20:471477 .

19. Centeno M, Vollmar C, O’Muircheartaigh J, Stretton J, Bonelli SB, Symms MR, Barker GJ, Kumari V, Thompson PJ, Duncan JS, Richardson MP, Koepp MJ. Memory in frontal lobe epilepsy: an fMRI study. Epilepsia 2012;53:1756-1764.

20. Roebling R, Scheerer N, Uttner I, Gruber O, Kraft E, Lerche H. Evaluation of cognition, structural, and functional MRI in juvenile myoclonic epilepsy. Epilepsia 2009;50:2456-2465. 
21. Vlooswijk MC, Jansen JF, Majoie HJ, Hofman PA, de Krom MC, Aldenkamp AP, Backes WH. Functional connectivity and language impairment in cryptogenic localization-related epilepsy. Neurology 2010;75:395-402.

22. Powell HW, Richardson MP, Symms MR, Boulby PA, Thompson PJ, Duncan JS, Koepp MJ. Reorganization of verbal and nonverbal memory in temporal lobe epilepsy due to unilateral hippocampal sclerosis. Epilepsia 2007;48:1512-1525.

23. Wagner K, Frings L, Spreer J, Buller A, Everts R, Halsband U, Schulze-Bonhage A. Differential effect of side of temporal lobe epilepsy on lateralization of hippocampal, temporolateral, and inferior frontal activation patterns during a verbal episodic memory task. Epilepsy Behav 2008;12:382-387.

24. Vannest J, Szaflarski JP, Privitera MD, Schefft BK, Holland S. Medial temporal fMRI activation reflects memory lateralization and memory performance in patients with epilepsy. Epilepsy Behav 2008;12:410-418.

25. Dupont S, Van de Moortele PF, Samson S, Hasboun D, Poline JB, Adam C, Lehéricy S, Le Bihan D, Samsom Y, Baulac M. Episodic memory in left temporal lobe epilepsy: a functional MRI study. Brain 2000;123:1722-1732.

26. Bettus G, Guedj E, Joyeux F, Confort-Gouny S, Soulier E, Laguitton V, Cozzone PJ, Chauvel P, Ranjeva JP, Bartolomei F, Guye M. Decreased basal fMRI functional connectivity in epileptogenic networks and contralateral compensatory mechanisms. Hum Brain Mapp 2009;30:1580-1591.

27. Waites AB, Briellmann RS, Saling MM, Abbott DF, Jackson GD. Functional connectivity networks are disrupted in left temporal lobe epilepsy. Ann Neurol 2006;59:335-343.

28. Voets NL, Adcock JE, Stacey R, Hart Y, Carpenter K, Matthews PM, Beckmann CF. Functional and structural changes in the memory network associated with left temporal lobe epilepsy. Hum Brain Mapp 2009;30:4070-4081.

29. Liao W, Zhang Z, Pan Z, Mantini D, Ding J, Duan X, Luo C, Lu G, Chen H. Altered functional connectivity and small-world in mesial temporal lobe epilepsy. PLoS One 2010;5:e8525.

30. Zhang Z, Lu G, Zhong Y, Tan Q, Liao W, Wang Z, Li K, Chen H, Liu Y. Altered spontaneous neuronal activity of the default-mode network in mesial temporal lobe epilepsy. Brain Res 2010;1323:152-160.

31. Luo C, Li Q, Lai Y, Xia Y, Qin Y, Liao W, Li S, Zhou D, Yao D, Gong Q. Altered functional connectivity in default mode network in absence epilepsy: a resting-state fMRI study. Hum Brain Mapp 2011;32:438-449.

32. Haenschel C, Bittner RA, Haertling F, Rotarska-Jagiela A, Maurer K, Singer W, Linden DEJ. Contribution of impaired early-stage visual processing to working memory dysfunction in adolescents with schizophrenia. A study with event-related potentials and functional magnetic resonance imaging. Arch Gen Psychiatry 2007;64:1229-1240.

33. White T, Schmidt M, Kim DI, Calhoun VD. Disrupted functional brain connectivity during verbal working memory in children and adolescents with schizophrenia. Cereb Cortex 2011;21:510-518.

34. Royall DR, Lauterbach EC, Cummings JL, Reeve A, Rummans TA, Kaufer DI, LaFrance WC Jr, Coffey CE. Executive control function: a review of its promise and challenges for clinical research. A report from the Committee on Research of the American Neuropsychiatric Association. J Neuropsychiatry Clin Neurosci 2002;14:377-405.

35. Cummings JL, Miller BL. Chapter 2: Conceptual and clinical aspects of the frontal lobes. The Human Frontal Lobes, Second Edition: Functions and Disorders (The Science and Practice of Neuropsychology). Bruce L, Miller MD (Editor), Jeffrey L, Cummings MD (Editor). The Guilford Press, New York, 2007.

36. Stoub TR, Rogalski EJ, Leurgans S, Bennett DA, deToledo-Morrell L. Rate of entorhinal and hippocampal atrophy in incipient and mild AD: relation to memory function. Neurobiol Aging 2010;31:1089-1098. 
37. Schultz CC, Koch K, Wagner G, Roebel M, Schachtzabel C, Nenadic I, Albrecht C, Reichenbach JR, Sauer H, Slösser RG. Psychopathological correlates of the entorhinal cortical shape in schizophrenia. Eur Arch of Psychiatry Clin Neurosci 2010;260:351-358.

38. Gärtner B, Seeck M, Michel CM, Delavelle J, Lazeyras F. Patients with extratemporal lobe epilepsy do not differ from healthy subjects with respect to subcortical volumes. J Neurol Neurosurg Psychiatry 2004;75:588-592.

39. Widjaja E, Mahmoodabadi SZ, Snead OC 3rd, Almehdar A, Smith ML. Widespread cortical thinning in children with frontal lobe epilepsy. Epilepsia 2011;52:1685-1691.

40. Baxendale SA, Van Paesschen W, Thompson PJ, Connelly A, Duncan JS, Harkness WF, Shorvon SD. The relationship between quantitative MRI and neuropsychological functioning in temporal lobe epilepsy. Epilepsia 1998;39:158-166.

41. Hermann B, Seidenberg M, Bell B, Rutecki P, Sheth R, Ruggles K, Wendt G, O'Leary D, Magnotta V. The neurodevelopmental impact of childhood-onset temporal lobe epilepsy on brain structure and function. Epilepsia 2002;43:1062-1071.

42. Catani M, Howard RJ, Pajevic S, Jones DK. Virtual in vivo interactive dissection of white matter fasciculi in the human brain. Neuroimage 2002;17:77-94.

43. Eriksson SH, Rugg-Gunn FJ, Symms MR, Barker GJ, Duncan JS. Diffusion tensor imaging in patients with epilepsy and malformations of cortical development. Brain 2001;124:617-626.

44. Rugg-Gunn FJ, Eriksson SH, Symms MR, Barker GJ, Duncan JS. Diffusion tensor imaging of cryptogenic and acquired partial epilepsies. Brain 2001;124:627-636.

45. Gross DW. Diffusion tensor imaging in temporal lobe epilepsy. Epilepsia 2011;52:32-34.

46. Concha L, Livy DJ, Beaulieu C, Wheatley BM, Gross DW. In vivo diffusion tensor imaging and histopathology of the fimbria-fornix in temporal lobe epilepsy. J Neurosci 2010;30:996-1002.

47. Hagmann P, Sporns O, Madan N, Cammoun L, Pienaar R, Wedeen VJ, Meuli R, Thiran JP, Grant PE. White matter maturation reshapes structural connectivity in the late developing human brain. Proc Natl Acad Sci USA 2010;107:19067-19072.

48. Lebel C, Walker L, Leemans A, Phillips L, Beaulieu C. Microstructural maturation of the human brain from childhood to adulthood. Neuroimage 2008;40:1044-1055.

49. Hutchinson E, Pulsipher D, Dabbs K, Myers y Gutierrez A, Sheth R, Jones J, Seidenberg M, Meyerand E, Hermann B. Children with new-onset epilepsy exhibit diffusion abnormalities in cerebral white matter in the absence of volumetric differences. Epilepsy Res 2010;88:208-214.

50. Kimiwada T, Juhász C, Makki M, Muzik O, Chugani DC, Asano E, Chugani HT. Hippocampal and thalamic diffusion abnormalities in children with temporal lobe epilepsy. Epilepsia 2006;47:167175.

51. Govindan RM, Makki MI, Sundaram SK, Juhász C, Chugani HT. Diffusion tensor analysis of temporal and extra-temporal lobe tracts in temporal lobe epilepsy. Epilepsy Res 2008;80:30-41.

52. Nilsson D, Go C, Rutka JT, Rydenhag B, Mabbott DJ, Snead OC 3rd, Raybaud CR, Widjaja E. Bilateral diffusion tensor abnormalities of temporal lobe and cingulate gyrus white matter in children with temporal lobe epilepsy. Epilepsy Res 2008;81:128-135.

53. Meng L, Xiang J, Kotecha R, Rose D, Zhao H, Zhao D, Yang J, Degrauw T. White matter abnormalities in children and adolescents with temporal lobe epilepsy. Magn Reson Imaging 2010;28:1290-1298.

54. Holt RL, Provenzale JM, Veerapandiyan A, Moon WJ, De Bellis MD, Leonard S, Gallentine WB, Grant GA, Egger H, Song AW, Mikati MA. Structural connectivity of the frontal lobe in children with drug-resistant partial epilepsy. Epilepsy Behav 2011;21:65-70.

55. Bhardwaj RD, Mahmoodabadi SZ, Otsubo H, Snead OC 3rd, Rutka JT, Widjaja E. Diffusion tensor tractography detection of functional pathway for the spread of epileptiform activity between temporal lobe and Rolandic region. Childs Nerv Syst 2010;26:185-190. 
56. Lui YW, Nusbaum AO, Barr WB, Johnson G, Babb JS, Orbach D, Kim A, Laliotis G, Devinsky O. Correlation of apparent diffusion coefficient with neuropsychological testing in temporal lobe epilepsy. AJNR Am J Neuroradiol 2005;26:1832-1839.

57. Diehl B, Busch RM, Duncan JS, Piao Z, Tkach J, Lüders HO. Abnormalities in diffusion tensor imaging of the uncinate fasciculus relate to reduced memory in temporal lobe epilepsy. Epilepsia 2008;49:1409-1418.

58. McDonald CR, Ahmadi ME, Hagler DJ, Tecoma ES, Iragui VJ, Gharapetian L, Dale AM, Halgren E. Diffusion tensor imaging correlates of memory and language impairments in temporal lobe epilepsy. Neurology 2008;71:1869-1876.

59. Yogarajah M, Powell HWR, Parker GJM, Alexander DC, Thompson PJ, Symms MR, Boulby P, Wheeler-Kingshott CA, Barker GJ, Koepp MJ, Duncan JS. Tractography of the parahippocampal gyrus and material specific memory impairment in unilateral temporal lobe epilepsy. Neuroimage 2008;40:1755-1764

60. Riley JD, Franklin DL, Choi V, Kim RC, Binder DK, Cramer SC, Lin JJ. Altered white matter integrity in temporal lobe epilepsy: association with cognitive and clinical profiles. Epilepsia 2010;51:536545.

61. Wang XQ, Lang SY, Hong LU, Lin MA, Yan-ling MA, Yang F. Changes in extratemporal integrity and cognition in temporal lobe epilepsy: a diffusion tensor imaging study. Neurol India 2010;58:891899.

62. Kucukboyaci NE, Girard HM, Hagler DJ, Kuperman J, Tecoma ES, Iragui VJ, Halgren E, McDonald CR. Role of fiber tract integrity in task-switching performance of healthy controls and patients with temporal lobe epilepsy. J Int Neuropsychol Soc 2012;18:57-67.

63 Byars AW, deGrauw TJ, Johnson CS, Fastenau PS, Perkins SM, Egelhoff JC, Kalnin A, Dunn DW, Austin JK. The association of MRI findings and neuropsychological functioning after the first recognized seizure. Epilepsia 2007;48:1067-1074.

64. Bethune A, Tipu V, Sled JG, Narayanan S, Arnold DL, Mabbott D, Rockel C, Ghassemi R, Till C, Banwell B. Diffusion tensor imaging and cognitive speed in children with multiple sclerosis. J Neurol Sci 2011;309:68-74.

65. Huang J, Auchus AP. Diffusion tensor imaging of normal appearing white matter and its correlation with cognitive functioning in mild cognitive impairment and Alzheimer's disease. Ann N Y Acad Sci 2007;1097:259-64.

66. Pal D, Gupta RK, Agarwal S, Yadav A, Ojha BK, Awasthi A, Rathore RKS, Pandey CM, Narayana PA. Diffusion tensor tractography indices in patients with frontal lobe injury and its correlation with neuropsychological tests. Clin Neurol Neurosurg 2012;114:564-571.

67. Carter JC, Lanham DC, Cutting LE, Clements-Stephens AM, Chen X, Hadzipasic M, Kim J, Denckla MB, Kaufmann WE. A dual DTI approach to analyzing white matter in children with dyslexia. Psychiatry Res 2009;172:215-219.

68. Clark K, Narr Kl, O’Neill J, Levitt J, Siddarth P, Philips O, Toga A, Caplan R. White matter integrity, language, and childhood onset schizophrenia. Schizophr Res 2012;138:150-156.

69. Nucifora PG, Verma R, Lee SK, Melhem ER. Diffusion-tensor MR imaging and tractography: exploring brain microstructure and connectivity. Radiology 2007;245:367-384.

70. Jones DK, Knösche TR, Turner R. White matter integrity, fiber count, and other fallacies: The do's and don'ts of diffusion MRI. Neuroimage 2012; doi:pii:S1053-8119(12)00730-6.

71. Friston KJ. Functional and effective connectivity in neuroimaging: A synthesis. Hum Brain Mapp 1994;2:56-78

72. Van den Heuvel MP, Hulshoff Pol HE. Exploring the brain network: a review on resting-state fMRI functional connectivity. Eur Neuropsychopharmacol 2010;20:519-534. 
73. Rubinov M, Sporns O. Complex network measures of brain connectivity: uses and interpretations. Neuroimage 2010;52:1059-1069.

74. Newman ME. Modularity and community structure in networks. Proc Natl Acad Sci USA 2006;103:8577-8582.

75. van den Heuvel MP, Stam CJ, Kahn RS, Hulshoff Pol HE. Efficiency of functional brain networks and intellectual performance. J Neurosci 2009;29:7619-7624.

76. Watts DJ, Strogatz SH. Collective dynamics of 'small-world' networks. Nature. 1998;393(6684):409-410.

77. Goldstein G, Welch RB, Rennick PM, Shelly CH. The validity of a visual searching task as an indicator of brain damage. J Consult Clin Psychol 1973;41:434.

78. Alpherts WCJ, Aldenkamp AP. FePSY: 'The Iron Psyche'. Instituut voor epilepsiebestrijding, Heemstede, the Netherlands; 1995.

79. Vlooswijk MC, Vaessen MJ, Jansen JF, de Krom MC, Majoie HJ, Hofman PA, Aldenkamp AP, Backes WH. Loss of network efficiency associated with cognitive decline in chronic epilepsy. Neurology 2011;77:938-944.

80. Ponten SC, Bartolomei F, Stam CJ. Small-world networks and epilepsy: graph theoretical analysis of intracerebrally recorded mesial temporal lobe seizures. Clin Neurophysiol 2007;118:918-927.

81. Ponten SC, Douw L, Bartolomei F, Reijneveld JC, Stam CJ. Indications for network regularization during absence seizures: weighted and unweighted graph theoretical analysis. Exp Neurol 2009;217:197-204.

82. Kramer MA, Kolaczyk ED, Kirsch HE. Emergent network topology at seizure onset in humans. Epilepsy Res 2008;79:173-186.

83 Kramer MA, Eden UT, KolaczykED, Zepeda R, Eskandar EN, Cash SS. Coalescence and fragmentation of cortical networks during focal seizures. J Neurosci 2010;30:10076-10085.

84. Schindler KA, Bialonski S, Horstmann MT, Elger CE, Lehnertz K. Evolving functional network properties and synchronizability during human epileptic seizures. Chaos 2008;18:033119.

85. Horstmann MT, Bialonski S, Noennig N, Mai H, Prusseit J, Wellmer J, Hinrichs H, Lehnertz K. State dependent properties of epileptic brain networks: comparative graph-theoretical analyses of simultaneously recorded EEG and MEG. Clin Neurophysiol 2010;121:172-185.

86. Bernardt et al. Graph-Theoretical Analysis Reveals Disrupted Small-World Organization of Cortical Thickness Correlation Networks in Temporal Lobe Epilepsy. Cerebral Cortex 2011.

87. van Dellen E, Douw L, Baayen JC, Heimans JJ, Ponten SC, Vandertop WP, Velis DN, Stam CJ, Reijnebeld JC. Long-term effects of temporal lobe epilepsy on local neural networks: a graph theoretical analysis of corticography recordings. Plos One 2009; 26:e8081.

88. van den Heuvel MP, Mandl RC, Stam CJ, Kahn RS, Hulshoff Pol HE. Aberrant frontal and temporal complex network structure in schizophrenia: a graph theoretical analysis. J Neurosci 2010;30:1591515926.

89. Wang Q, Su TP, Zhou Y, Chou KH, Chen IY, Jiang T, Lin CP. Anatomical insights into disrupted small-world networks in schizophrenia. Neuroimage 2012;59:1085-1093.

90. Sanz-Arigita EJ, Schoonheim MM, Damoiseaux JS, Rombouts SARB, Maris E, Barkhof F, Scheltens P, Stam CJ. Loss of 'small-world'networks in Alzheimer's disease: graph analysis of fMRI resting-state functional connectivity. Plos One 2010;5:e13788.

91. He Y, Dagher A, Chen Z, Charil A, Zijdenbos A, Worsley K, Evans A. Impaired small-world efficiency in structural cortical networks in multiple sclerosis associated with white matter lesion load. Brain 2009;132:3366-3379.

92. Honey CJ, Sporns O, Cammoun L, Gigandet X, Thiran JP, Meuli R, Hagmann P. Predicting human resting-state functional connectivity from structural connectivity. Proc Natl Acad Sci USA 2009;106:2035-2040. 
93. Johasen-Berg H. Imaging the relationship between structure, function and behaviour in the human brain. Brain Struct Funct 2009;213:499-500.

94. Rykhlevskaia E, Gratton G, Fabiani M. Combining structural and functional neuroimaging data for studying brain connectivity: a review. Psychophysiology 2008;45:173-187.

95. Zhang Z, Liao W, Chen H, Mantini D, Ding JR, Xu Q, Wang Z, Yuan C, Chen G, Jiao Q, Lu G. Altered functional-structural coupling of large-scale brain networks in idiopathic generalized epilepsy. Brain 2011;134:2912-2928.

96. Bullmore E, Sporns O. Complex brain networks: graph theoretical analysis of structural and functional systems. Nat Rev Neurosci 2009;10:312. 


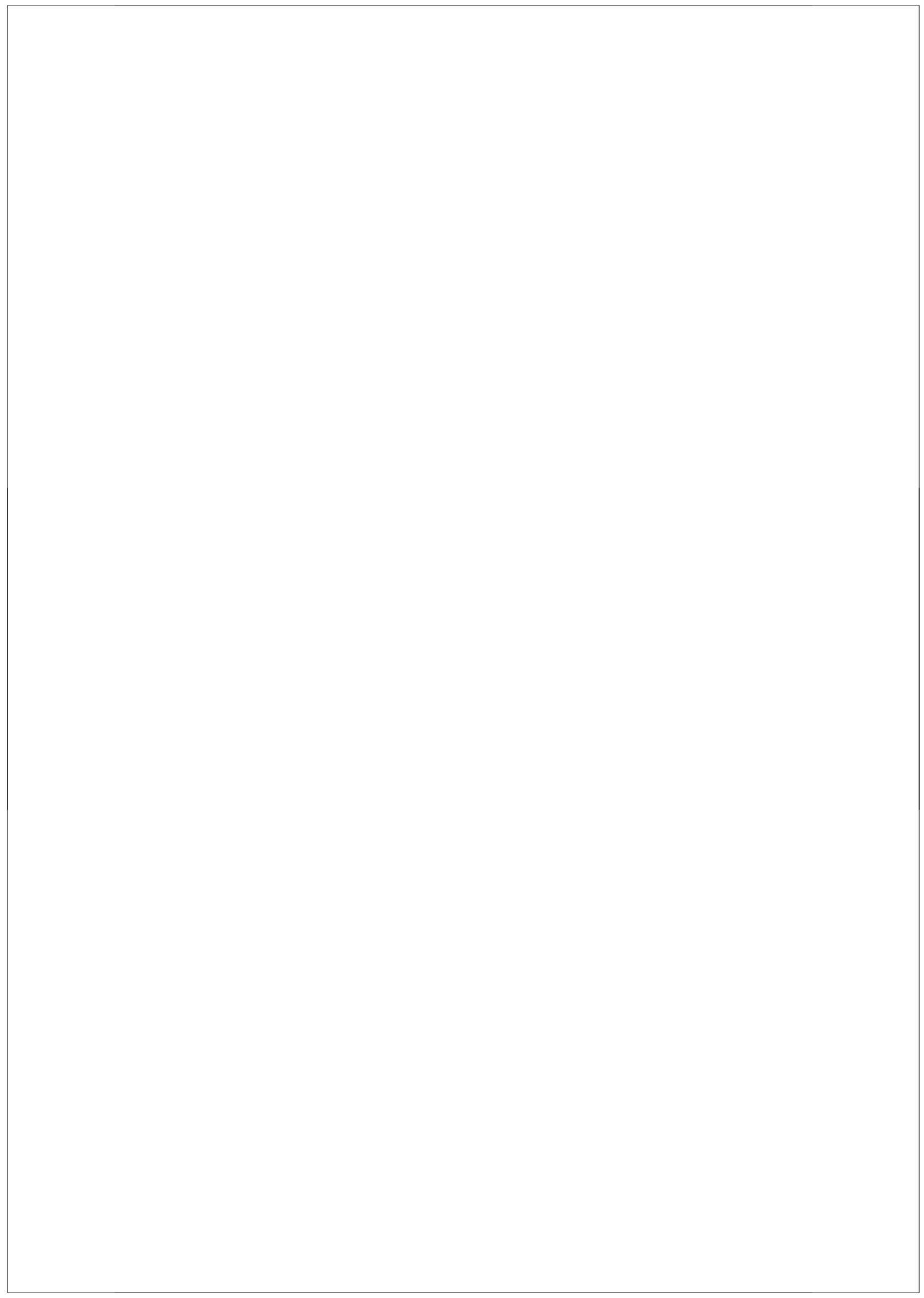




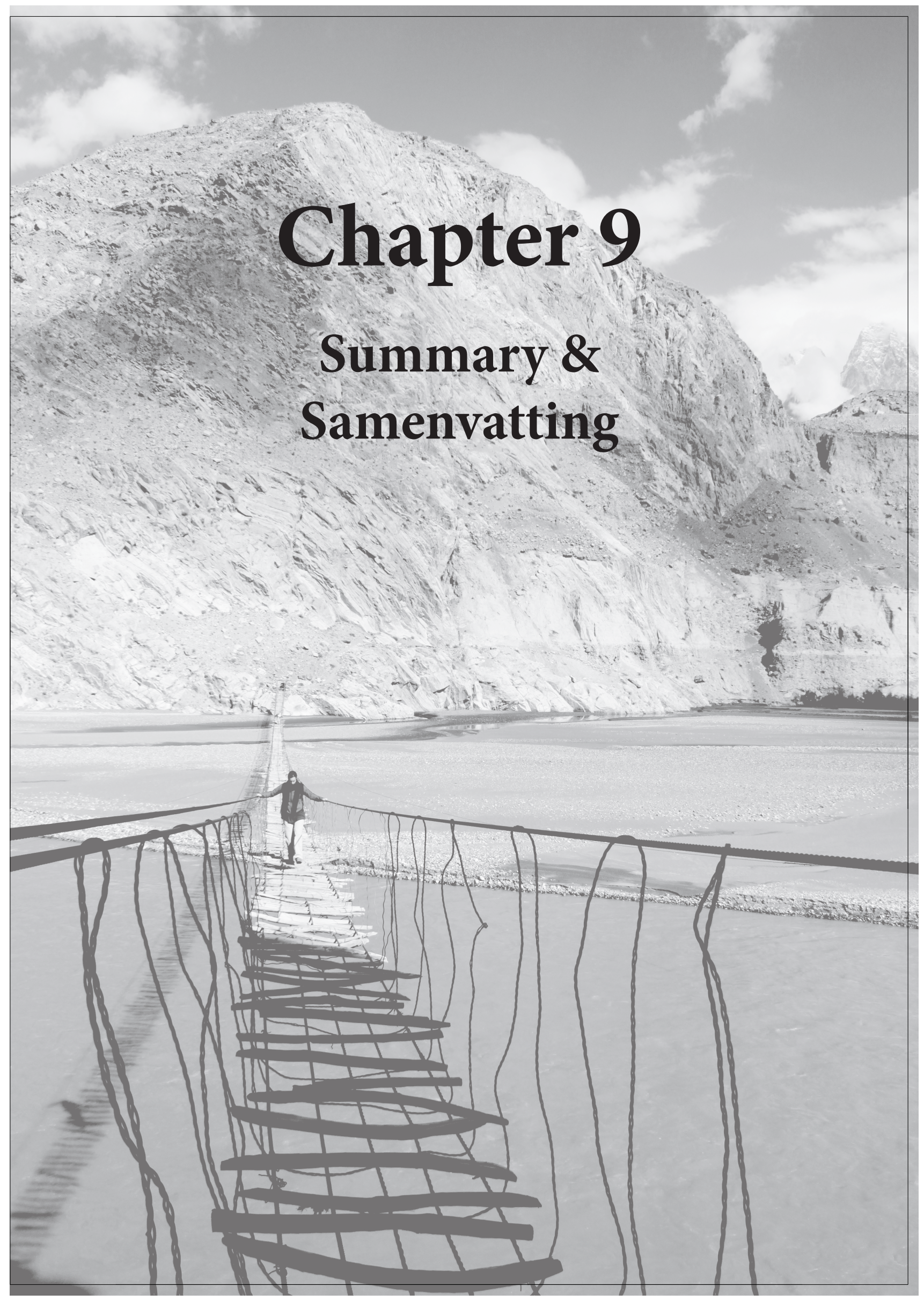




\section{Summary}

In this thesis we aimed to investigate whether cognitive impairment, one of the major comorbidities in children and adults with epilepsy, is also an important comorbidity of FLE in childhood. Therefore, in chapter 2, we studied the existing literature of FLE in childhood and measured the performance of 71 children with FLE of unknown cause on intelligence tests, neuropsychological tests, and by behavioural questionnaires.

We found that children with FLE performed worse on intellectual and neuropsychological tests compared to reference values. Most children had impairments on a broad range of cognitive domains, not restricted to the typical frontal lobe functions. The cognitive impairments often led to learning problems and a need for special education (Chapter 2.2).

FLE in childhood is mostly of unknown cause. Accordingly, no macrostructural brain abnormalities explain the cognitive impairment observed in children with FLE (Chapter 2.1). We found that clinical epilepsy factors such as age at seizure onset or seizure frequency did not explain cognitive impairments (Chapter 2.2). The cause of cognitive impairment in children with FLE therefore remains unclear.

The second aim of this thesis was to unravel these underlying causes of cognitive impairment in children with FLE of unknown cause. As gross structural brain abnormalities are generally absent in children with FLE, we hypothesized that the abnormalities associated with these cognitive impairments, thus the neuronal correlates of cognitive impairment in children with FLE, were to be found at the brain's functional or microstructural level. In the IMAGINE study (IMAGing study IN children with frontal lobe Epilepsy), we applied advanced MRI techniques, being functional MRI (fMRI), volumetric MRI, diffusion tensor imaging (DTI) as well as graph theoretical analysis, a sophisticated post-processing of MRI data, to explore neuronal correlates of cognitive impairment in children with FLE. In a case-control cohort study, we subjected children with FLE with and without cognitive impairment, as well as age-matched healthy controls to extensive neuropsychological assessment as well as the complete MRI protocol. As the cognitive impairments in children with FLE are diverse in nature and not limited to the typical frontal lobe functions, we focused on the whole brain to investigate neuronal correlates of cognitive impairment in children with FLE. Literature research revealed that these MRI techniques were potentially capable to demonstrate at least part of 
the neuronal correlates of cognitive impairment in patients with all forms of epilepsy (Chapter 3).

First, in Chapter 4, we applied fMRI to explore possible functional correlates of cognitive impairment in children with FLE. During scanning, the patients and controls performed a working memory task. We measured which brain areas showed activation induced by this task and to what extent. We found that similar brain regions were activated in the patient and the control group and to similar extent. Second, we investigated to which extent the different brain regions were connected. We found that children with FLE, regardless of their cognitive functioning, showed a significantly decreased functional connectivity throughout the whole brain compared to controls during working memory task performance. This implies that FLE in children is associated with a global network disorder. Importantly, cognitively impaired children with FLE had a decreased connectivity of a specific subset of frontal lobe connections compared to cognitively unimpaired children with FLE. This decreased frontal lobe connectivity comprised both connections within the frontal lobe as well as connections from the frontal lobe to the parietal lobe, temporal lobe, cerebellum, and basal ganglia (Chapter 4). The decreased connectivity between the frontal lobe and many other brain areas fits well with our observation that the cognitive impairments in children with FLE span multiple cognitive domains (Chapter 2) and implies that extensive coordinated networks are required for cognitive functioning.

Automated morphometric techniques such as volumetric MRI can detect more subtle morphological abnormalities than normal structural MRI. The four most important results of our volumetric MRI study in chapter 5 were that, first, children with FLE had larger total cerebral white matter volumes than controls. Second, children with FLE had smaller volumes of several frontal and extra-frontal cortex structures than controls. Third, cognitively impaired children with FLE had significantly smaller volumes of various cortex structures within the frontal lobes and in extra-frontal regions, most notably the temporal cortex, compared to cognitively unimpaired children with FLE. Last, within the temporal cortex, the middle temporal grey matter volume and entorhinal cortex thickness specifically were smaller in children with FLE with cognitive impairment than in the cognitively unimpaired children with FLE. Thus, FLE itself is associated with volumetric abnormalities of multiple cortical and subcortical structures throughout the brain and volumetric abnormalities of particular structures lead to, or are associated with, the development of cognitive impairment. The fact that we measured volumetric abnormalities 
throughout the brain might well explain the broad scale of cognitive domains affected in children with FLE complicated by cognitive impairment and highlights that FLE impacts on areas beyond the frontal lobe (Chapter 2.2).

In chapter 6, we used DTI to investigate whether disturbances in the structural brain network were associated with cognitive impairment. We found that in children with FLE, the diffusional properties of the cerebral white matter were affected and that the abnormalities were not confined to the regions in which the seizure focus resided. Rather, the abnormalities were mainly located in posterior brain regions. Our data suggest that FLE in the age category of our study cohort ( 8 to 13 years) affects the normal posterior to anterior brain maturation processes. None of the diffusional properties differed significantly between the cognitively impaired and unimpaired children with FLE. However, fractional anisotropy and bundle volumes differed significantly between cognitively impaired children with FLE and controls, but not between the cognitively unimpaired patients and controls. This suggests a sliding scale, in which abnormalities in fractional anisotropy and bundle volumes were most pronounced in the cognitively impaired children with FLE. These abnormalities might thus represent part of the etiology of cognitive impairment complicating FLE in children.

In chapter 7, we have used graph theoretical analysis to study network characteristics and investigated whether these differed between children with FLE with and without cognitive impairment and controls. We found two distinct differences between the functional networks in children with FLE and those of controls. First, functional networks in children with FLE demonstrated reduced connectivity between functional modules with a decrease in long-range connectivity, i.e. a decrease in integration. Second, their functional networks showed a higher modularity than those of the controls. Subnetworks in children with FLE are less interconnected than in controls and show persistent segregation. This suggests a lack of the normal age-related reorganization into long-range functional connectivity. In the cognitively impaired patients, the frontal lobe missed the characteristic module that functionally interacts with the temporal, parietal, and occipital regions, which was seen in the healthy control group. This suggests a delay in the functional development of the frontal lobe network in the cognitively impaired patients. The observation that modular abnormalities were not restricted to the frontal lobe could, again, explain the broad variety of cognitive impairment seen in children with FLE (Chapter 2). 
In chapter 8 we made a synthesis of the data obtained by the different imaging techniques. Based on our neuroradiological data, FLE presents as a cerebral network disorder characterized by functional, microstructural, and volumetric abnormalities, as well as an abnormal cerebral network organization. These abnormalities are not restricted to the frontal lobe where the seizure focus resides. FLE in childhood possibly affects the normal brain maturation processes. Based on these findings, we hypothesize that the functional disturbances represent a first phase, eventually leading to structural abnormalities. It remains unknown whether these widespread functional and structural network disturbances are a cause or an effect of FLE.

Applying the different MRI techniques, we were able to demonstrate the following neuronal correlates of cognitive impairment in children with FLE:

1. Decreased functional frontal lobe connectivity that comprised both connections within the frontal lobe as well as connections between the frontal lobe and the parietal lobe, temporal lobe, cerebellum, and basal ganglia (fMRI).

2. Smaller volumes of left and right frontal and temporal lobe cortex structures and left subcortical area structures, but larger volumes of right temporal, right parietal, and right occipital lobe cortex structures (volumetric MRI).

3. Abnormal diffusional properties mostly located in the posterior brain regions/occipital lobes (DTI).

4. The loss of the characteristic frontal lobe module that functionally interacts with the temporal, parietal, and occipital regions (graph theoretical analysis).

For all techniques, we observed that clinical epilepsy characteristics such as localization of the seizure focus and age at seizure onset, did not impact on these neuronal correlates of cognitive impairment. From the combined results of the various techniques, impaired functional connectivity appears to be the predominant factor associated with cognitive impairment in children with FLE.

There are no other studies in children with epilepsy that have compared the results of various MRI techniques. Therefore, comparison with other types of epilepsy is not yet possible. Moreover, we have only performed a single measurement for all participants. As a result, we cannot study the evolution of the observed changes over time. Such data are essential to determine the etiology of FLE and its associated cognitive impairment. 


\section{Samenvatting}

Het eerste doel van dit proefschrift was te onderzoeken of cognitieve stoornissen, één van de belangrijkste problemen voor kinderen en volwassenen met epilepsie, ook aanwezig zijn bij kinderen met frontaalkwab epilepsie (FKE). Hiervoor hebben we in hoofdstuk 2 de bestaande literatuur bestudeerd en 71 kinderen met FKE uitgebreid getest door middel van intelligentietesten, neuropsychologische testen en vragenlijsten over het gedrag.

We vonden dat kinderen met FKE slecht presteerden op intelligentietesten en neuropsychologische testen vergeleken met referentie waarden. De gevonden cognitieve stoornissen omvatten niet alleen de typische frontale functies zoals aandacht en executieve functies, maar ook problemen met ruimtelijk inzicht, geheugen, taal en intelligentie. Deze cognitieve stoornissen hebben grote gevolgen, want veel kinderen met FKE uit het door ons bestudeerde cohort hadden leerproblemen en een groot deel van deze kinderen volgde speciaal onderwijs (Hoofdstuk 2.2).

Voor FKE in kinderen wordt vaak geen onderliggende oorzaak gevonden; zo laten structurele MRI scans vaak geen afwijkingen zien (Hoofdstuk 2.1). Ook vonden we zelf in hoofdstuk 2.2 dat klinische epilepsiefactoren zoals de duur van de epilepsie, de aanvalsfrequentie en de lokalisatie van het epileptisch focus binnen de frontaalkwab geen verklaring geven voor het feit dat het ene kind wel en het andere kind geen cognitieve stoornissen krijgt.

Het tweede doel van dit proefschrift was daarom het ontrafelen van de onderliggende oorzaken van cognitieve stoornissen in kinderen met FKE. Omdat structurele hersenafwijkingen afwezig zijn in de meeste kinderen met FKE, was onze hypothese dat de afwijkingen die geassocieerd zijn met de cognitieve stoornissen, dus het neuronaal correlaat voor de cognitieve stoornissen, gevonden zou kunnen worden op functioneel of microstructureel hersenniveau. In de IMAGINE studie (IMAGing study IN children with frontal lobe Epilepsy) hebben we met geavanceerde MRI technieken, te weten functionele MRI (fMRI), volumetrie, diffusie tensor imaging (DTI) en graaftheorie analyse, een post-processing techniek voor MRI data, gezocht naar de neuronale correlaten voor de cognitieve stoornissen van kinderen met FKE. Dit hebben we gedaan middels een case-control cohortstudie waarin we zowel kinderen met FKE met en zonder cognitieve stoornissen alsook gezonde kinderen van overeenkomstige leeftijd onderzochten; alle kinderen ondergingen uitgebreid neuropsychologisch onderzoek en het volledig 
MRI protocol. Omdat de cognitieve stoornissen van kinderen met FKE zich niet beperken tot de typische frontale functies hebben we ons met deze technieken gericht op het hele brein om de onderliggende oorzaken hiervan te onderzoeken. Literatuuronderzoek toonde al aan dat deze MRI technieken potentieel in staat zijn om tenminste een deel van het neuronaal correlaat van cognitieve stoornissen in patiënten met alle vormen van epilepsie aan te tonen (Hoofdstuk 3).

Allereerst hebben we in hoofdstuk 4 fMRI gebruikt om te kijken naar functionele correlaten voor cognitieve stoornissen in kinderen met FKE. Tijdens het scannen voerden de kinderen met FKE en de controles een werkgeheugen taak uit. We keken naar de gebieden die geactiveerd werden tijdens deze taak en in welke mate deze gebieden geactiveerd werden. We vonden dat dezelfde hersengebieden in dezelfde mate geactiveerd werden in de patiënten groep als in de controle groep. In tweede instantie hebben we gekeken naar de mate waarin de verschillende hersengebieden met elkaar verbonden waren in functionele netwerken. We vonden dat kinderen met FKE, ongeacht hun cognitief functioneren, diffuus door het brein een significante vermindering van de functionele connectiviteit hadden vergeleken met controles tijdens uitvoering van een werkgeheugen taak. Dit impliceert dat FKE in kinderen geassocieerd is met een wijdverspreide stoornis in functionele hersennetwerken. Kinderen met FKE met cognitieve stoornissen hadden vergeleken met kinderen met FKE zonder cognitieve stoornissen een verminderde functionele connectiviteit van een aantal specifieke verbindingen die zowel binnen de frontaalkwab lagen als verbindingen van de frontaalkwab met de pariëtaalkwab, temporaalkwab, basale ganglia en het cerebellum (Hoofdstuk 4). De verminderde connectiviteit tussen de frontaalkwab en vele andere hersengebieden komt overeen met onze observatie dat de cognitieve stoornissen van kinderen met FKE meerdere cognitieve domeinen omvatten (Hoofdstuk 2).

De vier belangrijkste resultaten van het volumetrisch onderzoek in hoofdstuk 5 waren ten eerste dat kinderen met FKE een groter witte stofvolume hadden dan controles. Ten tweede hadden kinderen met FKE kleinere volumes van meerdere frontale en extra-frontale hersenschorsstructuren dan controles. Ten derde had de groep kinderen met FKE met cognitieve stoornissen significant kleinere volumes van verschillende hersenschorsstructuren in en buiten de frontaalkwab (voornamelijk de temporaalkwab), vergeleken met kinderen met FKE zonder cognitieve stoornissen. Tenslotte was in de temporaalkwab vooral de grijze stof van de mediale temporaalkwab en de dikte van de entorhinale schors kleiner in kinderen met FKE en cognitieve stoornissen dan in kinderen 
met FKE zonder cognitieve stoornissen. Dus FKE zelf is geassocieerd met volume afwijkingen in verschillende corticale en subcorticale structuren verspreid door het hele brein en volume afwijkingen van specifieke structuren leiden tot, of zijn geassocieerd met, cognitieve stoornissen. Ook deze bevindingen passen bij het brede scala aan cognitieve stoornissen dat gezien wordt bij kinderen met FKE (Hoofdstuk 2) en benadrukken wederom dat FKE invloed heeft op hersengebieden buiten de frontaalkwab (Hoofdstuk 2.2).

In hoofdstuk 6 hebben we DTI gebruikt om het structurele hersennetwerk in kaart te brengen en vonden we afwijkende diffusie eigenschappen van de cerebrale witte stof in kinderen met FKE. Deze afwijkingen beperkten zich niet tot de regio waarin het epileptisch focus zich bevond, maar waren voornamelijk gelokaliseerd in de posterieure hersengebieden. Onze data suggereren dat FKE in de leeftijdscategorie van ons studiecohort ( 8 tot 13 jaar) de normale van posterieur naar anterieur verlopende rijpingsprocessen beïnvloedt. Er werden geen significante verschillen in de diffusie eigenschappen gevonden tussen kinderen met FKE met en zonder cognitieve stoornissen. Echter, fractionele anisotropie en bundelvolumes verschilden significant tussen de kinderen met FKE en cognitieve stoornissen en controles, maar niet tussen de kinderen met FKE zonder cognitieve stoornissen en controles. Dit wijst op een glijdende schaal waarin afwijkingen in fractionele anisotropie en bundelvolumes het meest uitgesproken zijn in de kinderen met FKE en cognitieve stoornissen. Deze afwijkingen zouden dus een weerspiegeling kunnen zijn van (een deel van) de etiologie van de cognitieve stoornissen in kinderen met FKE.

In hoofdstuk 7 hebben we graaftheorie analyse gebruikt om cerebrale netwerkkarakteristieken te bestuderen en hebben we gekeken of deze karakteristieken verschilden tussen kinderen met FKE met en zonder cognitieve stoornissen en controles. Het functionele netwerk van kinderen met FKE verschilde op twee manieren van die van controles. Ten eerste lieten functionele netwerken in kinderen met FKE een verminderde connectiviteit zien tussen functionele modules met een vermindering van lange-afstandsconnectiviteit. Dit wijst op een afname van integratie. Ten tweede lieten hun functionele netwerken een hogere modulariteit zien dan die van controles. Subnetwerken in kinderen met FKE zijn minder goed met elkaar verbonden dan bij controles en laten een persisterende segregatie zien. Dit suggereert dat er sprake is van het ontbreken van de normale leeftijdsgerelateerde reorganisatie naar lange afstand functionele connectiviteit. Typisch voor de kinderen met FKE en cognitieve stoornissen was dat de frontaalkwab de karakteristieke module miste die functioneel interacteert met de temporale, pariëtale en occipitale 
gebieden, zoals gezien werd in de controle groep. Dit wijst op een vertraging in de functionele ontwikkeling van het frontaalkwabnetwerk in de groep kinderen met FKE en cognitieve stoornissen. De observatie dat de afwijkingen zich niet beperken tot de frontaalkwab past wederom bij de grote variëteit aan cognitieve stoornissen in kinderen met FKE (Hoofdstuk 2).

Op basis van onze neuroradiologische data concluderen wij in hoofdstuk 8 dat FKE een cerebrale netwerkstoornis is die gekenmerkt wordt door functionele, microstructurele en volumetrische afwijkingen alsook door een afwijkende cerebrale netwerkorganisatie. Deze afwijkingen beperken zich niet tot de frontaalkwab waarin het epileptisch focus zich bevindt. Mogelijk heeft FKE op de kinderleeftijd ook een negatieve invloed op de normale rijpingsprocessen van het brein. Op basis van onze gecombineerde bevindingen stellen wij dat de functionele stoornissen voorafgaan aan de structurele afwijkingen. Vooralsnog is het onbekend of deze uitgebreide functionele en structurele netwerkstoornissen een oorzaak of een gevolg zijn van FKE.

Met de verschillende MRI technieken werden de volgende neuronale correlaten voor cognitieve stoornissen in kinderen met FKE aangetoond:

1. Verminderde functionele frontaalkwab connectiviteit die zowel verbindingen in de frontaalkwab alsook verbindingen vanuit de frontaalkwab naar de pariëtaalkwab, temporaalkwab, cerebellum en basale ganglia omvat (fMRI).

2. Kleinere volumes van hersenschorsstructuren in de linker en rechter frontaalkwab en temporaalkwab en linker subcorticale gebieden, maar tevens grotere volumes van hersenschorsstructuren in de rechter temporaalkwab, pariëtaalkwab en occipitaalkwab (volumetrie).

3. Afwijkende diffusie eigenschappen welke voornamelijk gelokaliseerd zijn in de posterieure hersengebieden/occipitaalkwab (DTI).

4. Het ontbreken van de karakteristieke frontaalkwabmodule die functioneel interacteert met de temporale, pariëtale en occipitale gebieden (graaftheorie analyse).

Voor alle MRI technieken geldt dat klinische epilepsie karakteristieken zoals lokalisatie van het epileptisch focus en debuutsleeftijd van de epilepsie geen invloed hadden op de neuronale correlaten van cognitieve stoornissen. Uit de synthese van onze data blijkt gestoorde functionele connectiviteit de voornaamste factor geassocieerd met cognitieve stoornissen in kinderen met FKE. 
Er zijn geen eerdere studies in kinderen met epilepsie die de resultaten van verschillende MRI technieken met elkaar vergeleken hebben. Hierdoor is vergelijking met andere vormen van epilepsie nog niet mogelijk. We hebben slechts een enkele meting gedaan bij onze studiegroep. Dientengevolge kunnen we geen uitspraak doen over het beloop van de geobserveerde verschillen in de tijd. Dergelijke gegevens zijn essentieel voor het begrijpen van de etiologie van FKE en de geassocieerde cognitieve stoornissen. 


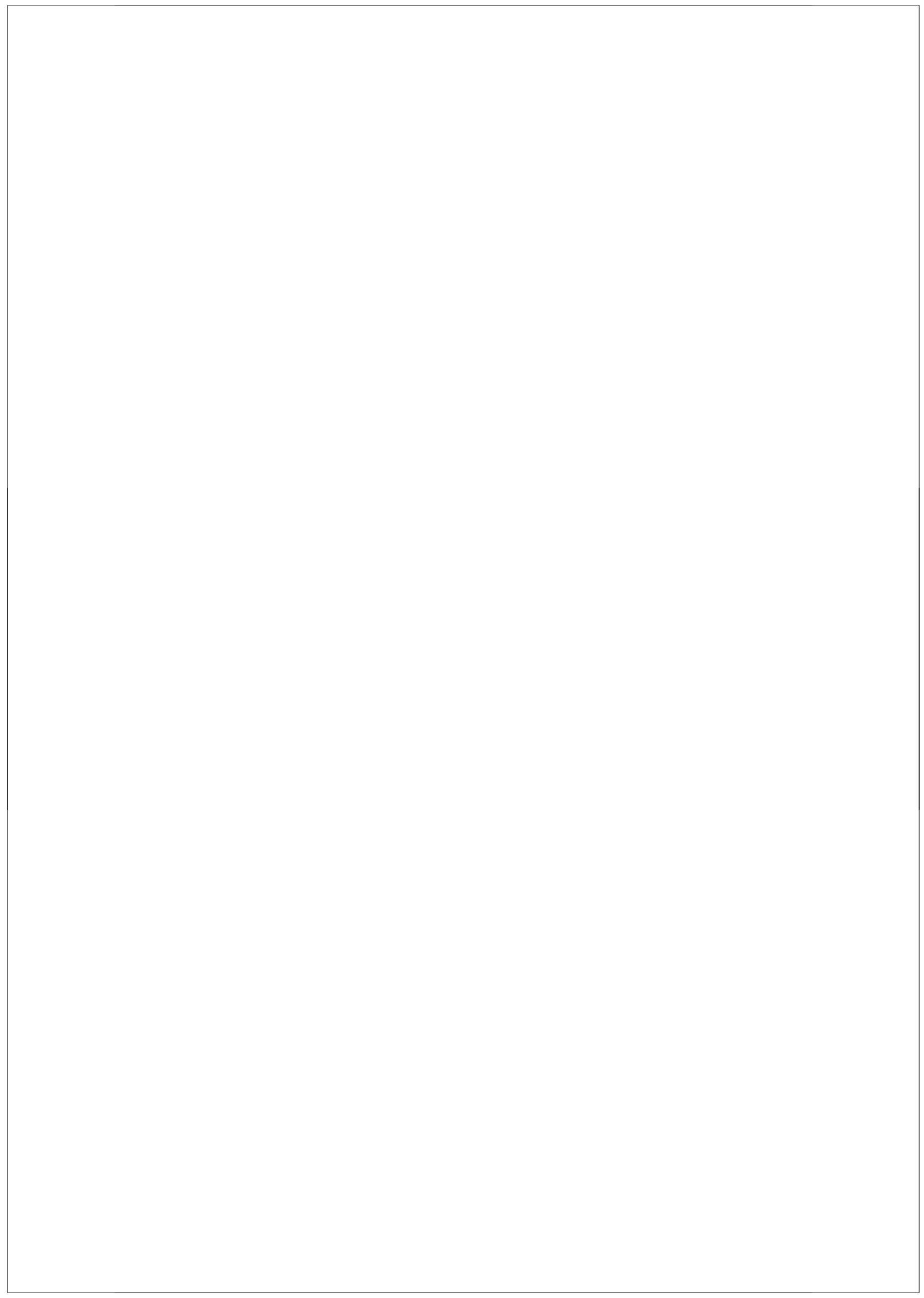




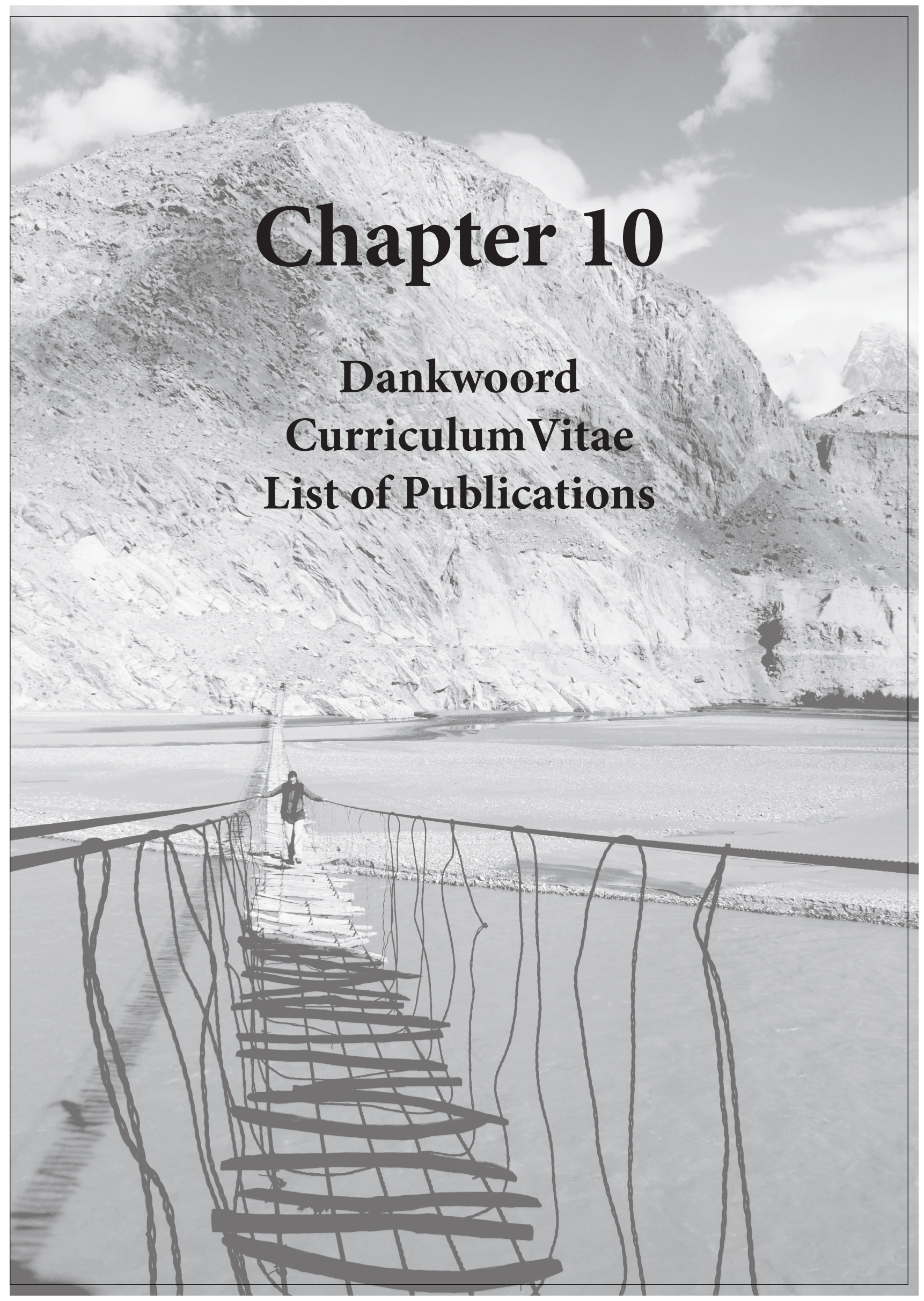




\section{Dankwoord}

En opeens is het af! De afgelopen jaren heb ik met veel plezier aan dit proefschrift gewerkt. Veel mensen hebben hier een belangrijke bijdrage aan geleverd en die wil ik dan ook graag bedanken.

Allereerst wil ik alle kinderen en hun ouders bedanken voor hun geduld en bereidheid om deel te nemen aan het IMAGINE onderzoek. Ondanks dat de kinderen met frontaalkwab epilepsie wisten hoe lastig het is om een uur lang stil te liggen in een MRI scan die veel herrie maakt wilden ze meehelpen aan het onderzoek. Zij zijn speciaal hiervoor vanuit heel Nederland opnieuw een dag naar Kempenhaeghe gekomen.

Ook alle controle kinderen en hun ouders wil ik bedanken; wat een fantastische mensen zijn jullie! We waren bang dat er totaal geen reacties zouden komen op zo'n piepklein advertentietjein een huis-aan-huisblaadje waarvan wevantevoren dachten dat het rechtstreeks op de bodem van een konijnenhok zou belanden. Wat een fantastische moraal heerst er in Brabant; beter nog dan geld geven aan een goed doel was om zelf mee te doen aan een goed doel! Als een lopend vuurtje ging het verhaal hoe leuk het was om aan dit onderzoek mee te doen; je kreeg dan een plaatje van je eigen hersenen mee naar huis! Het werd een hit; de spreekbeurten op school gingen over hersenen en de MRI scan en voor we het wisten hadden zich meer controle kinderen aangemeld dan we nodig hadden. Zonder de inzet van al deze kinderen was dit proefschrift niet tot stand gekomen.

In het bijzonder wil ik natuurlijk ook mijn promotoren en copromotoren bedanken.

Prof. dr. A.P. Aldenkamp, beste Bert, nog geen 5 minuten na mijn eerste functioneringsgesprek met Marc de Krom, waarin ik aangegeven had graag onderzoek te willen doen bij kinderen met epilepsie, zat ik bij jou op de kamer. Ik had het geluk dat 'de imaging-groep' (Bert Aldenkamp, Walter Backes, Paul Hofman, Jaap Jansen en Mariëlle Vlooswijk) al goed op stoom was en al gauw mocht ik meerijden op die trein. Het was helemaal mooi dat ik de mogelijkheid kreeg om het onderzoek bij kinderen met frontaalkwab epilepsie, waar ik als student al mee was begonnen, voort te zetten. Na heel wat brainstorm sessies in Maastricht en in Heeze, waar ik altijd trouw door je opgehaald en teruggebracht werd naar het station, en de goedkeuring door de Medisch Ethische Commissie (wat niet meeviel omdat het een studie met kinderen betrof...), kon het onderzoek van start gaan. Jij hebt me wegwijs gemaakt in de onderzoekswereld, waaronder de wereld van SPSS, je hield het 
overzicht en kon altijd in 1 zin samenvatten wat er precies moest gebeuren of wat de conclusie van een brei aan bevindingen was waar we soms wel een uur over hadden gepraat. Beslissingen werden altijd snel gemaakt en net zo snel was je in het beoordelen van manuscripten. Heel veel dank voor de prettige samenwerking en de goede begeleiding.

Prof dr. J.S.H. Vles, beste Hans, het was ontzettend fijn om ook begeleid te worden door een clinicus. Je was en bent altijd erg kritisch en behulpzaam, een perfecte combinatie voor een promovendus! Daarnaast ben je ook nog eens ontzettend snel. Zodra ik een nieuw manuscript rondgestuurd had kon ik de klok erop gelijk zetten dat het 24 uur later weer in mijn postvak of mailbox lag voorzien van commentaar waaruit bleek dat je het stuk van begin tot eind in detail gelezen had. Daarnaast ben je iemand met ontzettend veel kennis en kunde van de (kinder)neurologie. Het was ontzettend fijn om jou als supervisor/opleider te hebben en je vragen tijdens de neurologie overdrachten en kinderneurologie besprekingen stimuleerden altijd om nog dieper op het onderwerp in te gaan en leidden vaak tot diepgaande discussies. Mede dankzij jou ben ik enthousiast geworden voor de kinderneurologie. Maar niet alleen als promotor en supervisor wil ik je bedanken, maar vooral ook om wie je bent. Je persoonlijke interesse waardeer ik enorm.

Dr. ir. W.H. Backes, beste Walter, wat heb ik veel van je geleerd de afgelopen jaren! Ten eerste de verschillen in de manier van denken tussen clinici en technici. Het volgekalkte bord op je kamer gaf voor beide partijen altijd duidelijkheid en na verloop van tijd werd er nauwelijks meer op het bord geschreven. Ik heb enorm veel van je geleerd over hoe je interessante data ook echt kunt omvormen tot artikelen; de MRI artikelen kwamen dankzij jou goed uit de verf.

Dr. P.A.M. Hofman, beste Paul, wat heb jij een hoop werk verzet voor de IMAGINE-studie! Bedankt voor het beoordelen van alle MRI-scans. Het is erg fijn om begeleid te worden door iemand die met 1 been in de techniek en 1 been in kliniek staat. Mede hierdoor ben je de ideale copromotor. Niet alleen tijdens dit onderzoek maar ook tijdens mijn hele neurologie opleiding heb ik veel van je mogen leren van de neuroradiologie, kennis waar ik zowel in onderzoek als kliniek nog ontzettend veel aan ga hebben.

Heel veel dank ben ik verschuldigd aan Maarten Vaessen, 'de technicus' met wie ik samen dit onderzoek ben gestart. Een gouden combinatie, de koppeling van een technicus aan een clinicus. Zonder jou zouden er geen scans en MRI 
data zijn geweest. We hebben een ontzettend leuke tijd gehad samen en ik heb veel van je geleerd. Bedankt voor je geduld met deze digibeet! Ik ben erg blij dat je mijn paranimf wilt zijn. Gefeliciteerd met je prachtige post-doc positie! Heel veel succes en geluk in Genève samen met Ilona!

De drijvende krachten vanuit Kempenhaeghe achter deze studie zijn Mariette Debeij-van Hall en Anton de Louw, die de leiding hebben van het programma 'Epilepsie bij het Schoolgaande Kind.' Bedankt voor de hulp bij het includeren van de kinderen met frontaalkwab epilepsie en jullie nuttige bijdrage aan het verloop van de studie.

Onze 'trial-nurse' Petra van Mierlo. Petra: je bent goud waard! Ik ben ontzettend blij dat jij degene was die mee ging doen aan ons onderzoek, ook al lag dit aanvankelijk helemaal niet in jouw planning. Je bent een fantastische organisator, geweldig in de begeleiding van kinderen, enorm enthousiast en bent van alle markten thuis; zelfs voor de neuropsychologische onderzoeken konden we op jou rekenen. Bedankt voor al je hulp!

Esther Peeters en Remco Berting, bedankt voor het maken van alle MRI scans en jullie fantastische begeleiding van de kinderen tijdens het scannen!

Dank ook aan de andere leden van de imaging groep, Jaap Jansen voor de nuttige input tijdens ons tweewekelijkse IMAGINE-overleg en Mariëlle Vlooswijk, René Besseling, Geke Overvliet, Dominique Ijff, Sylvie van der Kruijs, Jorn Heerink en Evelyn Brandt-Wouters voor de prettige samenwerking.

Naast Mariette Debeij-van Hall en Anton de Louw wil ik Richard Lazeron en Boudewijn Gunning bedanken voor het helpen met de inclusie van de kinderen met frontaalkwab epilepsie.

Caroline van der Linden, bedankt voor het uitvoeren van de administratie en je enthousiasme voor de IMAGINE studie.

Johan Arends, bedankt dat je de onafhankelijk arts voor de IMAGINE studie wilde zijn.

Graag zou ik de medewerkers van Kempenhaeghe willen bedanken voor de ondersteuning van het onderzoek en het maken van ruimte voor het onderzoek bij de neuropsychologie en MRI op de vrijdagen. In het bijzonder wil ik Juliëtte Duisterwinkel bedanken voor de hulp bij het aanleveren van alle 
benodigde formulieren voor de METC. Daarnaast wil ik iedereen bedanken voor de fijne tijd die ik tijdens mijn epilepsie stage in Kempenhaeghe heb gehad. De korte lijntjes en goede sfeer zowel op de poli als op afdelingen als bij de neurofysiologie maken het niet alleen een leerzame maar ook een hele prettige stage.

Alle mede-onderzoekers van Kempenhaeghe en van de radiologie in de kelder bij MRI-3: bedankt voor de gezellige tijd samen.

De leden van de beoordelingscommissie, Prof dr. J.E. Wildberger, Prof. dr. K.P.J. Braun, Prof. dr. B.M. Jansma, Prof. dr. L. Lagae en Prof. dr. R.J. van Oostenbrugge, wil ik bedanken voor de tijd en moeite die jullie hebben genomen om mijn proefschrift te beoordelen.

Graag wil ik Prof. dr. W.O. Renier bedanken. Onder uw begeleiding heb ik mijn wetenschappelijke stage 'Frontaalkwab epilepsie bij kinderen: klinische en neuropsychologische kenmerken' gedaan. Mede op uw advies ben ik naar Maastricht gegaan waar ik het onderzoek voort kon zetten en is mijn enthousiasme voor de kinderneurologie en epilepsie ontstaan.

Beste Martien Limburg, Marc de Krom, Koos Keizer, Werner Mess, Hans Vles, Marian Majoie en Robert van Oostenbrugge. Bedankt voor de brede, goede en prettige opleiding die jullie mij als opleiders gegeven hebben.

De hele assistentengroep van de neurologie en neurochirurgie, alle neurologen, neurochirurgen, neurofysiologen, polimedewerksters, verpleegkundigen van C5 en de MC en KNF-laboranten wil ik bedanken voor de fijne tijd in Maastricht. Dankzij jullie werd Maastricht echt mijn 'home away from home'.

Iemand die zeker niet vergeten mag worden is Kitty Verwoerdt. Kitty, bedankt voor al het regelwerk en het inpassen van (soms ingewikkelde) stages in mijn opleidingsrooster.

Speciaal wil ik Yvonne Raaijmakers bedanken voor de gezellige tijd in Maastricht. We konden het al supergoed met elkaar vinden, maar dit werd nog versterkt tijdens onze KNF-stage. Samen met Oliver zaten we maandenlang in 1 hok zonder daglicht, maar met koffie, koekjes en stapels EEG's die beoordeeld moesten worden. Ik ben blij dat jij mijn paranimf wilt zijn en dat we elkaar met al onze mannen nog steeds regelmatig zien. 
De kinderneurologen (Hans Vles, Biene Weber, Joost Nicolai en Sylvia Klinkenberg) wil ik bedanken voor de fijne begeleiding tijdens mijn kinderneurologie stage, waardoor het enthousiasme voor kinderneurologie nog verder toe nam.

Mijn nieuwe collega's van de kinderneurologie in Utrecht: Kees Braun, Floor Jansen, Fréderique van Berkestijn, Inge Cuppen en Charlotte Haaxma. Bedankt voor de fijne en leerzame tijd, ik heb het ontzettend naar mijn zin bij jullie!

De Nederlandse Spoorwegen en Veolia: bedankt voor alle ritjes tussen Maastricht en Nijmegen.

Cafeïne was een belangrijke drijvende kracht achter dit proefschrift; graag bedank ik Maison Blanche Dael / Coffeelovers (Maastricht) en Coffyn (Nijmegen) voor het branden van fantastische koffie en de vele zaterdagen en zondagen die ik er heb mogen doorbrengen. De koffie gaf de nodige brandstof om onder andere het geduld op te brengen om met SPSS om te kunnen gaan. Het stuk taart erbij mocht natuurlijk niet ontbreken.

De Nijmegen clan: Menno, Mieke, Steven, Maartje, Femke, Koen, Janneke, Sander, Dagmar, Peter, Joost, Caroline, Sven, Marjolein, Joost en de kids. Gelukkig is er ook een leven naast het werk, al had ik jullie de laatste jaren best wat vaker willen zien. Het is geweldig dat niemand Nijmegen verlaten heeft na al die jaren, zelfs ik ben weer terug ;-). Bedankt voor de gezelligheid tijdens de wekelijkse etentjes, feestjes (omdat er altijd wel wat te vieren is) en weekendjes weg.

Matthijs Poll, bedankt voor al je hulp bij de lay-out van dit boek. Bedankt voor al het huiswerk dat je me meegaf, daardoor is het maken van het boek helemaal soepel verlopen. Gelukkig heb jij wel verstand van computers!

Lieve familie en schoonfamilie: jullie hebben mij altijd gesteund in mijn beslissingen. Verhuizen naar Nijmegen om te gaan studeren, een jaar lang met een rugzak op door Azië reizen, naar de andere kant van Nederland verhuizen om daar de opleiding neurologie te gaan doen, of naar een bruiloft in Afghanistan gaan...jullie keken nergens raar van op (althans dat leek zo). Bedankt voor jullie steun, het is fijn om zo'n fijne thuisbasis te hebben. 
En tot slot mijn drie lieve mannen:

Lieve Tom en Koen, jullie zijn nog veel te jong om te kunnen begrijpen wat mama in vredesnaam heeft bezield om zoveel tijd achter de laptop door te brengen. Jullie zijn een enorme stok achter de deur geweest om dit proefschrift af te maken. We gaan nog veel leuke dingen doen samen, 'high-five....psssj!' Lieve Jakko, als ik iemand moet bedanken ben jij het. Jij hebt me altijd gestimuleerd, geadviseerd en gemotiveerd. Jij was enthousiast (in tegenstelling tot sommigen die er slapeloze nachten van hadden...) toen ik vertelde aangenomen te zijn in Maastricht en denk je na al die jaren alles gehad te hebben, gaat ze weer naar Utrecht. Dankzij het parttime leven in Limburg hebben we kennis gemaakt met het Bourgondische leven en zijn we een stuk sportiever geworden; de Limburgse heuvels gaven zelfs inspiratie voor heuse wandel-, klim- en fietsvakanties! We zijn al bijna 15 jaar samen, hebben al veel van de wereld gezien, maar ons verlanglijstje staat nog steeds vol met mooie plannen. Bedankt voor alles, ik houd van je en ben verschrikkelijk trots op je, op naar Japan! 


\section{Curriculum Vitae}

Hilde Braakman werd op 13 oktober 1978 geboren in Eindhoven. Van 1991 tot 1997 volgde zij het VWO aan het Heerbeeck College te Best. Na afronding hiervan studeerde zij Geneeskunde aan de Radboud Universiteit Nijmegen. Alvorens aan de co-schappen te beginnen heeft zij een jaar lang gereisd door Azië. In 2003 werd het doctoraal examen met goed gevolg afgelegd, waarna de co-schappen volgden. De interesse in de neurologie was al gewekt, maar werd versterkt tijdens het keuze co-schap op de afdeling Neurologie van het Rijnstate ziekenhuis te Arnhem (supervisoren: dr. Q.H. Leijten \& dr. R.H. Boerman) en het afsluitende co-schap op de afdeling Neurologie van het UMC St Radboud te Nijmegen (supervisoren: Prof. dr. H.P.H. Kremer \& Prof. dr. B.G.M. van Engelen).

Van december 2004 tot april 2005 heeft ze haar wetenschappelijke stage 'Frontaalkwab epilepsie bij kinderen: klinische en neuropsychologische kenmerken' gedaan op de afdeling Neurologie \& Kinderneurologie van het UMC St Radboud, onder leiding van Prof. dr. W.O. Renier. In dezelfde periode volgde zij daar een klinische stage op de polikliniek 'Kinderen met Epilepsie en Paroxysmale Stoornissen,' eveneens onder leiding van Prof. dr. W.O. Renier.

Na het behalen van het artsexamen in 2005 begon zij als AGNIO op de afdeling Neurologie van het Rijnstate Ziekenhuis te Arnhem. Vanuit Arnhem volgde de overstap naar het Maastricht Universitair Medisch Centrum. Daar begon zij na een periode van 4 maanden als AGNIO aan de opleiding tot neuroloog, met als opleiders achtereenvolgens Prof. dr. M. Limburg, dr. M.C.T.F.M. de Krom en Prof. dr. R.J. van Oostenbrugge.

De interesse in de kinderneurologie en epileptologie werden tijdens de opleiding verder versterkt. Dit leidde er mede toe dat zij in 2008 naast de opleiding begon met het wetenschappelijk onderzoek dat heeft geleid tot dit proefschrift, onder leiding van Prof. dr. A.P. Aldenkamp, Prof. dr. J.S.H. Vles, dr. ir. W.H. Backes en dr. P.A.M. Hofman.

In mei 2012 werd de opleiding tot neuroloog voltooid. Sinds 1 augustus 2012 is ze werkzaam als fellow kinderneurologie in het Wilhelmina Kinderziekenhuis/Universitair Medisch Centrum Utrecht onder leiding van Prof. dr. K.P.J. Braun.

In 2010 is zij getrouwd met Jakko van Ingen. Ze hebben samen twee zonen, Tom ( 2 jaar) en Koen (4 maanden). 


\section{List of publications}

1. Braakman HM, Vaessen MJ, Jansen JF, Debeij-van Hall MH, de Louw A, Hofman PA, Vles JS, Aldenkamp AP, Backes WH.

Frontal lobe connectivity and cognitive impairment in pediatric frontal lobe epilepsy.

Epilepsia 2013;54:446-454.

2. Braakman HM, Vaessen MJ, Jansen JF, Debeij-van Hall MH, de Louw A, Hofman PA, Vles JS, Aldenkamp AP, Backes WH.

Reduced frontal and extra-frontal cortex volumes are associated with cognitive impairment in frontal lobe epilepsy.

Submitted for publication.

3. Braakman HM, Vaessen MJ, Jansen JF, Debeij-van Hall MH, de Louw A, Hofman PA, Vles JS, Aldenkamp AP, Backes WH.

White matter abnormalities and cognitive impairment in children with frontal lobe epilepsy.

Submitted for publication.

4. Braakman HM, van der Kruijs SJ, Vaessen MJ, Jansen JF, Debeij-van Hall MH, Vles JS, Aldenkamp AP, Backes WH, Hofman PA.

Microstructural and functional MRI studies of cognitive impairment in epilepsy.

Epilepsia 2012;53:1690-1699.

5. Vaessen MJ, Braakman HM, Heerink JS, Jansen JF, Debeij-van Hall MH, Hofman PA, Aldenkamp AP, Backes WH.

Abnormal Modular Organization of Functional Networks in Cognitively Impaired Children with Frontal Lobe Epilepsy.

Cereb Cortex 2012, Jul 6 [Epub ahead of print].

6. Braakman HM, Ijff DM, Vaessen MJ, Debeij-van Hall MH, Hofman PA, Backes WH, Vles JS, Aldenkamp AP.

Cognitive and behavioural findings in children with frontal lobe epilepsy. Eur J Paediatr Neurol 2012;16:707-715.

7. Besseling RM, Jansen JF, Overvliet GM, Vaessen MJ, Braakman HM, Hofman PA, Aldenkamp AP, Backes WH.

Tract specific reproducibility of tractography based morphology and diffusion metrics.

PLoS One 2012;7:e34125. 
8. Braakman HM, Vaessen MJ, Hofman PA, Debeij-van Hall MH, Backes WH, Vles JS, Aldenkamp AP.

Cognitive and behavioral complications of frontal lobe epilepsy in children: a review of the literature.

Epilepsia 2011;52:849-856.

9. Braakman HM, Moers-Hornikx VM, Arts BM, Hupperts RM, Nicolai J. Pearls \& Oy-sters: electroconvulsive therapy in anti-NMDA receptor encephalitis.

Neurology 2010;75:e44-46.

10. Braakman HM, Lodder J, Postma AA, Span LF, Mess WH.

Vasospasm is a significant factor in cyclosporine-induced neurotoxicity: case report.

BMC Neurol 2010;10:30.

11. Braakman HM, Knippenberg SA, de Bondt BJ, Lodder J.

An unusual cause of transient neurologic deficits: compression of the carotid artery by a thyroid cystic nodule.

J Stroke Cerebrovasc Dis 2010;19:73-74.

12. Braakman HM, van Oostenbrugge RJ, van Kranen-Mastenbroek VH, de Krom MC.

Rimonabant induces partial seizures in a patient with a history of generalized epilepsy.

Epilepsia 2009;50:2171-2172.

13. Braakman HM, van de Molengraft FJ, Hubert WW, Boerman DH.

Lethal African trypanosomiasis in a traveler: MRI and neuropathology.

Neurology 2006;66:1094-1096. 


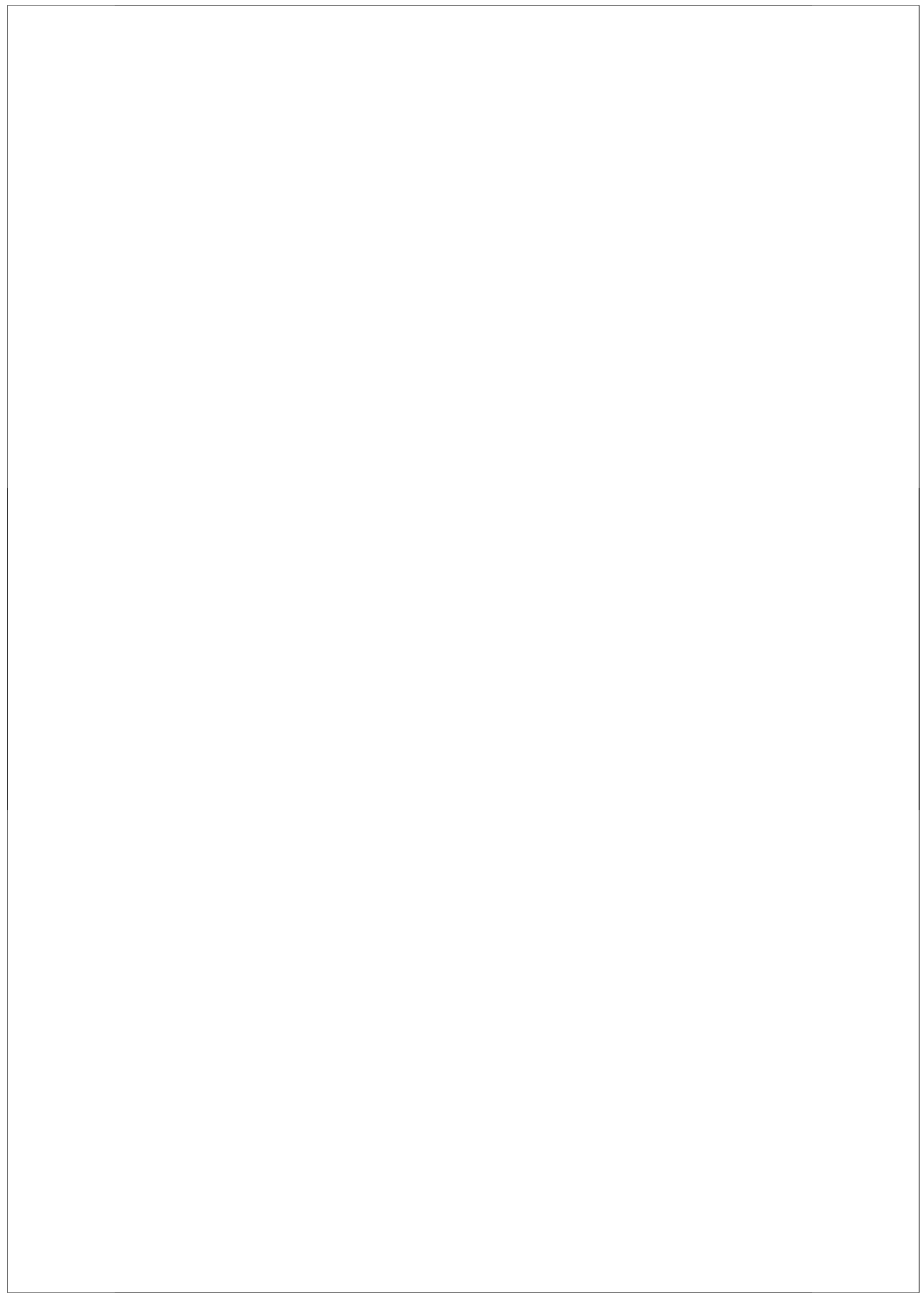




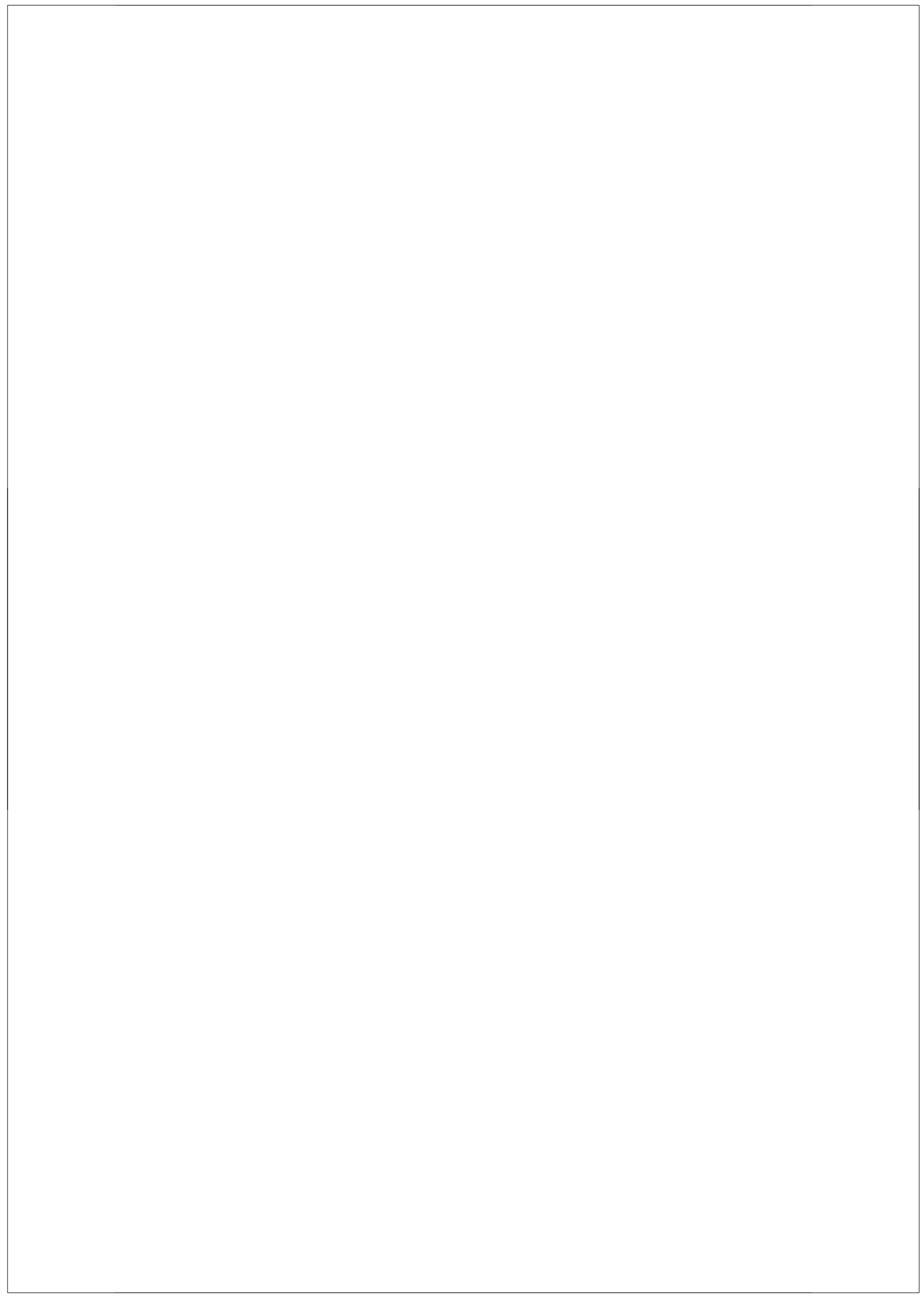




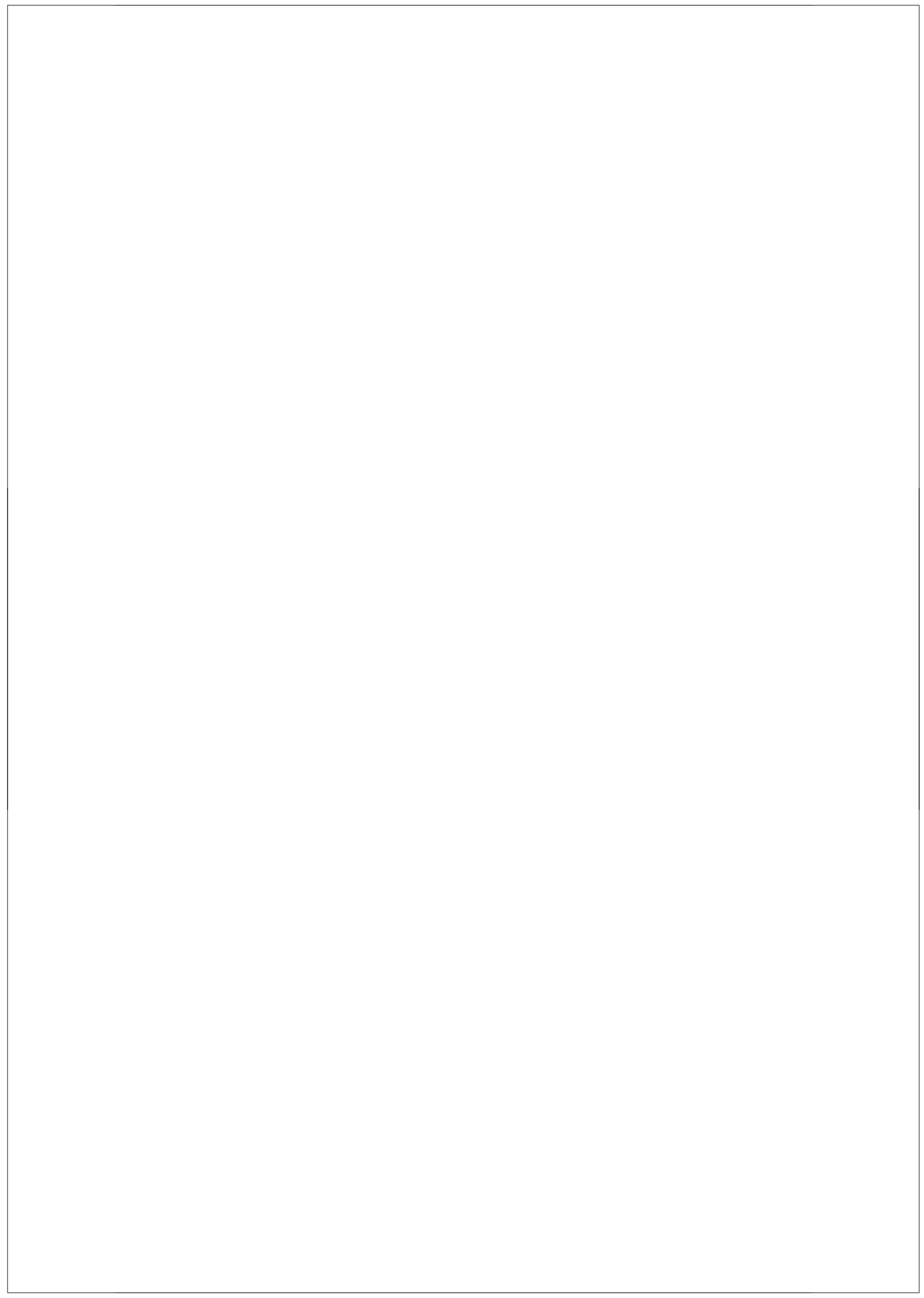




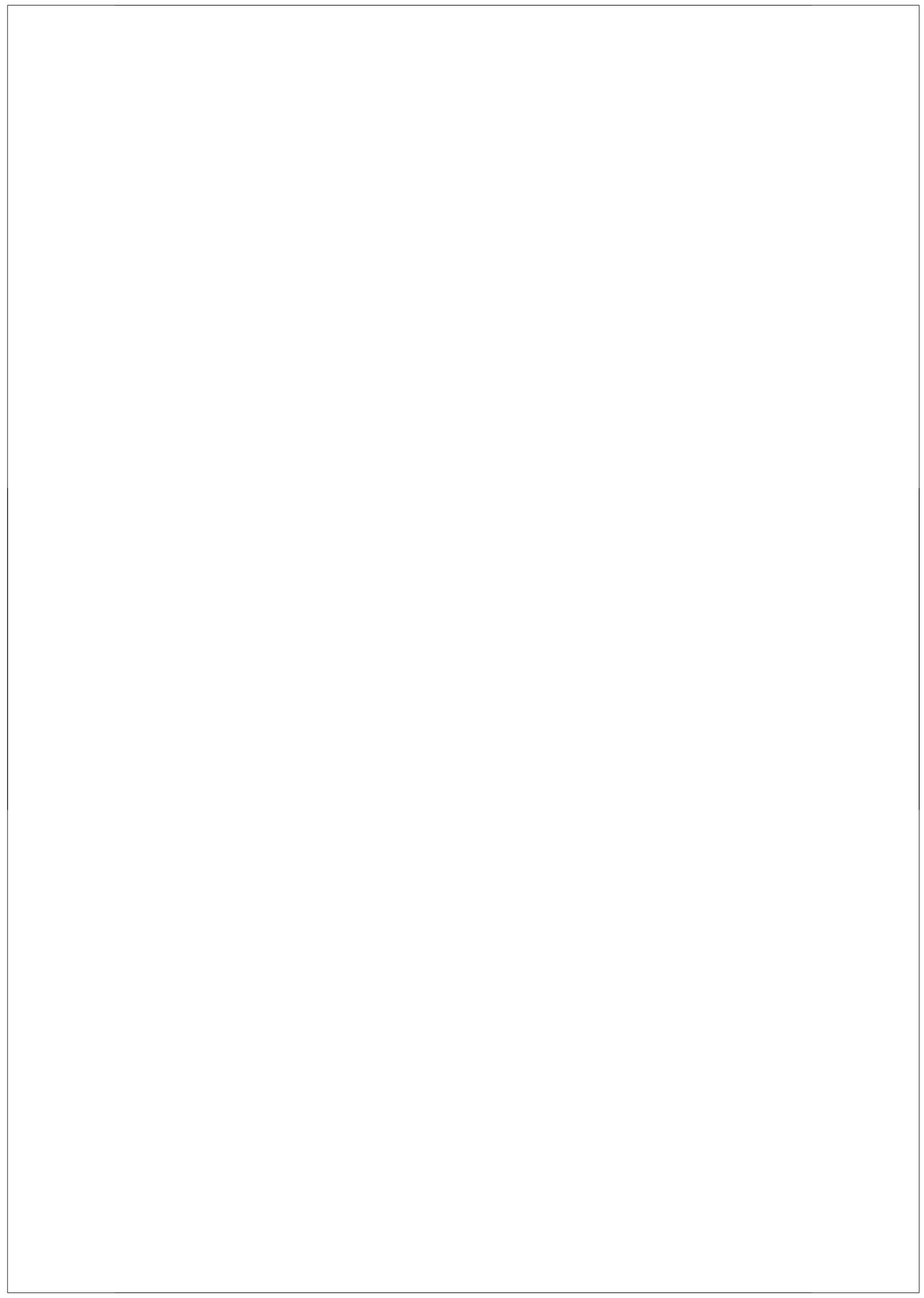




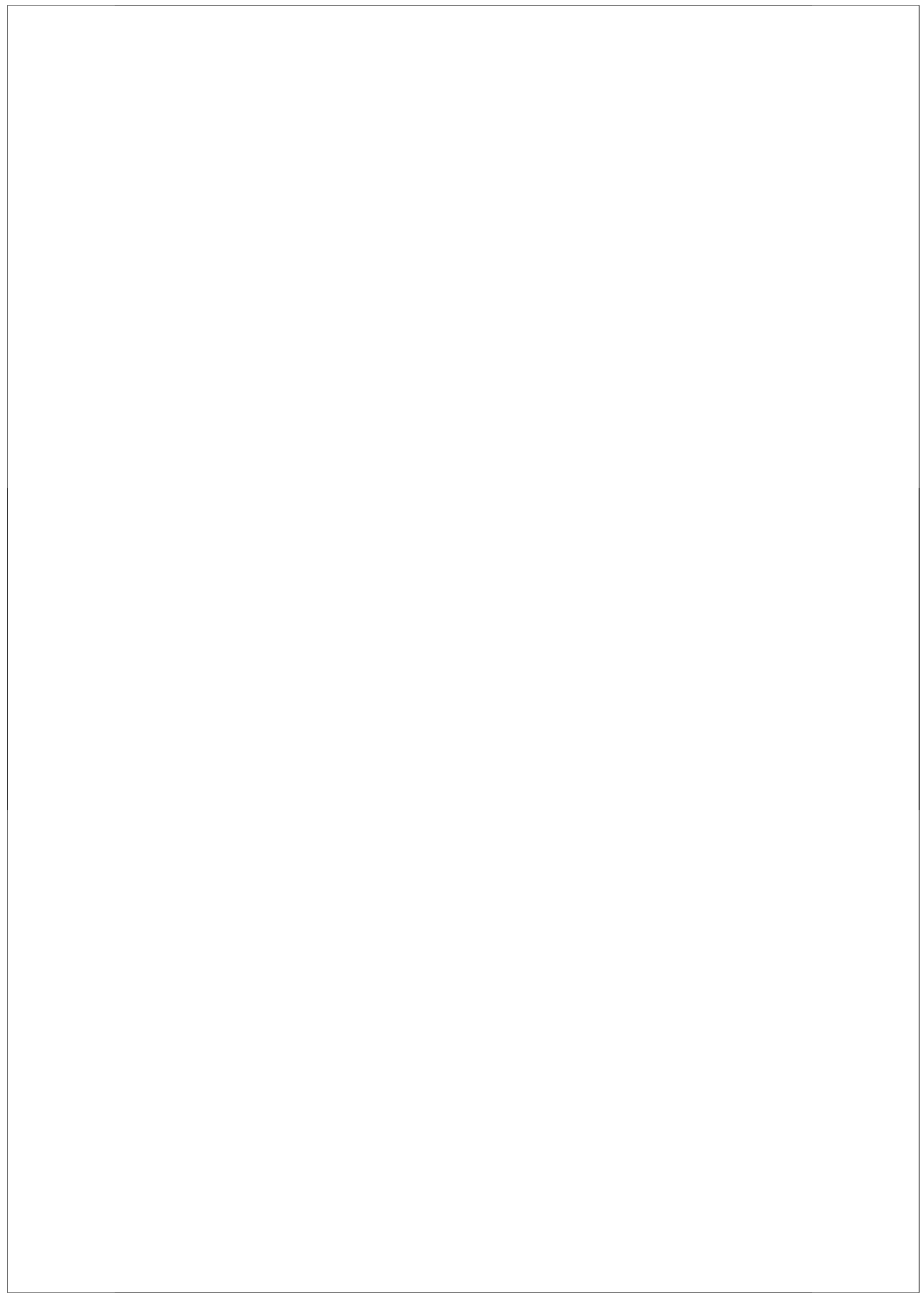

